A United States Department of Commerce Technology Administration

National Institute of Standards and Technology

NISTIR 5013

ELECTROMECHANICAL PROPERTIES

OF SUPERCONDUCTORS FOR DOE FUSION APPLICATIONS

J.W. Ekin

S.L. Bray

C.L. Lutgen

W.L. Bahn 



\title{
ELECTROMECHANICAL PROPERTIES \\ OF SUPERCONDUCTORS FOR DOE FUSION APPLICATIONS
}

\author{
J.W. Ekin \\ S.L. Bray \\ C.L. Lutgen \\ W.L. Bahn
}

Electromagnetic Technology Division

Electronics and Electrical Engineering Laboratory

National Institute of Standards and Technology

Boulder, Colorado 80303-3328

January 1994

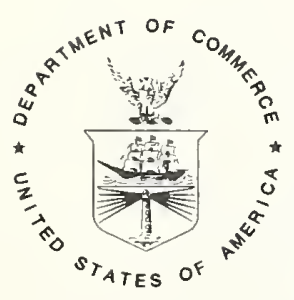

U.S. DEPARTMENT OF COMMERCE, Ronald H. Brown, Secretary

TECHNOLOGY ADMINISTRATION, Mary L. Good, Under Secretary for Technology

NATIONAL INSTITUTE OF STANDARDS AND TECHNOLOGY, Arati Prabhakar, Director 


\section{CONTENTS}

Executive Summary 2

Electromechanical Characteristics of $\mathrm{Nb}_{3} \mathrm{Sn}$ Superconductors:

Effect of Transverse Compressive Stress on the Critical

Current and Upper Critical Field of $\mathrm{Nb}_{3} \mathrm{Sn}$

J. W. Ekin

Transverse Stress Effect on Multifilamentary $\mathrm{Nb}_{3} \mathrm{Sn}$ Superconductor

J. W. Ekin 10

Transverse Stress Effect on the Critical Current of Internal

Tin and Bronze Process $\mathrm{Nb}_{3} \mathrm{Sn}$ Superconductors

J. W. Ekin, S. L. Bray, P. Danielson, D. Smathers,

R. L. Sabatini, and M. Suenaga

Effect of Transverse Stress on the Critical Current

of Bronze-Process and Internal-Tin $\mathrm{Nb}_{3} \mathrm{Sn}$

J. W. Ekin, S. L. Bray, and W. L. Bahn

Transverse Stress and Crossover Effect in $\mathrm{Nb}_{3} \mathrm{Sn}$

J. W. Ekin and S. L. Bray

Critical-Current Degradation in $\mathrm{Nb}_{3} \mathrm{Sn}$ Composite Wires

Due to Locally Concentrated Transverse Stress

S. L. Bray and J. W. Ekin

US-DPC Nb${ }_{3} \mathrm{Sn}$ Cable Strand

$\mathrm{Nb}_{3} \mathrm{Sn}$ LLNL Cable Test Strand

$\mathrm{Nb}_{3} \mathrm{Sn}$ ITER Candidate Conductor 45

Electromechanical Characteristics of Experimental High-Field Superconductors:

$\mathrm{Nb}_{3} \mathrm{Sn}$ Conductors Reinforced with Dispersion-Hardened Copper Alloy 51

$\mathrm{V}_{3} \mathrm{Ga}$ Tape

Critical-Current Degradation in Multifilamentary $\mathrm{Nb}_{3} \mathrm{Al}$ Wires

from Transverse Compressive and Axial Tensile Stress

S. L. Bray, J. W. Ekin, and T. Kuroda. 
Appendices:

"Superconductor Specification," Concise Encyclopedia of Magnetic \& Superconducting Materials

J. W. Ekin

The Development of an Internal-Tin $\mathrm{Nb}_{3} \mathrm{Sn}$ Strand for Fusion Applications

E. Gregory, J. W. Ekin, G. Grunblatt, H. G. Ky,

G. M. Ozeryansky, and B. A. Zeitlin

VAMAS Intercomparison of Critical Current Measurement in $\mathrm{Nb}_{3} \mathrm{Sn}$ Wires

K. Tachikawa, K. Itoh, H. Wada, D. Gould, H. Jones, C. R. Walters,

L. F. Goodrich, J. W. Ekin, and S. L. Bray

VAMAS Interlaboratory Comparisons of Critical Current vs. Strain in $\mathrm{Nb}_{3} \mathrm{Sn}$

J. W. Ekin

Strain Effects in VAMAS Round Robin Test Wires

K. Katagiri, K. Saito, M. Ohgami, T. Okada, A. Nagata,

K. Noto, K. Watanabe, K. Itoh, H. Wada, K. Tachikawa,

J. W. Ekin, and C. R. Walters 100

VAMAS $\mathrm{Nb}_{3} \mathrm{Sn}$ Test Conductor 108 


\title{
Electromechanical Properties of Superconductors for DOE Fusion Applications
}

\author{
J. W. Ekin, S. L. Bray, C. L. Lutgen, and W. L. Bahn \\ Electromagnetic Technology Division \\ Electronics and Electrical Engineering Laboratory \\ National Institute of Standards and Technology \\ Boulder, Colorado 80303
}

The electrical performance of many superconducting materials is strongly dependent on mechanical load. This report presents electromechanical data on a broad range of high-magnetic-field superconductors. The conductors that were studied fall into three general categories: candidate conductors, experimental conductors, and reference conductors. Research on candidate conductors for fusion applications provides screening data for superconductor selection as well as engineering data for magnet design and performance analysis. The effect of axial tensile strain on critical-current density was measured for several $\mathrm{Nb}_{3} \mathrm{Sn}$ candidate conductors including the US-DPC (United States Demonstration Poloidal Coil) cable strand and an ITER (International Thermonuclear Experimental Reactor) candidate conductor. Also, data are presented on promising experimental superconductors that have strong potential for fusion applications. Axial strain measurements were made on a $\mathrm{V}_{3} \mathrm{Ga}$ tape conductor that has good performance at magnetic fields up to $20 \mathrm{~T}$. Axial strain data are also presented for three experimental $\mathrm{Nb}_{3} \mathrm{Sn}$ conductors that contain dispersion hardened copper reinforcement for increased tensile strength. Finally, electromechanical characteristics were measured for three different $\mathrm{Nb}_{3} \mathrm{Sn}$ reference conductors from the first and second VAMAS (Versailles Project on Advanced Materials and Standards) international $\mathrm{Nb}_{3} \mathrm{Sn}$ critical-current round robins. Published papers containing key results, including the first measurement of the transverse stress effect in $\mathrm{Nb}_{3} \mathrm{Sn}$, the effect of stress concentration at cable-strand crossovers, and electromechanical characteristics of $\mathrm{Nb}_{3} \mathrm{Al}$, are included throughout the report.

Key words: axial stress effect; electromechanical; fusion; $\mathrm{Nb}_{3} \mathrm{Al} ; \mathrm{Nb}_{3} \mathrm{Sn}$; stress effect; superconductor; transverse stress effect; $\mathrm{V}_{3} \mathrm{Ga}$ 


\section{Executive Summary}

This report presents the results of work done for the U. S. Department of Energy, Office of Fusion Energy, during the period 1986-1993, under interagency agreement No. DE-AI01-84ER52113.

Within the windings of an energized superconducting magnet, the Lorentz force can produce large stresses that increase with magnet size and field. These stresses can significantly degrade the performance of the magnet through a reduction in the superconductor's critical-current density $\left(\mathrm{J}_{\mathrm{C}}\right)$. There are two dominant stress components, a tensile stress that is aligned with the wire's longitudinal axis (axial stress) and a compressive stress that is perpendicular to its axis (transverse stress).

Presently, the most common conductor material used in high-field $(>10 \mathrm{~T})$ superconducting magnet designs is $\mathrm{Nb}_{3} \mathrm{Sn}$. The $\mathrm{J}_{\mathrm{c}}$ of $\mathrm{Nb}_{3} \mathrm{Sn}$ is highly sensitive to its stress state. Consequently, it is the internal stress state of the magnet windings, rather than the $\mathrm{J}_{\mathrm{C}}$ of the unstressed superconductor, that determines the design limits for large high-field magnets. Electromechanical measurements of $\mathrm{Nb}_{3} \mathrm{Sn}$ candidate conductors for ITER (International Thermonuclear Experimental Reactor) provide screening data for superconductor selection as well as engineering data for magnet design and performance analysis. Data are presented on several $\mathrm{Nb}_{3} \mathrm{Sn}$ candidate conductors.

As new magnet designs call for larger coils and higher fields, stresses must be limited by structural reinforcement of the magnet windings. Control of the stress, which accumulates radially within the windings, requires distributed reinforcement. Aside from complicating the design and increasing the cost of the magnet, additional internal reinforcement limits the superconductor packing fraction and, thus, reduces the magnetic field. At present, the determining factors of the amount of reinforcement are not just structural, but dominated by the stress sensitivity of $\mathrm{Nb}_{3} \mathrm{Sn}$. Consequently, a superconductor less sensitive to stress than the existing high-field conductors, but comparable in $\mathrm{J}_{\mathrm{C}}$, could significantly extend the present magnet design limits. Data are presented on five experimental conductors that have strong potential for fusion applications with lowered stress sensitivity $-\mathrm{V}_{3} \mathrm{Ga}, \mathrm{Nb}_{3} \mathrm{Al}$, and $\mathrm{Nb}_{3} \mathrm{Sn}$ superconductors with dispersion hardened copper.

The consistency of interlaboratory $\mathrm{J}_{\mathrm{C}}$ measurements of $\mathrm{Nb}_{3} \mathrm{Sn}$ superconductors is typically much lower than for NbTi. This is largely due to stress effects, which are much smaller for NbTi. Since measurement inconsistency implies uncertainty in the engineering data for these conductors, it directly impacts DOE magnet designs. In response to this situation, two studies on $\mathrm{J}_{\mathrm{C}}$ measurements of $\mathrm{Nb}_{3} \mathrm{Sn}$, the first and second VAMAS (Versailles Project on Advanced Materials and Standards) international $\mathrm{Nb}_{3} \mathrm{Sn}$ critical-current round robins, have been conducted. NIST participated in both of these studies, providing electromechanical data on the superconductors. The results of these measurements are presented in the Appendices.

The report has three main sections: Electromechanical Characteristics of $\mathrm{Nb}_{3} \mathrm{Sn}$ Superconductors, Electromechanical Characteristics of Experimental High-Field Superconductors, and the Appendices. Within each main section, the data are presented in two formats: published papers, which present comprehensive results, and unpublished data on specific conductors. 
The first section contains papers reporting seminal measurements of the transverse stress effect in $\mathrm{Nb}_{3} \mathrm{Sn}$, a comparison of transverse stress effects in bronzeprocess and internal-tin $\mathrm{Nb}_{3} \mathrm{Sn}$ conductors, and the effect of concentrated transverse stress at cable-strand crossover points. Key results from these publications show that the effect of transverse stress on the $\mathrm{J}_{\mathrm{C}}$ of $\mathrm{Nb}_{3} \mathrm{Sn}$ is much greater than that of axial stress, that anisotropy in stress sensitivity is not a peculiarity associated with a specific $\mathrm{Nb}_{3} \mathrm{Sn}$ processing method, and that transverse stress data from measurements of single wires subjected to uniform stress are applicable in modeling the concentrated stress at strand crossover points in superconducting cables. Also, complete sets of axial stress data are presented for the US-DPC (United States Demonstration Poloidal Coil) $\mathrm{Nb}_{3} \mathrm{Sn}$ cable strand, the LLNL (Lawrence Livermore National Laboratory) cable-test strand, and an ITER (International Thermonuclear Experimental Reactor) candidate conductor.

The section on experimental superconductors includes a paper on stress effects in $\mathrm{Nb}_{3} \mathrm{Al}$, where this superconducting compound was shown to be significantly less sensitive to both axial and transverse stress than $\mathrm{Nb}_{3} \mathrm{Sn}$. Like $\mathrm{Nb}_{3} \mathrm{Sn}$, the $\mathrm{Nb}_{3} \mathrm{Al}$ conductor was more sensitive to transverse stress than axial stress. This demonstrates that the anisotropy, which was first observed in $\mathrm{Nb}_{3} \mathrm{Sn}$, is not associated with a particular processing method or even a particular material, but is much more general. Axial stress data are also presented for a $\mathrm{V}_{3} \mathrm{Ga}$ tape conductor that has good performance at magnetic fields up to $20 \mathrm{~T}$ and for three experimental $\mathrm{Nb}_{3} \mathrm{Sn}$ conductors that contain dispersion hardened copper reinforcement for increased tensile strength.

In addition to the VAMAS publications and data, the Appendices contain an excerpt from the Concise Encyclopedia of Magnetic \& Superconducting Materials entitled "Superconductor Specification" and a paper on the development of an internal-tin $\mathrm{Nb}_{3} \mathrm{Sn}$ conductor for fusion applications, which is processed using hot isostatic pressure (HIP) to double its intrinsic irreversible strain limit.

Unless otherwise noted, the critical-current measurement accuracy is $\pm 2 \%$. Axial strains were determined within $\pm 0.02 \%$, and transverse loads were determined within \pm $1 \%$. 


\title{
Effect of transverse compressive stress on the critical current and upper critical field of $\mathrm{Nb}_{3} \mathrm{Sn}$
}

\author{
J.W. Ekin \\ Electromagnetic Technology Division, National Bureau of Standards, Boulder, Colorado 80303
}

(Received 29 May 1987; accepted for publication 3 September 1987)

\begin{abstract}
A large reversible degradation of the critical current of multifilamentary $\mathrm{Nb}_{3} \mathrm{Sn}$ superconductors has been observed when uniaxial compressive stress is applied transverse to the conductor axis at $4 \mathrm{~K}$. In bronze-process multifilamentary $\mathrm{Nb}_{3} \mathrm{Sn}$, the onset of significant degradation occurs at about $50 \mathrm{MPa}$. In an applied field of $10 \mathrm{~T}$, the magnitude of the effect is about seven times larger for transverse stress than for stress applied along the conductor axis. The transverse stress effect increases with magnetic field and is associated with a reversible degradation of the upper critical field. The intrinsic effect of transverse stress on the upper critical field is about ten times greater than for axial stress. Although axial stresses on the $\mathrm{Nb}_{3} \mathrm{Sn}$ filaments are greater than transverse stresses in most applications, the transverse stress effect will need to be considered in the internal design of large magnets because of the greater sensitivity of $\mathrm{Nb}_{3} \mathrm{Sn}$ to transverse stress. It is shown that the transverse stress from the Lorentz force on the conductor is proportional to conductor thickness. This will place limits on conductor dimensions and the spacing between distributed reinforcement in large magnets. The effect may be particularly significant in cabled conductors where large transverse stress concentrations can occur at strand crossover points.
\end{abstract}

\section{INTRODUCTION}

A large data base has been obtained for the effect of axial tensile stress and strain on the critical current of A 15 superconductors. ' However, little is known about the effects of stress components other than the axial component. In practical superconducting magnets, however, the superconductor is subjected to three-dimensional stresses. Typically, the transverse component of stress is large and compressive. For example, in solenoidal magnets the transverse component arises from hoop stress which compresses the magnet winding radially, and in dipole magnets it arises from Lorentz force compression of the magnet windings at the midplane. This article reports the first measurements of the effect of transverse stress on the critical current and upper critical field of $\mathrm{Nb}_{3} \mathrm{Sn}^{2}$

\section{EXPERIMENT}

\section{A. Apparatus}

To obtain data on the electrical effects of the transverse component of stress, an apparatus was designed and built to simultaneously apply mutually perpendicular components of current, magnetic field, and transverse compressive stress to a single-strand superconductor in a $4-\mathrm{K}$ liquid helium bath. Current was supplied by a 900 -A battery supply, magnetic field by a 10-T split-pair magnet, and compressive stress by a servohydraulic testing system.

Considerable care was used to ensure drag-free stress application as well as uniform stress over the test section between the voltage taps. As shown in Fig. 1, the sample was compressed between two stainless-steel anvil heads. One of the anvil heads was fixed. The other was designed to pivot so that it conforms to the flat surface of the first anvil head. This ensures that stress is applied uniformly along the sample length. The edges of the anvil heads were tapered and rounded in order to avoid any stress concentration where the sample enters and exits the pressure section. Voltage taps were soldered to the sample within the compressed region so that the electric field was measured only over the region where stress was uniformly applied to the test specimen.

\section{B. Sample characteristics}

These results were obtained on a $\mathrm{Nb}_{3} \mathrm{Sn}$ strand material used to make internally-cooled cabled superconductors for several large magnet systems. Sample characteristics are given in Table I. Two types of samples of the same bronzeprocess starting material were tested, one with a round cross section of diameter $0.69 \mathrm{~mm}$, the other flattened before reaction to a rectangular shape $0.38 \times 0.76 \mathrm{~mm}^{2}$. The samples were composed of 2869 filaments, each about $3.8 \mu \mathrm{m}$ in di-

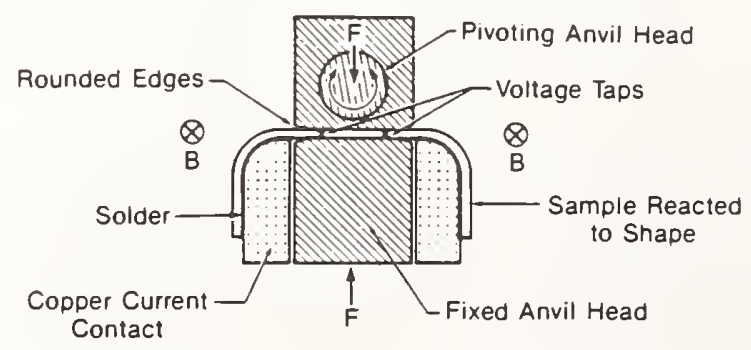

FIG. 1. Schematic view of transverse stress test apparatus showing mutually perpendicular magnetic field, current, and stress. Anvil edges are tapered and rounded to avoid stress concentration. Voltage taps are attached to the side of the sample within the uniform compression region. 
TABLE I. Sample characteristics.

\begin{tabular}{ll}
\hline \hline Size (round) & $0.70 \mathrm{~mm}$ \\
$\quad$ (flat) & $0.38 \times 0.76 \mathrm{~mm}^{2}$ \\
No. filaments & 2869 \\
Filament size & $3.8 \mathrm{~mm}$ \\
Filament twist pitch & $25 \mathrm{~mm}$ \\
Composition (vol \%) & $25 \%$ bronze \\
& $64 \% \mathrm{Cu}$ \\
& $2.4 \% \mathrm{Ta}$ \\
Noncopper area & $8.6 \% \mathrm{Nb}_{3} \mathrm{Sn}$ and Nb \\
Reaction & $1.35 \times 10^{-7} \mathrm{~m}^{2}$ \\
& 4 days at $700^{\circ} \mathrm{C}$ \\
& 2 days at $730^{\circ} \mathrm{C}$ \\
\hline \hline
\end{tabular}

ameter, and were stabilized by $64 \mathrm{vol} \%$ copper in the form of an external ring around the $\mathrm{Nb}_{3} \mathrm{Sn}$ filament-bronze core. All samples were reacted for four days at $700^{\circ} \mathrm{C}$ followed by two days at $730^{\circ} \mathrm{C}$. The cross section of each sample is shown in Fig. 2.

\section{Experimental procedure}

The critical current was initially measured as a function of magnetic field under no stress. Stress was then applied to the sample at $4 \mathrm{~K}$, the critical current measured, the sample unloaded, and critical current measured again. This process was then repeated many times to generate the data in Fig. 3.

A critical-current criterion of $2 \mu \mathrm{V} / \mathrm{cm}$ was used. Overall precision of the critical current data is about $\pm 0.5 \%$.

\section{RESULTS}

\section{A. Critical current: Round sample}

Figure 3 (a) shows the critical current of the round sample as a function of transverse compressive stress for applied fields of 8 and $10 \mathrm{~T}$. The ordinate is the measured critical current normalized to the starting (zero-stress) value. The abscissa is the effective overall transverse stress obtained by dividing the applied load by the area of the sample. A projected area in the direction of the transverse load is used. consisting of the length $(9.5 \mathrm{~mm})$ over which compressive load is applied times the original sample diameter $(0.70$ $\mathrm{mm}$ ).

In this test, the anvil heads were flat in order to apply uniaxial transverse load. The sample was round, however, so this simple method of estimating stress does not take into account the change in contact area between the anvil heads and the sample as the sample was compressed. However, the change in contact area was small at the low strain levels required to degrade the critical current and, more importantly, was limited to the external copper stabilizer. The copper layer completely surrounded the $\mathrm{Nb}_{3} \mathrm{Sn}$ filament region and was relatively thick, so it served to uniformly distribute the load into the filament region (see Fig. 2). Thus, the effective stress from the projected area represents reasonably well the approximate average stress experienced by the $\mathrm{Nb}_{3} \mathrm{Sn}$ filaments within the composite. This has been confirmed by data on the preflattened conductor, described below.

Also shown in Fig. 3 (a) for comparison are data on the critical-current degradation from axial stress. These data were obtained from critical-current degradation measurements on another piece of the same conductor using a technique where precompression of the $\mathrm{Nb}_{3} \mathrm{Sn}$ filaments by the conductor matrix is incrementally relieved by the external application of axial tension. ${ }^{3}$ Under axial stress, the axial force is apportioned among the various composite materials because they all occupy parallel load-bearing paths. This is different from the transverse case where all the components of the composite experience approximately the same stress, which is transferred from one material to the next in a serial
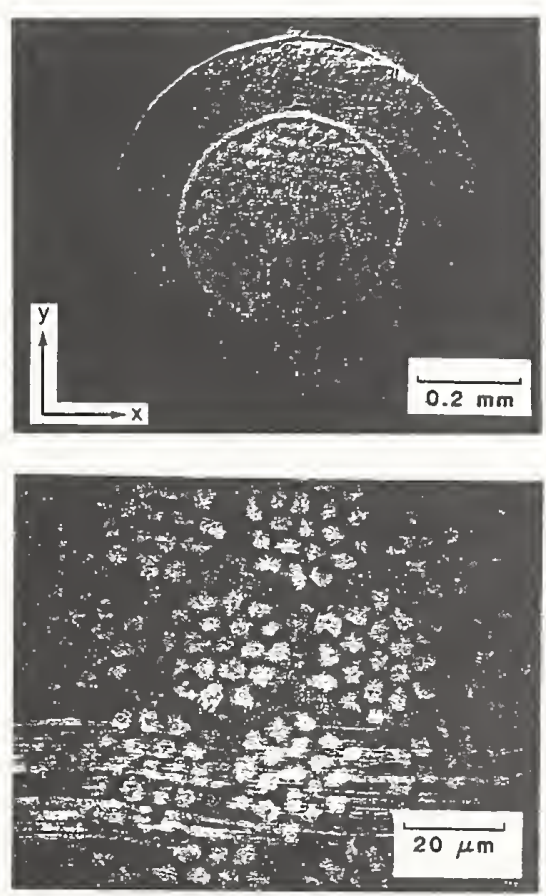

Round Sample
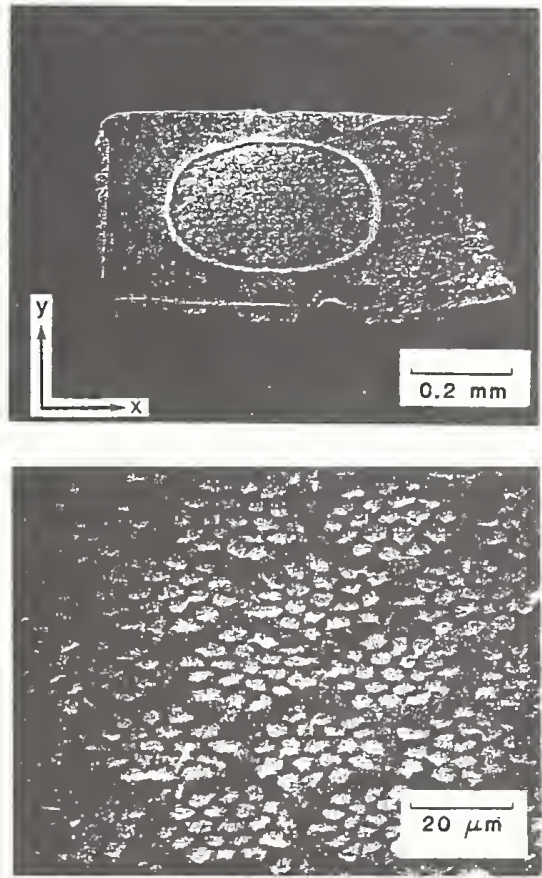

Flat Sample
FIG. 2. Cross-sectional view of each type of sample in the unstressed state. 


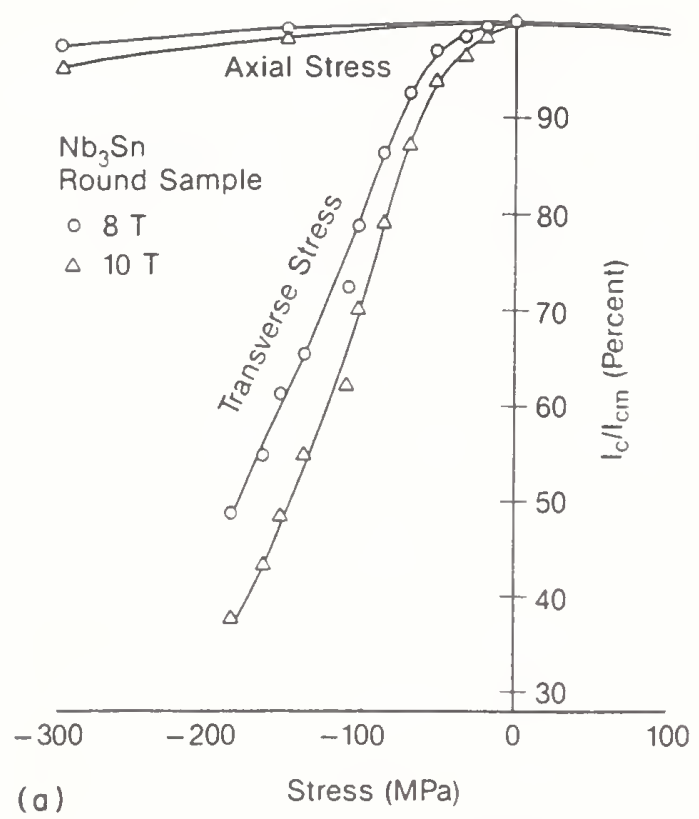

(a)

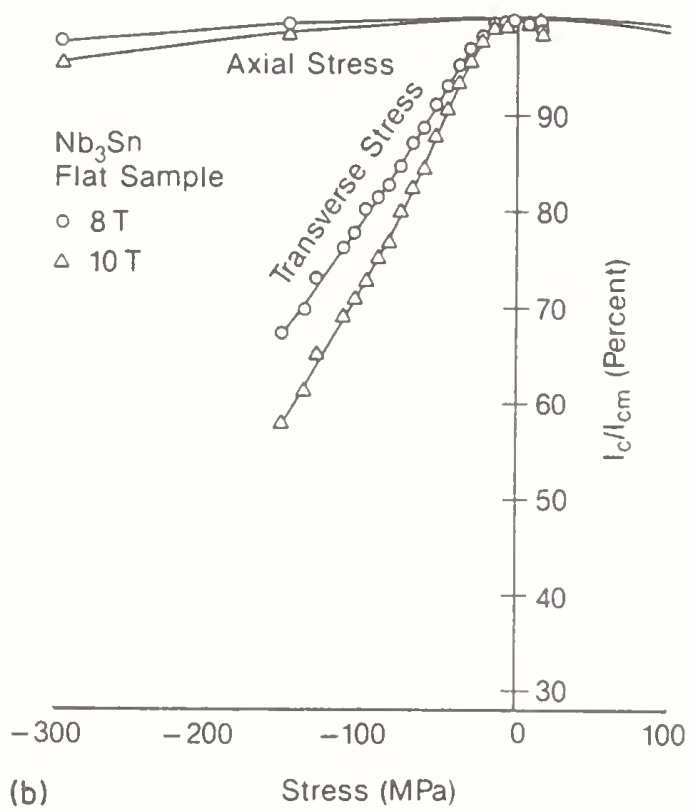

FIG. 3. Comparison of critical-current degradation in multifilamentary $\mathrm{Nb}_{1} \mathrm{Sn}$ for transverse and axial compressive stress in magnetic fields of 8 and $10 \mathrm{~T}$. Transverse stress degradation is shown for both (a) round and (b) flat samples. Negative values of stress represent compression, positive values represent tension.

load chain (from matrix to filament, to matrix, to filament, etc.). Fortunately, the axial strain intrinsic to the $\mathrm{Nb}_{3} \mathrm{Sn}$ filaments can be measured ${ }^{3-5}$ and this can be used to calculate the axial stress in the $\mathrm{Nb}_{3} \mathrm{Sn}$ filaments. This was done assuming a $\mathrm{Nb}_{3} \mathrm{Sn}$ elastic modulus ${ }^{6}$ of $165 \mathrm{GPa}$ to generate the axial stress curve in Fig. 3(a). (Conversely, all of the results could be given in terms of strain by dividing the reported stresses by the modulus of $\mathrm{Nb}_{3} \mathrm{Sn}$.)

Figure 3(a) shows the difference in the magnitudes of the transverse and axial stress effects. For transverse stress, the degradation is a little less than $10 \%$ at $10 \mathrm{~T}$ under a transverse pressure of $50 \mathrm{MPa}$ and rises to nearly $30 \% \mathrm{deg}$ radation at a transverse pressure of $100 \mathrm{MPa}$. For axial stress, on the other hand, the degradation was less than $2 \%$ up to about $200 \mathrm{MPa}$. Looking at the data in Fig. 3(a) over a wide range shows that the stress which causes a given amount of critical-current degradation at $10 \mathrm{~T}$ is generally about seven times less for transverse stress than for axial stress. This ratio will increase at higher magnetic fields because of the effect of the upper critical field, as discussed below.

The critical-current degradation was reversible in character. Upon unloading the sample, the critical current recovered toward its nondegraded value. The recovery was not total, probably because the $\mathrm{Nb}_{3} \mathrm{Sn}$ filaments were kept in partial compression by the plastically deformed soft matrix material.

\section{B. Critical current: Flat sample}

Figure 3(b) shows the critical current of a piece of the same conductor which was flattened to a rectangular cross section $0.38 \times 0.76 \mathrm{~mm}$ prior to reacting. Preflattening the conductor eliminates any ambiguities associated with a change in the contact area for the round sample. Figure 3 (b) shows that the decrease with transverse stress is nearly the same as for the round sample at degradation levels up to about $30 \%$. This indicates that the copper matrix does indeed distribute the stress relatively uniformly into the filament region, and that the effective stress described above is a good approximation to the average stress experienced by the $\mathrm{Nb}_{3} \mathrm{Sn}$ filaments.

Figure 3(b) also shows that the transverse stress effect in the flat sample has a small peak in critical current as a function of transverse stress. The data in Fig. 3(b) have been plotted with the transverse stress curves shifted so the peak occurs at the abscissa zero. This peak is not present in the results for the round sample. We postulate that this effect in the flattened sample is due to anisotropic precompression from thermal contraction of the matrix material. Each filament has a slightly flattened cross section prior to reaction, with an average aspect ratio of slightly less than $2: 1$, as shown in Fig. 2. After cooldown from reacting the $\mathrm{Nb}_{3} \mathrm{Sn}$, this results in less thermal compression by the bronze matrix along the shorter axis marked $y$ in Fig. 2 than along the longer $x$ axis. A finite element calculation by Fukumoto $e t$ $a l^{7}$ showed this effect quite clearly for in situ conductors, which have highly aspected filament cross sectional shapes prior to reaction. Thus, the $\mathrm{Nb}_{3} \mathrm{Sn}$ filaments in the flat sample are under more thermal precompression along their width than along their narrow dimension.

The effect of this anisotropic precompression on the critical current can be understood in terms of distortional strain. Distortional strain produces a much greater degradation of the critical current of a superconductor than hydrostatic strain. ${ }^{8}$ One method for combining the effect of different strain components $\epsilon_{x}, \epsilon_{y}$, and $\epsilon_{z}$ along the three major axes is to use the geometric average strain $\langle\epsilon\rangle^{5.8}$ :

$$
\begin{aligned}
\langle\epsilon\rangle= & 2^{1 / 2}(1+\nu)^{-1}\left[\left(\epsilon_{x}-\epsilon_{y}\right)^{2}+\left(\epsilon_{y}-\epsilon_{z}\right)^{2}\right. \\
& \left.+\left(\epsilon_{z}-\epsilon_{x}\right)^{2}\right]^{1 / 2},
\end{aligned}
$$

where $v$ is Poisson's ratio. This represents the distortional strain state of the material. Anisotropic thermal precompression along the $x$ and $y$ transverse axes of the flat 
sample leads to a compressive prestrain along the $y$ axis which is less than along the $x$ axis, i.e., a finite value for the first term in Eq. (1). As external transverse pressure is applied along the $y$ axis. the initial effect is to remove the distortional strain between the $x$ and $y$ axes, reducing the difference between $\epsilon_{x}$ and $\epsilon_{y}$ in the first term of Eq. (1). This reduces the distortional geometric average strain and thus increases the critical current. As more transverse stress is applied, the critical current eventually passes through a peak and starts to decrease. This is because the strain along the $y$ axis exceeds that along the $x$ axis, thereby increasing the distortional strain. For the round sample, on the other hand, the precompression from thermal contraction in the transverse direction is isotropic and thus, the symmetry breaking application of transverse stress along the $x$ axis immediately leads to crystal distortion and a monotonically decreasing critical current. These results are a strong indication that a distortional strain expression such as Eq. (1) can be used for combining multi-axial strains in analyzing strain degradation of the critical current in practical superconductor applications.

If this is true, the results for the round and flat samples can be compared with each other by defining the zero transverse stress state for the flat sample as being where the peak in the critical current occurs. This procedure has been followed in Fig. 3(b) and for the results on the upper critical field in Sec. IV.

Figures 3(a) and 3(b) also show the scaling of the transverse stress effect with magnetic field $B$. The effect was significantly greater at $10 \mathrm{~T}$ than at $8 \mathrm{~T}$ in both the round and flat samples. For example, at $100 \mathrm{MPa}$ transverse compression, the critical-current degradation increased from $20 \%$ at $8 \mathrm{~T}$ to $29 \%$ at $10 \mathrm{~T}$. The increase of the degradation with magnetic field suggests that the transverse stress effect is associated with a reversible degradation of the upper critical field.

\section{Upper critical field}

The effective upper critical field $B c_{c 2}^{*}\left(\equiv \mu_{0} H_{c 2}^{*}\right)$ was determined as a function of stress by extrapolating the $J_{c}$ vs $B$ data to high fields for each transverse stress level. Instead of using the Kramer extrapolation, which is inaccurate for many conductors, the extrapolation was carried out using

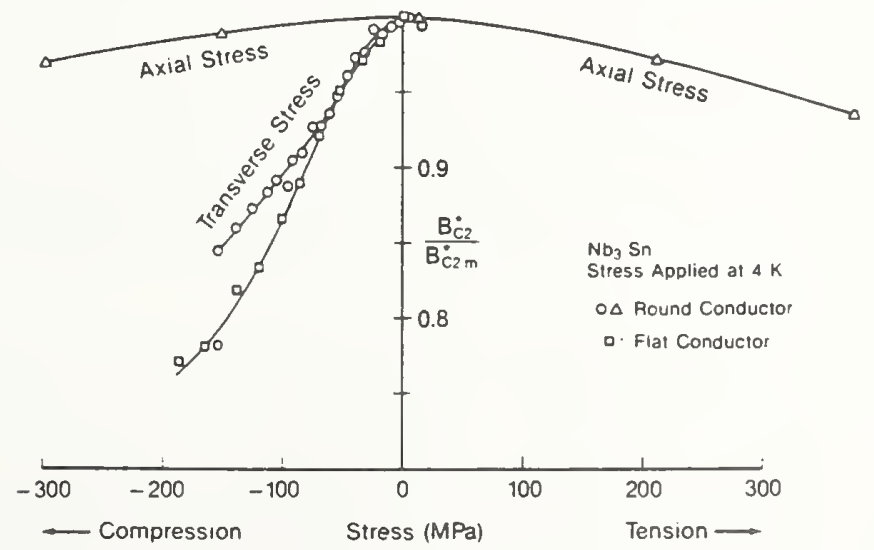

FIG. 4. Intrinsic effect of transverse and axial stress on the upper critical field of $\mathrm{Nb}_{3} \mathrm{Sn}$. the strain scaling law ${ }^{3}$ (SSL) and the actual shape of the $J_{c}(B)$ curve measured for this conductor up to fields of $19 \mathrm{~T}$. Because of the universality of the strain scaling law for many different materials having widely varying strain sensitivitie. and shapes of the Lorentz-force curve, we believe its validity for transverse stress to be a good assumption. Using a general form for the shape of the field-dependent pinning force curve. the SSL for the Lorentz force $F$ in the elastic regime (where applied stress $\sigma$ is proportional to strain) can be expressed as ${ }^{3}$

$$
\begin{aligned}
F & \equiv J_{c}(\sigma, B) \\
& =K(\sigma)\left[B / B_{c 2}^{*}(\sigma)\right]^{p}\left\{1-\left[B / B_{c 2}^{*}(\sigma)\right]\right\}^{4} .
\end{aligned}
$$

where $K(\sigma)$ is a stress-dependent factor proportional to the maximum Lorentz force, and $p$ and $q$ are parameters that are independent of transverse stress. $P$ and $q$ were determined from zero-stress $J_{c}$ vs $B$ data measured at magnetic fields from 8 to $19 \mathrm{~T}$ and found to have the values of 0.89 and 2.0. respectively.

Using the strain scaling relation given in Eq. (2) and the measured shape of the high-field $J_{c}(B)$ data for this conductor, values of $B_{c 2}^{*}(\sigma)$ were determined from the $J_{c}(\sigma, B)$ data of Fig. 3 and are plotted in Fig. 4. Again. the striking result is the large effect of transverse stress on this intrinsic parameter. The effect is much larger than for axial stress. The transverse stress that gives rise to a given level of $B_{c: 2}^{*}$ degradation is generally about ten times less than the axial stress. For example, the degradation in the upper critical field reaches $5 \%$ at about $45 \mathrm{MPa}$ of transverse stress, compared with $430 \mathrm{MPa}$ of axial stress within the $\mathrm{Nb}_{3} \mathrm{Sn}$ filaments. Thus, the intrinsic sensitivity of the upper critical field to transverse compressive stress is significantly greater than for axial stress.

\section{DISCUSSION}

The relatively large magnitude of the transverse stress effect compared with the axial stress effect is striking. The effect is much larger than the error limits on the value of the elastic modulus used to compare axial and transverse stress results. The difference in sensitivity of the critical current appears to be intrinsic, as evidenced by the reversibility of the effect and by the large difference in sensitivity (about an order of magnitude) observed for the upper critical field.

One possible explanation for the difference between the magnitudes of the axial and transverse effects may be a preferred crystal growth orientation in the $\mathrm{Nb}_{3} \mathrm{Sn}$ reaction layer. The growth pattern in multifilamentary samples is radial within each filament, which would define an anisotropy between axial and transverse properties. Togano and $\mathrm{Ta}$ chigawa ${ }^{4}$ have reported a very strong (100) [011] texture in $\mathrm{Nb}_{3} \mathrm{Sn}$ and $\mathrm{V}_{3} \mathrm{Ga}$ tapes. Further micrographic characterization of multifilamentary conductors might help clarify this.

The observation of a small peak in the $J_{c}$ vs stress curve for the flat sample, compared with the absence of such a peak for the round sample, is significant in light of its consistency with the three-dimensional treatment of strain expressed by Eq. (1). If this, or an expression modified to account for the observed anisotropy in stress sensitivity, could be proven quantitatively accurate, it would represent an important 
simplification in the engineering analysis of three-dimensional strain effects in magnet design. The extensive body of data that already exists for axial stress effects could be applied to three-dimensional analyses.

Equation (1) also shows that when both axial tensile and transverse compressive strains are present. they will combine to create a greater distortional state in the material (i.e., greater $\langle\epsilon\rangle$ ). Axial tension will produce a positive $\epsilon_{z}$ and transverse compression a negative $\epsilon_{y}$, enhancing $\langle\epsilon\rangle$ through the last term in Eq. (1). This situation is the usual case for the three-dimensional stress state in most magnets. For example, in a solenoid, the Lorentz force generates axial tension through hoop stress and transverse compression through radial pressure. Thus, the effects reported here for transverse compression will in general add to (not compensate) the effects of axial tension.

\section{APPLICATION}

First, it should be noted that the large sensitivity of the critical current and upper critical field of $\mathrm{Nb}_{3} \mathrm{Sn}$ to transverse stress does not necessarily mean that transverse stress will be a significantly worse design problem than axial stress. The transverse stress effect is about an order of magnitude greater than the axial effect, but its relative importance is tempered by the fact that axial stresses in the $\mathrm{Nb}_{3} \mathrm{Sn}$ filaments can, in practice, accumulate to much higher values than transverse stresses. This is because the axial stress on the conductor is concentrated in the $\mathrm{Nb}_{3} \mathrm{Sn}$ filaments with the majority of the conductor cross section (the soft copper and bronze) not bearing much of the load. Also, for the axial case, the stress is not transmitted to the $\mathrm{Nb}_{3} \mathrm{Sn}$ filaments through a soft matrix material, which limits the stress for the transverse case.

The axial st ress also scales with winding radius. For example, in a simple solenoid, the hoop stress on the overall conductor $\sigma_{\|}$will be given by

$\sigma=J B R$,

where $J$ is the overall current density in the conductor, $B$ is the magnetic field, and $R$ is the radius of the winding. The intrinsic stress experienced by the $\mathrm{Nb}_{3} \mathrm{Sn}$ filaments will be significantly greater than the overall stress given by Eq. (3), however. The exact enhancement depends on the volume ratio of superconductor in the conductor and the mechanical properties of the nonsuperconducting material. The important point is that axial stress scales with the winding radius and can become significant in large applications.

Transverse stress $\sigma_{1}$, on the other hand, scales with the thickness of the conductor $t$ (or accumulated winding thickness between distributed reinforcements), in the direction perpendicular to both the current and field (which would be in the radial direction for a solenoid):

$$
\sigma_{\downarrow}=J B t \text {. }
$$

Thus, transverse stress is dependent on conductor size and shape, not directly on overall magnet size as for axial stress.

Transverse stress effects will become important mainly as applications call for larger conductors needed to limit inductance and keep induced quench voltages low in large magnet applications. The transverse stress effect will place limits on both the conductor dimensions and on the radial spacing between distributed reinforcement in the magnet.

As an example of the application of these results. consider the transverse stress degradation of the critical current at $10 \mathrm{~T}$, given by the data in Fig. 3. The decrease in critical current becomes significant (i.e., exceeds $10 \%$ ) at about 50 $\mathrm{MPa}$. Substituting this value for $\sigma$. in Eq. (4) and assuming a current density of $10^{4} \mathrm{~A} / \mathrm{m}^{2}$ at $10 \mathrm{~T}$ leads to a limit on the radial thickness of the conductor of about $5 \mathrm{~mm}$. This is a worst-case situation with no shared support of the Lorentz force from hoop stress, for example. Other values can be substituted for the parameters in Eq. (4) to determine limits on unsupported conductor thicknesses for specific applications.

In cabled conductors, stress concentrations at strand crossover points could aggravate the transverse stress effects reported here, because the stress is no longer uniformly applied to the conductor, but is concentrated at the crossover points. Since the critical current of the conductor is a weak link problem, the effect could be significant in the design of cabled conductors. The stress state inside cabled conductors may be as important as what happens outside the conductor, i.e., the internal stress design of large conductors needs to be considered along with the overall conductor stress.

\section{CONCLUSION}

These data show that there is a relatively large effect of transverse stress on the critical current of $\mathrm{Nb}_{3} \mathrm{Sn}$ multifilamentary conductors. The onset of significant (10\%) transverse stress degradation occurs at about $50 \mathrm{MPa}$. The magnitude of the effect is significantly larger than for stress applied along the conductor axis. At $10 \mathrm{~T}$, for example, comparable degradation of the critical current is observed at transverse stress levels seven times smaller than for axial stress.

The effect on the critical current has been shown to be associated with a reversible transverse stress degradation of the upper critical field. The intrinsic sensitivity of the upper critical field to transverse compressive stress is significantly greater than for axial stress. The stress that gives rise to a given level of $B_{c 2}^{*}$ degradation is generally about ten times less for transverse stress than for axial stress. The transverse stress effect on $B_{c 2}^{*}$ will be the dominating factor in determining the degradation of the critical current at high fields; the relative degradation of $J_{c}$ will increase as the magnetic field approaches the upper critical field.

Based on the universality of the axial strain effect ${ }^{1.3}$ and the intrinsic effect of transverse stress on the upper critical field, we believe the effect of transverse stress is a general effect and will be operable not only in $\mathrm{Nb}_{3} \mathrm{Sn}$ conductors, but also other $\mathrm{A}-15$ superconductors such as $\mathrm{V}_{3} \mathrm{Ga}, \mathrm{Nb}_{3} \mathrm{Al}$, and $\mathrm{Nb}_{3} \mathrm{Ge}$.

The geometric average strain expressed by Eq. (1) gives a consistent account of the presence of a peak in the flat samples and the absence of such a peak in the round samples. This, or a modified representation of the distortional strain state, could be an important simplification in the engineering analysis of three-dimensional strain effects in magnet design.

As magnet systems are scaled to larger size, the transverse stress effect will have an impact on their design. The 
transverse stress scales with the thickness of the conductor as described in Eq. (4). This places a limit on the dimensions of the conductor and conductor stacking without support in the direction mutually perpendicular to field and current. It will also affect the internal stress design of cabled conductors, "since stress concentration at strand crossover points can significantly enhance the effect.

\section{ACKNOWLEDGMENTS}

The author wishes to thank D. Rule for help with data reduction and photomicroscopy, C. Thompson and $J$. Brauch for assistance with apparatus design, and J. M. Moreland, L. F. Goodrich, S. Bray, M. Fukumoto, D. Welch, and R. Flukiger for valuable discussions. The high ( >10T) magnetic field data in this study were obtained using the magnet facilities of the Francis Bitter National Magnet Laboratory. This work was supported by the Office of Fusion
Department of Energy; under Contract No. DE-AI0184ER52113.

'See, for example, the references given in J. W'. Ekın. Adv. Cryog. Eng. 30. 823 (1984).

'This article is based on data presented by the author at the L'.S. Depl. of Energy Workshop on N,Sn, Cambridge, MA. A ugust +-5, 1986

${ }^{3} \mathrm{~J}$ W. Ekin. Cryogenics 20.611 (1980).

"G. Rupp, IEEE Trans. Magn. MAG-13, 1565 (1977).

${ }^{3}$ R. M. Scanlan, R. W. Hoard. D. N. Cornish. and J. P. Zbasnik, in Filamentary A15 Superconduciors. edited by M. Suenaga and A. F. Clark ( Plenum. New York, 1980), p. 221.

${ }^{\circ}$ D. S. Easton. D. M. Kroeger, W. Speckıng, and C. C. Koch. J. Appl. Phy's. 51, 2748 (1980).

'M. Fukumoto. K. Katagiri, T. Okada. and K. Yasohama. in Proceedings of the International Symposium on Flux Pinning and Electromagnetic Properties in Superconductors, edited by T. Matsushita, K. Yamafuji, and F. Irie (Matsukuma, Fukuoka, Japan, 1986), p. 278.

${ }^{8}$ D. O. Welch, Adv. Cryo. Eng. 26, 48 (1980).

"K. Togano and K. Tachikawa. J. Appl. Phys. 50. 3495 (1979). 
TRANSVERSE STRESS EFFECT ON MULTIFILAMENTARY $\mathrm{Nb}_{3} \mathrm{Sn}$ SUPERCONDUCTOR*

\author{
J. W. Ekin \\ Electromagnetic Technology Division \\ National Bureau of Standards \\ Boulder, CO 80303
}

\title{
ABSTRACT
}

A large reversible degradation of the critical current of multifilamentary $\mathrm{Nb}_{3} \mathrm{Sn}$ superconductors has been observed under the application of uniaxial compressive stress applied transverse to the conductor axis at $4 \mathrm{~K}$. In bronze-process multifllamentary $\mathrm{Nb}_{3} \mathrm{Sn}$, the onset of significant degradation occurs at about $50 \mathrm{MPa}$. The intrinsic effect of transverse stress on the upper critical field is about ten times greater than for axial stress. Although transverse stress on the $\mathrm{Nb}_{3} \mathrm{Sn}$ filaments is less than axial stress in most applications, it will need to be considered in the internal stress design of large magnets because of the greater sensitivity of $\mathrm{Nb}_{3} \mathrm{Sn}$ to transverse stress. The effect scales with conductor thickness and this will place limits on conductor dimensions and the spacing between distributed reinforcement in large magnets.

\section{INTRODUCTION}

The effects of axial stress on the critical current of practical multifilamentary $\mathrm{Nb}_{3} \mathrm{Sn}$ superconductors were first measured about a decade ago.1-3 A large amount of data has been accumulated on this component of stress since then. ${ }^{4}$ In practical superconducting magnets, however, the superconductor is subjected to three-dimensional stresses. Typically the transverse component of stress is large and compressive. The first data on the effect of transverse compressive stress on the critical current of $\mathrm{Nb}_{3} \mathrm{Sn}$ were reported last year. 5 The effect has subsequently been observed by the group at Karlsruhe. 6

In this paper we summarize the main properties of the transverse stress effect given in Ref. 5, and consider the application to large magnet design. The effect of the transverse component of stress on the critical current is significantly greater than the axial component, about seven time greater at $10 \mathrm{~T}$. The effect has its origin in an intrinsic reversible degradation of the upper critical field. The effect of transverse stress on the upper critical field is about an order of magnitude greater than for axial stress.

*Coneribution of NBS, not subject to copyright. 

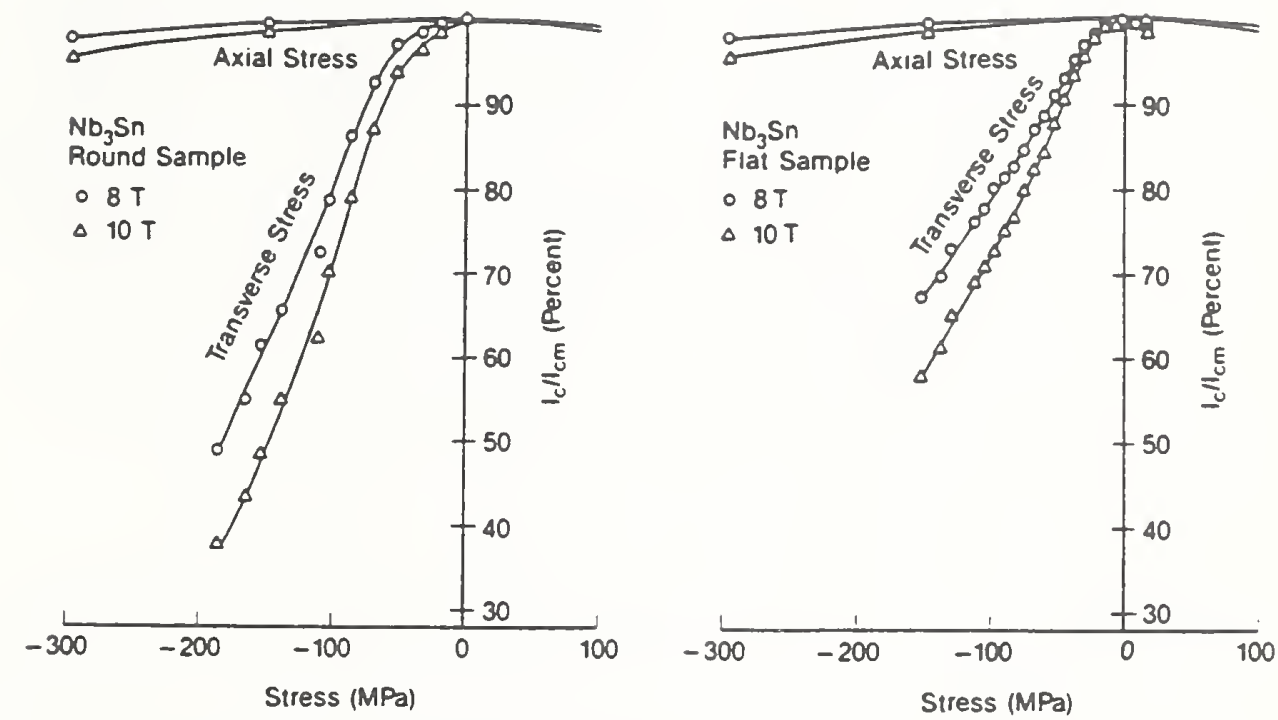

Fig. 1. Comparison of critical current degradation in multifilamentary $\mathrm{Nb}_{3} \mathrm{Sn}$ for transverse and axial compressive stress in magnetic fields of 8 and $10 \mathrm{~T}$. Transverse stress degradation is shown for both round (a) and flat (b) samples. Negative values of stress represent compression, positive values represent tension (after Ref. 5).

The transverse stress effect scales with the thickness of the conductor. The main impact of the effect will be to place limits on both the conductor thickness and the radial spacing between distributed reinforcement in large superconducting magnet design.

\section{RESULTS}

\section{Critical Current}

Fig. la shows the critical current of a multifilamentary bronze-process $\mathrm{Nb}_{3} \mathrm{Sn}$ conductor as a function of transverse compressive stress for applied fields of 8 and $10 \mathrm{~T}$. The ordinate is the measured critical current normalized to the starting (zero-stress) value. The abscissa is the effective overall transverse stress obtained by dividing the applied load by the area of the sample. A projected area in the direction of the transverse load is used, consisting of the length $(9.5 \mathrm{~mm})$ over which compressive load is applied times the original sample diameter $(0.70 \mathrm{~mm})$.

In this test, the anvil heads were flat in order to apply uniaxial transverse load. The sample was round, however, so this simple method of estimating stress does not take into account the change in contact area between the anvil heads and the sample as the sample was compressed. However, the copper layer completely surrounded the $\mathrm{Nb}_{3} \mathrm{Sn}$ filament region and was relatively thick, so it served to uniformly distribute the load into the filament region. Thus, the effective stress from the projected area represents reasonably well the approximate average stress experienced by the $\mathrm{Nb}_{3} \mathrm{Sn}$ filaments within the composite. This has been confirmed by data on the preflattened conductor, described below. 
Also shown in Fig. la for comparison are data on the critical current degradation from axial stress. These data were obtained from criticalcurrent degradation measurements on another piece of the same conductor which was subjected to axial stress. 7 Under axial stress, the total axial force is known, but it is apportioned among the various composite materials because they all occupy parallel load-bearing paths. This is different from the transverse case where all the components of the composite experience approximately the same stress, which is transferred from one material to the next in a serial load chain (from matrix to filament, to matrix, to filament, etc.) Fortunately, the axial strain intrinsic to the $\mathrm{Nb}_{3} \mathrm{Sn}$ filaments can be measured ${ }^{8}, 9^{\prime}$ and this can be used to calculate the axial stress in the $\mathrm{Nb}_{3} \mathrm{Sn}$ filaments. This was done assuming a $\mathrm{Nb}_{3} \mathrm{Sn}$ elastic modulus ${ }^{10}$ of $165 \mathrm{GPa}$ to generate the axial stress curve in Fig. 1.

(Conversely, all of the results presented could be given in terms of strain by dividing the reported stress values by the modulus of $\mathrm{Nb}_{3} \mathrm{Sn}$.)

Note the difference in the magnitudes of the transverse and axial stress effects. For transverse stress, the degradation is a little less than $10 \%$ at $10 \mathrm{~T}$ under a transverse pressure of $50 \mathrm{MPa}$ and rises to nearly 308 degradation at a transverse pressure of $100 \mathrm{MPa}$. For axial stress, on the other hand, the degradation is unmeasurable ( $\leq 18$ ) up to about $200 \mathrm{MPa}$. Looking at the data in Fig. 1 over a wide range shows that the stress which causes a given amount of critical-current degradation at $10 \mathrm{~T}$ is generally about seven times less for transverse stress than for axial stress. This ratio will increase at higher magnetic fields because of the effect of the upper critical field, as discussed below.

The critical current degradation was reversible. Upon unloading the sample, the critical current recovered toward its non-degraded value. The recovery was not total, probably because the $\mathrm{Nb}_{3} \mathrm{Sn}$ filaments were kept in partial compression by the plastically deformed soft matrix material.

Fig. Ib shows the critical current of a piece of the same conductor which was flattened to a rectangular cross section $0.38 \mathrm{~mm} \times 0.76 \mathrm{~mm}$ prior to reacting. This eliminates any ambiguities associated with a change in the contact area for the round sample. Note in Fig. 1b that the decrease with transverse stress is nearly the same as for the round sample at degradation levels up to about 308 . This indicates that the copper matrix does indeed distribute the stress relatively uniformly into the filament region and that the effective stress described above is a reasonable approximation to the average stress experienced by the $\mathrm{Nb}_{3} \mathrm{Sn}$ filaments.

The transverse stress effect in the flat sample shows a small peak in critical current as a function of transverse stress. The data in Fig. 1b has been plotted with the transverse stress curve shifted so the peak occurs at the abscissa zero. This peak is not present in the results for the round sample. We believe this effect in the flattened sample is due to anisotropic precompression from thermal contraction of the matrix material. Each filament has a slightly flattened cross section prior to reaction, with an average aspect ratio of slightly less than 2:1. After cooldown from reacting the $\mathrm{Nb}_{3} \mathrm{Sn}$, this results in less thermal compression by the bronze matrix along the narrow dimension of the filaments than along their width. A finite element calculation by Fukumoto et al. 11 showed this effect quite clearly for in-situ conductors, which have highly aspected filament cross sectional shapes prior to reaction.

As external transverse pressure is applied along the narrow dimension of the filaments, the initial effect is to remove the distortional strain in the filament, increasing the critical current. As more transverse stress is applied, the critical current eventually passes through a peak and starts to decrease. This is because the strain along the narrow dimension exceeds the 


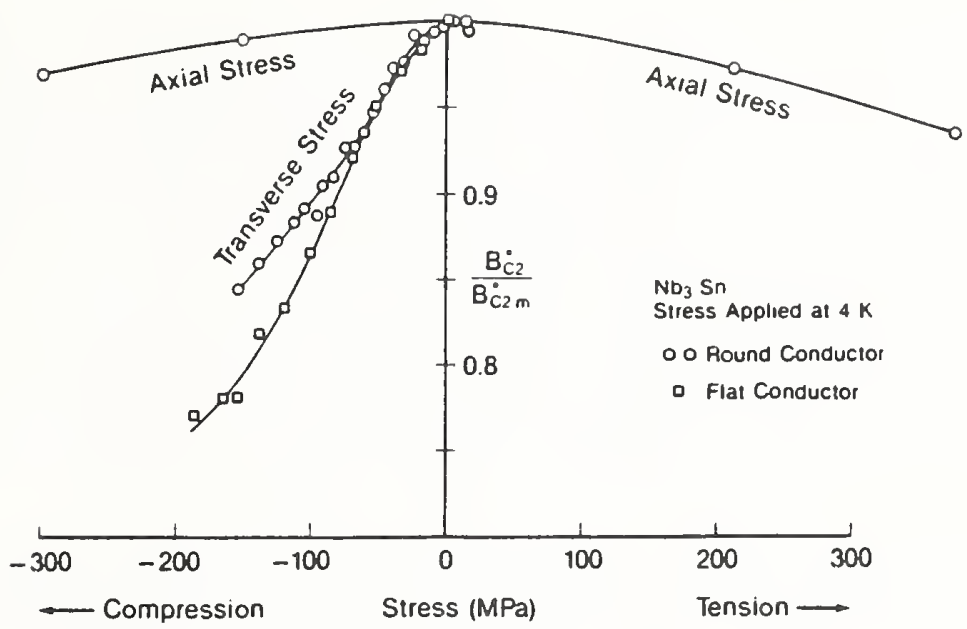

Fig. 2. Intrinsic effect of transverse and axial stress on the upper critical field of $\mathrm{Nb}_{3} \mathrm{Sn}$ (after Ref. 5).

precompression along the filament width, thus increasing the distortional strain of the crystal structure. For the round sample, on the other hand, the precompression from thermal contraction transverse to the filament is isotropic and thus the symmetry breaking application of uniaxial transverse stress immediately leads to crystal distortion and a monotonically decreasing critical current.

Figs. $1 \mathrm{a}$ and $1 \mathrm{~b}$ also show the scaling of the transverse stress effect with magnetic field, $B$. The effect was significantly greater at $10 \mathrm{~T}$ than at $8 \mathrm{~T}$ in both the round and flat samples. The increase of the degradation with magnetic field suggests that the transverse stress effect has its origin in a reversible degradation of the upper critical field.

\section{Upper Critical Field}

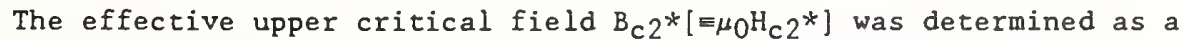
function of stress by extrapolating the $J_{C}$ vs. B data to high fields for each transverse stress level. This was done by using the zero-stress $\mathrm{J}_{\mathrm{c}}$-vs.-B characteristic measured at magnetic fields from $8 \mathrm{~T}$ to $19 \mathrm{~T}$ and then assuming that the strain scaling law holds for transverse stress (i.e. that the shape of the Lorentz force curve remains the same and simply scales with transverse stress, just as has been shown for axial stress). 7

The results are shown in Fig. 2. Again, the striking result is the large difference in the sensitivity of the superconductor properties to transverse stress compared with axial stress. The stress that gives rise to a given level of $\mathrm{B}_{\mathrm{c}} 2^{*}$ degradation is generally about ten times less for the transverse direction than for the axial direction. For example, the degradation in the upper critical field reaches 58 at an axial stress of 430 $\mathrm{MPa}$ within the $\mathrm{Nb}_{3} \mathrm{Sn}$ filaments, compared with about $45 \mathrm{MPa}$ of transverse stress. Thus the intrinsic sensitivity of the upper critical field to transverse compressive stress is significantly greater than for axial stress and is the dominating factor in degrading the critical current at high fields. 


\section{APPLICATION}

First, it should be noted that the large sensitivity of the critical current and upper critical field of $\mathrm{Nb}_{3} \mathrm{Sn}$ to transverse stress does not necessarily mean that transverse stress will be a significantly worse design problem than axial stress. The transverse stress effect is about an order of magnitude greater than the axial effect, but its relative importance is tempered by the fact that axial stresses in the $\mathrm{Nb}_{3} \mathrm{Sn}$ filaments can, in practice, accumulate to much higher values than transverse stresses. This is because the axial stress on the conductor is concentrated in the $\mathrm{Nb}_{3} \mathrm{Sn}$ filaments with the majority of the conductor cross section (the soft copper and bronze) not bearing much of the load. Also, for the axial case, the stress is not transmitted to the $\mathrm{Nb}_{3} \mathrm{Sn}$ filaments through a soft matrix material, which limits the stress for the transverse case.

Axial stress scales with the winding radius and can become significant in large applications. Transverse stress, $\sigma_{\perp}$, on the other hand, scales with the thickness of the conductor, $t$, in the direction perpendicular to both the current and field (which would be the radial direction for a solenoid):

$$
\sigma_{\perp}-J B t
$$

Consequently, transverse stress is dependent on conductor size and shape, not directly on overall magnet size as for axial stress.

Thus, transverse stress effects will become important mainly as applications call for larger conductors needed to limit inductance and keep induced quench voltages low in large magnet applications. The transverse stress effect will place limits on both the conductor dimensions and on the radial spacing between distributed reinforcement in the magnet.

As an example of the application of these results, consider the transverse stress degradation of the critical current at $10 \mathrm{~T}$, given by the data in Fig. 1. The decrease in critical current becomes significant (i.e. exceeds 10\%) at about $50 \mathrm{MPa}$. Substituting this value for $\sigma_{\perp}$ in $\mathrm{Eq}$. (1) and assuming a current density of $10^{9} \mathrm{~A} / \mathrm{m}^{2}$ at $10 \mathrm{~T}$ leads to a limit on the radial thickness of the conductor of about 5 mra. Other values can be substituted for the parameters in Eq. (1) to determine limits on unsupported conductor thicknesses for specific applications.

In cabled conductors, stress concentrations at strand crossover points could aggravate the transverse stress effects reported here, because the stress is no longer uniformly applied to the conductor but is concentrated at the crossover points. Since the critical current of the conductor is a weak link problem, the effect could be significant in the design of cabled conductors. The stress state inside cabled conductors may be as important as what happens outside the conductor, i.e. the internal stress design of large conductors needs to be considered along with the overall conductor stress.

\section{CONCLUSION}

The onset of significant (10z) transverse stress degradation in $\mathrm{Nb}_{3} \mathrm{Sn}$ multifilamentary conductors occurs at about $50 \mathrm{MPa}$. The magnitude of the effect is significantly larger than for stress applied along the conductor axis. At $10 \mathrm{~T}$, for example, comparable degradation of the critical current is observed at transverse stress levels seven times smaller than for axial stress. 
The data indicate that the effect has its origin in a reversible degradation of the upper critical field. The intrinsic sensitivity of the upper critical field to transverse compressive stress is significantly greater than for axial stress. The stress that gives rise to a given level of $\mathrm{B}_{\mathrm{c}} 2^{*}$ degradation is generally about ten times less for transverse stress than for axial stress. Because of the intrinsic decrease in the upper critical field, the effect on the critical current will become increasingly greater at fields higher than those reported here.

We have also measured the effect of transverse stress on a multifilamentary jelly-roll conductor and obtained results similar to those reported here for a bronze-process $\mathrm{Nb}_{3} \mathrm{Sn}$ conductor. Based on the universality of the axial strain effect, 7,4 we believe the effect of transverse stress is a general effect and will be operable not only in $\mathrm{Nb}_{3} \mathrm{Sn}$ conductors, but also other A-15 superconductors such as $\mathrm{V}_{3} \mathrm{Ga}, \mathrm{Nb}_{3} \mathrm{Al}$; and $\mathrm{Nb}_{3} \mathrm{Ge}$.

As magnet systems are scaled to larger size, the transverse stress effect will have an impact on their design. The transverse stress scales with the thickness of the conductor as described in Eq. (1). This places a limit on the dimensions of the conductor and conductor stacking without support in the direction mutually perpendicular to field and current. It will also affect the internal stress design of cabled conductors, since stress concentration at strand crossover points can significantly enhance the effect.

\section{ACKNOWLEDGMENTS}

The author wishes to thank D. Rule for help with data reduction and photomicroscopy, C. Thompson and J. Brauch for assistance with apparatus design, J. Moreland, L. Goodrich, M. Fukumoto, D. Welch, and R. Flukiger for valuable discussions. The high (>10 T) magnetic field data in this study were obtained using the magnet facilities of the Francis Bitter National Magnet Laboratory. This work was supported by the Office of Fusion Energy, U.S. Department of Energy, under contract No. DE-AI01-84ER52113

\section{REFERENCES}

1. J. W. Ekin, Appl. Phys. Lett. 29, 216 (1976).

2. D. S. Easton and R. E. Schwall, Appl. Phys. Lett. 29, 319 (1976).

3. J. L. McDougall, Proc. ICEC 6 , IPC Science and Technology Press, 396 (1976).

4. See, for example, the references given in J. W. Ekin, Adv. Cryog. Eng. 30, 823 (1984).

5. J. W. Ekin, Jour. Appl. Physics, 1987, to be published; presented at the U.S. Dept. of Energy Workshop on $\mathrm{Nb}_{3} \mathrm{Sn}$, Cambridge, MA, August 4-5, 1986 .

6. W. Specking, W. Goldacker, and R. Flukiger, these conference proceedings.

7. J. W. Ekin, Cryogenics 20,611 (1980).

8. G. Rupp, IEEE Trans. Mag. MAG-13, 1565 (1977).

9. R. M. Scanlan, R. W. Hoard, D. N. Cornish, and J. P. Zbasnik, in Filamentary A15 Superconductors, edited by M. Suenaga and A. F. Clark, Plenum, NY (1980), P. 221.

10. D. S. Easton, D. M. Kroeger, W. Specking, and C. C. Koch, J. Appl. Phys. 51, 2748 (1980).

11. M. Fukumoto, K. Katagiri, and $T$. Okada, and K. Yasohama, in Proc. Int. Symp, on Flux Pinning and Electromagnetic Properties in Superconductors, edited by T. Matsushita, K. Yamafuji, and F. Irie, Matsukuma Press, Fukuoka, Japan (1986), p. 278. 
Iransverse Stress Effect on the Critical Current of Internal Iin and Bronze Process $\mathrm{Nb}_{3} \mathrm{Sn}$ Superconductors

J. W. Ekin and S. L. Bray

National Institure of Standards and Technology, Boulder, Co

P. Danielson and D. Smathers

Teledyne Wah Chang, Albany, OR

R. I. Sabatini and M. Suenaga

Brookhaven National Lab., Upton, NY

The effect of transverse stress on the critical current density, $J_{C}$, has been shown to be significant in bronze process $\mathrm{Nb}_{3} \mathrm{Sn}$, with the onset of significant degradation at about 50 $\mathrm{MPa}{ }^{1}$ In an applied field of $10 \mathrm{I}$, the magnitude of the effect is about seven times larger for transverse stress than for axial tensile stress. In a subsequent study, ${ }^{2}$ similar results were observed in another bronze process $\mathrm{Nb}_{3} \mathrm{Sn}$ conductor made by a different manufacturer.

Because axial tensile stress on typical magnet conductors is usually greater than transverse stress, the effect on $J_{c}$ of the two types of stress will be comparable in importance in magnet engineering. The main effect of transverse stress will be to place limits on the conductor thickness in the direction of the Lorentz force. This can be particularly significant in cabled conductors where stress concentrations can occur at strand crossover points.

In bronze process wires, the magnitude of the effect has been observed to be the same for round strands as for flattened strands (round strands that were flattened prior to reaction) except that there is a small peak in the $J_{c} v s$. compression curve for the flattened sample due to anisotropic precompression of the filaments. 1

Contribution of NIST, not subject to copyright.
The mechanism accounting for the transverse stress effect and its large magnitude compared with the axial tensile effect is still the subject of speculation. In an attempt to better understand the nature of the effect, we have undertaken a series of experiments to determine whether the transverse stress effect depends on the grain morphology of the $\mathrm{Nb}_{3} \mathrm{Sn}$ reaction layer in the superconductor.

To do this, we have measured the effect in an internal tin conductor with excess $t i n$, which yields a more equiaxed $\mathrm{Nb}_{3} \mathrm{Sn}$ grain morphology than for bronze process $\mathrm{Nb}_{3} \mathrm{Sn}$, where the grains are more columnar. ${ }^{3}$

The results for the effect of transverse compression on the $J_{c}$ of a round bronze process $\mathrm{Nb}_{3} \mathrm{Sn}$ wire are shown in Fig. 1.1 Fig. 2 shows the results for a round internal tin superconductor. A comparison of the two sets of results shows nearly the same transverse stress effect in each within the limits of error. The unloaded values of $J_{C}$ recovered more for the bronze process $\mathrm{Nb}_{3} \mathrm{Sn}$ than for the internal tin $\mathrm{Nb}_{3} \mathrm{Sn}$, probably because the yield strength of the matrix may have been greater for the bronze process wire, retaining more residual transverse stress on the $\mathrm{Nb}_{3} \mathrm{Sn}$ filaments upon unloading.

Proceedings of the 6th Japan-U.S. Workshop on High Field Superconducting Materials and Standard Proceedures for High Field Superconducting Materials Testing Edited by K. Tachikawa, K. Yamafuji, H. Wada, J.W. Ekin, and M. Suenaga Japan, 1989 
However, the effect of transverse stress on $J_{c}$ was nearly identical for the two conductors, indicating that the transverse stress effect is probably not dependent on grain morphology. The data also indicate that the effect is not highly sensitive to the conductor fabrication procedure, and hence these data are probably applicable to a wide variety of $\mathrm{Nb}_{3} \mathrm{Sn}$ conductors for magnet engineering.

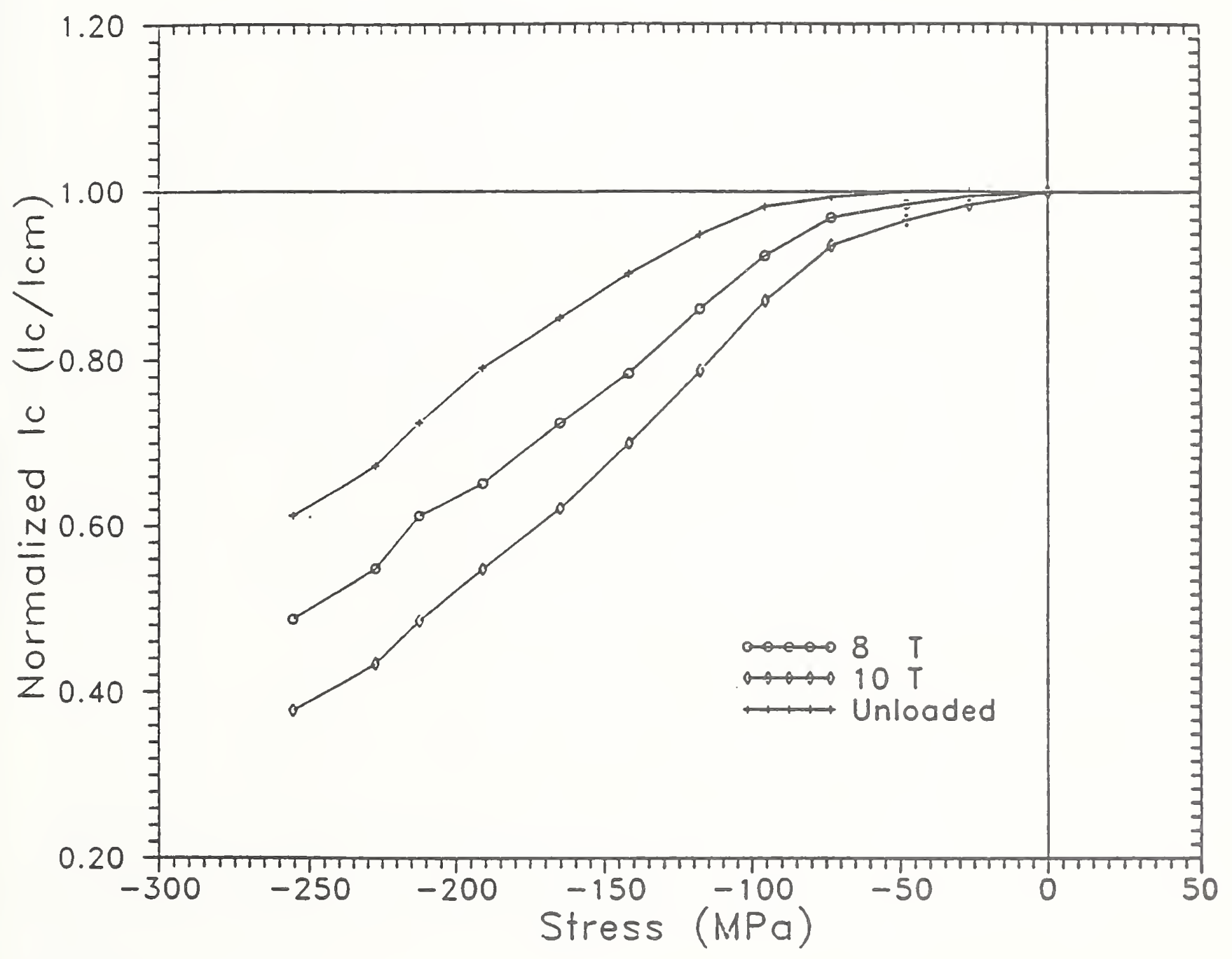

Fig. 1. Bronze process $\mathrm{N}_{3} \mathrm{Sn} \mathrm{I}_{\mathrm{C}}$-vs-stress curves at 8 and $10 \mathrm{~T}$. The critical current has been normalized by its maximum value. Icm. The "Unloaded" data points indicate the measured $I_{c}$ at 10 I after unloading the sample from the indicated stress level. 


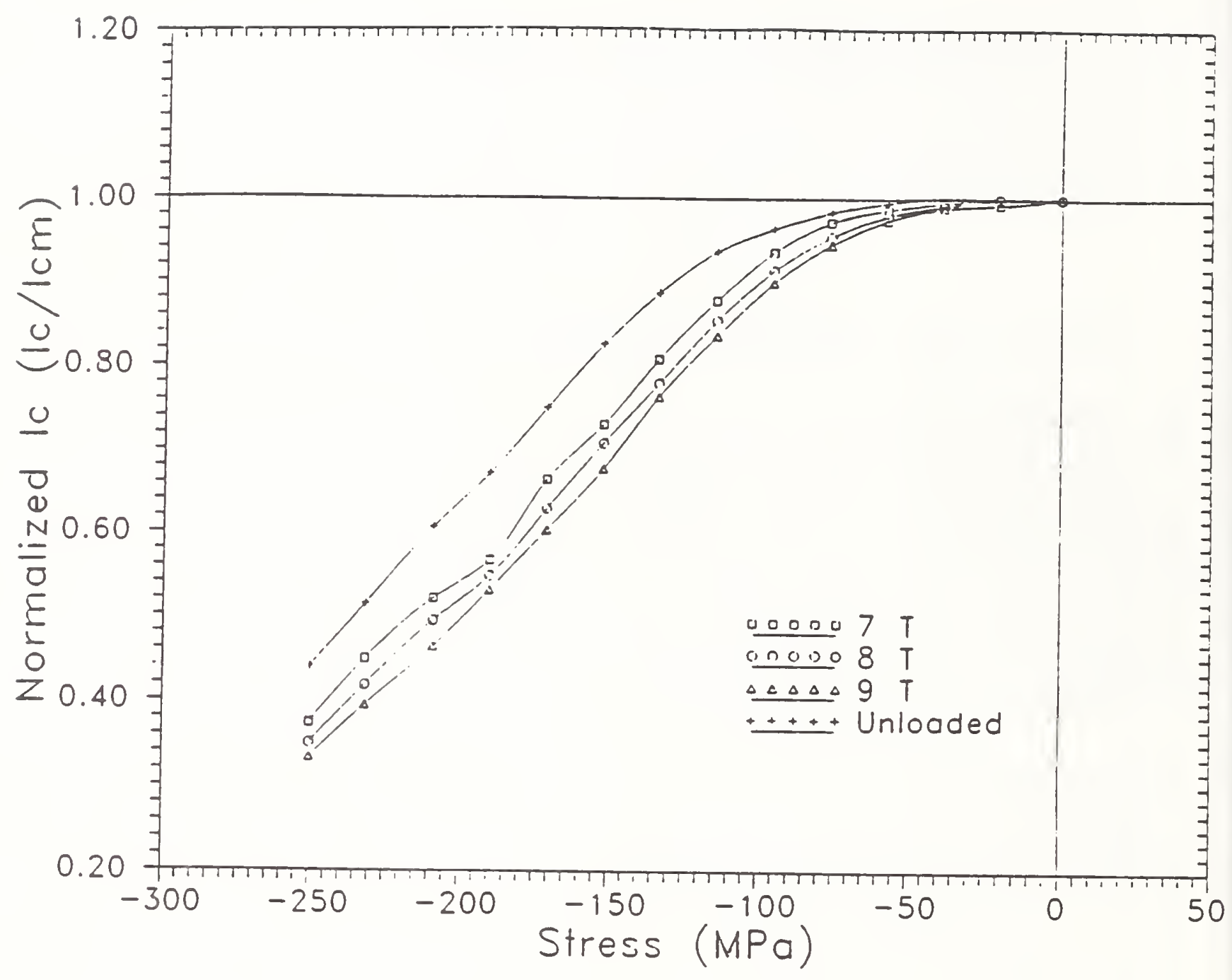

Fig. 2. Internal tin process $\mathrm{Nb}_{3} \mathrm{Sn} \mathrm{I}_{\mathrm{C}}$-vs-stress curves at 7,8 , and $9 \mathrm{I}$. The critical current has been normalized by its maximum value, Icm. The "Unloaded" data points indicate the measured $I_{C}$ at $9 \mathrm{~T}$ after unloading the sample from the indicated stress level.

References:

1. J. W. Ekin, Appl. Physics 62,4829 (1987).

3. M. Suenaga, Metallurgy of Continuous Filamentary AIS Superconductors," in Superconductor

2. W. Specking, W. Goldacker, and R. Flukiger, Adv. Cryo. Eng. 34, 569 Materials Science, edited by $S$. Foner (1988). and B. B. Schwartz, Plenum Press, New York 1980, PP. 201-274. 


\title{
Effect of transverse stress on the critical current of bronze-process and internal-tin $\mathrm{Nb}_{3} \mathrm{Sn}$
}

\author{
J. W. Ekin, S. L. Bray, and W. L. Bahn \\ Electromagnetic Technology Division. National Institute of Standards and Technology, \\ Boulder, Colorado 80303
}

(Received 28 September 1990; accepted for publication 14 January 1991)

\begin{abstract}
The effect of transverse stress on the critical current of two substantially different $\mathrm{Nb}_{3} \mathrm{Sn}$ superconductors, a bronze-process conductor and an internal-tin conductor, has been measured. Photomicrographs of the two conductors reveal a basic difference in their microstructure. The bronze-process conductor exhibits columnar grains that are radially oriented within the $\mathrm{Nb}_{3} \mathrm{Sn}$ filaments, while the grains of the internal-tin conductor are more equiaxed and randomly oriented. The radial orientation of the bronze-process grains defines an anisotropy between the axial and transverse directions that might account for the greater sensitivity of the critical current to transverse stress reported previously. The effect of transverse stress measured on the internal-tin conductor, however, is comparable to that of the bronze-process conductor. Thus, these data indicate that the transverse stress effect is not highly dependent on either grain morphology or fabrication process. From an engineering standpoint the similarity of the transverse stress effect for these two types of $\mathrm{Nb}_{3} \mathrm{Sn}$ superconductors represents an important simplification for setting first-order quantitative limits on the mechanical design of large superconducting magnets.
\end{abstract}

Internally generated stresses within the windings of a superconducting magnet can adversely affect its performance through a reduction in the superconductor's critical current $\left(I_{c}\right)$. The superconducting wire is subjected to two dominant stress components, a tensile stress that is aligned with the wire's longitudinal axis (axial stress) and a compressive stress that is perpendicular to its axis (transverse stress). The effect of axial stress on the $I_{c}$ of A 15 superconductors has been the subject of extensive research.' More recently, the first measurement of the effect of transverse stress was made, ${ }^{2}$ and it was significant in bronzeprocess $\mathrm{Nb}_{3} \mathrm{Sn}$, with the onset of degradation occurring at about $50 \mathrm{MPa}$. In an applied field of $10 \mathrm{~T}$, the effect of transverse stress is about seven times the effect of axial tensile stress. Subsequently, the results of these measurements were substantiated at several other laboratories. ${ }^{3-5} \mathrm{~A}$ bronze-process $\mathrm{Nb}_{3} \mathrm{Sn}$ conductor was used for the initial transverse stress measurements and for several later measurements. The bronze process results in a characteristic grain morphology ${ }^{6}$ that might explain the greater sensitivity of these conductors to transverse stress. Because of its dissimilarity to bronze-process conductors, an internal-tin $\mathrm{Nb}_{3} \mathrm{Sn}$ conductor was selected for this study to directly address the effect of grain morphology on the transverse stress effect.

The apparatus allows measurement of the superconducting sample's $I_{c}$ as a function of magnetic field and transverse stress at $4 \mathrm{~K}$. Figure I shows the mutually perpendicular orientation of the current, magnetic field, and force. Force is applied to the sample through a pivoting self-aligning anvil that ensures uniform force application along the sample's compressed length. The voltage leads are soldered to the sample within this region so that the electric field is measured only over the uniformly stressed portion of the sample. The force is supplied by a servohydraulic test system, the current by a 900 A battery- powered supply, and the magnetic field by a $10 T$ split-pair magnet.

The characteristics of the two conductors that were tested are given in Table I. The cross section of each sample is shown in Fig. 2. The bronze-process conductor is stabilized with an external 64 vol\% copper ring which surrounds the $\mathrm{Nb}_{3} \mathrm{Sn}$ filament-bronze core and is separated from it by a tantalum diffusion barrier. The tin core modified jelly roll internal-tin conductor is stabilized with 65 vol\% copper. The copper is separated from each of the conductor's $42 \mathrm{Nb}_{3} \mathrm{Sn}$ and bronze subelements by diffusion barriers consisting of a ring of niobium surrounded by a ring of vanadium.

Figures 3(a) and 3(b) show the shape and orientation of grains within the $\mathrm{Nb}_{3} \mathrm{Sn}$ filaments for the bronze-process and internal-tin samples, respectively. The photographs show fractured transverse cross sections of the filaments. In the case of the bronze-process conductor, the grains have a columnar shape with their longitudinal axes oriented approximately radially within the filament. This microstructural anisotropy is a possible source of the conductor's greater sensitivity to transverse stress than to axial

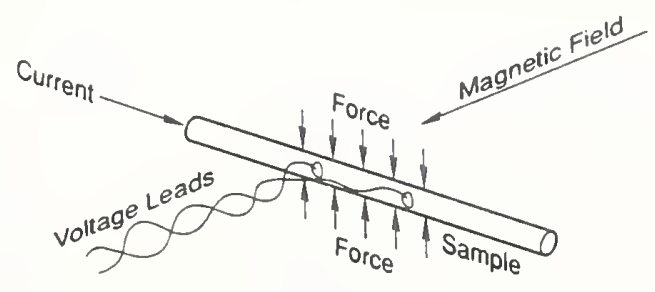

FIG. 1. Relative orientation of test sample, current, magnetıc field, applied transverse force, and voltage sensing leads. 
TABLE I. Sample characteristics.

\begin{tabular}{|c|c|c|}
\hline & Bronze-process & Internal-tin \\
\hline Diameter & $0.70 \mathrm{~mm}$ & $0.60 \mathrm{~mm}$ \\
\hline No. filaments & 2869 & $=15800$ \\
\hline Filament size & $3.8 \mu \mathrm{m}$ & $=1.1 \mu \mathrm{m} \times(1.1-2.2) \mu \mathrm{m}$ \\
\hline Filament twist pitch & $25 \mathrm{~mm}$ & $12.1 \mathrm{~mm}$ \\
\hline \multirow[t]{4}{*}{ Composition (vol\%) } & $64 \% \mathrm{Cu}$ & $65 \% \mathrm{Cu}$ \\
\hline & $25 \%$ bronze & $12.0 \% \mathrm{Nb}$ ) \\
\hline & $2.4 \% \mathrm{Ta}$ & $11.8 \% \mathrm{Cu}$ \\
\hline & $8.6 \% \mathrm{Nb}_{3} \mathrm{Sn}$ and $\mathrm{Nb}$ & $\left.\begin{array}{l}6.3 \% \mathrm{Sn} \\
2.45 \% \mathrm{Nb} \\
2.45 \% \mathrm{~V}\end{array}\right\}$ Noncopper \\
\hline Noncopper area & $1.35 \times 10^{-7} \mathrm{~m}^{2}$ & $9.90 \times 10^{-8} \mathrm{~m}^{2}$ \\
\hline \multirow[t]{2}{*}{ Reaction } & $96 \mathrm{~h}$ at $700^{\circ} \mathrm{C}$ & $220 \mathrm{~h}$ at $220^{\circ} \mathrm{C}$ \\
\hline & $48 \mathrm{~h}$ at $730^{\circ} \mathrm{C}$ & $\begin{array}{l}16 \mathrm{~h} \text { at } 340^{\circ} \mathrm{C} . \\
110 \mathrm{~h} \text { at } 650^{\circ} \mathrm{C}\end{array}$ \\
\hline
\end{tabular}

stress. In contrast, the internal-tin grains are more equiaxed, as described in Ref. 6. If the source of the transverse stress sensitivity of bronze-process $\mathrm{Nb}_{3} \mathrm{Sn}$ is in fact the anisotropy, then the internal-tin conductor would be expected to show a smaller sensitivity to transverse stress.

The critical current of the test sample was measured at zero applied force and $4 \mathrm{~K}$ as a function of magnetic field. Force was then applied to the sample at $4 \mathrm{~K}$ and again the $I_{c}$ was measured as a function of field. This process was continued while incrementally increasing the applied force to generate the data shown in Fig. 4.

The effective overall transverse stress is calculated by dividing the applied force by the compressed area of the sample. A projected area equal to the sample diameter multiplied by the length of the compressed region is used for this calculation. This simple technique is justified by the results of previous comparative measurements between otherwise identical round and rectangular $\mathrm{Nb}_{3} \mathrm{Sn}$ samples. ${ }^{2}$

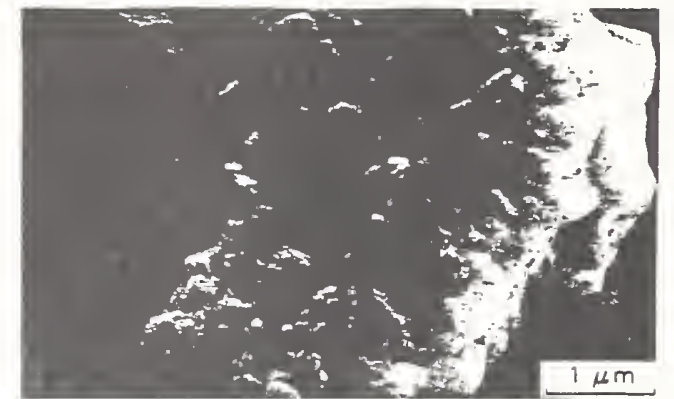

(a)

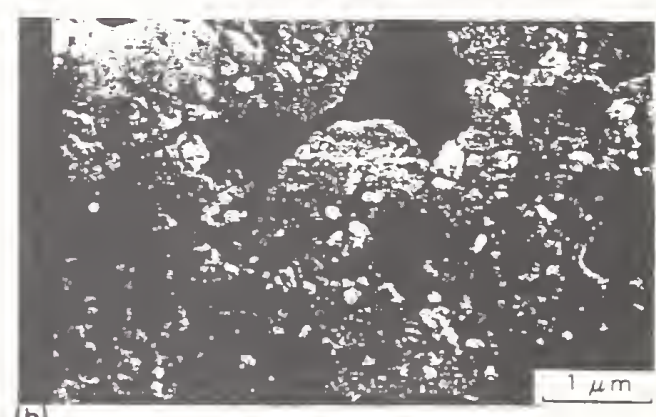

(b)

FIG. 3. Micrographs of bronze-process conductor (a) showing columnar radially oriented grains, and internal-tin conductor (b) showing more equiaxed and randomly oriented grains.

An electric-field criterion of $2 \mu \mathrm{V} / \mathrm{cm}$ was used to determine the $I_{c}$. The overall precision of the $I_{c}$ data is about $\pm 3 \%$.

Figure 4 (a) shows the critical current of the internaltin conductor as a function of transverse compressive stress for several applied magnetic fields. The ordinate is the measured critical current normalized to the starting (zerostress) value, and the abscissa is the effective overall transverse stress. Figure $4(\mathrm{~b})$ shows the 8 and $10 T$ internal-tin data compared with the bronze-process data.
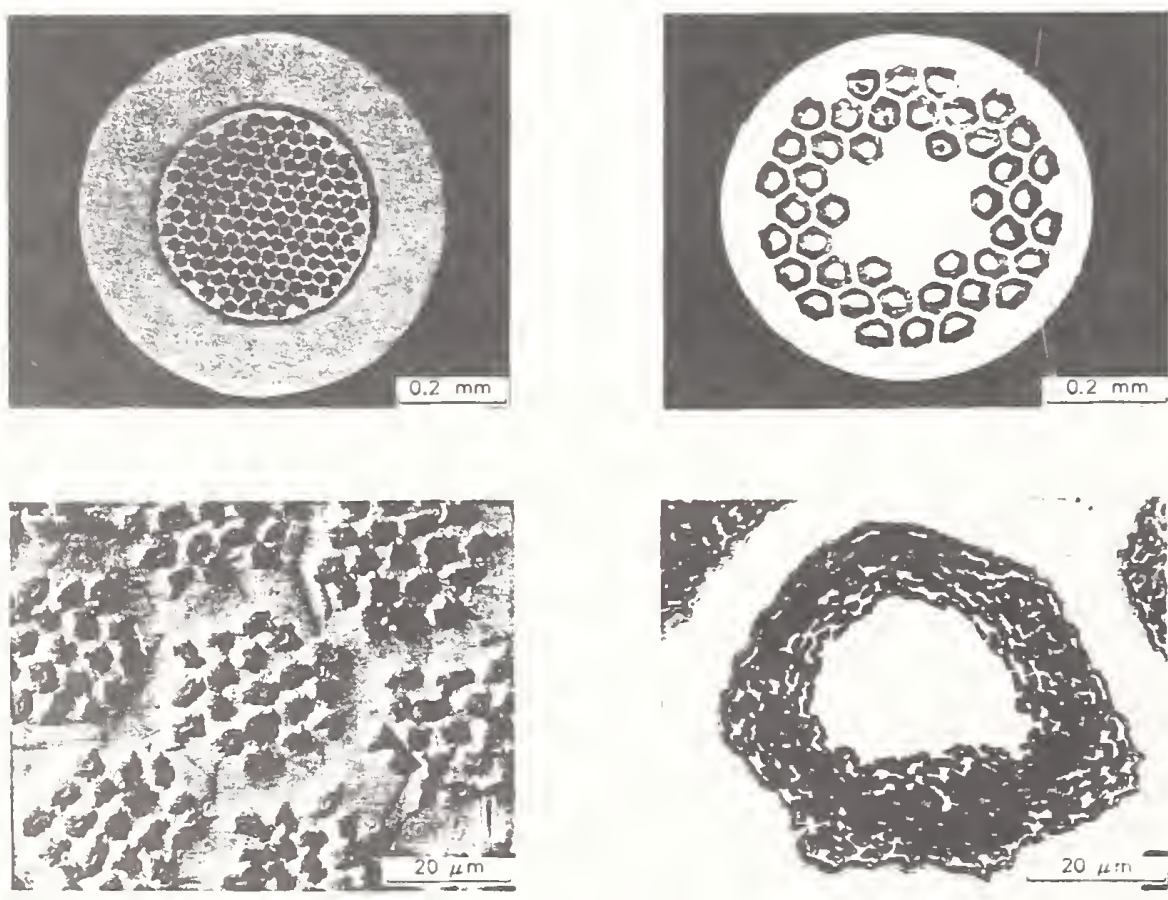

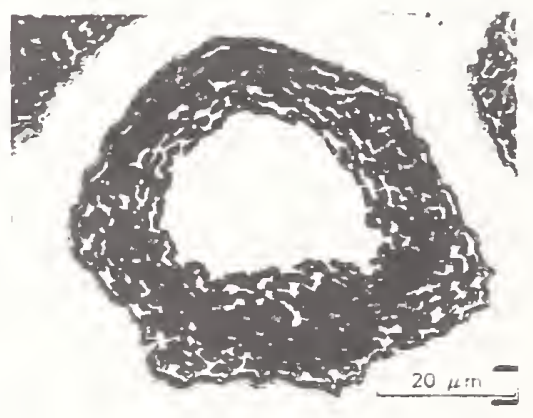

20
FIG. 2. Cross-sectional view of bronze-process sample (top) and internal-tin sample (bottom). 

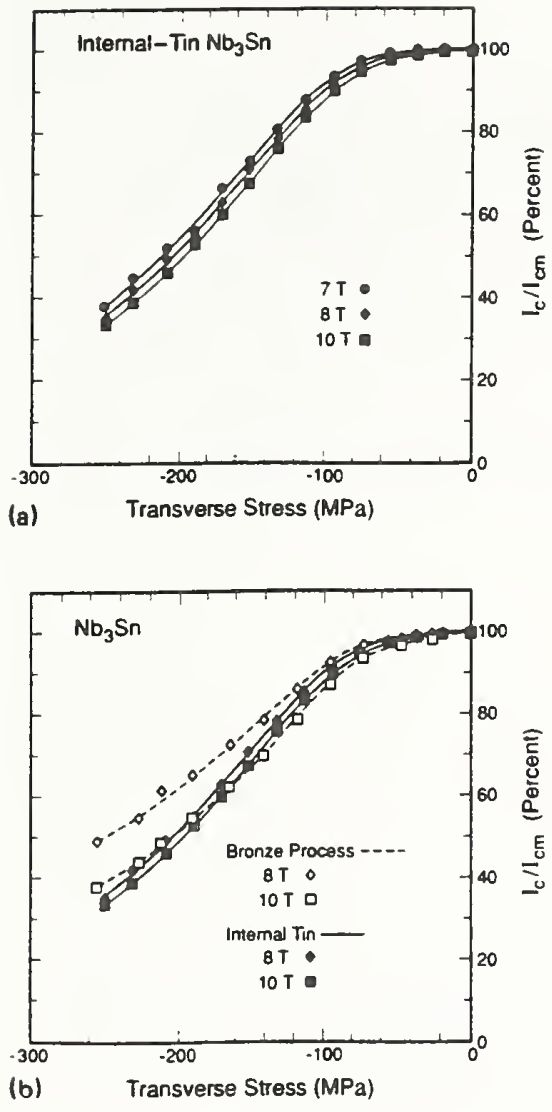

FIG. 4. Critical-current degradation as a function of transverse stress and magnetic field for the internal-tin conductor (a) and (b) a comparison of the effect in internal-tin and bronze-process conductors. By convention, the negative values of stress indicate compression.

Comparing the $8 T$ internal-tin and bronze-process data of Fig. 4 (b), a $10 \%$ reduction in the $I_{c}$ occurs at a transverse stress of approximately $100 \mathrm{MPa}$ for both samples. Moreover, the two sets of results show nearly the same transverse stress effect, within the limits of error, over the entire measured range of transv'rse stress. If anything, the internal-tin sample has a slightly greater $I_{c}$ degradation than the bronze-process sample, which is opposite to what would be expected if the columnar grain morphology was the source of the transverse stress sensitivity. At a stress of $200 \mathrm{MPa}$, the internal-tin sample shows a degradation of approximately $50 \%$, whereas the bronze-process sample is degraded slightly less than $40 \%$. Considering that the two test conductors were fabricated by different manufacturers using fundamentally different processes, the two data sets are in surprisingly close agreement.

The difference between the magnitude of the effect of axial and transverse stress on the $I_{c}$ of $\mathrm{Nb}_{3} \mathrm{Sn}$ is presently the source of speculation. Based on these data, however, the difference would not appear to be due to microstructural anisotropy. Moreover, recent measurements of the transverse stress effect in $\mathrm{Nb}_{3} \mathrm{Al}$ (Ref. 7) and $\mathrm{PbMo}_{6} \mathrm{~S}_{8}$ (Ref. 8) demonstrate that the large difference between the two effects is not limited to $\mathrm{Nb}_{3} \mathrm{Sn}$ or even to Al 15 superconductors. If, in general, this is a common characteristic of superconductors, the transverse stress effect may be important for developing a fundamental understanding of stress effects in superconductors. From a practical point of view, the relatively large magnitude of the transverse stress effect makes it a significant factor in the designing of large magnets where the large radial thickness of the conductor can lead to accumulation of high internal transverse stress loading of the strands within cabled conductors. ${ }^{2}$ Although the effect of transverse stress on the $I_{c}$ of $\mathrm{Nb}_{3} \mathrm{Sn}$ is considerably greater than that of axial stress, their relative importance in magnet design may be comparable because the axial stress imposed on typical magnet conductors is usually greater than transverse stress. The main effect of transverse stress will be to place limits on the conductor thickness in the direction of the Lorentz force. This can be particularly significant in cabled conductors where stress concentrations can occur at strand crossover points.

The effect of transverse stress on the critical current of internal-tin $\mathrm{Nb}_{3} \mathrm{Sn}$ superconductors was nearly identical to that measured for bronze-process $\mathrm{Nb}_{3} \mathrm{Sn}$. The magnitude of the effect was nearly the same even though photomicroscopic analysis revealed significant difference in grain morphology and orientation for the two conductor types; the bronze-process conductor grains had a columnar shape and were oriented in a radial pattern within each $\mathrm{Nb}_{3} \mathrm{Sn}$ filament, while the internal-tin conductor grains were more equiaxed. These data also indicate that the transverse stress effect is not highly sensitive to the $\mathrm{Nb}_{3} \mathrm{Sn}$ fabrication procedure. The data shown in Fig. 4, thus, should serve as a general starting point for determining the effect of transverse stress and setting engineering design limits for the conductor windings in $\mathrm{Nb}_{3} \mathrm{Sn}$ magnets.

The authors wish to thank P. Danielson and D. Smathers for preparing the cross-sectional views of the superconductors, and R. L. Sabatini and M. Suenaga for making the photomicrographs of the filament cross sections. This work was supported by the Office of Fusion, Department of Energy, under contract No. DE-AIO184ER52113.

'See, for example, the references given in J. W. Ekin, Adv. Cryo. Eng. 30 823 (1984).

${ }^{2}$ J. W. Ekin, J. Appl. Phys. 62, 4829 (1987).

${ }^{3}$ W. Specking, W. Goldacker, and R. Flükiger, Adv. Cryo. Eng. 34, 569 (1988).

${ }^{4}$ L. T. Summers and J. R. Miller, IEEE Trans. Magn. 25. 1835 (1989).

${ }^{5}$ H. Boschman and L. J. M. van de Klundert, Adv. Cryo. Eng. 36, 93 (1990).

${ }^{6} \mathrm{M}$. Suenaga, C. J. Klamut, N. Higuchi, and T. Kuroda. IEEE Trans. Magn. 21, 305 (1985).

${ }^{7}$ D. Zeritis, T. Ando, Y. Takahashi, M. Nishi, H. Nakajima, and S. Shimamoto, Appl. Phys. Lett 57, 506 (1990)

${ }^{8}$ W. Goldacker, W. Specking, F. Weiss, G. Rimikis, and R. Flükıger, Cryogenics 29, 955 (1989). 
Transverse Stress and Crossover Effect in $\mathrm{Nb}_{3} \mathrm{Sn}^{\circ}$

J. W. Ekin and S. L. Bray

Electromagnetic Technology Division, National Institute of Standards and Technology. Boulder, Colorado 80303

Abstract: The superconducting wires in an energized magnet coil are subjected to mechanical stresses caused by the Lorentz force. Previous measurements have shown that either axial tensile stress or transverse compressive stress, the two dominant stresses on the wire, can cause substantial degradation in the superconductor's critical current. The previous transverse stress measurements were made with uniformly applied stress; however, many superconductor applications employ cables where the strands experience stress concentrations at the points where they cross one another. For this study, a single stress concentration point was simulated by applying transverse stress to two $\mathrm{Nb}_{3} \mathrm{Sn}$ wires, which were crossed over one another at an angle, while measuring the critical current of one of the wires at magnetic fields up to $9 \mathrm{~T}$. A comparison between the crossover-transverse-stress measurements and the uniform-transversestress measurements shows a critical-current degradation at equivalent load that is significantly greater for the crossover situation due to the reduced area. However, these preliminary data indicate that the concentration effect can be simply predicted because the degradation in critical current is comparable at equivalent stress.

\section{INTRODUCTION}

The two dominant components of stress in a magnet winding are a tensile stress that is aligned with the wire's longitudinal axis (axial stress) and a compressive stress that is perpendicular to its axis (transverse stress). The effect of axial stress on the critical current $\left(\mathrm{L}_{c}\right)$ of A15 superconductors has been the subject of extensive research. ${ }^{1}$ More recently, the effect of transverse stress on the $\mathrm{I}_{c}$ of $\mathrm{Nb}_{3} \mathrm{Sn}$ has been studied, ${ }^{2-6}$ and its effect is several times greater than that of axial stress. In previous measurements of the transverse stress effect, a uniform stress was applied over the length of the test wire. ${ }^{26}$ In this study, stress was applied to the test wire through a second sample of the same wire (crossover wire) to simulate a concentrated-stress condition that can occur within the strands of a superconducting cable. The superconductor used for these measurements is a tin-core modified jelly roll $\mathrm{Nb}_{3} \mathrm{Sn}$ wire. This is the wire that was used to construct the cable-in-conduit conductor for the US-Demonstration Poloidal Coil (US-DPC).

"Contribution of NIST, not subject to copyright. 
The test configuration of the crossover wire and the test wire are shown in Fig. 1. The voltage sensing leads were connected to the test wire outside its stressed region; consequently, an "effective voltage tap separation" was calculated from the crossover angle, $\Theta$, and the wire diameter, $d$. The $I_{c}$ values were determined using an electric field criterion of $2 \mu \mathrm{V} / \mathrm{cm}$, where the electric field was calculated from the effective voltage tap separation. Moreover, the difference between $I_{c}$ based on the actual tap separation and $I_{c}$ based on the effective separation. at zero stress and all tested magnetic fields, was less than $6 \%$. The overall precision of the $\mathbb{L}_{c}$ data is about $\pm 3 \%$.

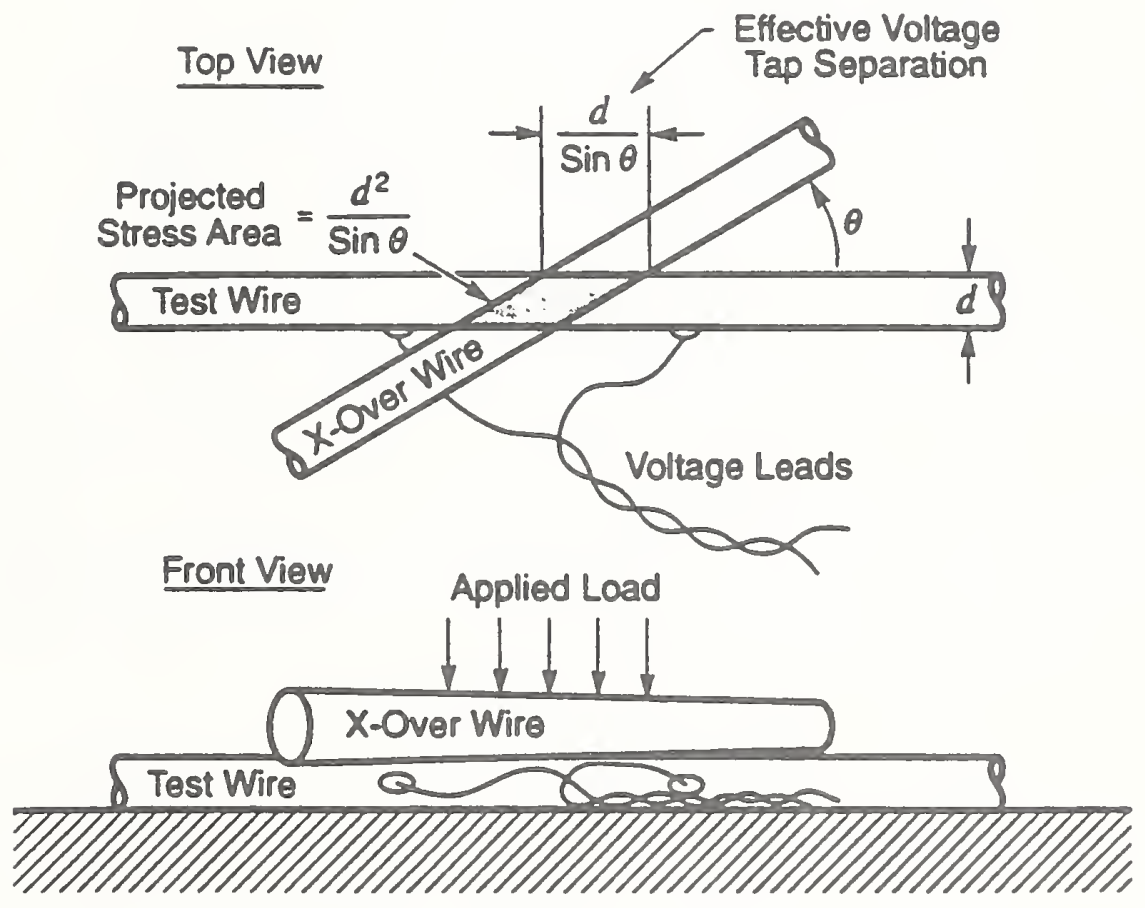

Fig. 1. Schematic diagram showing the test configuration of the test wire and crossover (X-over) wire.

For the purposes of this study, the transverse compressive stress is defined as the applied load divided by the "projected stress area," which is also shown in Fig. 1. A crossover angle of $30^{\circ}$ was selected for these measurements based on cable strand crossover angles observed in the USDPC cable. All of the $I_{c}$ measurements were made at a temperature of $4 \mathrm{~K}$. 


\section{RESULTS}

The results of the crossover measurements are shown in Fig. 2 where the $I_{c}$ is plotted as a function of transverse load for several magnetic fields. The ordinate is the measured $I_{c}$ normalized to the starting (zero-stress) value, and the abscissa is the transverse load applied to the test wire through the crossover wire. By convention, the load is negative to indicate compression. For comparison, the results of a uniform stress test on another sample of the same wire are also shown. In this case, the transverse load is evenly distributed along the length of the wire. At $9 \mathrm{~T}$, a $60 \%$ reduction in the $I_{c}$ occurs at a load of approximately $-1760 \mathrm{~N}$ for uniform stress and at only $1 / 6$ this load $(-290 \mathrm{~N})$ for crossover stress. The stressed area of the conductor in the uniform stress test is $7.48 \mathrm{~mm}^{2}$, and the stressed area of the crossover test wire is only $1.24 \mathrm{~mm}^{2}$, also $1 / 6$ the area.

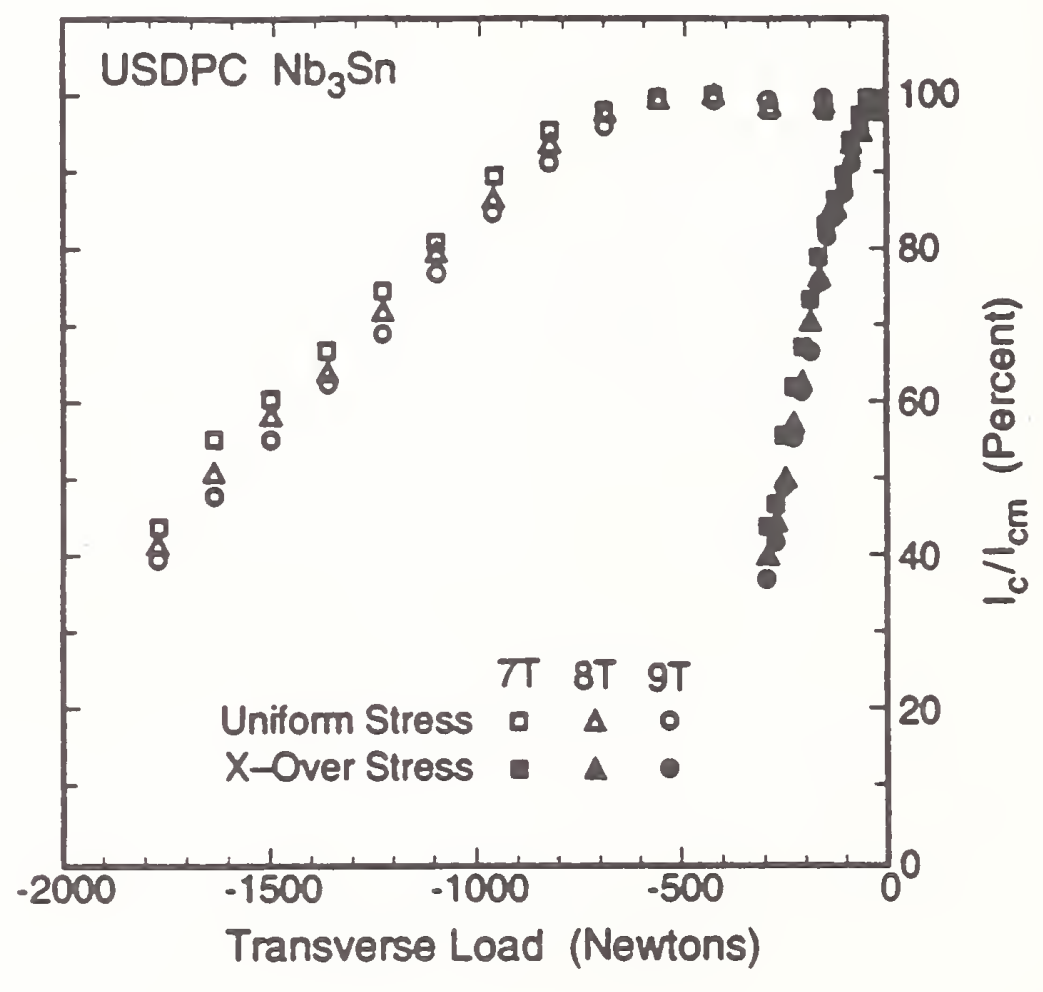

Fig. 2. Critical-current degradation as a function of transverse load and magnetic field for uniform and crossover stress.

Figure 3 shows the same $I_{c}$ data as Fig. 2, but in Fig. 3 it is plotted as a function of transverse stress instead of load. This plot shows that, for the same transverse stress, the $L_{c}$ degradation is comparable up to $-240 \mathrm{MPa}$ for uniform or crossover stress. These data show that the $I_{c}$ 


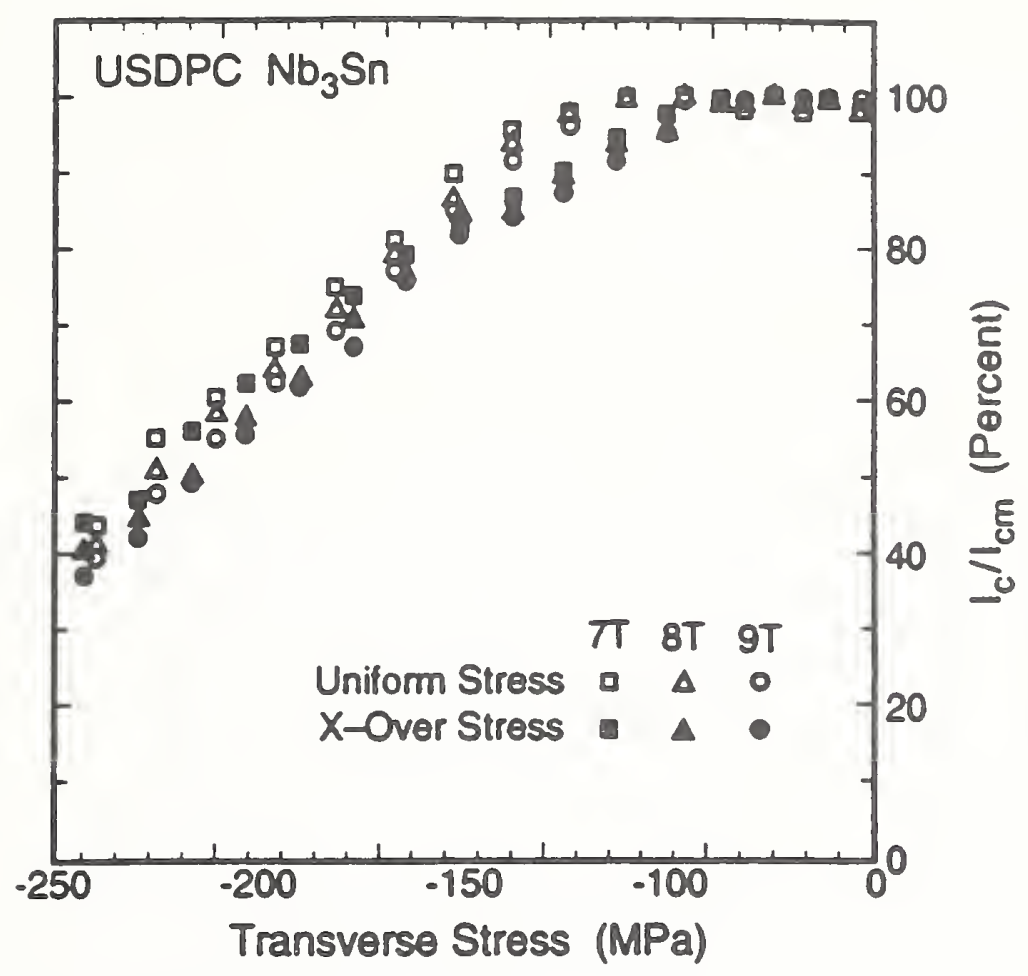

Fig. 3. Critical-current degradation as a function of transverse stress and magnetic field for uniform and crossover stress.

degradation caused by concentrated transverse stress at a strand crossover point is nearly the same as the degradation caused by uniform transverse stress. For both tests, there is no significant $I_{c}$ recovery when the tansverse load is removed from the test wire.

\section{CONCLUSIONS}

The transverse stress generated by the Lorentz force within the windings of a superconducting magnet can substantially degrade the $I_{c}$ of the superconductor and the performance of the magnet. Distributed structural reinforcement of the windings can limit the peak transverse load, but its use is restricted by inductance and current-density requirements. These data show that the effect of transverse load on the superconductor greatly depends on the load distribution. At a load that caused no measurable $I_{c}$ degradation for the uniform stress test, the $I_{c}$ degradation was over $60 \%$ for the crossover test. Consequently, internal cable design may be important in controlling degradation from this effect. When the results of the crossover and uniform stress tests are compared based on the applied stress, rather than load, the $\mathbb{L}_{s}$ degradation is nearly the same for both tests. This is an important result from an engineering analysis standpoint because it may allow the estimation of $I_{c}$ degradation and the design of cables from uniform transverse stress data and the cable strand geometry. 


\section{ACKNOWLEDGEMENT}

This work was supported by the Office of Fusion, Department of Energy, under contract No. DE-AIO1-84ER52113.

\section{REFERENCES}

1. See, for example, the references given in J. W. Ekin, Adv. Cryog. Eng. 30:823 (1984).

2. J. W. Ekin, Effect of transverse compressive stress on the critical current and upper critical field of $\mathrm{Nb}_{3} \mathrm{Sn}, \mathrm{J}$. Appl. Phys. 62:4829 (1987).

3. W. Specking, W. Goldacker, and R. Flükiger, Effect of transverse compression on $I_{c}$ of $\mathrm{Nb}_{3} \mathrm{Sn}$ multifilamentary wire, Adv. Cryog. Eng. 34:569 (1988).

4. L. T. Summers and J. R. Miller, The effect of transverse stress on the critical current of $\mathrm{Nb}_{3} \mathrm{Sn}$ ' cable-in-conduit superconductors, IEEE Trans. Magn. 25:1835 (1989).

5. H. Boschman and L. J. M. van de Klundert, Effects of transverse stress on the current carrying capacity of multifilamentary wires, Adv. Cryog. Eng. 36:93 (1990).

6. J. W. Ekin and S. L. Bray, Effect of transverse stress on the critical current of bronzeprocess and internal-tin $\mathrm{Nb}_{3} \mathrm{Sn}, \mathrm{J}$. Appl. Phys. 69:4436 (1991). 


\title{
CRITICAL-CURRENT DEGRADATION IN Nb,Sn COMPOSITE
}

\section{WIRES DUE TO LOCALLY CONCENTRATED TRANSVERSE STRESS}

\author{
S. L. Bray and J. W. Ekin
}

Electromagnetic Technology Division

National Institute of Standards and Technology

Boulder, Colorado 80303

\begin{abstract}
The superconducting wires in an energized magnet coil are subjected to mechanical stresses caused by the Lorentz force. Previous measurements have shown that either arial tensile stress or transverse compressive stress. the two dominant stresses on the wire, can cause substantial degradation in the superconductor's critical current. The previous transverse stress measurements were made with uniformly applied stress; however, many superconductor applications employ cables where the strands experience stress concentrations at the points where they cross one another. For this sudy, a single stress concentration point was simulated by applying transverse stress to two $\mathrm{Nb}_{3} \mathrm{Sn}$ wires, which were crossed over one another at an angle, while measuring the critical current of one of the wires at magnetic fields up to $9 \mathrm{~T}$. A comparison between the crossover-transversestress measurements and the uniform-transverse-stress measurements shows a critical-current degradation at equivalent load that is significantly greater for the crossover situation due to the reduced area. However, these preliminary data indicate that the concentration effect can be simply predicted because the degradation in critical current is comparable at equivalent stress.
\end{abstract}

\section{INTRODUCTION}

The Lorentz forces generated within the windings of a súperconducting magnet can be large enough to significantly degrade the critical current $\left(I_{j}\right)$ of the superconductor and, thus, the performance of the magnet. The two dominant components of stress are a tensile stress that is aligned with the wire's longitudinal axis (axial suress) and a compressive stress that is perpendicular to its axis (transverse stress). The effect of axial stress on the $I_{c}$ of Als superconductors has been the subject of extensive research. ${ }^{1}$ More recently, the effect of ransverse stress on the $\mathrm{I}_{c}$ of $\mathrm{Nb}_{3} \mathrm{Sn}$ has been saudied, ${ }^{26}$ and its effect is several times greater than that of axial stress. In previous measurements of the transverse stress effect, a uniform stress was applied over the length of the test wire. ${ }^{26}$ In this study. stress was applied to the test wire through a second sample of the same wire (crossover wire) to simulate a concentrated-stress condition that can occur within the strands of a superconducting cable. The superconductor used for these measurements is a tin-core modified jelly roll $\mathrm{Nb}_{3} \mathrm{Sn}$ wire. This is the wire that was used to construct the cable-in-conduit conductor for the US-Demonstration Poloidal Coil (US-DPC).

"Contribution of NIST, not subject to copyright 


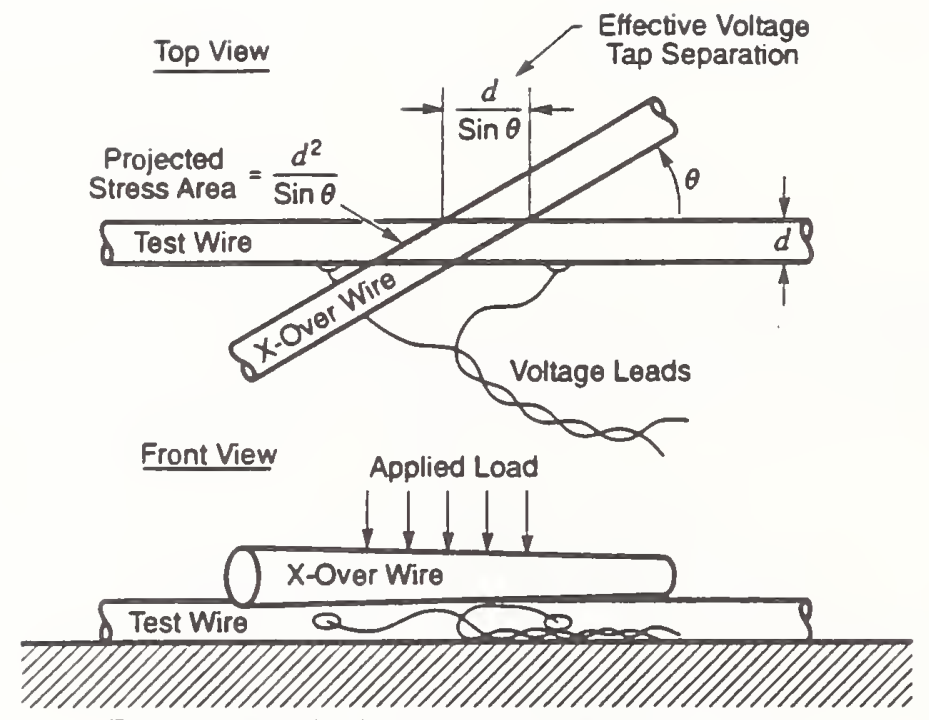

Fig. 1. Schematic diagram showing the test configuration of the test wire and crossover (X-over) wire.

\section{EXPERIMENTAL DETAILS}

The $\mathrm{L}_{\mathrm{e}}$ of a Nb $\mathrm{N}_{3} \mathrm{Sn}$ superconducting wire was measured at $4 \mathrm{~K}$ as a function of magnetic field and transverse compressive stress. The relative orientations of the current. magnetic field. and stress were mutually perpendicular to simulate the conditions within the windings of a superconducting magnet. The current was supplied by a 900 A bantery-powered supply, the magnetic field by a 9 T split-pair magnet, and the stress by a servohydraulic test system.

The test configuration of the crossover wire and the test wire are shown in Fig. 1. The voltage sensing leads were connected to the test wire outside its stressed region; consequently, an "effective voltage tap separation" was calculated from the crossover angle, $\theta$, and the wire diameter. $d$. The $I_{c}$ values were determined using an electric field criterion of $2 \mu \mathrm{V} / \mathrm{cm}$, where the electric field was calculated from the effective voltage tap separation. Moreover, the difference between $I_{c}$ based on the actual tap separation and $I_{c}$ based on the effective separation, at zero stress and all tested magnetic fields, was less than $6 \%$. The overall precision of the $\mathrm{I}_{\epsilon}$ data is about $\pm 3 \%$.

Table 1. $\mathrm{Nb}_{3} \mathrm{Sn}$ Wire Specifications

\begin{tabular}{|c|c|}
\hline Wire Diameter & $0.78 \mathrm{~mm}$ \\
\hline Stabilizing Copper & 54 vol. $\%$ \\
\hline Non-Copper & $46 \mathrm{vol} . \%$ \\
\hline Nb Filament & 22.9 vol. \% \\
\hline Copper & $48.7 \mathrm{vol} . \%$ \\
\hline Tin & $15.8 \mathrm{voL} \%$ \\
\hline Vanadium & $12.6 \mathrm{vol} . \%$ \\
\hline Local Cu/Nb Ratio & 1.7 \\
\hline Filament Size & $3 \mu \mathrm{m}$ \\
\hline Filament Composition & $\mathrm{Nb}-1 \mathrm{wt} . \% \mathrm{Ti}$ \\
\hline Subelements & 18 \\
\hline Twist Pitch & 2 twists per inch \\
\hline \multicolumn{2}{|l|}{ Critical Current } \\
\hline 7 Tesla & $309 \mathrm{~A}$ \\
\hline 8 Tesla & $256 \mathrm{~A}$ \\
\hline 9 Tesla & $213 \mathrm{~A}$ \\
\hline
\end{tabular}




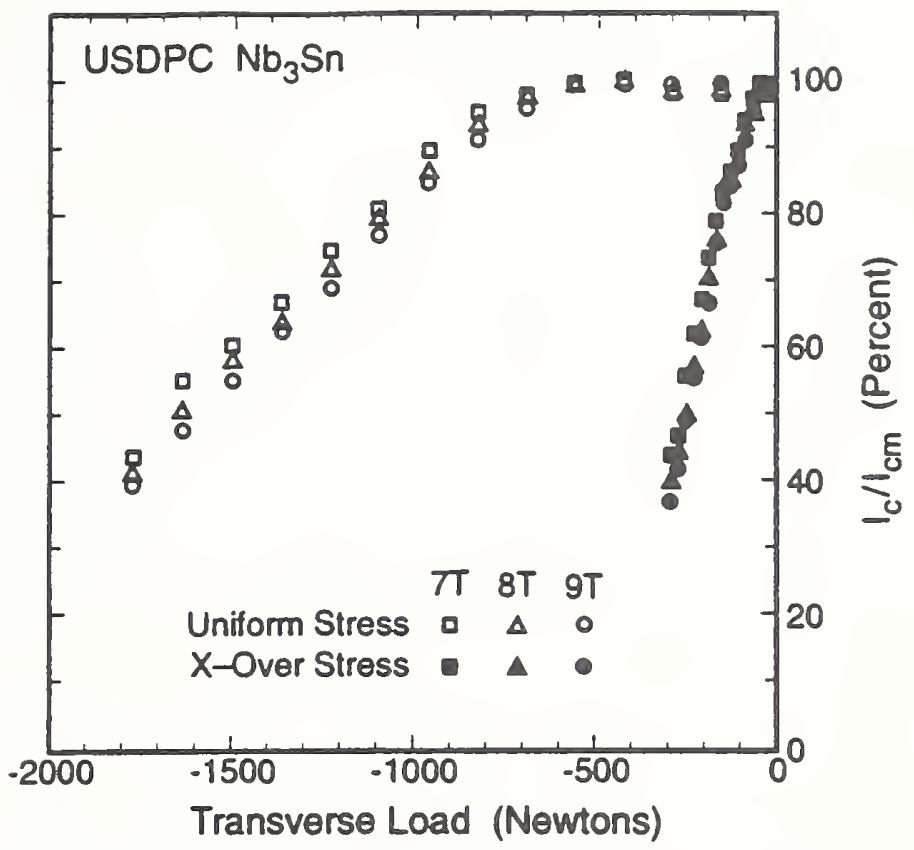

Fig. 2. Critical-current degradation as a function of transverse load and magnetic field for uniform and crossover stress.

For the purposes of this study, the transverse compressive stress is defined as the applied load divided by the "projected stress area." which is also shown in Fig. 1. A crossover angle of $30^{\circ}$ was selected for these measurements based on cable strand crossover angles observed in the US-DPC cable. The characteristics of the $\mathrm{Nb}_{3} \mathrm{Sn}$ wire that was used for this study are given in Table 1 .

\section{RESULTS}

The results of the crossover measurements are shown in Fig. 2 where the $\mathrm{L}_{c}$ is plotted as a function of transverse load for several magnetic fields. The ordinate is the measured $l_{c}$ normalized to the stanting (zero-stress) value, and the abscissa is the transverse load applied to the test wire through the crossover wire. By convention. the load is negative to indicate compression. For comparison. the results of a uniform stress test on another sample of the same wire are also shown. In this case, the transverse load is evenly distributed along the length of the wire. At $9 \mathrm{~T}$, a $60 \%$ reduction in the $I_{c}$ occurs at a load of approximately $-1760 \mathrm{~N}$ for uniform stress and at only $1 / 6$ this load $(-290 \mathrm{~N})$ for crossover stress. The stressed area of the conductor in the uniform stress test is $7.48 \mathrm{~mm}^{2}$, and the stressed area of the crossover test wire is only $1.24 \mathrm{~mm}^{2}$, also $1 / 6$ the area.

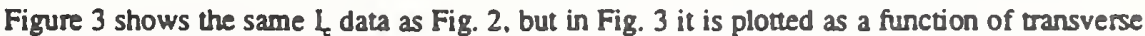
stress instead of load. This plot shows that, for the same transverse stress, the $I_{c}$ degradation is comparable up to $-240 \mathrm{MPa}$ for uniform or crossover stress. These data show that the $L$ degradation caused by concentrated transverse stress at a strand crossover point is nearly the same as the degradation caused by uniform transverse stress. For both tests. there is no significant $L_{c}$ recovery when the transverse load is removed from the test wire.

\section{DISCUSSION}

The data analysis was greatly simplified by defining the stress as the applied load divided by the area projected from the compressed section of the test wire. For the uniform stress test this area is simply the diameter of the wire multiplied by its compressed length.and for the crossover test it 


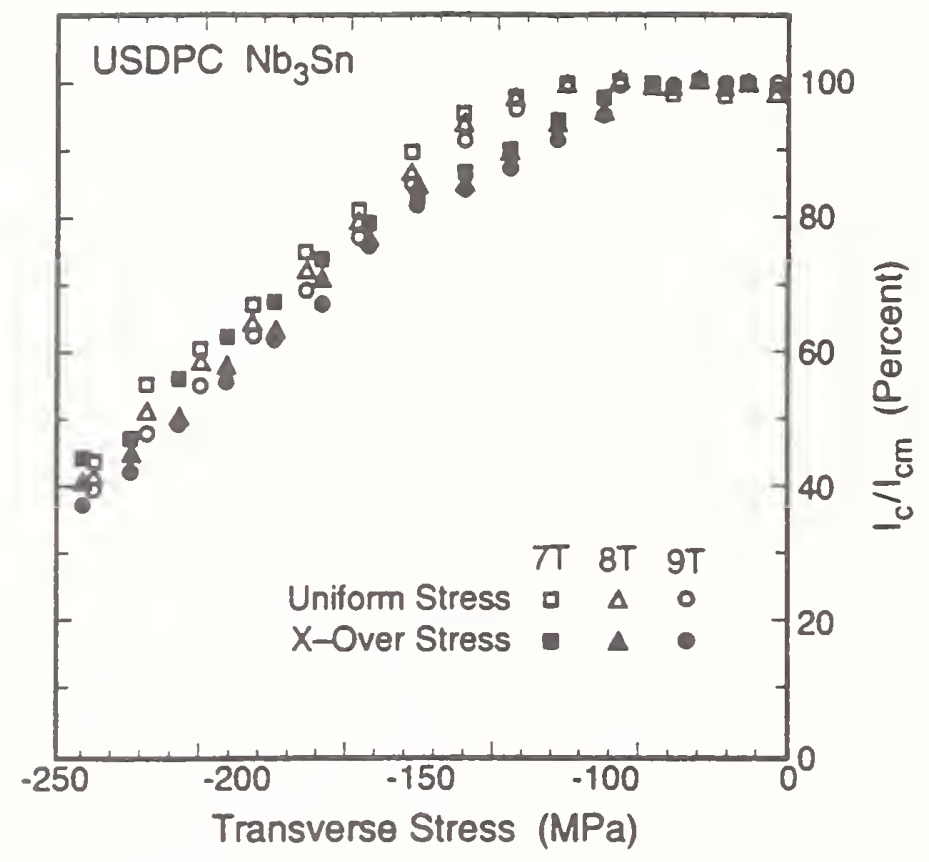

Fig. 3. Critical-current degradation as a function of transverse stress and magnetic field for uniform and crossover stress.

is the area of the parallelogram shown in Fig. 1. The validity of this procedure was demonstrated for uniform transverse stress through comparative measurements of round and rectangular specimens of the same wire. ${ }^{2}$

There is a second simplifying assumption unique to the analysis of the crossover data. If the voltage taps are connected to the test wire with a separation equal to the compressed length of the wire. it is extremely difficult to precisely align the crossover wire with the voltage taps. Consequently, the voltage tap separation must be greater than the length of the test wire's compressed region to ensure that the voltage taps span this entire region. However, the "effective voltage tap separation." which is simply the length of this compressed region, (shown in Fig. 1) is used to calculate the electric field for $I_{c}$ analysis. This procedure is appropriate because, at stresses where substantial degradation of the $\mathrm{L}_{c}$ occurs, the measured voltage will be generated over the stressed region of the conductor. Moreover, the difference between $\mathrm{I}_{c}$ based on the actual voltage tap separation and the effective separation is too small to affect the conclusions of the paper.

\section{CONCLUSIONS}

The transverse stress generated by the Lorentz force within the windings of a superconducting magnet can substantially degrade the $L_{c}$ of the superconductor and the performance of the magnet. Distributed structural reinforcement of the windings can limit the peak transverse load, but its use is restricted by inductance and current-density requirements. These data show that the effect of transverse load on the superconductor greatly depends on the load distribution. At a load that caused no measurable $I_{c}$ degradation for the uniform stress test, the $I_{c}$ degradation was over $60 \%$ for the crossover test. Consequenty, intemal cable design may be important in controlling degradation from this effect. When the results of the crossover and uniform stress tests are compared based on the applied stress, rather than load. the $\mathrm{I}_{\mathrm{c}}$ degradation is nearty the same for both tests. This is an important result from an engineering analysis standpoint because it may allow the estimation of $\mathrm{L}_{c}$ degradation and the design of cables from uniform transverse stress data and the cable strand geometry. 


\section{ACKNOWLEDGEMENT}

This work was supported by the Office of Fusion. Departunent of Energy. under contract No DE.AIO1-84ER52113.

\section{REFERENCES}

1. See, for example, the references given in J. W. Ekin, Adv. Cryog. Eng. 30:823 (1984)

2. J. W. Ekin. Effect of transverse compressive stress on the critical current and upper critical field of Nb,Sn. J. Appl. Phys. 62:4829 (1987).

3. W. Specking, W. Goldacker, and R. Flükiger. Effect of transverse compression on $\mathrm{I}_{c}$ of $\mathrm{Nb}_{3} \mathrm{Sn}$ multifilamentary wire. Adv. Cryog. Eng. 34:569 (1988).

4. L. T. Summers and J. R. Miller. The effect of transverse stress on the critical current of $\mathrm{Nb}_{3} \mathrm{Sn}$ cable-in-conduit superconductors, IEEE Trans. Magn. 25:1835 (1989).

5. H. Boschman and L. J. M. van de Klundert. Effects of transverse stress on the current carrying capacity of multifilamentary wires. Adv. Cryog. Eng. 36:93 (1990).

6. J. W. Ekin and S. L. Bray. Effect of transverse stress on the critical current of bronze-process and intemal-tin Nb,Sn. J. Appl. Phys. 69:4436 (1991). 


\section{US-DPC Nb 33 Sn Cable Strand}

A complete set of axial strain data was obtained for the critical current of the USDPC cable strand at magnetic fields from $10 \mathrm{~T}$ to $24 \mathrm{~T}$. The conductor specifications are shown in Table 1, and the measured data are shown in Table 2. The data are presented graphically in Figs. 1-4. The $\mathrm{I}_{\mathrm{C}}$ and $\mathrm{J}_{\mathrm{C}}$ values are based on an electric field criterion $\left(\mathrm{E}_{\mathrm{C}}\right)$ of $2 \mu \mathrm{V} / \mathrm{cm}$. The results show a zero-strain $12 \mathrm{~T}$ value of $\mathrm{J}_{\mathrm{C}}$ (referred to the noncopper area) which was $0.54 \mathrm{GA} / \mathrm{m}^{2}$ and a peak (strain-free) $\mathrm{J}_{\mathrm{C}}$ value of $0.62 \mathrm{GA} / \mathrm{m}^{2}$. The irreversible strain limit was reasonably high, $0.82 \%$, and the compressive prestrain was $0.38 \%$. The sample did not fracture until $1.31 \%$ strain.

Table 1. US-DPC Nb 33 Sn conductor specifications.

$\begin{array}{ll}\text { Wire diameter } & 0.78 \mathrm{~mm} \\ \text { Stabilizing Copper } & 54 \text { vol.\% } \\ \text { Noncopper } & 46 \text { vol.\% } \\ \quad \text { Nb Filament } & 22.9 \text { vol.\% } \\ \text { Copper } & 48.7 \text { vol. } \% \\ \text { Tin } & 15.8 \text { vol.\% } \\ \text { Vanadium } & 12.6 \text { vol. } \% \\ \text { Local Cu:Nb Ratio } & 1.7: 1 \\ \text { Filament Size } & 3 \mu \mathrm{m} \\ \text { Filament Composition } & \text { Nb-1 wt. } \% \mathrm{Ti} \\ \text { Subelements } & 18 \\ \text { Twist Pitch } & 2 \text { twists per inch }\end{array}$


Table 2. High-field critical current of US-DPC Nb 33 Sn sample CRE 1087 B4H21 as a function of axial tensile strain applied at $4 \mathrm{~K}$.

\begin{tabular}{|c|c|c|c|c|c|c|}
\hline $\begin{array}{l}E \\
(\%)\end{array}$ & $\begin{array}{l}\text { Eo } \\
(\%)\end{array}$ & $\begin{array}{c}\text { Ic } \\
\text { (Amperes) }\end{array}$ & $\begin{array}{l}\text { Field } \\
\text { (Tesla) }\end{array}$ & $\begin{array}{c}J c \\
\left(G A / m^{\wedge} 2\right)\end{array}$ & $\begin{array}{c}J C B \\
\left(G N / m^{\wedge} \xi\right)\end{array}$ & $I \mathrm{c} / I \mathrm{~cm}$ \\
\hline 0.00 & -.38 & $\begin{array}{r}183.460 \\
121.140 \\
74.870 \\
42.423 \\
19.799 \\
7.209 \\
3.793 \\
1.724 \\
0.665\end{array}$ & $\begin{array}{l}10.00 \\
12.00 \\
14.00 \\
16.00 \\
18.00 \\
20.00 \\
21.00 \\
22.00 \\
23.00\end{array}$ & $\begin{array}{l}0.819 \\
0.541 \\
0.334 \\
0.189 \\
0.088 \\
0.032 \\
0.017 \\
0.008 \\
0.003\end{array}$ & $\begin{array}{l}8.190 \\
6.490 \\
4.679 \\
3.030 \\
1.591 \\
0.544 \\
0.356 \\
0.169 \\
0.058\end{array}$ & 0.8576 \\
\hline
\end{tabular}

$\begin{array}{rrrrrrr}0.18 & -.20 & 197.230 & 10.00 & 0.880 & 8.805 & \\ & & 134.810 & 12.00 & 0.602 & 7.222 & 0.9543 \\ 0.23 & -.16 & 138.430 & 12.00 & 0.618 & 7.416 & 0.9800 \\ 0.30 & -.08 & 141.260 & 12.00 & 0.631 & 7.568 & 1.0000 \\ & & & & & & \\ 0.41 & 0.03 & 140.020 & 12.00 & 0.625 & 7.501 & 0.9912 \\ & & 90.757 & 14.00 & 0.405 & 5.672 & \\ & 53.369 & 16.00 & 0.238 & 3.812 & \\ & 27.644 & 18.00 & 0.123 & 2.221 & \\ & 11.528 & 20.00 & 0.051 & 1.029 & \\ & 6.746 & 21.00 & 0.030 & 0.632 & \\ & 3.503 & 22.00 & 0.016 & 0.344 & \\ & 1.581 & 23.00 & 0.007 & 0.162 & \\ & 0.538 & 24.00 & 0.002 & 0.058 & \end{array}$
0.52
0.14
132.150
12.00
0.590
7.080
0.9355

0.6

0.25

117.940

12.00

0.527

6.318

0.8349

0.72

0.34

103.970

12.00

0.464

5.570

0.7360

0.3

$-.05$

140.880

12.00

0.629

7.547

0.9973

0.82

0.44

87.687

12.00

0.391

4.698

0.6208

0.40

0.02

135.650

12.00

0.506

7.267

0.9605

0.90

0.52

75.108

12.00

0.335

4.024

0.5317

0.45

0.07

127.270

12.00

0.568

6.818

0.9010

0.96

0.58

60.134

12.00

0.268

3.222

0.4257 
Table 2 cont'd

\begin{tabular}{|c|c|c|c|c|c|c|}
\hline $\begin{array}{l}E \\
(\%)\end{array}$ & $\begin{array}{l}\text { Eo } \\
(\%)\end{array}$ & $\begin{array}{c}\text { Ic } \\
\text { (Amperes) }\end{array}$ & $\begin{array}{l}\text { Field } \\
\text { (Tesla) }\end{array}$ & $\begin{array}{c}J c \\
\left(G A / m^{\wedge} 2\right)\end{array}$ & $\begin{array}{c}J c B \\
\left(G N / m^{\wedge} 3\right)\end{array}$ & $I \mathrm{c} / I \mathrm{~cm}$ \\
\hline 0.49 & 0.11 & 116.870 & 12.00 & 0.522 & 6.261 & 0.8273 \\
\hline 1.07 & 0.69 & 40.730 & 12.00 & 0.182 & 2.182 & 0.2883 \\
\hline 0.53 & 0.15 & 94.626 & 12.00 & 0.422 & 5.069 & 0.6699 \\
\hline 1.17 & 0.79 & $24.36 \overline{3}$ & 12.00 & 0.109 & 1.305 & 0.1725 \\
\hline 0.58 & 0.20 & 67.861 & 12.00 & 0.303 & 3.635 & 0.4804 \\
\hline 1.27 & 0.89 & 11.251 & 12.00 & 0.050 & 0.603 & 0.0796 \\
\hline 0.66 & 0.28 & 34.885 & 12.00 & 0.156 & 1.869 & 0.2470 \\
\hline
\end{tabular}




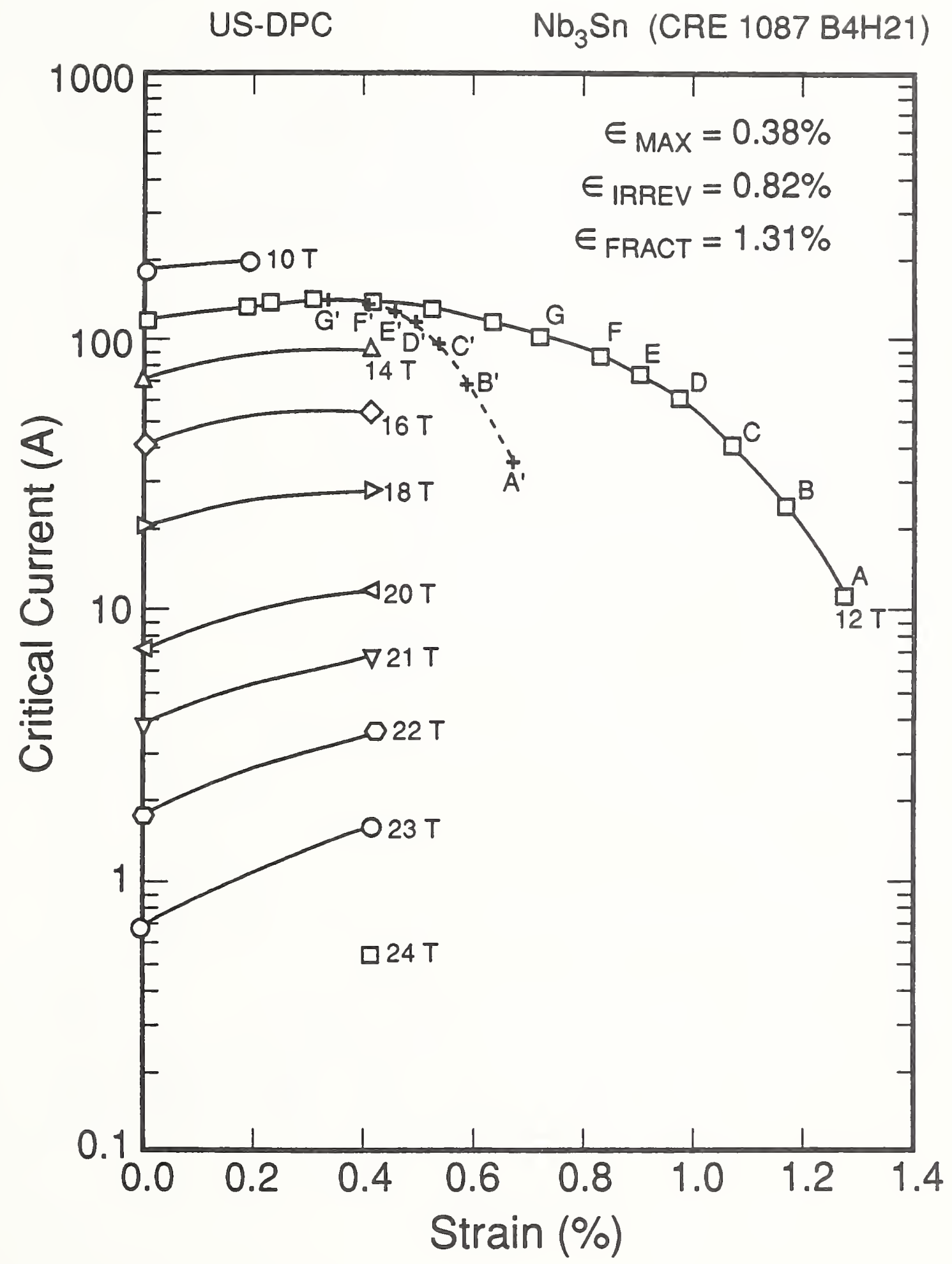

Figure 1. Effect of axial tensile strain on the critical current of US-DPC $\mathrm{Nb}_{3} \mathrm{Sn}$ sample CRE $1087 \mathrm{~B} 4 \mathrm{H} 21$ at $4 \mathrm{~K}$ and several magnetic fields. 


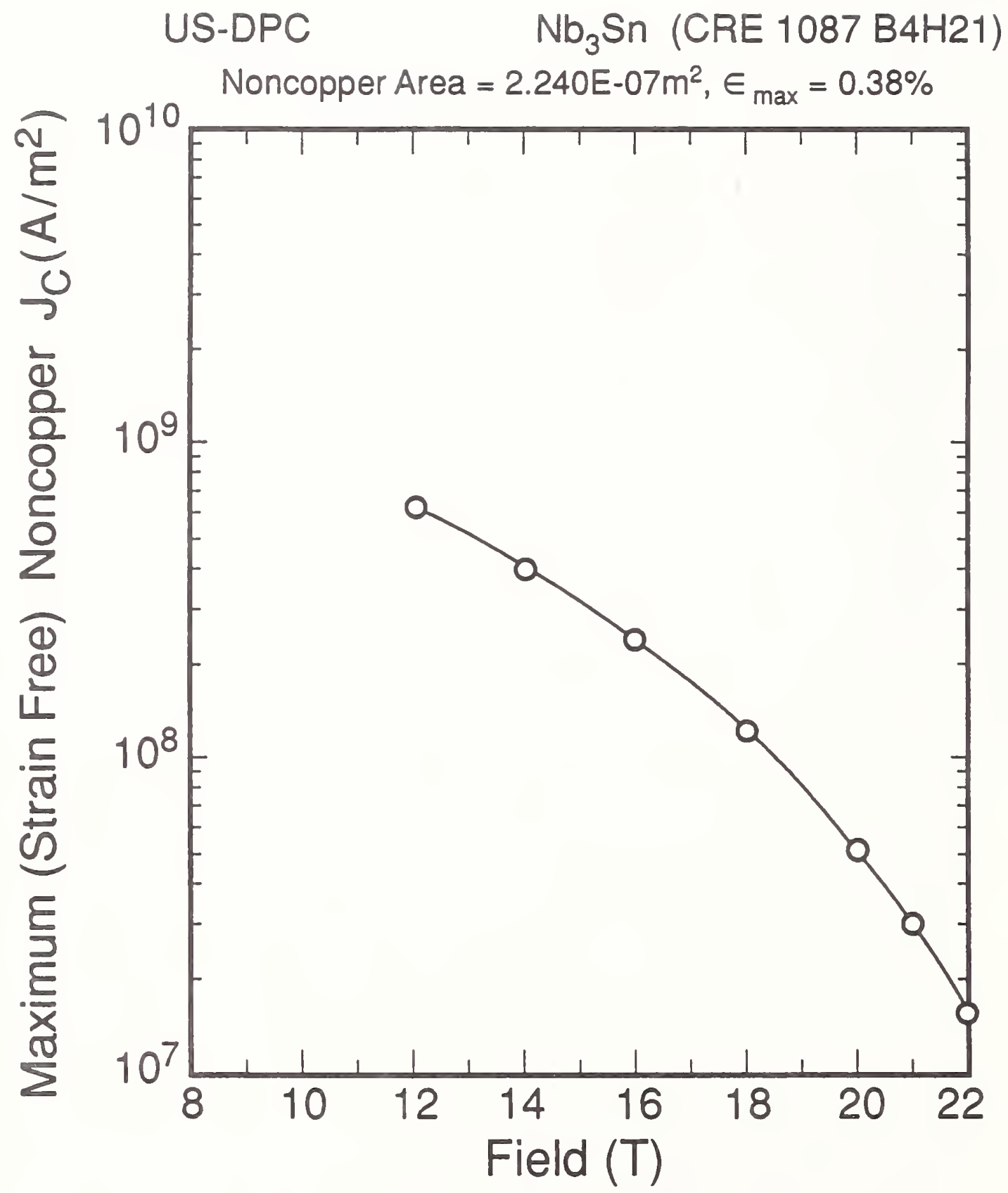

Figure 2. Effect of magnetic field on the critical current density of US-DPC $\mathrm{Nb}_{3} \mathrm{Sn}$ sample CRE $1087 \mathrm{~B} 4 \mathrm{H} 21$ at $4 \mathrm{~K}$. 


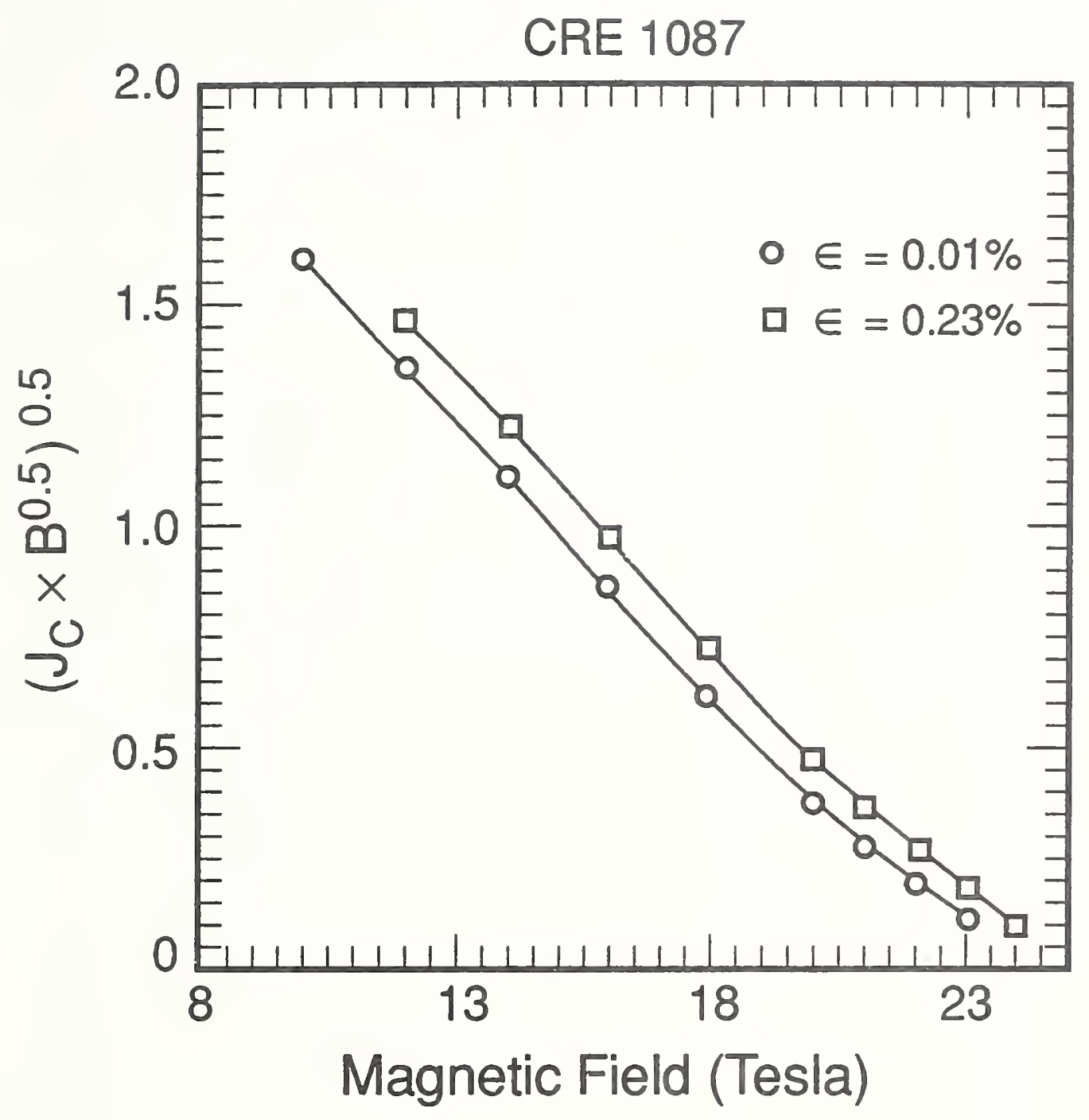

Figure 3. $\left(J_{C} \times B^{0.5}\right)^{0.5}$ as a function of magnetic field for US-DPC Nb${ }_{3} S n$ sample CRE $1087 \mathrm{~B} 4 \mathrm{H} 21$ at $0.01 \%$ and $0.23 \%$ strain. 


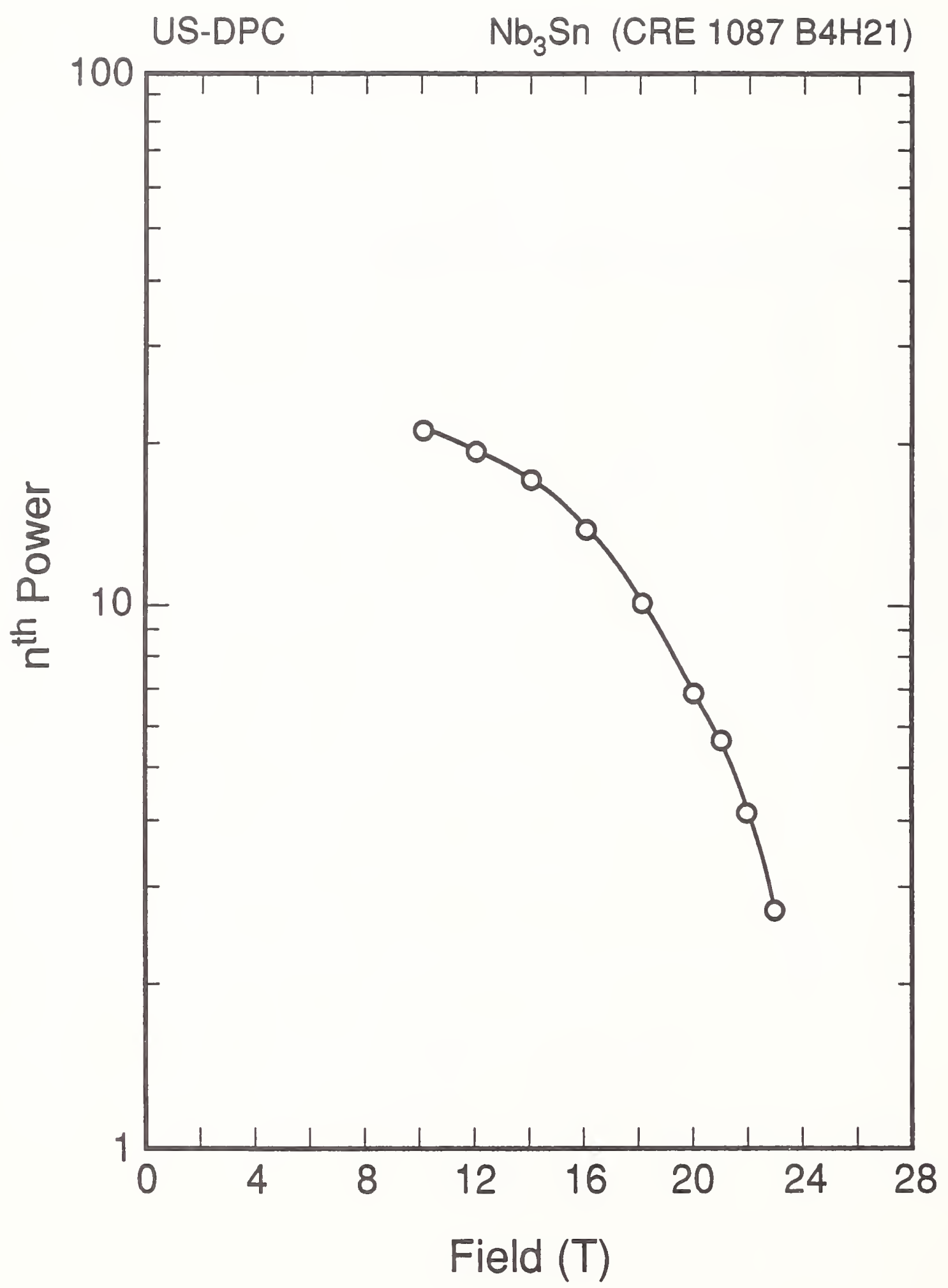

Figure 4. Effect of magnetic field on $n^{\text {th }}$ power of US-DPC Nb${ }_{3}$ Sn sample CRE 1087 $\mathrm{B} 4 \mathrm{H} 21$ at $4 \mathrm{~K}$. 


\section{$\mathrm{Nb}_{3} \mathrm{Sn}$ LLNL Cable Test Strand}

Axial strain characterization was completed for a $\mathrm{Nb}_{3} \mathrm{Sn}$ conductor from Lawrence Livermore National Lab used in a transverse stress test of a cable-in-conduit conductor. The effect of axial strain on the critical current of the LLNL $\mathrm{Nb}_{3} \mathrm{Sn}$ test strand was measured at magnetic fields from $8 \mathrm{~T}$ to $22 \mathrm{~T}$. The conductor specifications are shown in Table 3, and the measured data are shown in Table 4. The data are presented graphically in Figs. 5 through 7 . The $\mathrm{I}_{\mathrm{c}}$ and $\mathrm{J}_{\mathrm{c}}$ values are based on an electric field criterion $\left(\mathrm{E}_{\mathrm{C}}\right)$ of $2 \mu \mathrm{V} / \mathrm{cm}$. The zero-strain $12 \mathrm{~T}$ value of $\mathrm{J}_{\mathrm{c}}$ (referred to the noncopper area) was measured to be $0.36 \mathrm{GA} / \mathrm{m}^{2}$ and the peak (strain-free) $\mathrm{J}_{\mathrm{C}}$ at $12 \mathrm{~T}$ was $0.39 \mathrm{GA} / \mathrm{m}^{2}$. The irreversible strain limit was quite high, $1.0 \%$ strain, and the compressive prestrain was relatively low at $0.27 \%$. Fracture strain was $1.10 \%$.

Table 3. LLNL $\mathrm{Nb}_{3} \mathrm{Sn}$ cable test strand specifications.

\begin{tabular}{|c|c|}
\hline Wire Diameter & $0.533 \mathrm{~mm}$ \\
\hline Local Cu:Nb Ratio & $1.0: 1.0$ \\
\hline Copper Stabilizer & $50 \%$ \\
\hline 7 Subelements & \\
\hline Filament Composition & $1.2 \mathrm{wt} \% \mathrm{Ti}$ \\
\hline Filament Dia. & $\sim 4 \mu \mathrm{m}$ \\
\hline
\end{tabular}


Table 4. High-field critical current of LLNL Nb$b_{3} \mathrm{Sn}$ cable test strand.

\begin{tabular}{|c|c|c|c|c|c|c|}
\hline $\begin{array}{c}E \\
\langle \%\rangle\end{array}$ & $\begin{array}{l}\text { Eo } \\
(\%)\end{array}$ & $\begin{array}{c}\text { Ic } \\
\text { (Amperes) }\end{array}$ & $\begin{array}{l}\text { Field } \\
\text { (Tesla) }\end{array}$ & $\begin{array}{c}\mathrm{Jc} \\
\left(6 \mathrm{~A} / \mathrm{m}^{\wedge} 2\right)\end{array}$ & $\begin{array}{c}\mathrm{JcB} \\
\left(6 \mathrm{~N} / \mathrm{m}^{\wedge} 3\right)\end{array}$ & $I \mathrm{c} / I \mathrm{~cm}$ \\
\hline 0.00 & -.27 & $\begin{array}{r}145.290 \\
110.270 \\
80.560 \\
53.920 \\
32.595 \\
17.377 \\
7.169 \\
1.738\end{array}$ & $\begin{array}{l}8.00 \\
10.00 \\
12.00 \\
14.00 \\
16.00 \\
18.00 \\
20.00 \\
22.00\end{array}$ & $\begin{array}{l}0.650 \\
0.493 \\
0.360 \\
0.241 \\
0.146 \\
0.078 \\
0.032 \\
0.008\end{array}$ & $\begin{array}{l}5.201 \\
4.934 \\
4.325 \\
3.378 \\
2.333 \\
1.399 \\
0.542 \\
0.171\end{array}$ & $\begin{array}{l}0.9400 \\
0.8841 \\
0.8267 \\
0.7837 \\
0.6709 \\
0.4791\end{array}$ \\
\hline 0.11 & -.16 & $\begin{array}{r}117.860 \\
83.413 \\
58.083 \\
37.288 \\
20.045 \\
8.838 \\
2.782\end{array}$ & $\begin{array}{l}10.00 \\
12.00 \\
14.00 \\
16.00 \\
18.00 \\
20.00 \\
22.00\end{array}$ & $\begin{array}{l}0.527 \\
0.373 \\
0.260 \\
0.167 \\
0.090 \\
0.040 \\
0.012\end{array}$ & $\begin{array}{l}5.273 \\
4.479 \\
3.638 \\
2.669 \\
1.614 \\
0.791 \\
0.274\end{array}$ & $\begin{array}{l}0.9732 \\
0.9523 \\
0.9457 \\
0.9040 \\
0.8271 \\
0.7669\end{array}$ \\
\hline 0.22 & -.05 & $\begin{array}{r}86.088 \\
62.262 \\
39.527 \\
22.082 \\
10.435 \\
3.578\end{array}$ & $\begin{array}{l}12.00 \\
14.00 \\
15.00 \\
18.00 \\
20.00 \\
22.00\end{array}$ & $\begin{array}{l}0.385 \\
0.279 \\
0.177 \\
0.099 \\
0.047 \\
0.016\end{array}$ & $\begin{array}{l}4.622 \\
3.900 \\
2.830 \\
1.778 \\
0.934 \\
0.352\end{array}$ & $\begin{array}{l}1.0044 \\
1.0208 \\
1.0025 \\
0.9959 \\
0.9765 \\
0.9862\end{array}$ \\
\hline 0.30 & 0.03 & $\begin{array}{r}85.707 \\
60.991 \\
39.428 \\
22.173 \\
10.686 \\
3.628\end{array}$ & $\begin{array}{l}12.00 \\
14.00 \\
16.00 \\
18.00 \\
20.00 \\
22.00\end{array}$ & $\begin{array}{l}0.383 \\
0.273 \\
0.175 \\
0.099 \\
0.048 \\
0.016\end{array}$ & $\begin{array}{l}4.602 \\
3.820 \\
2.823 \\
1.786 \\
0.956 \\
0.357\end{array}$ & $\begin{array}{l}1.0000 \\
1.0000 \\
1.0000 \\
1.0000 \\
1.0000 \\
1.0000\end{array}$ \\
\hline 0.14 & -.13 & 84.150 & 12.00 & 0.377 & 4.518 & 0.9818 \\
\hline 0.42 & 0.15 & $\begin{array}{r}81.861 \\
56.325 \\
35.765 \\
19.807 \\
8.360 \\
2.505\end{array}$ & $\begin{array}{l}12.00 \\
14.00 \\
16.00 \\
18.00 \\
20.00 \\
22.00\end{array}$ & $\begin{array}{l}0.366 \\
0.252 \\
0.160 \\
0.089 \\
0.037 \\
0.012\end{array}$ & $\begin{array}{l}4.395 \\
3.528 \\
2.560 \\
1.595 \\
0.748 \\
0.256\end{array}$ & $\begin{array}{l}0.9551 \\
0.9235 \\
0.9071 \\
0.8933 \\
0.7823 \\
0.7179\end{array}$ \\
\hline 0.21 & -.05 & 86.830 & 12.00 & 0.389 & 4.652 & 1.0131 \\
\hline 0.58 & 0.31 & 68.364 & 12.00 & 0.306 & 3.671 & 0.7977 \\
\hline
\end{tabular}


Table 4 cont'd

\begin{tabular}{|c|c|c|c|c|c|c|}
\hline $\begin{array}{l}E \\
(\%)\end{array}$ & $\begin{array}{l}\text { Eo } \\
(\%)\end{array}$ & $\begin{array}{c}\text { Ic } \\
\text { (Amperes) }\end{array}$ & $\begin{array}{l}\text { Field } \\
\text { (Tesla) }\end{array}$ & $\begin{array}{c}J c \\
\left(G A / m^{\wedge} 2\right)\end{array}$ & $\begin{array}{c}\mathrm{JcB} \\
\left(6 N / \mathrm{m}^{\wedge} 3\right)\end{array}$ & $I \mathrm{c} / I \mathrm{~cm}$ \\
\hline 0.58 & 0.31 & $\begin{array}{r}43.135 \\
25.307 \\
11.253 \\
3.882 \\
0.821\end{array}$ & $\begin{array}{l}14.00 \\
16.00 \\
18.00 \\
20.00 \\
22.00\end{array}$ & $\begin{array}{l}0.193 \\
0.113 \\
0.050 \\
0.017 \\
0.004\end{array}$ & $\begin{array}{l}2.702 \\
1.812 \\
0.905 \\
0.347 \\
0.081\end{array}$ & $\begin{array}{l}0.7072 \\
0.5419 \\
0.5075 \\
0.3633 \\
0.2264\end{array}$ \\
\hline 0.30 & 0.03 & 86.684 & 12.00 & 0.388 & 4.654 & 1.0114 \\
\hline 0.72 & 0.45 & $\begin{array}{r}54.983 \\
32.503 \\
15.588 \\
5.680 \\
1.214 \\
0.153\end{array}$ & $\begin{array}{l}12.00 \\
14.00 \\
16.00 \\
18.00 \\
20.00 \\
22.00\end{array}$ & $\begin{array}{l}0.246 \\
0.145 \\
0.070 \\
0.025 \\
0.005 \\
0.001\end{array}$ & $\begin{array}{l}2.952 \\
2.036 \\
1.116 \\
0.457 \\
0.109 \\
0.015\end{array}$ & $\begin{array}{l}0.6415 \\
0.5329 \\
0.3954 \\
0.2562 \\
0.1136 \\
0.0422\end{array}$ \\
\hline 0.41 & 0.14 & 85.143 & 12.00 & 0.381 & 4.571 & 0.9934 \\
\hline 0.82 & 0.55 & $\begin{array}{r}48.772 \\
25.524 \\
9.981 \\
2.889 \\
0.395\end{array}$ & $\begin{array}{l}12.00 \\
14.00 \\
16.00 \\
18.00 \\
20.00\end{array}$ & $\begin{array}{l}0.218 \\
0.114 \\
0.045 \\
0.013 \\
0.002\end{array}$ & $\begin{array}{l}2.619 \\
1.599 \\
0.715 \\
0.233 \\
0.035\end{array}$ & $\begin{array}{l}0.5691 \\
0.4185 \\
0.2532 \\
0.1303 \\
0.0369\end{array}$ \\
\hline 0.50 & 0.23 & 80.263 & 12.00 & 0.359 & 4.309 & 0.9365 \\
\hline 0.96 & 0.69 & 37.542 & 12.00 & 0.168 & 2.015 & 0.4380 \\
\hline 0.59 & 0.32 & 70.639 & 12.00 & 0.315 & 3.793 & 0.8242 \\
\hline 1.03 & 0.76 & 25.740 & 12.00 & 0.115 & $1 . \overline{382}$ & $0.300 \overline{3}$ \\
\hline 0.60 & 0.33 & 52.654 & 12.00 & 0.235 & 2.827 & 0.6144 \\
\hline
\end{tabular}




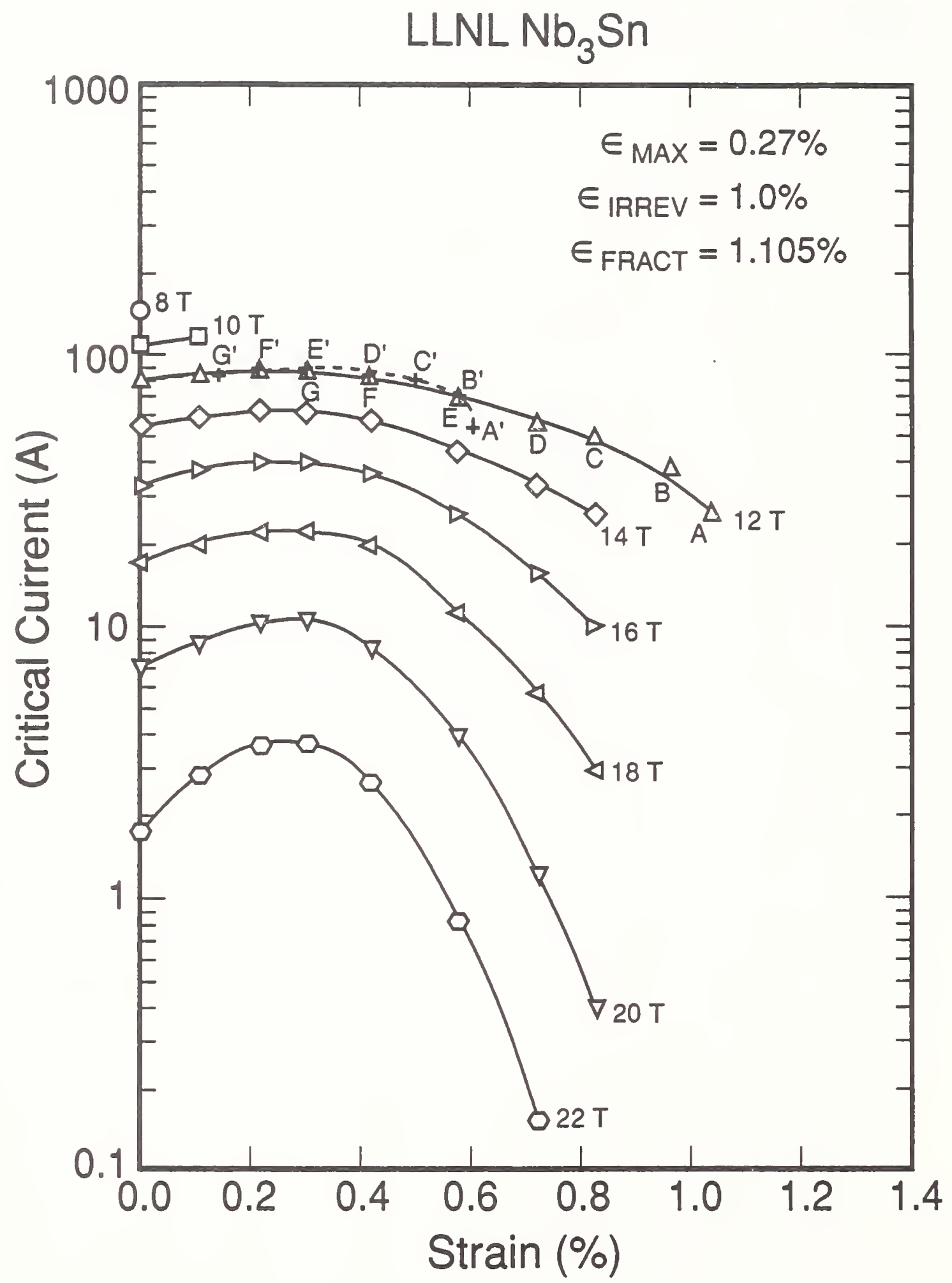

Figure 5. Effect of axial tensile strain on the critical current of LLNL Nb 33 Sn cable test strand at $4 \mathrm{~K}$ and several magnetic fields. 


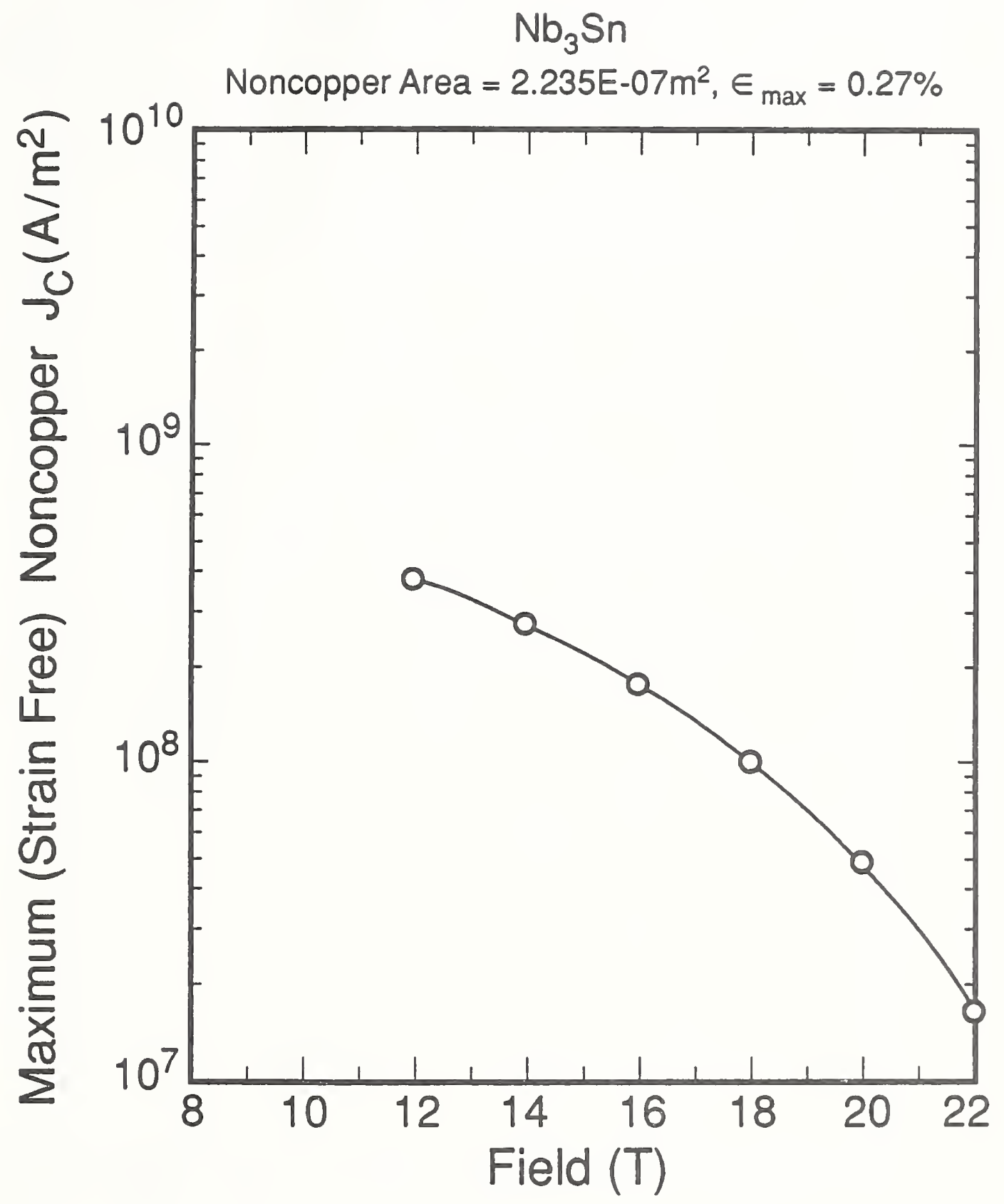

Figure 6. Effect of magnetic field on the critical current density of LLNL $\mathrm{Nb}_{3} \mathrm{Sn}$ cable test strand at $4 \mathrm{~K}$. 


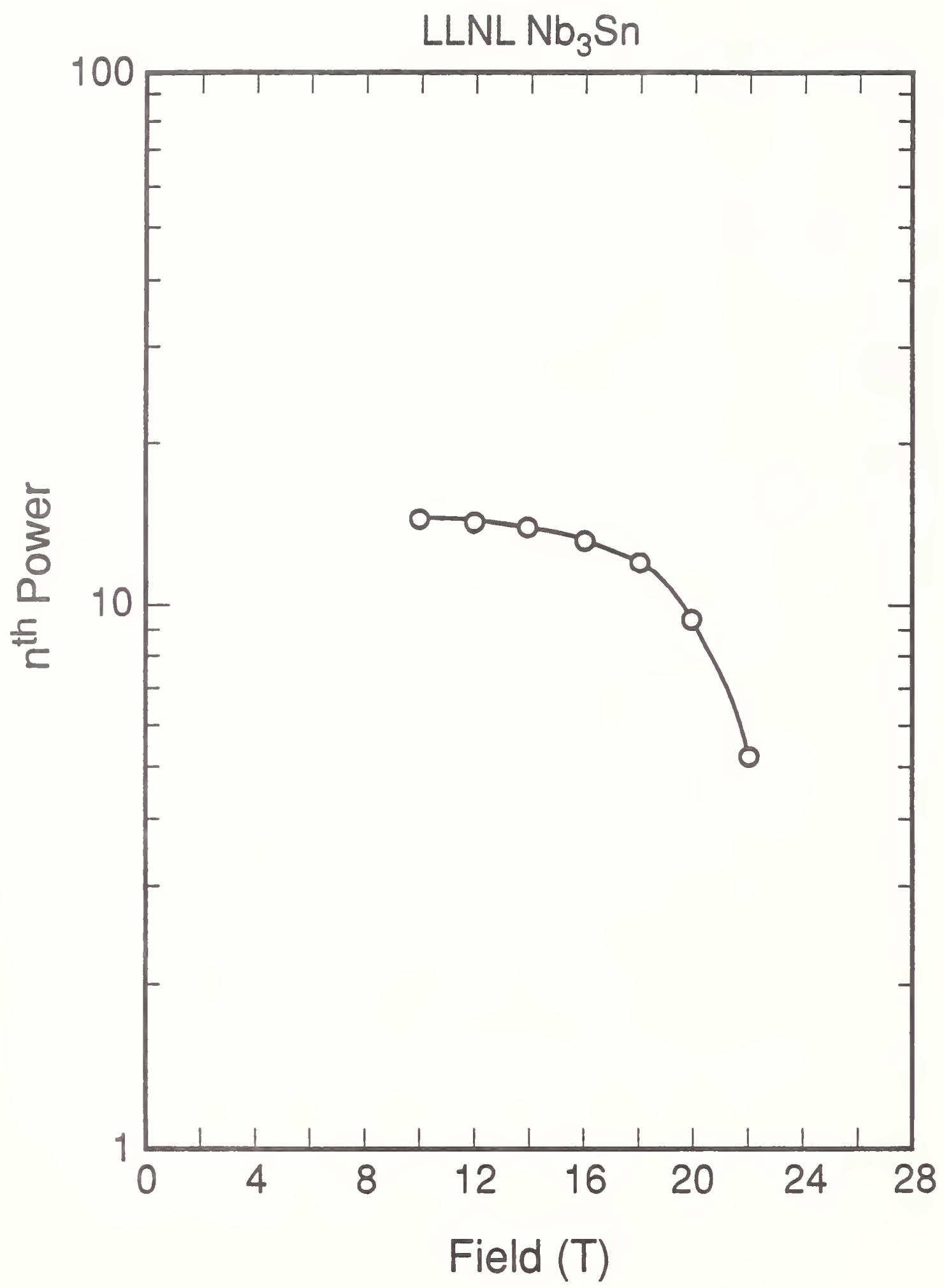

Figure 7. Effect of magnetic field on the $n^{\text {th }}$ power of LLNL Nb$b_{3} S n$ cable test strand at $4 \mathrm{~K}$. 


\section{$\mathrm{Nb}_{3} \mathrm{Sn}$ ITER Candidate Conductor}

An internal-tin-process $\mathrm{Nb}_{3} \mathrm{Sn}$ conductor, which is a prototype for the International Thermonuclear Experimental Reactor (ITER), was tested. The axial strain measurements were made over a range of magnetic fields from 15 to $25 \mathrm{~T}$. The conductor specifications are given in Table 5, and the measured data are presented in Table 6 and Figs. 8 through 10. The $\mathrm{I}_{\mathrm{c}}$ and $\mathrm{J}_{\mathrm{c}}$ values are based on an electric field criterion $\left(\mathrm{E}_{\mathrm{c}}\right.$ ) of $2 \mu \mathrm{V} / \mathrm{cm}$. The results show a zero-strain $15 \mathrm{~T}$ value of $\mathrm{J}_{\mathrm{c}}$ (referred to the noncopper area) which was $0.50 \mathrm{GA} / \mathrm{m}^{2}$ and a peak (strain-free) $\mathrm{J}_{\mathrm{c}}$ value of 0.55 $\mathrm{GA} / \mathrm{m}^{2}$. The irreversible strain limit was reasonably high, $0.92 \%$, and the compressive prestrain was $0.28 \%$. The sample did not fracture until $1.09 \%$ strain.

Table 5. ITER conductor specifications.

$\begin{array}{ll}\text { Wire Diameter } & 0.817 \mathrm{~mm} \\ \begin{array}{l}\text { Copper Stabilizer } \\ \text { Nb Diffusion Barrier } \\ \text { (of Non-Cu Area) }\end{array} & 46.5 \% \\ \text { Noncopper } & 8.5 \% \\ \text { Filament No. } & 53.5 \% \\ \text { Filament Dia. } & 4902 \\ \text { Subelement No. } & 3.5 \mu \mathrm{m} \\ \text { Ti Addition } & 19 \\ & 1.2 \%\end{array}$


Table 6. High-field critical current of $\mathrm{Nb}_{3} \mathrm{Sn}$ ITER candidate conductor as a function of axial tensile strain applied at $4 \mathrm{~K}$.

\begin{tabular}{|c|c|c|c|c|c|c|c|}
\hline SP & $E(\%)$ & E0 $(\%)$ & FIELD (T) & Ic (A) & $\mathrm{Jc}\left(\mathrm{MA} / \mathrm{m}^{\wedge} 2\right)$ & Ic/lemax & $\mathbf{N}$ \\
\hline \multirow[t]{7}{*}{0} & 0.048 & -0.232 & 15 & 139.99 & 499.24 & 0.91 & 20.95 \\
\hline & & & 16 & 109.56 & 390.73 & 0.90 & 17.73 \\
\hline & & & 18 & 62.83 & 224.09 & 0.85 & 13.40 \\
\hline & & & 20 & 27.43 & 97.82 & 0.74 & 8.33 \\
\hline & & & 22 & 7.71 & 27.51 & 0.57 & 4.65 \\
\hline & & & 24 & 0.47 & 1.68 & 0.23 & 1.78 \\
\hline & & & 25 & & & & 1.26 \\
\hline \multirow[t]{7}{*}{1} & 0.12 & -0.16 & 15 & 149.89 & 534.55 & 0.97 & 18.47 \\
\hline & & & 16 & 122.29 & 436.13 & 1.00 & 19.53 \\
\hline & & & 18 & 72.23 & 257.60 & 0.97 & 15.16 \\
\hline & & & 20 & 35.98 & 128.31 & 0.97 & 11.10 \\
\hline & & & 22 & 11.86 & 42.31 & 0.88 & 6.02 \\
\hline & & & 24 & 1.30 & 4.65 & 0.65 & 2.30 \\
\hline & & & 25 & 0.11 & 0.41 & 0.50 & 1.48 \\
\hline \multirow[t]{7}{*}{2} & 0.232 & -0.048 & 15 & 153.94 & 548.99 & 1.00 & 19.35 \\
\hline & & & 16 & 117.86 & 420.34 & 0.96 & 13.27 \\
\hline & & & 18 & 74.34 & 265.12 & 1.00 & 13.83 \\
\hline & & & 20 & 37.00 & 131.94 & 1.00 & 9.19 \\
\hline & & & 22 & 13.51 & 48.18 & 1.00 & 5.80 \\
\hline & & & 24 & 2.01 & 7.17 & 1.00 & 2.59 \\
\hline & & & 25 & 0.23 & 0.82 & 1.00 & 1.55 \\
\hline \multirow[t]{7}{*}{3} & 0.321 & 0.041 & 15 & 133.33 & 475.49 & 0.87 & 11.17 \\
\hline & & & 16 & 118.64 & 423.11 & 0.97 & 17.35 \\
\hline & & & 18 & 68.70 & 245.02 & 0.92 & 11.67 \\
\hline & & & 20 & 34.23 & 122.06 & 0.93 & 8.53 \\
\hline & & & 22 & 11.31 & 40.35 & 0.84 & 4.91 \\
\hline & & & 24 & 1.75 & 6.24 & 0.87 & 2.50 \\
\hline & & & 25 & 0.21 & 0.73 & 0.90 & 1.55 \\
\hline \multirow[t]{7}{*}{4} & 0.439 & 0.159 & 15 & 122.38 & 436.44 & 0.79 & 11.44 \\
\hline & & & 16 & 97.63 & 348.18 & 0.80 & 11.35 \\
\hline & & & 18 & 55.95 & 199.52 & 0.75 & 9.19 \\
\hline & & & 20 & 25.39 & 90.55 & 0.69 & 6.53 \\
\hline & & & 22 & 7.26 & 25.90 & 0.54 & 3.90 \\
\hline & & & 24 & 0.71 & 2.52 & 0.35 & 1.92 \\
\hline & & & 25 & 0.04 & 0.14 & 0.18 & 1.41 \\
\hline $4 U$ & 0.221 & -0.059 & 15 & 152.11 & 542.48 & 0.99 & 18.17 \\
\hline 5 & 0.546 & 0.266 & 15 & 107.88 & 384.73 & 0.70 & 12.30 \\
\hline
\end{tabular}


Table 6 cont'd

SP E (\%) E0 (\%) FIELD (T) Ic (A) Jc (MA/m^2) Ic/lcmax

$\begin{array}{rrrrr}16 & 82.70 & 294.92 & 0.68 & 10.89 \\ 18 & 41.28 & 147.22 & 0.56 & 7.35 \\ 20 & 14.49 & 51.69 & 0.39 & 4.55 \\ 22 & 3.23 & 11.51 & 0.24 & 2.83 \\ 24 & 0.08 & 0.27 & 0.04 & 1.39 \\ 25 & & & & 1.15\end{array}$

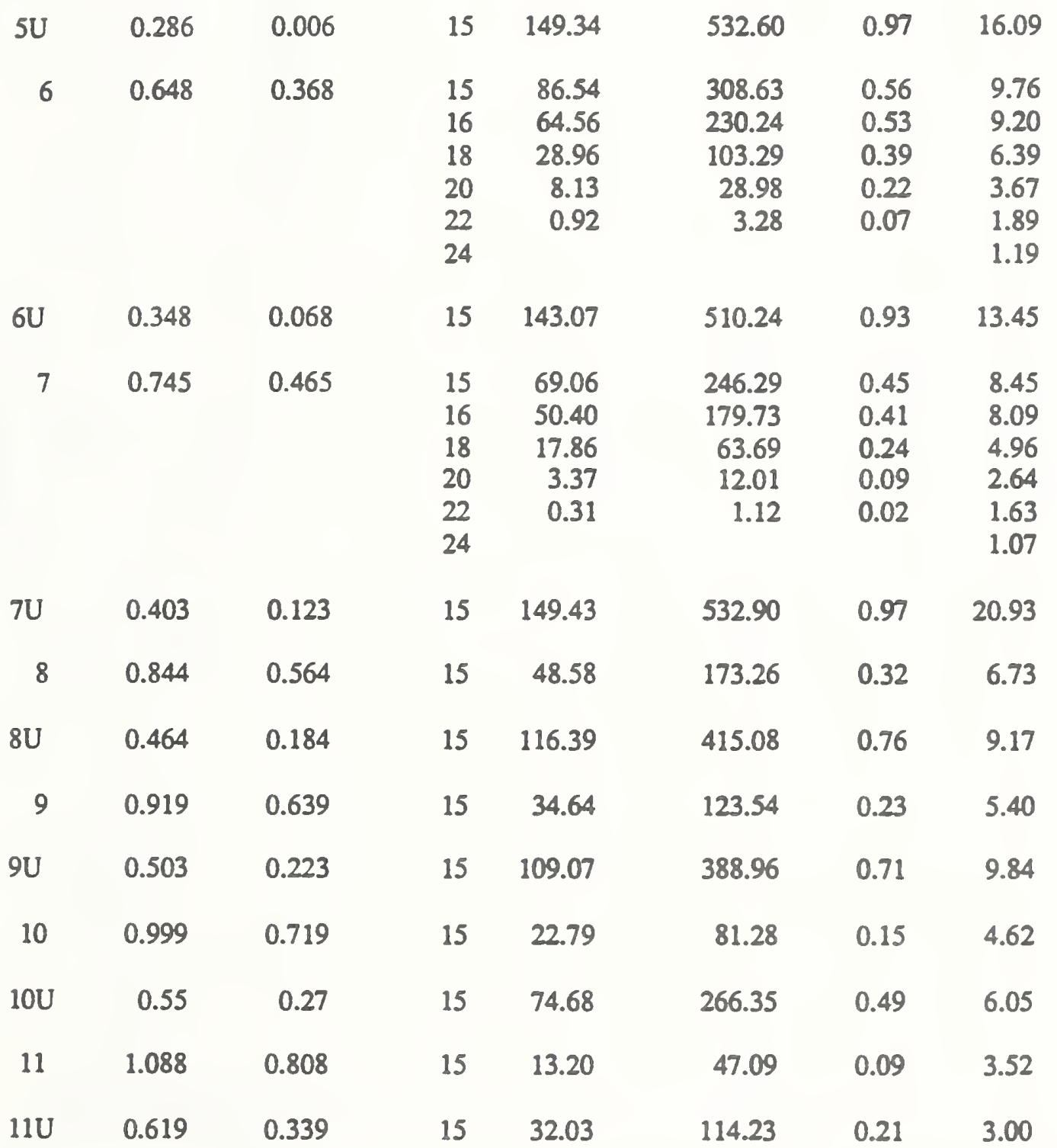




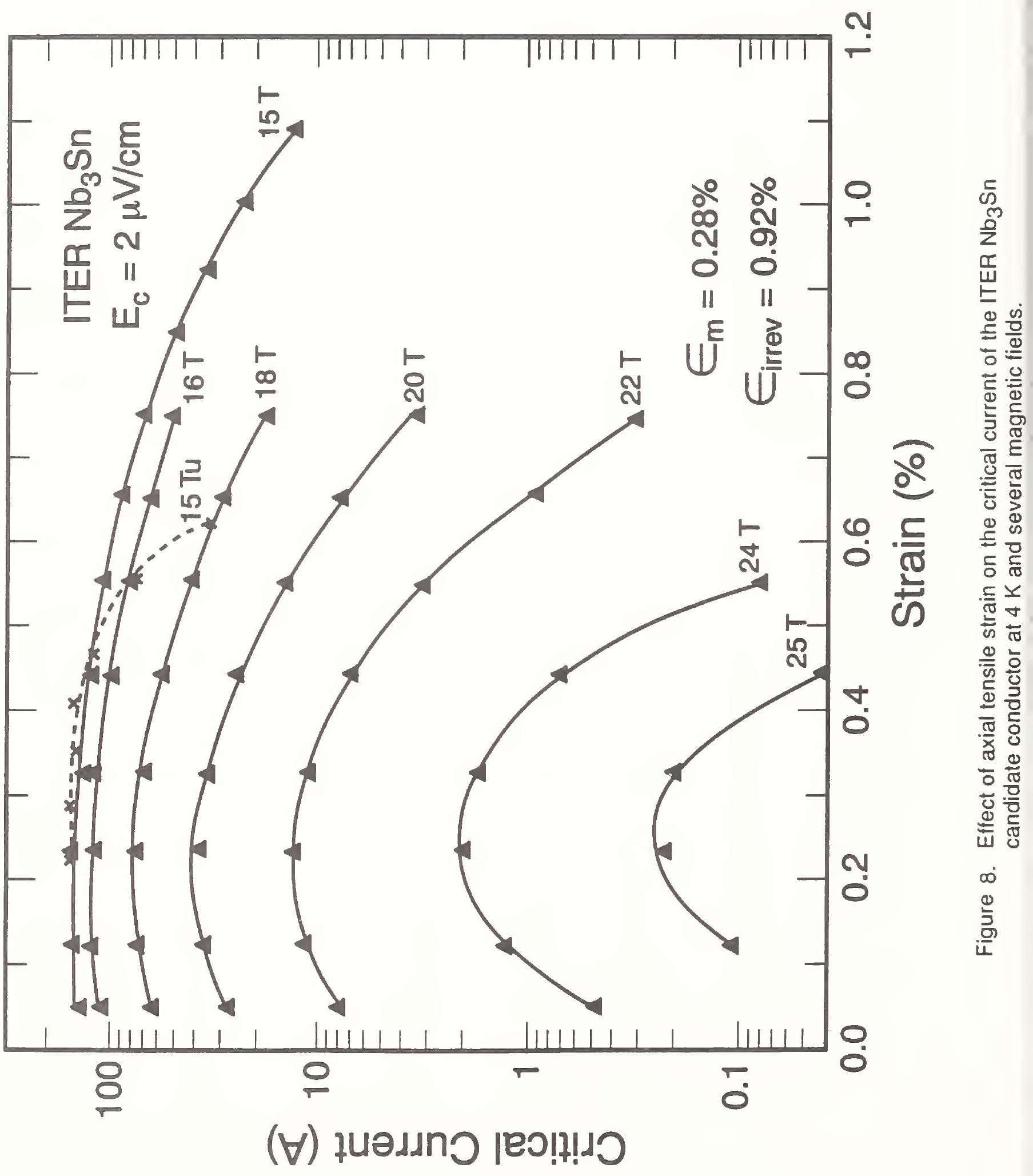




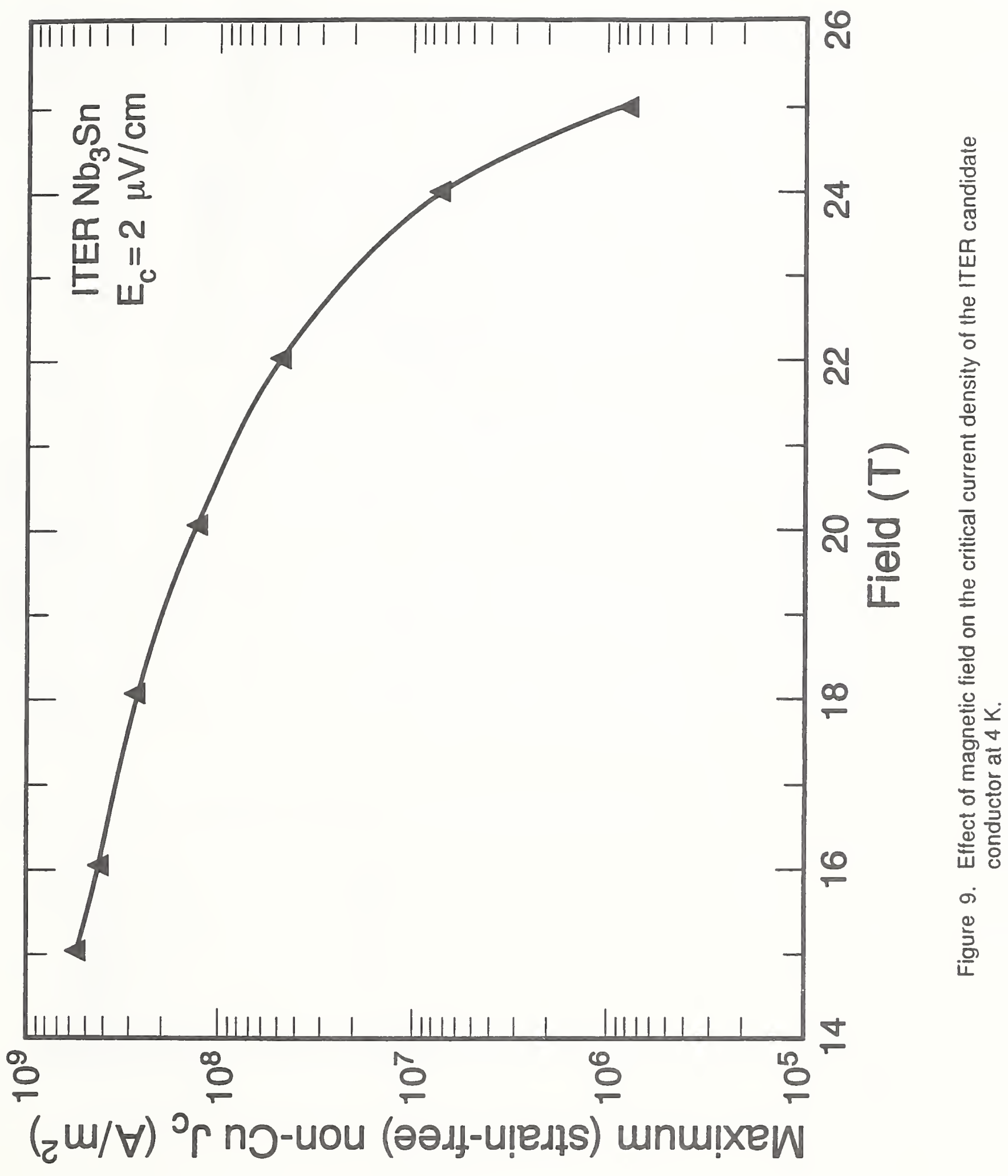




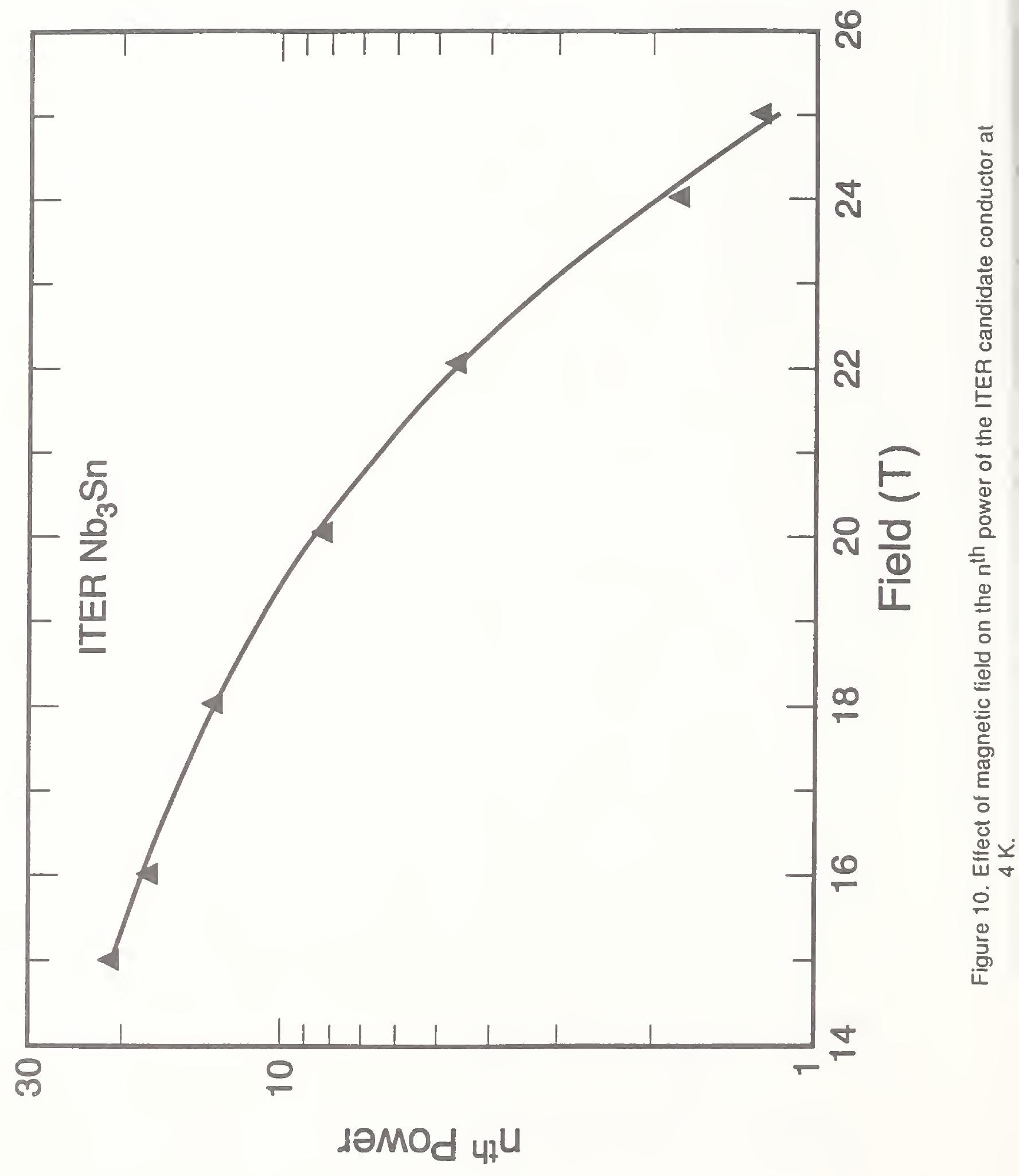




\section{$\mathrm{Nb}_{3} \mathrm{Sn}$ Conductors Reinforced with Dispersion-Hardened Copper (DHC) Alloy}

The axial strain characteristics of a group of three similar experimental $\mathrm{Nb}_{3} \mathrm{Sn}$ superconductors were measured over a broad range of magnetic fields. All three conductors were manufactured using the internal-tin process, and a dispersion-hardenedcopper (DHC) reinforcement was used in each conductor for increased tensile strength. The first conductor has two concentric rings of stabilizing copper surrounding the noncopper core, which contains the internal tin. The inner ring is pure copper and the outer ring is DHC. The copper stabilizer makes up $72 \%$ of the conductor's total volume. Both of the other conductors have an internal-tin ring surrounding their cores and $56 \%$ external copper stabilizer. One of the conductors uses pure copper for the stabilizer and DHC for the core's matrix; the other conductor has the opposite configuration, a purecopper matrix and DHC stabilizer. All three conductors have tantalum diffusion barriers between core and stabilizer. The conductor specifications are given in Tables 7 through 9. The $I_{C}$ and $J_{C}$ values are based on an electric field criterion $\left(E_{c}\right)$ of $2 \mu \mathrm{V} / \mathrm{cm}$.

The measured data for the tin-core conductor are presented in Table 10 and in Figs. 11 through 13 . The large prestrain $\left(\varepsilon_{\mathrm{m}}=0.55 \%\right)$ for this conductor is caused by the high copper fraction, $72 \%$. The $\mathrm{I}_{\mathrm{c}}$ doubles at $12 \mathrm{~T}$ between $\varepsilon=0$ and $\varepsilon=\varepsilon_{\mathrm{m}}$ because of the large value of $\varepsilon_{\mathrm{m}}$. The noncopper peak $\mathrm{J}_{\mathrm{c}}\left(\varepsilon=\varepsilon_{\mathrm{m}}\right)$ at $12 \mathrm{~T}$ is $850 \mathrm{~A} / \mathrm{mm}^{2}$.

The measured data for the tin-ring conductors are presented in Tables 11 and 12 and in Figs. 14 through 19. The lower copper-stabilizer fraction $(56 \%)$ results in a smaller prestrain for both conductors $\left(\varepsilon_{\mathrm{m}}=0.3 \%\right)$. The noncopper peak $\mathrm{J}_{\mathrm{C}}\left(\varepsilon=\varepsilon_{\mathrm{m}}\right)$ at $12 \mathrm{~T}$ is $1120 \mathrm{~A} / \mathrm{mm}^{2}$ for the pure-copper stabilized conductor and $1030 \mathrm{~A} / \mathrm{mm}^{2}$ for the DHC stabilized conductor. The low-field $\mathrm{n}$-value for the pure-copper stabilized wire is $\sim 30$ and $\sim 20$ for the other wire. This difference is probably associated with the smaller filament diameter for the DHC stabilized conductor ( $1.7 \mu \mathrm{m}$ compared to $3 \mu \mathrm{m})$.

Table 7. $\mathrm{DHC}$ reinforced tin-core $\mathrm{Nb}_{3} \mathrm{Sn}$ conductor specifications.

$\begin{array}{ll}\text { Wire Diameter } & 0.389 \mathrm{~mm} \\ \text { DHC (outside) } & 33 \% \\ \text { Copper Stabilizer } & 39 \% \\ \text { Noncopper Core } & 28 \% \\ \text { Nb in Core } & \sim 31 \% \\ \text { Ta Barrier } & 3.8 \% \\ \text { Filament No. } & 37 \times 894=33078 \\ \text { Filament Dia. } & 0.6 \mu \mathrm{m} @ 0.389 \mathrm{~mm} \text { dia. } \\ \text { Local Cu:Nb Ratio } & 0.8: 1\end{array}$


Table 8. Conductor specifications for $\mathrm{DHC}$ reinforced tin-ring $\mathrm{Nb}_{3} \mathrm{Sn}$ wire with purecopper stabilizer.

$\begin{array}{ll}\text { Wire Diameter } & 0.267 \mathrm{~mm} \\ \text { Noncopper Core } & 44 \% \\ \text { DHC Core } & \\ \text { Pure Copper Stabilizer } & 56 \% \\ \text { Ta Barrier } & 8 \% \\ \text { Nb-1.3 wt.\% Ti } & \sim 8 \% \\ \text { Filament No. } & 624 \\ \text { Filament Dia. } & \sim 3 \mu \mathrm{m} \\ \text { Local Cu:Nb Ratio } & 1: 1\end{array}$

Table 9. Conductor specifications for $\mathrm{DHC}$ reinforced tin-ring $\mathrm{Nb}_{3} \mathrm{Sn}$ with $\mathrm{DHC}$ stabilizer.

$\begin{array}{ll}\text { Wire Diameter } & 0.267 \mathrm{~mm} \\ \text { Local Cu:Nb Ratio } & 0.8: 1 \\ \text { Noncopper Core } & 44 \% \\ \text { DHC Stabilizer (outside) } & 56 \% \\ \text { Ta Barrier } & 8 \% \\ \text { Nb-1.3 wt.\% Ti } & 13.5 \% \\ \text { Filament No. } & 2796 \\ \text { Filament Dia. } & \sim 1.7 \mu \mathrm{m}\end{array}$


Table 10. High-field critical current of copper-alloy reinforced tin-core $\mathrm{Nb}_{3} \mathrm{Sn}$ as a function of axial tensile strain applied at $4 \mathrm{~K}$.

\begin{tabular}{|c|c|c|c|c|c|c|}
\hline $\begin{array}{c}E \\
(\%)\end{array}$ & $\begin{array}{l}\text { Eo } \\
(\%)\end{array}$ & $\begin{array}{c}\text { Ic } \\
\text { (Amperes) }\end{array}$ & $\begin{array}{l}\text { Field } \\
\text { (Tesla) }\end{array}$ & $\begin{array}{c}J c \\
\left(6 A / m^{n} Z\right)\end{array}$ & $\begin{array}{c}J C B \\
\left(G N / m^{n} \bar{\jmath}\right)\end{array}$ & $I \mathrm{c} / I \mathrm{~cm}$ \\
\hline 0.00 & -.55 & $\begin{array}{r}74.530 \\
36.650 \\
14.918 \\
4.284 \\
0.747\end{array}$ & $\begin{array}{r}8.00 \\
10.00 \\
12.00 \\
14.00 \\
16.00\end{array}$ & $\begin{array}{l}2.241 \\
1.101 \\
0.448 \\
0.129 \\
0.022\end{array}$ & $\begin{array}{r}17.929 \\
11.005 \\
5.376 \\
1.801 \\
0.359\end{array}$ & 0.7957 \\
\hline 0.08 & -.47 & 78.200 & 8.00 & 2.348 & 18.786 & 0.8338 \\
\hline $0.2 \overline{3}$ & -.32 & 87.400 & 8.00 & 2.625 & 20.997 & 0.9319 \\
\hline 0.55 & -.20 & 93.790 & 8.00 & 2.817 & 22.532 & 1.0000 \\
\hline 0.51 & -.04 & $\begin{array}{r}54.505 \\
28.265 \\
12.293 \\
3.971 \\
0.765\end{array}$ & $\begin{array}{l}10.00 \\
12.00 \\
14.00 \\
16.00 \\
18.00\end{array}$ & $\begin{array}{l}1.640 \\
0.849 \\
0.369 \\
0.119 \\
0.023\end{array}$ & $\begin{array}{r}16.398 \\
10.186 \\
5.158 \\
1.908 \\
0.414\end{array}$ & \\
\hline 0.59 & 0.04 & 54.270 & 10.00 & 1.530 & 16.297 & \\
\hline 0.71 & 0.16 & 43.855 & 10.00 & 1.317 & 13.170 & \\
\hline 0.80 & 0.25 & 29.455 & 10.00 & 0.885 & 8.845 & \\
\hline 0.41 & -.14 & 31.195 & 10.00 & 0.957 & 9.568 & \\
\hline 0.88 & $0 . \overline{3}$ & 15.580 & 10.00 & 0.468 & 4.679 & \\
\hline 0.47 & -.08 & 18.250 & 10.00 & 0.548 & 5.484 & \\
\hline 0.97 & 0.42 & 5.410 & 10.00 & 0.162 & 1.525 & \\
\hline 0.53 & -.02 & 3.450 & 10.00 & 0.104 & 1.035 & \\
\hline
\end{tabular}




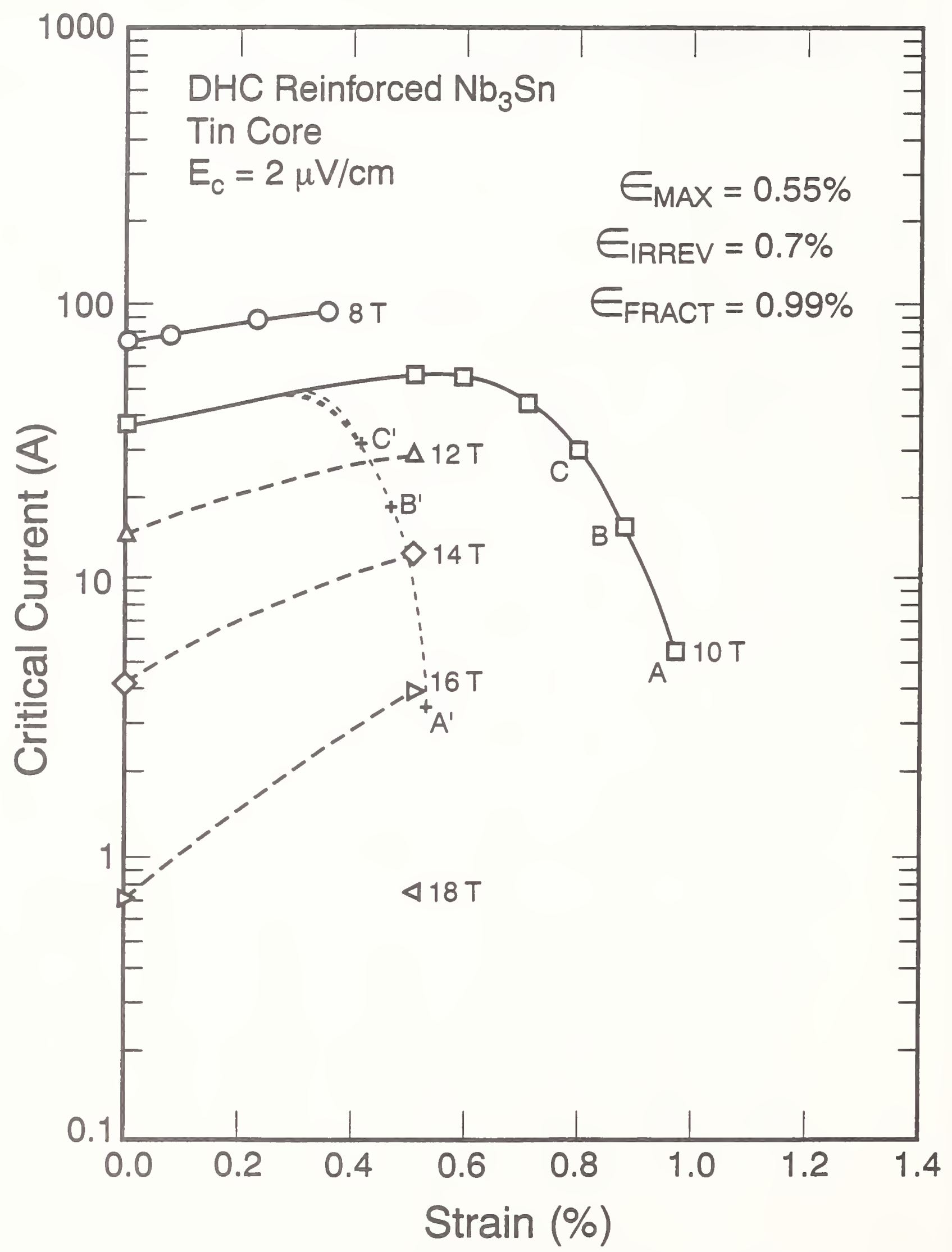

Figure 11. Effect of axial tensile strain on the critical current of $\mathrm{DHC}$ reinforced $\mathrm{Nb}_{3} \mathrm{Sn}$ conductor at $4 \mathrm{~K}$ and several magnetic fields. 


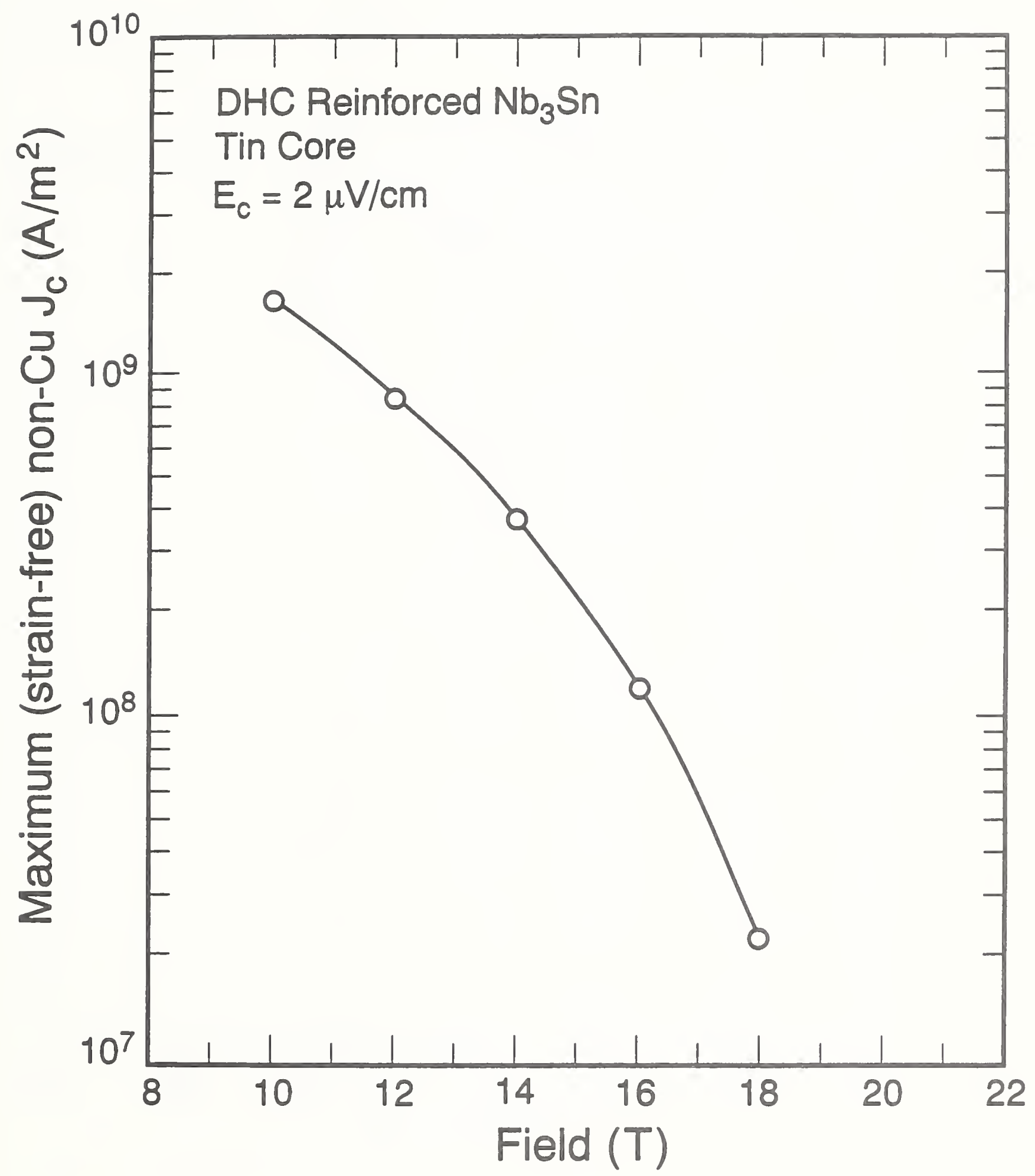

Figure 12. Effect of magnetic field on the critical current density of DHC reinforced $\mathrm{Nb}_{3} \mathrm{Sn}$ conductor at $4 \mathrm{~K}$. 


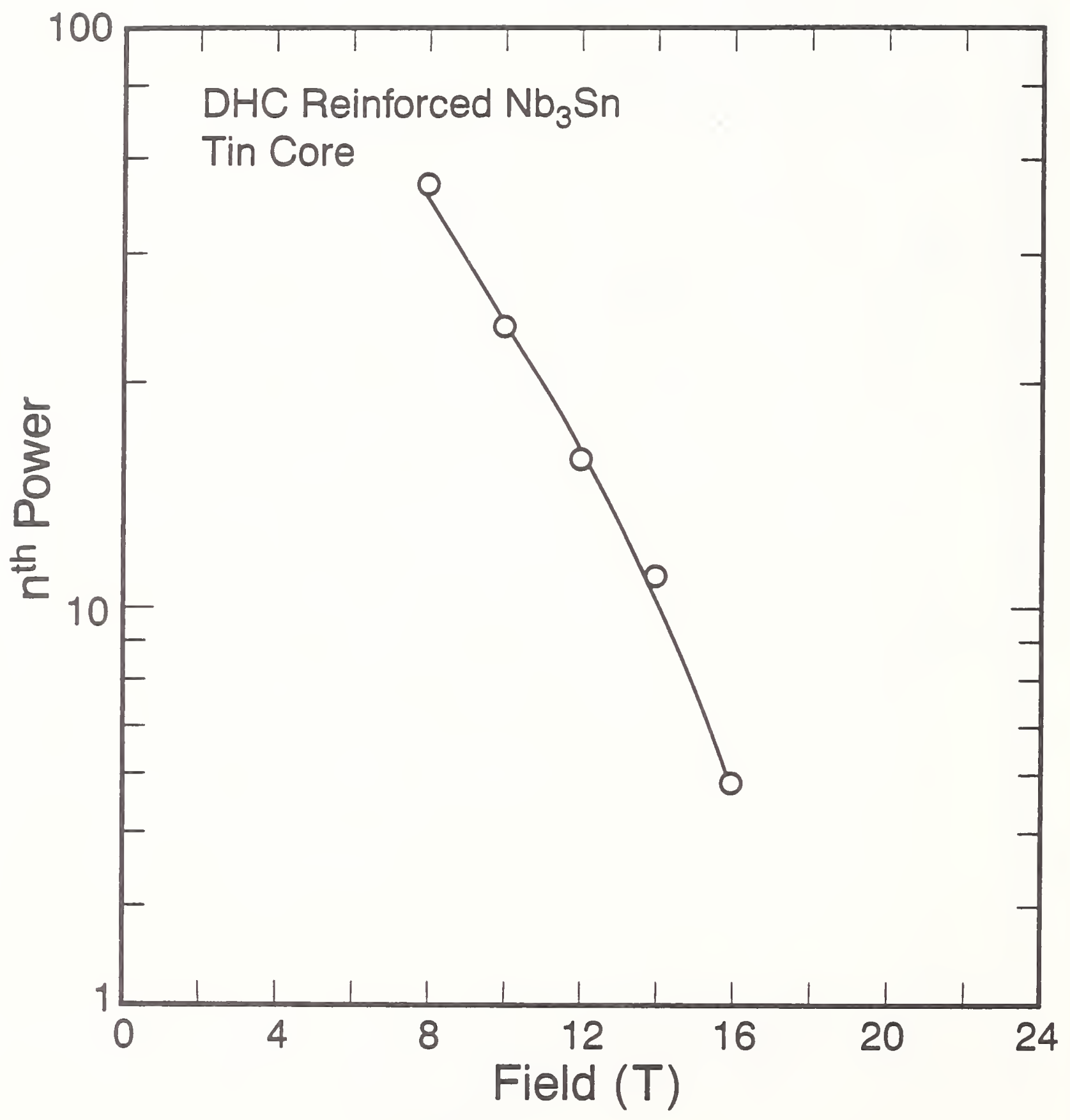

Figure 13. Effect of magnetic field on the $n^{\text {th }}$ power of $\mathrm{DHC}$ reinforced $\mathrm{Nb}_{3} \mathrm{Sn}$ conductor at $4 \mathrm{~K}$. 
Table 11. High-field critical current of $\mathrm{DHC}$ reinforced tin-ring $\mathrm{Nb}_{3} \mathrm{Sn}$ with pure copper stabilizer as a function of axial tensile strain applied at $4 \mathrm{~K}$.

\begin{tabular}{|c|c|c|c|c|c|c|}
\hline $\begin{array}{l}E \\
(\%)\end{array}$ & $\begin{array}{l}\text { Eo } \\
(\xi)\end{array}$ & $\begin{array}{l}\text { Field } \\
(\mathrm{T})\end{array}$ & $\begin{array}{l}\text { Ic } \\
(A)\end{array}$ & $\begin{array}{c}\text { Jc } \\
\left(\mathrm{MA} / \mathrm{m}^{-2}\right)\end{array}$ & $I C / I C m$ & ת value \\
\hline 0.00 & -.30 & $\begin{array}{l}10.00 \\
12.00 \\
14.00 \\
16.00 \\
18.00 \\
20.00 \\
22.00 \\
24.00 \\
25.00\end{array}$ & $\begin{array}{r}36.49 \\
26.30 \\
18.49 \\
12.28 \\
7.63 \\
4.08 \\
1.66 \\
0.37 \\
0.10\end{array}$ & $\begin{array}{r}1484.72 \\
1070.00 \\
752.13 \\
499.54 \\
310.58 \\
165.99 \\
67.45 \\
15.09 \\
4.27\end{array}$ & $\begin{array}{l}0.958 \\
0.957 \\
0.945 \\
0.926 \\
0.907 \\
0.866 \\
0.777 \\
0.640 \\
0.529\end{array}$ & $\begin{array}{r}30.0 \\
30.3 \\
29.8 \\
28.5 \\
23.7 \\
17.8 \\
11.7 \\
6.3 \\
3.6\end{array}$ \\
\hline 0.09 & -.21 & $\begin{array}{l}10.00 \\
12.00 \\
14.00 \\
16.00 \\
18.00 \\
20.00 \\
22.00 \\
24.00\end{array}$ & $\begin{array}{r}36.68 \\
26.30 \\
18.45 \\
12.28 \\
7.52 \\
3.96 \\
1.58 \\
0.36\end{array}$ & $\begin{array}{r}1492.41 \\
1070.08 \\
750.44 \\
499.66 \\
305.80 \\
161.18 \\
64.10 \\
14.57\end{array}$ & $\begin{array}{l}0.962 \\
0.957 \\
0.943 \\
0.926 \\
0.893 \\
0.841 \\
0.738 \\
0.618\end{array}$ & $\begin{array}{r}32.4 \\
31.8 \\
30.7 \\
28.8 \\
23.1 \\
17.5 \\
11.1 \\
7.3\end{array}$ \\
\hline 0.16 & -.14 & $\begin{array}{l}10.00 \\
12.00 \\
14.00 \\
16.00 \\
18.00 \\
20.00 \\
22.00 \\
24.00 \\
25.00\end{array}$ & $\begin{array}{r}37.48 \\
27.12 \\
19.24 \\
13.06 \\
8.19 \\
4.45 \\
1.92 \\
0.46 \\
0.15\end{array}$ & $\begin{array}{r}1524.77 \\
1103.40 \\
782.63 \\
531.45 \\
333.19 \\
180.85 \\
78.06 \\
18.89 \\
6.25\end{array}$ & $\begin{array}{l}0.983 \\
0.987 \\
0.983 \\
0.985 \\
0.973 \\
0.943 \\
0.899 \\
0.801 \\
0.774\end{array}$ & $\begin{array}{r}32.1 \\
34.6 \\
34.0 \\
33.3 \\
28.8 \\
19.8 \\
13.3 \\
6.5 \\
4.4\end{array}$ \\
\hline 0.33 & 0.03 & $\begin{array}{l}10.00 \\
12.00 \\
14.00 \\
16.00 \\
18.00 \\
20.00 \\
22.00 \\
24.00 \\
25.00\end{array}$ & $\begin{array}{r}38.11 \\
27.48 \\
19.56 \\
13.26 \\
8.42 \\
4.71 \\
2.13 \\
0.58 \\
0.20\end{array}$ & $\begin{array}{r}1550.59 \\
1117.80 \\
795.77 \\
539.65 \\
342.39 \\
191.69 \\
86.80 \\
23.58 \\
8.07\end{array}$ & $\begin{array}{l}1.000 \\
1.000 \\
1.000 \\
1.000 \\
1.000 \\
1.000 \\
1.000 \\
1.000 \\
1.000\end{array}$ & $\begin{array}{r}35.8 \\
33.3 \\
31.2 \\
29.5 \\
23.7 \\
18.1 \\
13.8 \\
7.4 \\
4.8\end{array}$ \\
\hline 0.48 & 0.18 & $\begin{array}{l}10.00 \\
12.00 \\
14.00 \\
16.00 \\
18.00 \\
20.00\end{array}$ & $\begin{array}{r}34.19 \\
24.28 \\
16.68 \\
10.83 \\
6.26 \\
2.98\end{array}$ & $\begin{array}{r}1391.03 \\
987.95 \\
678.64 \\
440.43 \\
254.68 \\
121.16\end{array}$ & $\begin{array}{l}0.897 \\
0.884 \\
0.853 \\
0.816 \\
0.744 \\
0.632\end{array}$ & $\begin{array}{l}27.4 \\
25.8 \\
25.1 \\
21.9 \\
14.5 \\
10.1\end{array}$ \\
\hline
\end{tabular}


Table 11 cont'd

\begin{tabular}{|c|c|c|c|c|c|c|}
\hline $\begin{array}{l}E \\
(\delta)\end{array}$ & $\begin{array}{l}\text { Eo } \\
(z)\end{array}$ & $\begin{array}{l}\text { Field } \\
\text { (T) }\end{array}$ & $\begin{array}{l}\text { Ic } \\
\text { (A) }\end{array}$ & $\begin{array}{c}J C \\
(M A / m-2)\end{array}$ & Ic/Icm & n value \\
\hline & & $\begin{array}{l}22.00 \\
24.00 \\
25.00\end{array}$ & $\begin{array}{l}0.94 \\
0.15 \\
0.03\end{array}$ & $\begin{array}{r}38.27 \\
5.91 \\
1.31\end{array}$ & $\begin{array}{l}0.441 \\
0.251 \\
0.162\end{array}$ & $\begin{array}{l}5.1 \\
3.2 \\
2.0\end{array}$ \\
\hline 0.64 & 0.34 & $\begin{array}{l}10.00 \\
12.00 \\
14.00 \\
16.00 \\
18.00 \\
20.00 \\
22.00\end{array}$ & $\begin{array}{r}29.33 \\
19.91 \\
12.74 \\
7.30 \\
3.40 \\
1.08 \\
0.18\end{array}$ & $\begin{array}{r}1193.16 \\
810.06 \\
518.15 \\
296.80 \\
138.16 \\
43.77 \\
7.30\end{array}$ & $\begin{array}{l}0.769 \\
0.725 \\
0.651 \\
0.550 \\
0.404 \\
0.228 \\
0.084\end{array}$ & $\begin{array}{r}24.7 \\
24.2 \\
21.1 \\
14.1 \\
10.4 \\
6.0 \\
3.9\end{array}$ \\
\hline 0.33 & 0.03 & 10.00 & 36.53 & 1486.03 & 1.000 & 28.8 \\
\hline 0.77 & 0.47 & 10.00 & 23.21 & 944.15 & 0.609 & 20.0 \\
\hline 0.39 & 0.09 & 10.00 & 33.67 & 1369.79 & 0.922 & 23.4 \\
\hline 0.87 & 0.57 & 10.00 & 18.68 & 760.07 & 0.490 & 21.5 \\
\hline 0.44 & 0.14 & 10.00 & 28.84 & 1173.51 & 0.790 & 15.6 \\
\hline 0.97 & 0.67 & 10.00 & 12.38 & 503.63 & 0.325 & 10.8 \\
\hline 0.49 & 0.19 & 10.00 & 22.79 & 927.05 & 0.624 & 12.3 \\
\hline
\end{tabular}




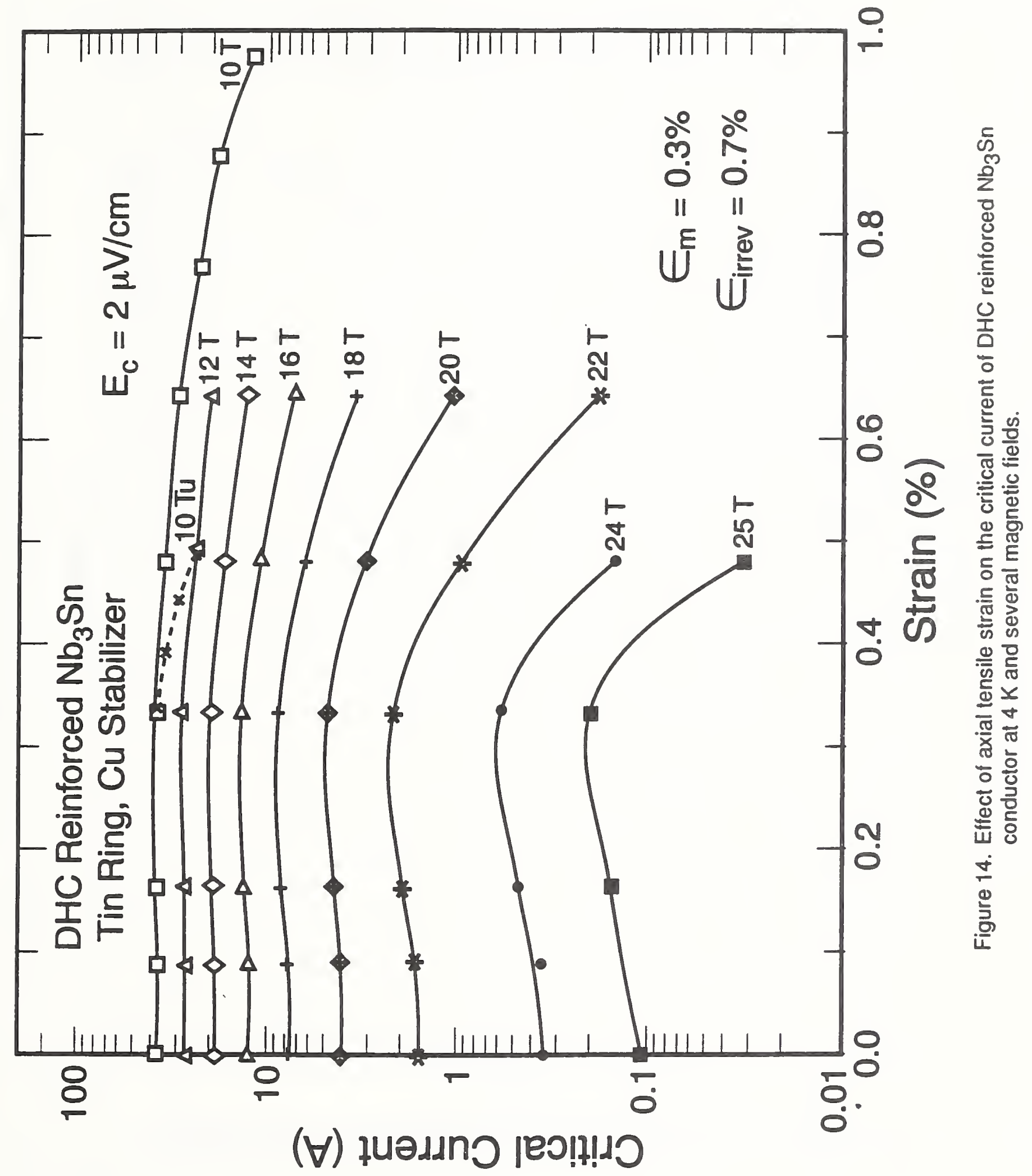




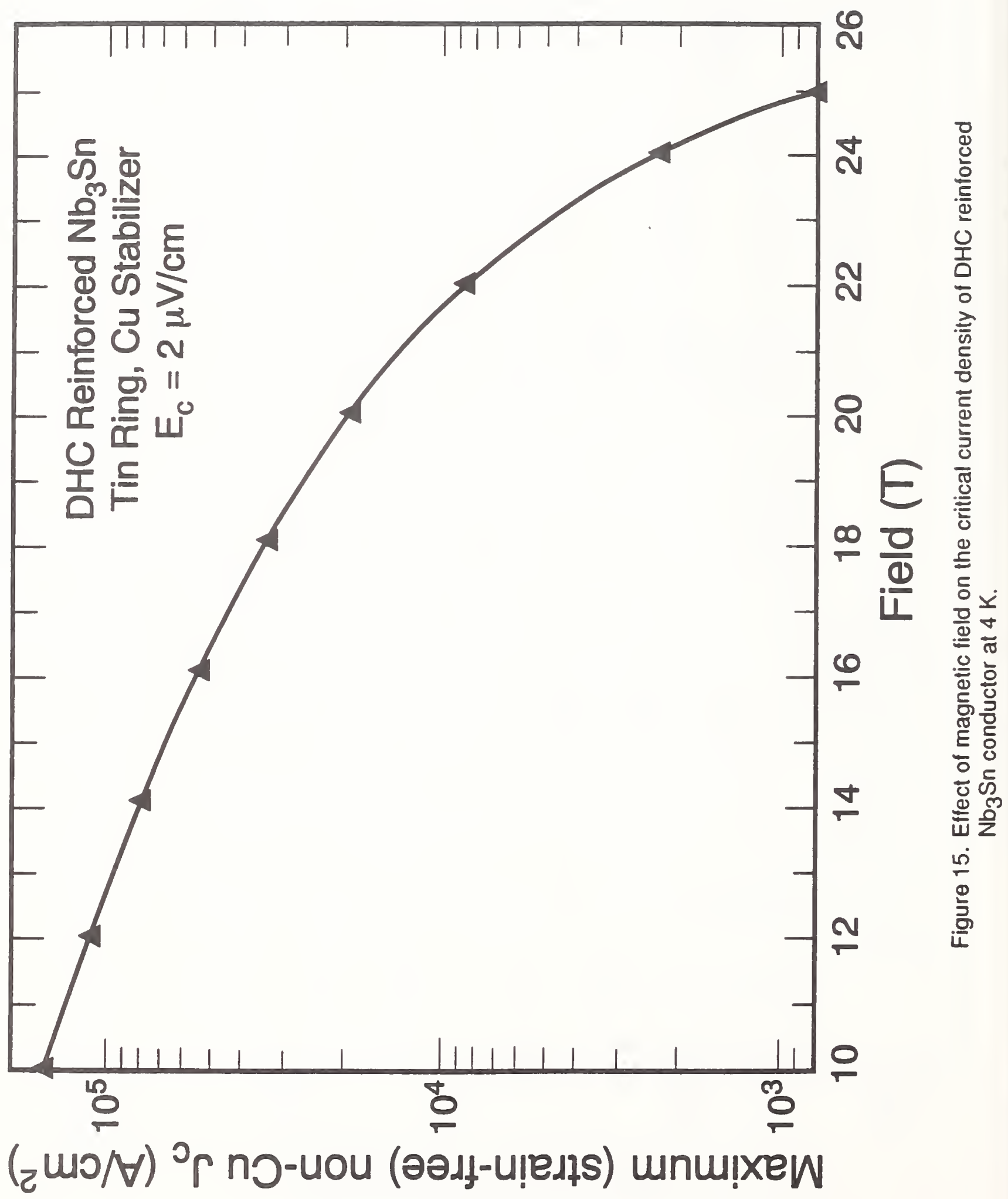




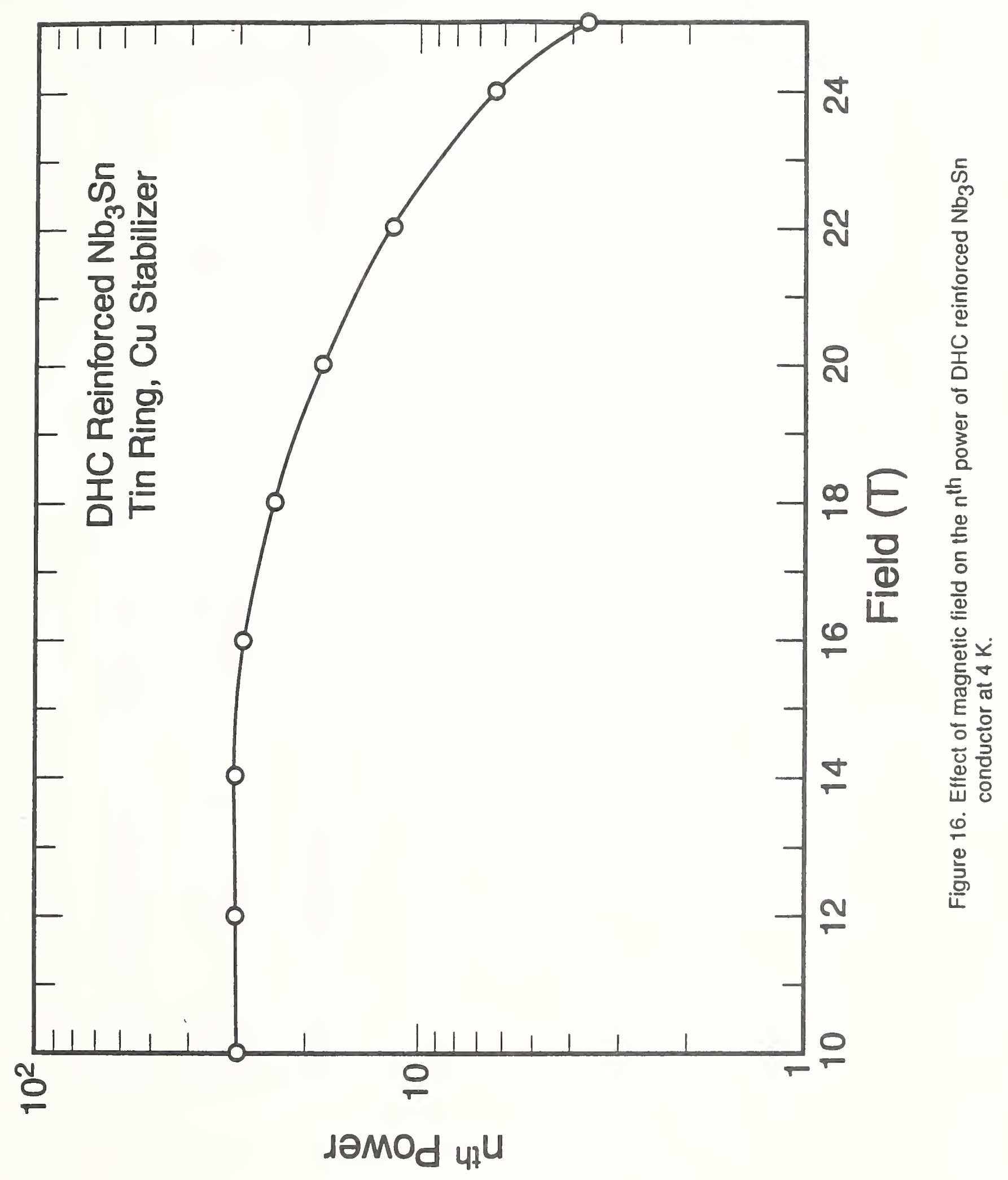


Table 12. High-field critical current of $\mathrm{DHC}$ reinforced tin-ring $\mathrm{Nb}_{3} \mathrm{Sn}$ with $\mathrm{DHC}$ stabilizer as a function of axial tensile strain applied at $4 \mathrm{~K}$.

\begin{tabular}{|c|c|c|c|c|c|c|c|}
\hline SP & $E(\%)$ & $\mathrm{E} 0(\%)$ & FIELD $(T)$ & Ic (A) & $\mathrm{Jc}\left(\mathrm{MA} / \mathrm{m}^{\wedge} 2\right)$ & Ic/Icmax & $\mathrm{N}$ \\
\hline \multirow[t]{10}{*}{0} & 0.205 & -0.095 & 10 & 33.85 & 1376.20 & 1.00 & 19.14 \\
\hline & & & 12 & 24.62 & 1000.80 & 0.97 & 20.80 \\
\hline & & & 14 & 17.09 & 694.69 & 0.96 & 19.93 \\
\hline & & & 15 & 14.03 & 570.16 & 0.97 & 17.81 \\
\hline & & & 16 & 11.25 & 457.51 & 0.97 & 17.76 \\
\hline & & & 18 & 6.75 & 274.49 & 0.94 & 16.26 \\
\hline & & & 20 & 3.39 & 137.68 & 0.90 & 14.26 \\
\hline & & & 22 & 1.25 & 50.82 & 0.86 & 9.32 \\
\hline & & & 24 & 0.22 & 8.94 & 0.78 & 4.77 \\
\hline & & & 25 & 0.05 & 2.04 & 0.75 & 2.64 \\
\hline \multirow[t]{9}{*}{1} & 0.286 & -0.014 & 12 & 25.45 & 1034.44 & 1.00 & 29.26 \\
\hline & & & 14 & 17.73 & 720.73 & 1.00 & 25.60 \\
\hline & & & 15 & 14.52 & 590.43 & 1.00 & 22.01 \\
\hline & & & 16 & 11.65 & 473.74 & 1.00 & 18.06 \\
\hline & & & 18 & 7.21 & 293.00 & 1.00 & 20.94 \\
\hline & & & 20 & 3.75 & 152.55 & 1.00 & 15.15 \\
\hline & & & 22 & 1.45 & 59.01 & 1.00 & 11.66 \\
\hline & & & 24 & 0.28 & 11.41 & 1.00 & 5.40 \\
\hline & & & 25 & 0.07 & 2.71 & 1.00 & 3.46 \\
\hline \multirow[t]{9}{*}{2} & 0.387 & 0.087 & 12 & 24.14 & 981.39 & 0.95 & 15.33 \\
\hline & & & 14 & 17.06 & 693.31 & 0.96 & 18.67 \\
\hline & & & 15 & 14.14 & 574.85 & 0.97 & 21.45 \\
\hline & & & 16 & 11.34 & 461.04 & 0.97 & 17.70 \\
\hline & & & 18 & 6.88 & 279.64 & 0.95 & 16.03 \\
\hline & & & 20 & 3.49 & 141.97 & 0.93 & 14.06 \\
\hline & & & 22 & 1.28 & 52.10 & 0.88 & 9.86 \\
\hline & & & 24 & 0.20 & 8.20 & 0.72 & 4.69 \\
\hline & & & 25 & 0.04 & 1.60 & 0.59 & 2.42 \\
\hline \multirow[t]{7}{*}{3} & 0.515 & 0.215 & 14 & 15.45 & 628.01 & 0.87 & 19.06 \\
\hline & & & 15 & 12.15 & 493.83 & 0.84 & 16.12 \\
\hline & & & 16 & 9.69 & 393.80 & 0.83 & 17.93 \\
\hline & & & 18 & 5.40 & 219.53 & 0.75 & 13.89 \\
\hline & & & 20 & 2.33 & 94.67 & 0.62 & 8.97 \\
\hline & & & 22 & 0.62 & 25.09 & 0.43 & 5.25 \\
\hline & & & 24 & 0.06 & 2.37 & 0.21 & 2.38 \\
\hline $3 U$ & 0.298 & -0.002 & 12 & 24.80 & 1008.03 & 0.97 & 15.24 \\
\hline \multirow[t]{2}{*}{4} & 0.643 & 0.343 & 14 & 12.25 & 497.83 & 0.69 & 16.40 \\
\hline & & & 15 & 9.47 & 384.76 & 0.65 & 16.37 \\
\hline
\end{tabular}


Table 12 cont'd

\begin{tabular}{|c|c|c|c|c|c|c|c|}
\hline$S P$ & $E(\%)$ & E0 $(\%)$ & FIELD (T) & Ic (A) & $\mathrm{Jc}\left(\mathrm{MA} / \mathrm{m}^{\wedge} 2\right)$ & Ic/Icmax & $\mathrm{N}$ \\
\hline & & & 16 & 6.96 & 282.84 & 0.60 & 12.69 \\
\hline & & & 18 & 3.30 & 133.96 & 0.46 & 10.44 \\
\hline & & & 20 & 0.96 & 39.05 & 0.26 & 5.42 \\
\hline & & & 22 & 0.13 & 5.11 & 0.09 & 2.79 \\
\hline & & & 24 & 0.01 & 0.51 & 0.04 & 1.38 \\
\hline $4 \mathrm{U}$ & 0.341 & 0.041 & 12 & 24.90 & 1012.01 & 0.98 & 21.63 \\
\hline 5 & 0.755 & 0.455 & 12 & 15.70 & 638.11 & 0.62 & 14.49 \\
\hline $5 \mathrm{U}$ & 0.41 & 0.11 & 12 & 24.01 & 976.14 & 0.94 & 19.69 \\
\hline 6 & 0.863 & 0.563 & 12 & 13.00 & 528.55 & 0.51 & 17.10 \\
\hline $6 \mathrm{U}$ & 0.48 & 0.18 & 12 & 22.83 & 928.24 & 0.90 & 20.82 \\
\hline 7 & 0.972 & 0.672 & 12 & 10.15 & 412.76 & 0.40 & 13.83 \\
\hline $7 U$ & 0.526 & 0.226 & 12 & 20.55 & 835.30 & 0.81 & 11.90 \\
\hline 8 & 1.08 & 0.78 & 12 & 7.65 & 310.97 & 0.30 & 9.85 \\
\hline $8 \mathrm{U}$ & 0.581 & 0.281 & 12 & 17.88 & 726.83 & 0.70 & 10.38 \\
\hline 9 & 1.188 & 0.888 & 12 & 6.37 & 259.12 & 0.28 & 7.07 \\
\hline $9 \mathrm{U}$ & 0.681 & 0.381 & 12 & 11.00 & 447.07 & 0.68 & 9.02 \\
\hline
\end{tabular}




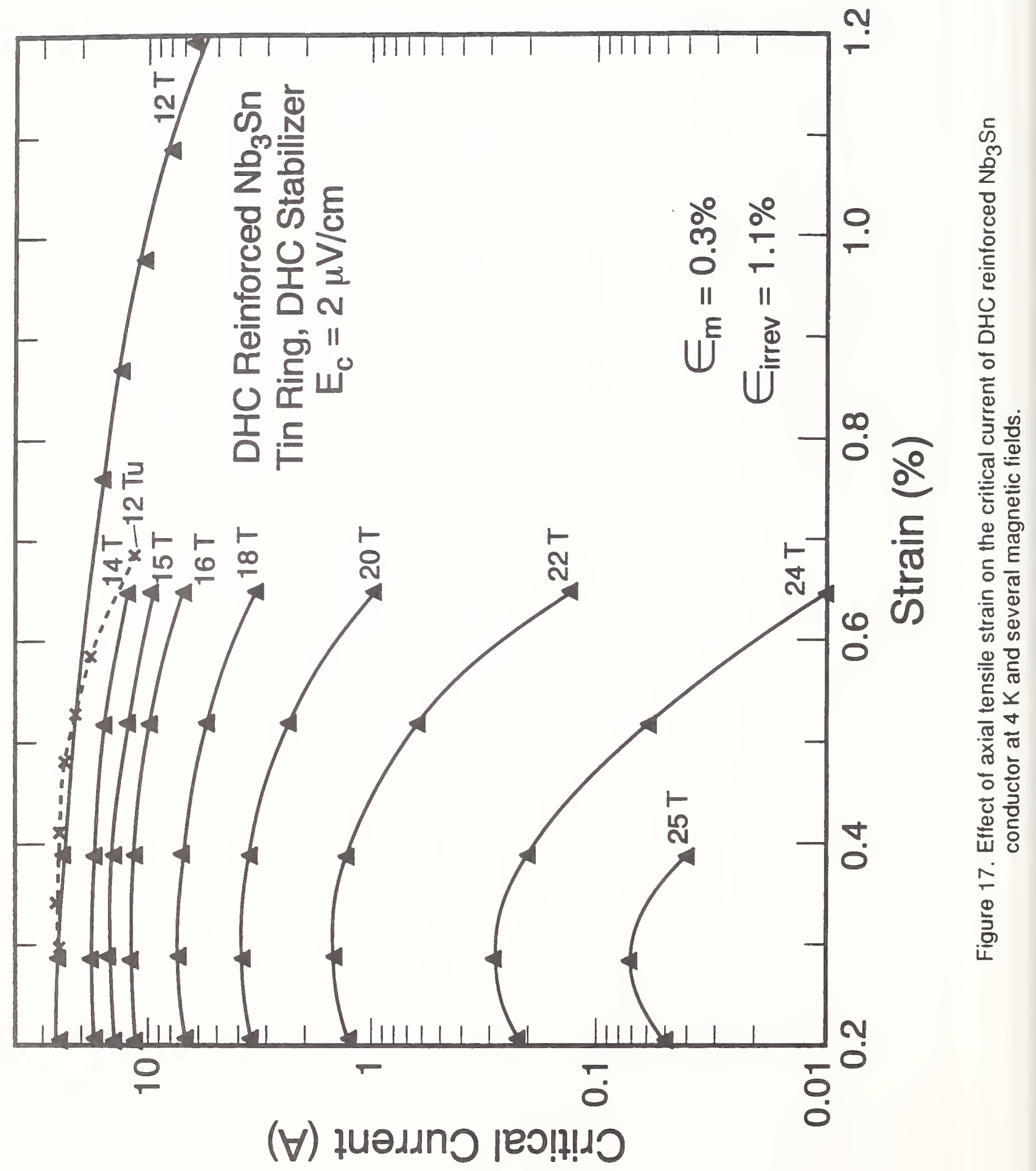




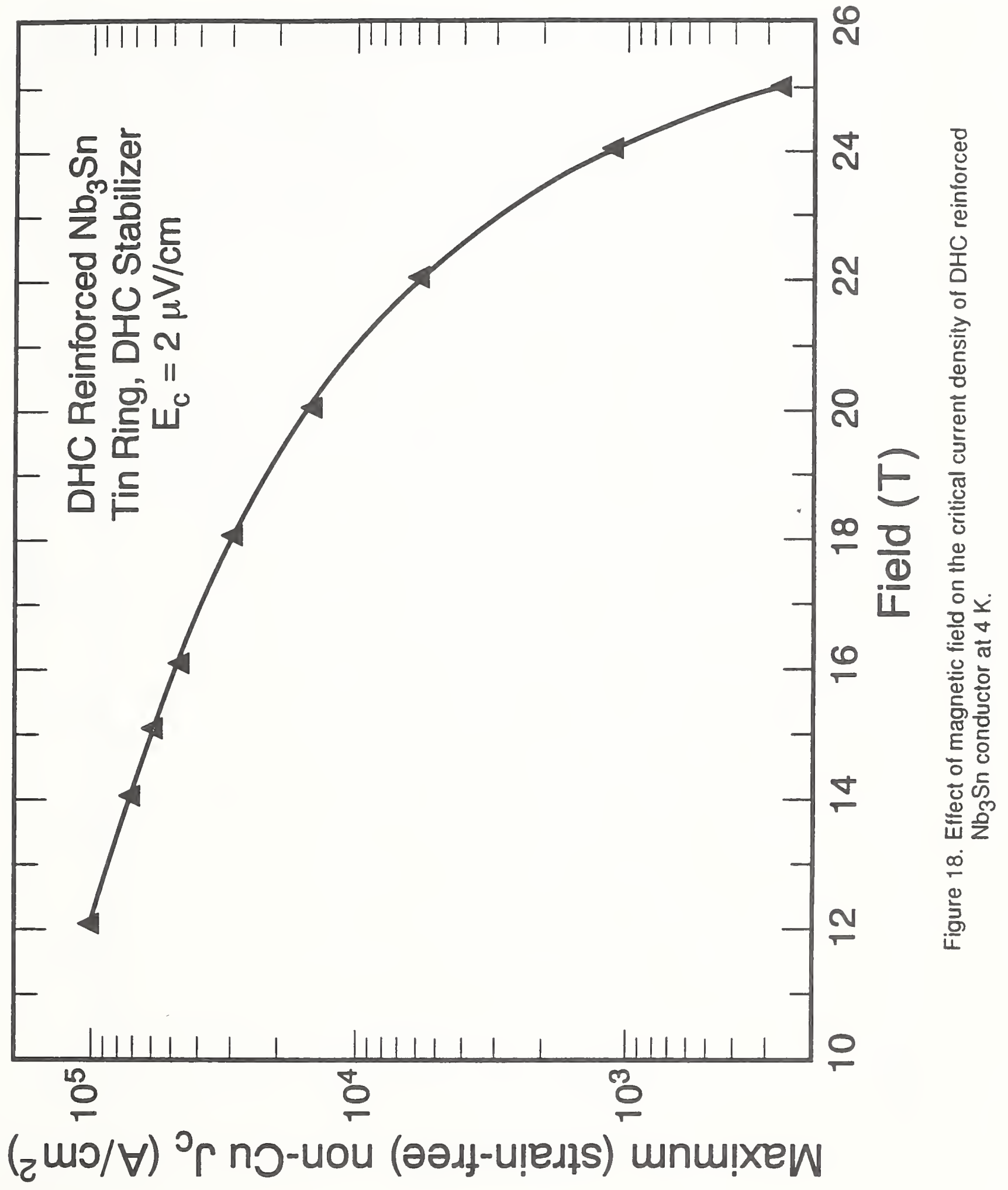




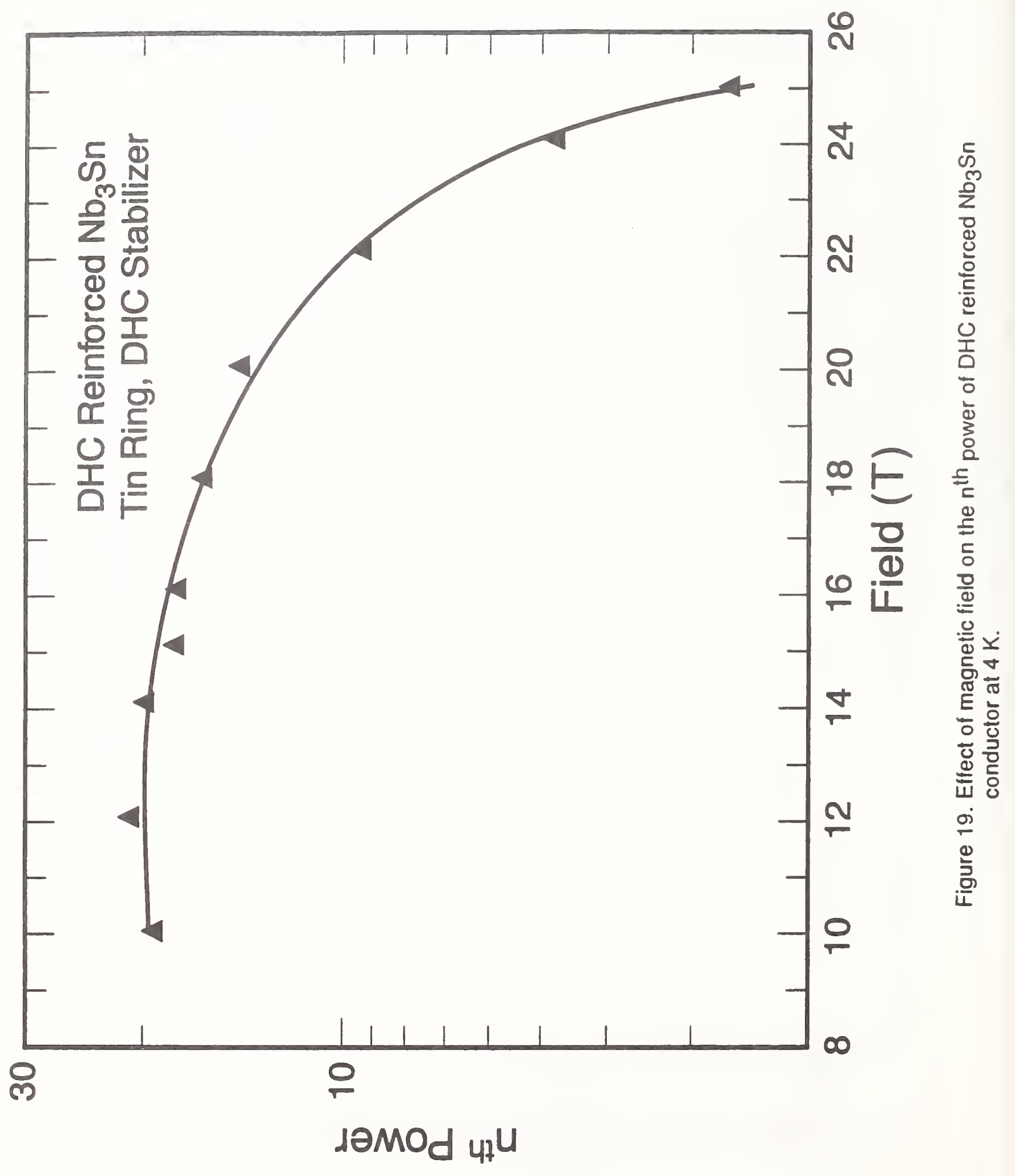




\section{$\mathrm{V}_{\mathbf{3}} \mathrm{Ga}$ Tape}

We also tested an experimental high-field $\mathrm{V}_{3} \mathrm{Ga}$ tape conductor manufactured in Japan, which is not available from US manufacturers. The conductor specifications are shown in Table 13. The complete set of $\mathrm{J}_{\mathrm{C}}$ vs. strain data at magnetic fields from $10 \mathrm{~T}$ to 19.65 $\mathrm{T}$ is given in Table 14, and the data are presented graphically in Figs. 20 through 22. The $I_{C}$ and $J_{C}$ values are based on an electric field criterion $\left(E_{C}\right)$ of $2 \mu \mathrm{V} / \mathrm{cm}$. This material has good $\mathrm{J}_{\mathrm{C}}$ properties out to $20 \mathrm{~T}$ and is a viable candidate material for extending superconducting magnets to this field range. The results show a peak (strainfree) $J_{C}$ that is high and nearly constant out to $20 \mathrm{~T}$. The initial prestrain, however, is very low, only about $0.05 \%$, and the irreversible strain limit is only $0.2 \%$.

Table 13. $V_{3} G a$ tape specifications.

In-Situ Process

Cross-Sectional Dimensions $4 \mathrm{~mm} \times 150 \mu \mathrm{m}$

Noncopper Area

$0.440 \mathrm{~mm}^{2}$

Superconductor Area

$0.1016 \mathrm{~mm}^{2}$

Core Composition

Cu-35at.\%V 
Table 14. High-field critical current of $V_{3} G a$ tape.

\begin{tabular}{|c|c|c|c|c|c|c|}
\hline $\begin{array}{c}E \\
(\%)\end{array}$ & $\begin{array}{l}\text { Eo } \\
(\%)\end{array}$ & $\begin{array}{c}\text { Ic } \\
\text { (Amperes) }\end{array}$ & $\begin{array}{c}\text { Field } \\
\text { (Tesla) }\end{array}$ & $\begin{array}{c}J c \\
\left(6 A / m^{\wedge} 2\right)\end{array}$ & $\begin{array}{c}J c B \\
\left(G N / m^{n} \overline{3}\right)\end{array}$ & $1 \mathrm{c} / 1 \mathrm{~cm}$ \\
\hline 0.00 & -.05 & $\begin{array}{r}154.700 \\
143.530 \\
126.130 \\
117.850 \\
103.680 \\
87.320 \\
69.980\end{array}$ & $\begin{array}{l}10.00 \\
12.00 \\
14.00 \\
16.00 \\
18.00 \\
19.00 \\
19.65\end{array}$ & $\begin{array}{l}0.103 \\
0.096 \\
0.084 \\
0.079 \\
0.069 \\
0.058 \\
0.047\end{array}$ & $\begin{array}{l}1.031 \\
1.148 \\
1.177 \\
1.257 \\
1.244 \\
1.106 \\
0.917\end{array}$ & $\begin{array}{l}0.9937 \\
1.0527 \\
0.9953 \\
0.9940 \\
1.0026 \\
1.0029 \\
0.9779\end{array}$ \\
\hline 0.05 & 0.00 & $\begin{array}{r}155.680 \\
136.350 \\
126.730 \\
118.560 \\
103.410 \\
87.070 \\
71.560\end{array}$ & $\begin{array}{l}10.00 \\
12.00 \\
14.00 \\
15.00 \\
18.00 \\
19.00 \\
19.65\end{array}$ & $\begin{array}{l}0.104 \\
0.091 \\
0.084 \\
0.079 \\
0.069 \\
0.058 \\
0.048\end{array}$ & $\begin{array}{l}1.038 \\
1.091 \\
1.183 \\
1.265 \\
1.241 \\
1.103 \\
0.937\end{array}$ & $\begin{array}{l}1.0000 \\
1.0000 \\
1.0000 \\
1.0000 \\
1.0000 \\
1.0000 \\
1.0000\end{array}$ \\
\hline
\end{tabular}

\begin{tabular}{|c|c|c|c|c|c|c|}
\hline \multirow[t]{7}{*}{0.15} & 0.11 & 152.730 & 10.00 & 0.102 & 1.018 & 0.9811 \\
\hline & & 132.000 & 12.00 & 0.088 & 1.056 & 0.9681 \\
\hline & & 118.300 & 14.00 & 0.079 & 1.104 & 0.9335 \\
\hline & & 102.970 & 16.00 & 0.069 & 1.098 & 0.8685 \\
\hline & & 83.980 & 18.00 & 0.056 & 1.008 & 0.8121 \\
\hline & & 69.720 & 19.00 & 0.046 & 0.883 & 0.8007 \\
\hline & & 58.090 & 19.65 & 0.039 & 0.761 & 0.8118 \\
\hline \multirow[t]{7}{*}{0.19} & 0.14 & 137.900 & 10.00 & 0.092 & 0.919 & 0.8859 \\
\hline & & 118.600 & 12.00 & 0.079 & 0.949 & 0.8698 \\
\hline & & 106.980 & 14.00 & 0.071 & 0.998 & 0.8442 \\
\hline & & 94.270 & 16.00 & 0.063 & 1.006 & 0.7951 \\
\hline & & 75.810 & 18.00 & 0.051 & 0.910 & 0.7331 \\
\hline & & 63.610 & 19.00 & 0.042 & 0.806 & 0.7306 \\
\hline & & 52.190 & 19.65 & 0.035 & 0.684 & 0.7293 \\
\hline 0.07 & 0.02 & 136.500 & 10.00 & 0.091 & 0.910 & 0.8768 \\
\hline \multirow[t]{7}{*}{0.26} & 0.21 & 125.430 & 10.00 & 0.084 & 0.836 & 0.8057 \\
\hline & & 104.400 & 12.00 & 0.070 & 0.835 & 0.7557 \\
\hline & & 94.280 & 14.00 & 0.063 & 0.880 & 0.7439 \\
\hline & & 81.630 & 16.00 & 0.054 & 0.871 & 0.6885 \\
\hline & & 66.490 & 18.00 & 0.044 & 0.798 & 0.6430 \\
\hline & & 54.710 & 19.00 & 0.036 & 0.693 & 0.6284 \\
\hline & & 44.870 & 19.65 & 0.030 & 0.588 & 0.6270 \\
\hline
\end{tabular}
0.09
0.04
117.050
10.00
0.078
0.780
0.7519 
Table 14 cont'd

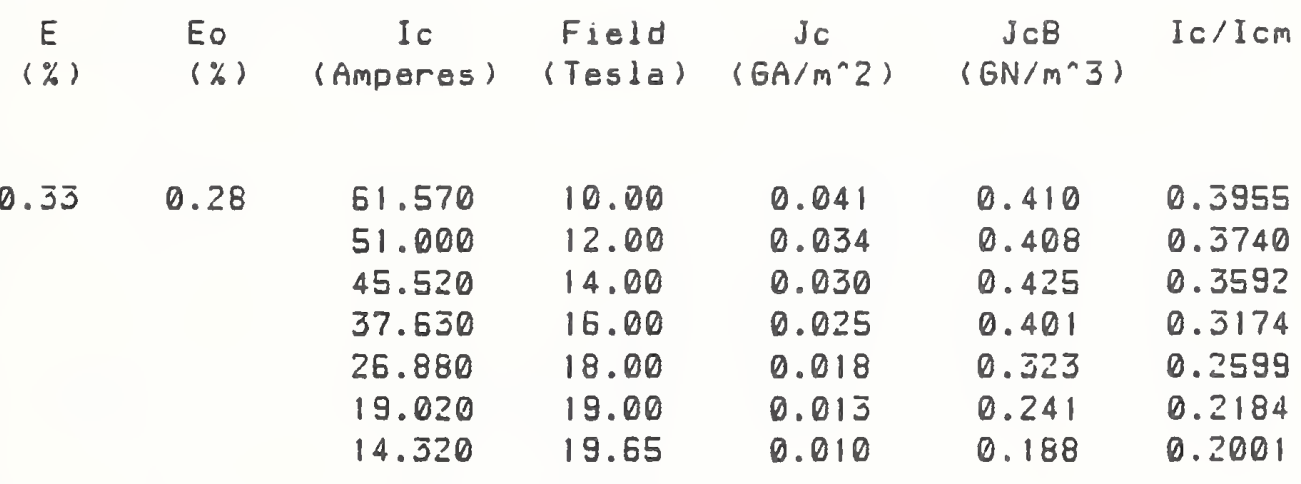

$\begin{array}{ccccccc}0.11 & 0.05 & 60.430 & 10.00 & 0.040 & 0.403 & 0.3882 \\ 0.38 & 0.33 & 40.050 & 10.00 & 0.027 & 0.267 & 0.2573 \\ & & 26.090 & 12.00 & 0.017 & 0.209 & 0.1914 \\ & 20.130 & 14.00 & 0.013 & 0.188 & 0.1588 \\ & 14.565 & 16.00 & 0.010 & 0.155 & 0.1229 \\ & 8.505 & 18.00 & 0.006 & 0.102 & 0.0822 \\ & 5.378 & 19.00 & 0.004 & 0.068 & 0.0618 \\ & 3.460 & 19.65 & 0.002 & 0.045 & 0.0484\end{array}$

$\begin{array}{lllllll}0.13 & 0.08 & 47.850 & 10.00 & 0.032 & 0.319 & 0.3074\end{array}$ 
$\mathrm{V}_{3} \mathrm{Ga}$ Tape \#VA12-115H

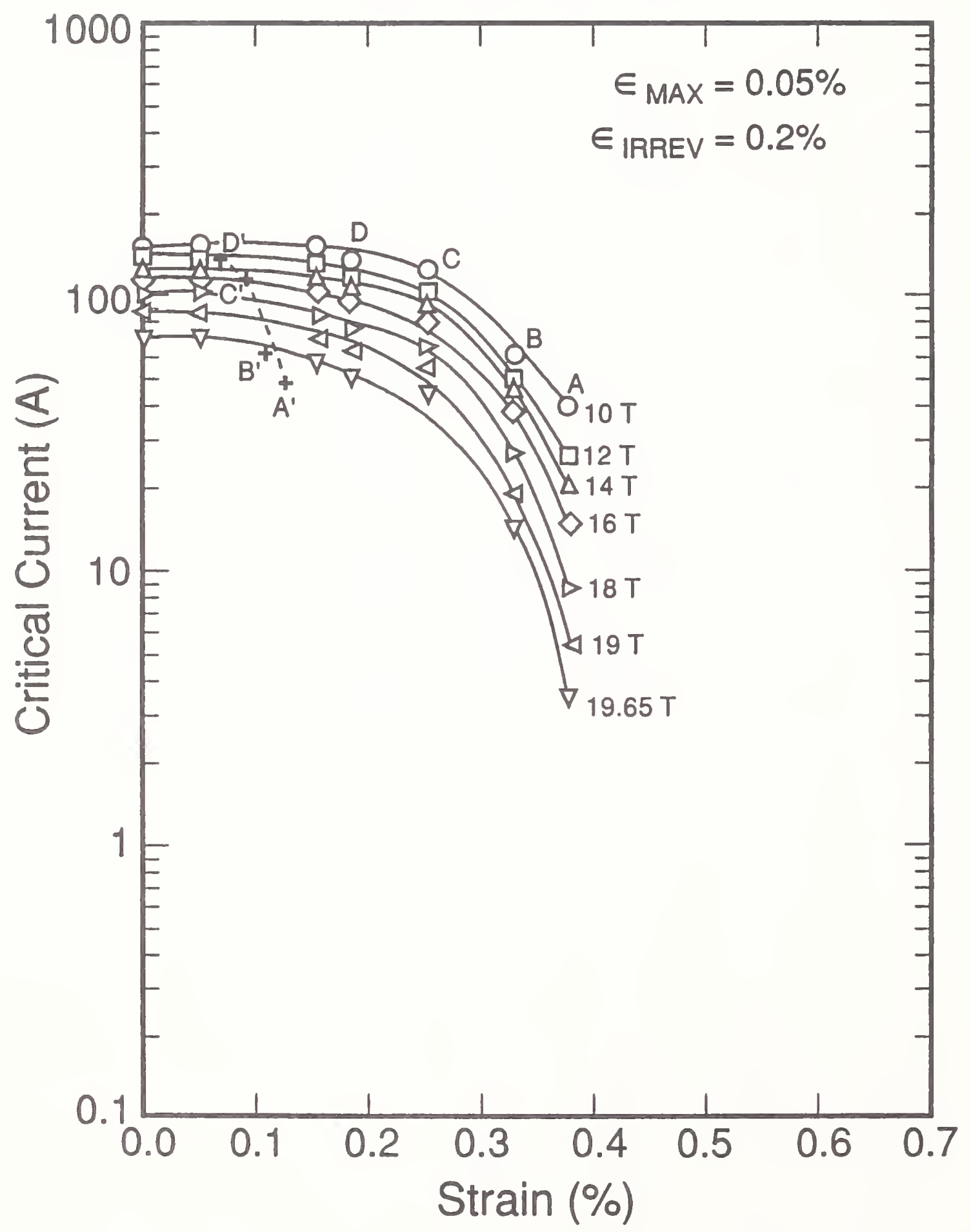

Figure 20. Effect of axial tensile strain on the critical current of $V_{3} G$ a tape at $4 \mathrm{~K}$ and several magnetic fields. 


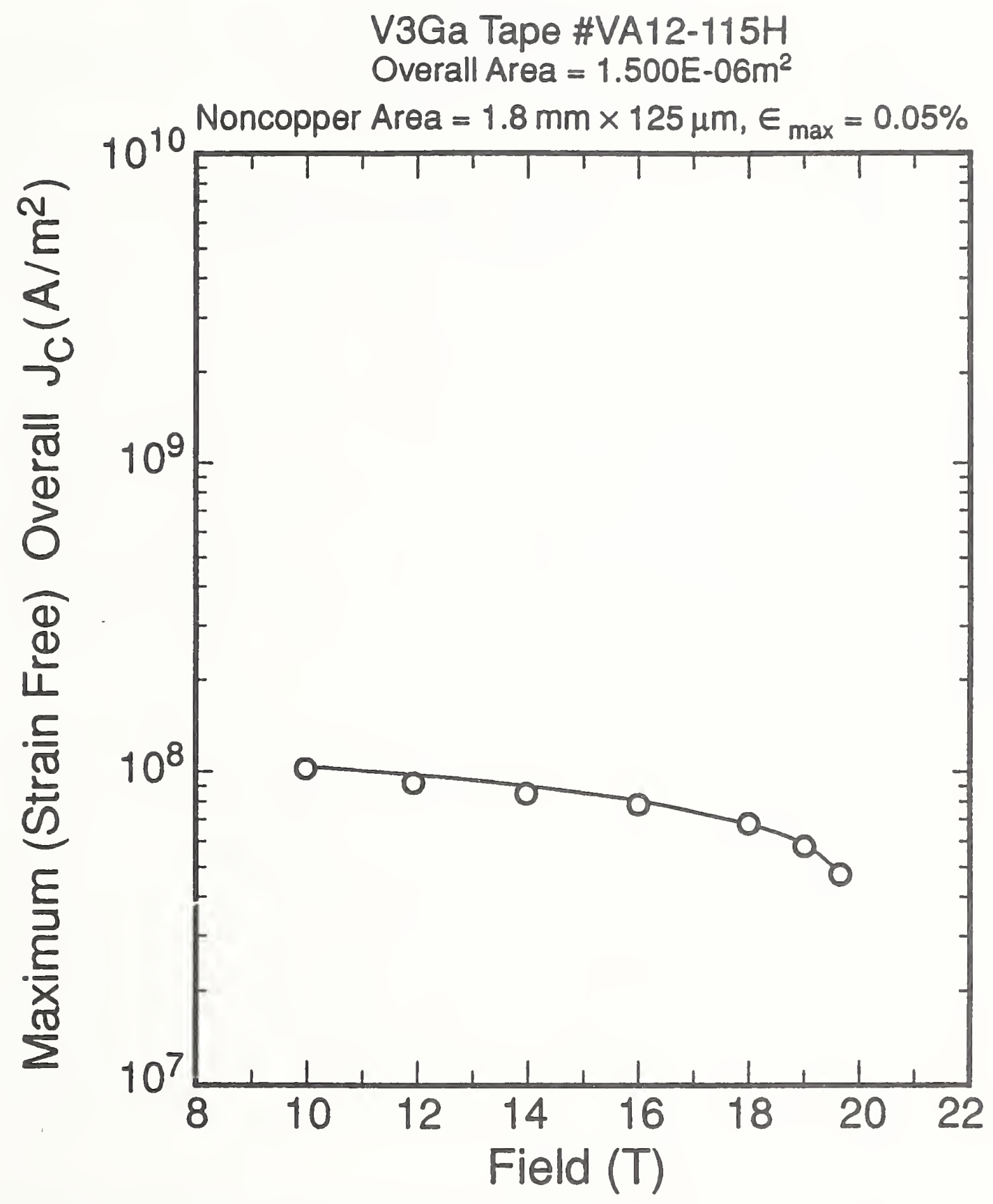

Figure 21. Effect of magnetic field on the critical current density of $V_{3} G$ a tape at $4 \mathrm{~K}$. 


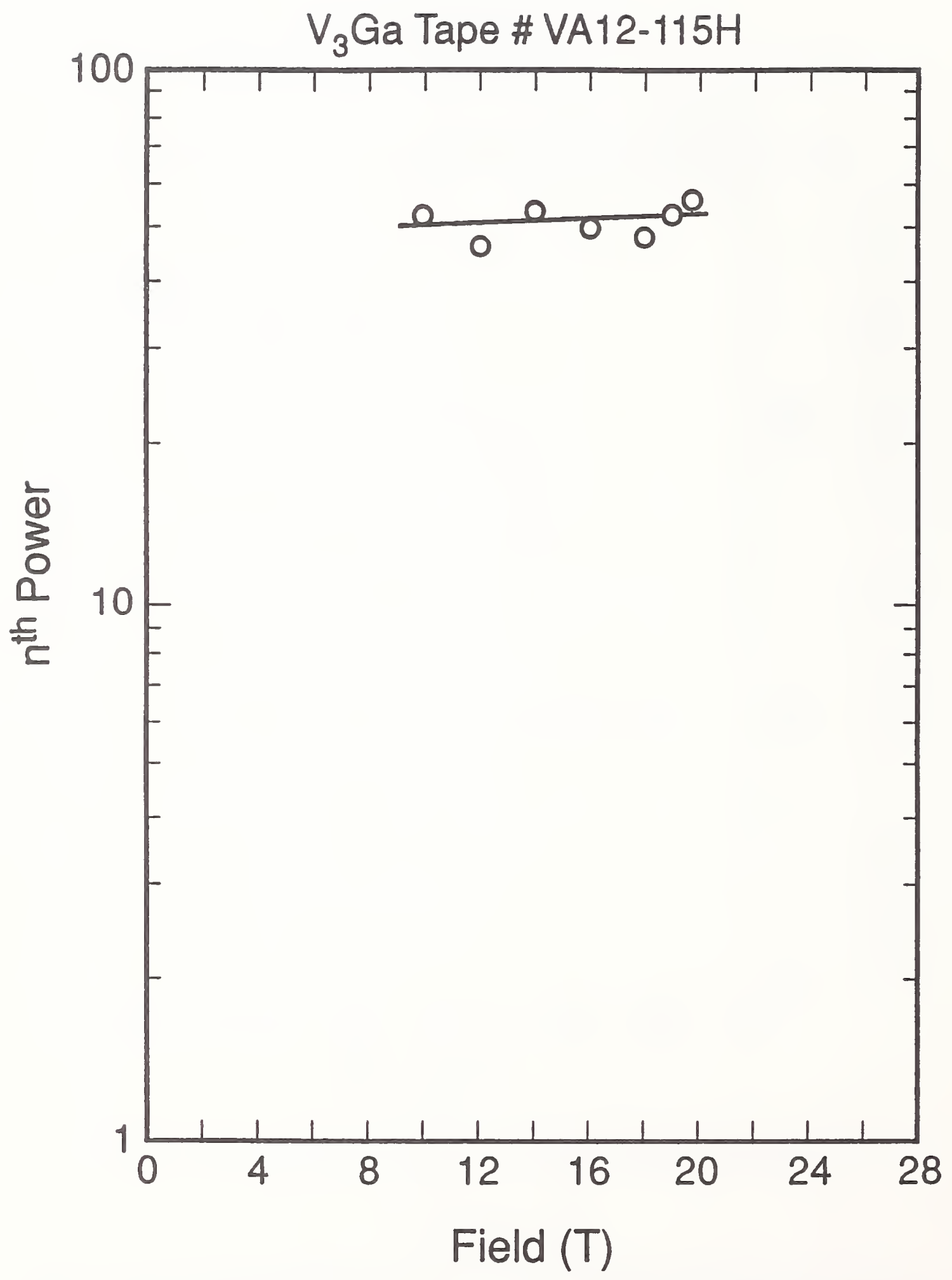

Figure 22. Effect of magnetic field on the $n^{\text {th }}$ power of $V_{3} G$ a tape at $4 \mathrm{~K}$. 


\title{
CRITICAL-CURRENT DEGRADATION IN MULTIFILAMENTARY Nb3AI WIRES FROM TRANSVERSE COMPRESSIVE AND AXIAL TENSILE STRESS
}

\author{
S. L. Bray and J. W. Ekin \\ National Institute of Standards and Technology \\ 325 Broadway \\ Boulder, CO 80303 \\ T. Kuroda \\ National Research Institute for Metals \\ Ibaraki 305, Japan
}

Abstract--The effect of transverse compressive stress and axial tensile stress on the critical current of multifilamentary $\mathrm{Nb}_{3} \mathrm{Al}$ superconducting wires has been measured. Compared with commercial $\mathrm{Nb}_{3} \mathrm{Sn}, \mathrm{Nb}_{3} \mathrm{Al}$ exhibits a relatively small sensitivity to both axial and transverse stress. For a given degradation of critical current at $9 \mathrm{~T}, \mathrm{Nb}_{3} \mathrm{Al}$ will tolerate about twice as much axial stress as $\mathrm{Nb}_{3} \mathrm{Sn}$ and about five times the transverse stress. The elastic modulus of $\mathrm{Nb}_{3} \mathrm{Al}$, $169 \pm 20 \mathrm{GPa}$, was measured for the first time at cryogenic temperatures and found comparable to that of $\mathrm{Nb}_{3} \mathrm{Sn}$. A comparison between the effect of axial and transverse stress showed that $\mathrm{Nb}_{3} \mathrm{Al}$, like $\mathrm{Nb}_{3} \mathrm{Sn}$, is more sensitive to transverse stress than axial stress. For a given level of criticalcurrent degradation, the transverse stress tolerance of $\mathrm{Nb} 3 \mathrm{Al}$ is about half the axial stress tolerance. The favorable electromechanical characteristics of $\mathrm{Nb}_{3} \mathrm{Al}$, compared with $\mathrm{Nb}_{3} \mathrm{Sn}$, may allow increased operating limits for the next generation of large high-field superconducting magnets.

\section{INTRODUCTION}

Presently, the most common conductor material used in high-field (>10 T) superconducting magnet designs is $\mathrm{Nb}_{3} \mathrm{Sn}$. Commercially available multifilamentary $\mathrm{Nb}_{3} \mathrm{Sn}$ conductors typically have noncopper critical-current densities $\left(\mathrm{J}_{\mathrm{C}}\right)$ exceeding $10^{5} \mathrm{~A} / \mathrm{cm}^{2}$ at a magnetic field of $10 \mathrm{~T}$. High current densities and high fields interact within magnet windings to produce large Lorentz forces supported by the conductor and the magnet stiucture. The two dominant components of stress in the windings are a tensile stress aligned with the conductor's longitudinal axis (axial stress) and a compressive stress that is perpendicular to its axis (transverse stress). The $\mathrm{J}_{\mathrm{c}}$ of $\mathrm{Nb}_{3} \mathrm{Sn}$ is highly sensitive to its stress state. Consequently, it is the internal stress state of the magnet windings, rather than the $\mathrm{J}_{\mathrm{C}}$ of the unstressed superconductor, that determines the design limits for large high-field magnets.

As new magnet designs call for larger coils and higher fields, stresses must be limited by structural reinforcement of the windings. Control of the stress, which accumulates radially within the windings, requires distributed internal reinforcement. Aside from complicating the design and increasing the cost of the magnet, additional internal

Publication of NIST, not subject to copyright. Manuscript Received August 24, 1992. reinforcement limits the superconductor packing fraction and, thus, reduces the magnetic field. Also, internal stresses within cable-in-conduit conductors can be difficult to control; thus, a superconducting material that is less sensitive to stress but comparable to $\mathrm{Nb}_{3} \mathrm{Sn}$ in $\mathrm{J}_{\mathrm{c}}$ has significant design advantages. A promising candidate material for this application is the A-15 superconductor $\mathrm{Nb}_{3} \mathrm{Al}$.

Early measurements of $\mathrm{Nb}_{3} \mathrm{Al}$ wires demonstrated their relative insensitivity to axial stress [1], but these experimental conductors were only available in short test sample lengths, unsuitable for magnet applications. More recently, technologies have been developed that allow fabrication of multifilamentary $\mathrm{Nb}_{3} \mathrm{Al}$ wires of practical lengths [2]. In this paper, both the axial and transverse stress effects for these conductors are investigated, and their performance is compared with that of a commercial binary $\mathrm{Nb}_{3} \mathrm{Sn}$ conductor. Also, results from the first elastic-modulus measurements of $\mathrm{Nb}_{3} \mathrm{Al}$ at cryogenic temperatures, which were required to compare the axial and transverse stress effect in $\mathrm{Nb}_{3} \mathrm{Al}$, are presented.

\section{EXPERIMENTAL DETAILS}

The critical-current $\left(I_{C}\right)$ degradation of round multifilamentary $\mathrm{Nb}_{3} \mathrm{Al}$ composite wires, caused by both axial and transverse stress, was measured at a temperature of $4 \mathrm{~K}$ and as a function of magnetic field. An electric-field criterion of $2 \mu \mathrm{V} / \mathrm{cm}$ was used for determining the $I_{c}$. The overall precision of the $I_{C}$ data is about $\pm 0.5 \%$. In the case of the transverse tests, a servohydraulic actuator and load cell are used to apply a compressive transverse load to the sample. The apparatus design allows mutually perpendicular application of current, field, and load [3] to simulate the conditions within the windings of a magnet. The transverse stress is calculated by dividing the load by the projected area of the compressed region of the sample. This technique is justified by previous comparative transverse stress measurements between round and rectangular $\mathrm{Nb}_{3} \mathrm{Sn}$ samples [3].

In the case of the axial tests, an axial tensile load is applied to the sample and the resulting axial strain is measured with an extensometer [4]. The magnetic field is perpendicular to the strain and current, which are coaxial, again simulating the conditions within a magnet. The characteristics of the $\mathrm{Nb} 3 \mathrm{Al}$ samples, which were prepared by the $\mathrm{Nb}$-tube process [2], are given in Table 1. 
Table 1. Nb3 Al Sample Characteristics

\begin{tabular}{ll}
\hline Wire diameter & $0.5-0.57 \mathrm{~mm}$ \\
Matrix material & $\mathrm{Nb}$ \\
Filament composition & $\mathrm{Al}-1$ at\% Cu-1 at\% Ge \\
& (prior to heat treatment) \\
Matrix-to-filament volume ratio & $31: 1$ \\
No. filaments & $1,728,000$ \\
Filament size & $-80 \mathrm{~nm}$ \\
Heat treatment & 3 hours at $800{ }^{\circ} \mathrm{C}$ \\
Overall $J_{c}$ at $12 \mathrm{~T}$ & $8,600 \mathrm{~A} / \mathrm{cm}^{2}$ \\
Filament $J_{c}$ at $12 \mathrm{~T}$ & $274,000 \mathrm{~A} / \mathrm{cm}^{2}$
\end{tabular}

\section{RESULTS}

The results of the $\mathrm{Nb}_{3} \mathrm{Al}$ axial strain measurements are shown in Fig. 1 where $I_{c}$ is plotted as a function of axial strain for several magnetic fields. The ordinate is the measured $I_{c}$ normalized to the starting (zero-strain) value $\left(I_{c m}\right)$. For comparison, previously acquired data for a commercial bronze-process $\mathrm{Nb}_{3} \mathrm{Sn}$ conductor [3] are also presented. The available data do not allow direct comparison of the $\mathrm{Nb}_{3} \mathrm{Al}$ and $\mathrm{Nb}_{3} \mathrm{Sn}$ conductors at a common field; however, interpolation of the $\mathrm{Nb}_{3} \mathrm{Sn}$ data allows comparison at $9 \mathrm{~T}$. For $I_{c}$ degradations greater than $10 \%$, the $\mathrm{Nb} 3 \mathrm{Al}$ will tolerate approximately twice the strain of the $\mathrm{Nb}_{3} \mathrm{Sn}$ while undergoing the same degradation in $\mathrm{I}_{\mathrm{C}}$.

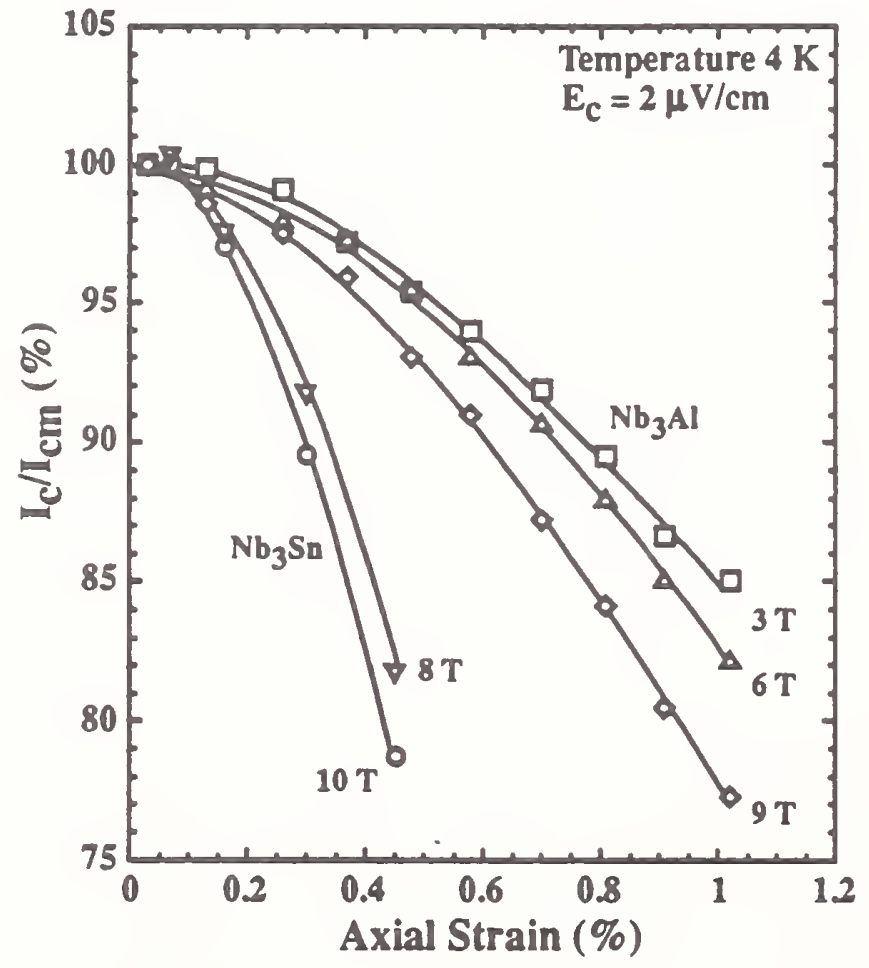

Fig. 1. Critical-current degradation caused by axial tensile strain.

Figure 2 shows a similar comparison between $\mathrm{Nb}_{3} \mathrm{Al}$ and $\mathrm{Nb}_{3} \mathrm{Sn}$ subjected to transverse stress. By convention, the stress is negative to indicate compression. The difference between $\mathrm{Nb}_{3} \mathrm{Al}$ and $\mathrm{Nb}_{3} \mathrm{Sn}$ is even greater in the case of transverse stress. For $\mathrm{I}_{C}$ degradations greater than $10 \%$ at $9 \mathrm{~T}$, the $\mathrm{Nb} 3 \mathrm{Al}$ will tolerate approximately five times the stress of the $\mathrm{Nb}_{3} \mathrm{~S} n$ while undergoing equal $\mathrm{I}_{C}$ degradation.

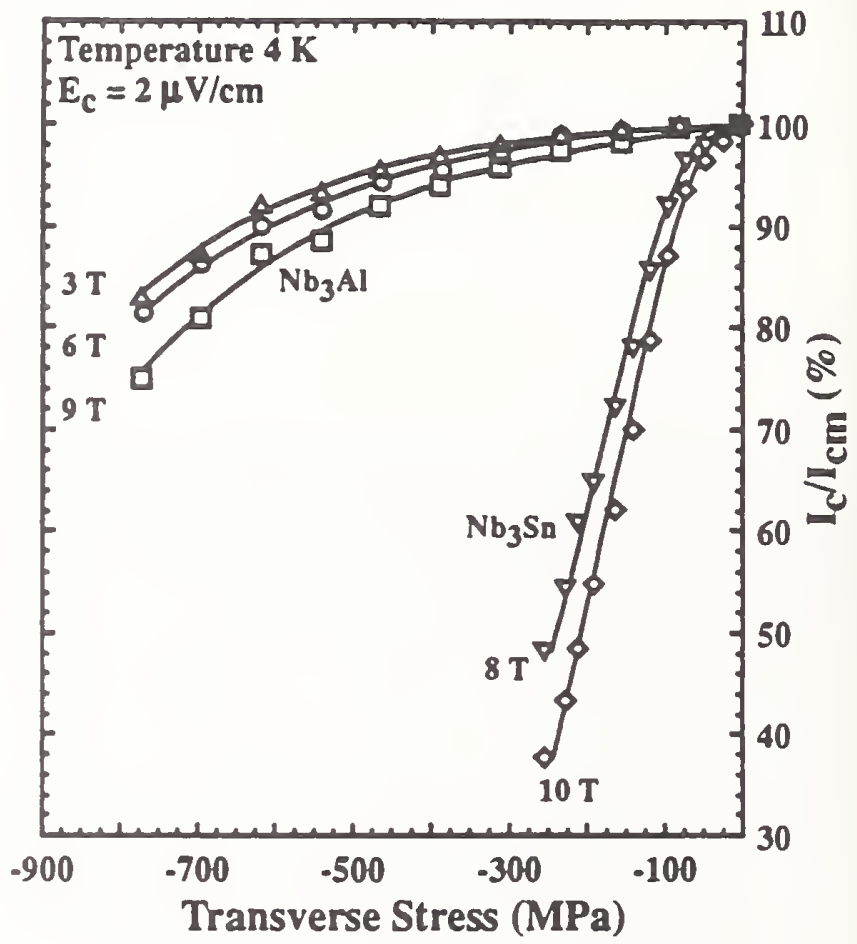

Fig. 2. Critical-current degradation caused by transverse compressive stress.

Previous studies comparing the axial and transverse stress effects in $\mathrm{Nb}_{3} \mathrm{Sn}[3],[5],[6],[7]$ have all shown a much greater sensitivity to transverse stress than axial stress. This type of comparison requires a conversion of the axial strain data, the measured quantity, to axial stress. The relationship between stress and strain (elastic modulus) has previously been measured at cryogenic temperature for $\mathrm{Nb}_{3} \mathrm{Sn}(165 \mathrm{GPa})$ [8] but not for $\mathrm{Nb3} \mathrm{Al}$. Consequently, to allow comparison of axial and transverse stress effects, elastic-modulus measurements of $\mathrm{Nb}_{3} \mathrm{Al}$ at cryogenic temperatures were made.

The $\mathrm{Nb}_{3} \mathrm{Al}$ samples used in the $\mathrm{I}_{\mathrm{C}}$ tests are not well suited for modulus measurements because of their ultra-fine filaments and small superconductor-to-matrix ratio. Consequently, a group of three different large monofilament $\mathrm{Nb}_{3} \mathrm{Al}$ conductors were used for the modulus measurements. These are powder-process wires that vary in $\mathrm{Nb} 3 \mathrm{Al}$ content $(45 \pm 15 \%, 60 \pm 10 \%$, and $81 \pm 2 \% \mathrm{Nb} 3 \mathrm{Al})$. A detailed description of the wires is contained in [9]. All of the samples were $5 \mathrm{~cm}$ long. The results of these measurements are shown in Fig. 3 where the elastic moduli of the three different conductors are plotted as a function of their $\mathrm{Nb}_{3} \mathrm{Al}$ content. Since the sample with the highest $\mathrm{Nb}_{3} \mathrm{Al}$ content is $81 \pm 2 \%$ $\mathrm{Nb}_{3} \mathrm{Al}$, the elastic modulus of pure $\mathrm{Nb} 3 \mathrm{Al}$ was extrapolated from the measured data.

Two samples of the $60 \%-\mathrm{Nb} 3 \mathrm{Al}$ conductor were measured at both $76 \mathrm{~K}$ and $4 \mathrm{~K}$. For both samples, the difference between measurements at $4 \mathrm{~K}$ and $76 \mathrm{~K}$ was less than $5 \%$. 


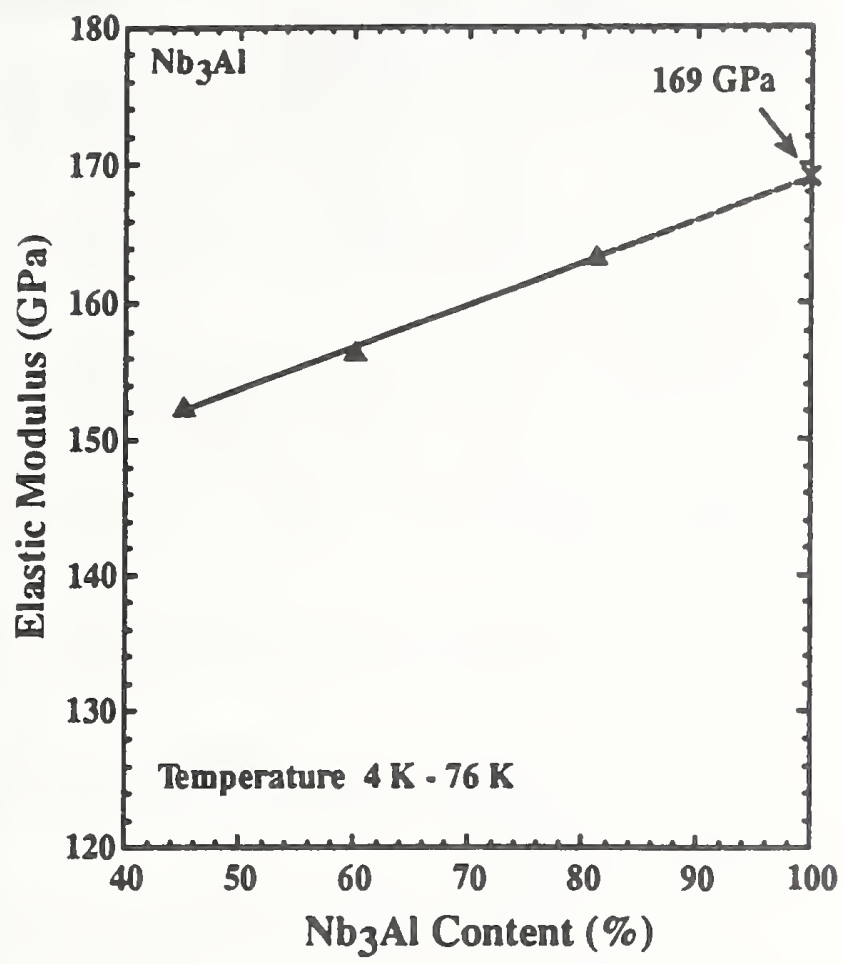

Fig. 3. Elastic modulus of three $\mathrm{Nb} 3 \mathrm{Al}$ wires, each with a different $\mathrm{Nb}_{3} \mathrm{Al}$ content.

Given an overall experimental error of about $5 \%$ for the modulus measurements, the difference in the $4 \mathrm{~K}$ and $76 \mathrm{~K}$ measurements can reasonably be neglected.

Two 45\%-Nb3Al wires were measured, and the average of these measurements is plotted in the figure. The two measurements varied $\pm 1.6 \%$ from the mean. Seven total measurements of four different $60 \%-\mathrm{Nb} 3 \mathrm{Al}$ wires were made with a maximum variation of $\pm 9.2 \%$ from the plotted mean value. For the $81 \%-\mathrm{Nb} 3 \mathrm{Al}$ wire, two measurements were made, and the variation was $\pm 4.0 \%$. The mean values are plotted for each type of conductor in Fig. 3; a linear extrapolation of the data yields an elastic modulus of approximately $169 \pm 20 \mathrm{GPa}$

Using this modulus value, axial stress values were calculated from the axial strain data and plotted in Fig. 4 for comparison with the transverse data. Like $\mathrm{Nb}_{3} \mathrm{Sn}, \mathrm{Nb}_{3} \mathrm{Al}$ is more sensitive to transverse stress than to axial stress; however, the difference in sensitivity is much greater for $\mathrm{Nb}_{3} \mathrm{Sn}$ than for Nb3Al. From Fig. 4, the stress that causes a given amount of $I_{C}$ degradation at $9 \mathrm{~T}$ is almost two times smaller for transverse stress than for axial stress. In contrast, this ratio for $\mathrm{Nb}_{3} \mathrm{~S} \mathrm{n}$ at $10 \mathrm{~T}$ is approximately five [3].

As indicated in Fig. 4, transverse compressive stress is being compared with axial tensile stress. There are two practical reasons for this. First, these are the conditions that actually exist in the windings of an energized magnet, thus these data are useful from an engineering design standpoint for estimating magnet performance. Also, it is difficult to apply axial compressive stress to a superconducting wire. The effect of axial compressive stress has been measured in $\mathrm{Nb}_{3} \mathrm{Sn}$ by taking advantage of the compressive prestrain of the superconductor [4]. The $\mathrm{Nb}_{3} \mathrm{Al}$ samples did not exhibit this prestrain, so the effect of axial compressive stress could not conveniently be measured. However, assuming that $\mathrm{Nb}_{3} \mathrm{Al}$ behaves similarly to $\mathrm{Nb}_{3} \mathrm{Sn}$, in which the effects of tensile and compressive axial stress are approximately equal, the sense of the axial stress does not affect these results.

\section{CONCLUSIONS}

For a given degradation of $\mathrm{I}_{c}$ at $9 \mathrm{~T}, \mathrm{Nb}_{3} \mathrm{Al}$ will tolerate about twice as much axial stress as $\mathrm{Nb}_{3} \mathrm{Sn}$ and about five times the transverse stress. The elastic modulus of $\mathrm{Nb}_{3} \mathrm{Al}$, $169 \pm 20 \mathrm{GPa}$, was measured for the first time at cryogenic temperatures and found comparable to that of $\mathrm{Nb}_{3} \mathrm{Sn}, 165$ $\mathrm{GPa}$. The elastic modulus of $\mathrm{Nb} 3 \mathrm{Al}$ was needed in this study for comparing the axial and transverse stress effects, but, in a more general sense, it will ultimately be important for $\mathrm{No}_{3} \mathrm{Al}$ magnet design.

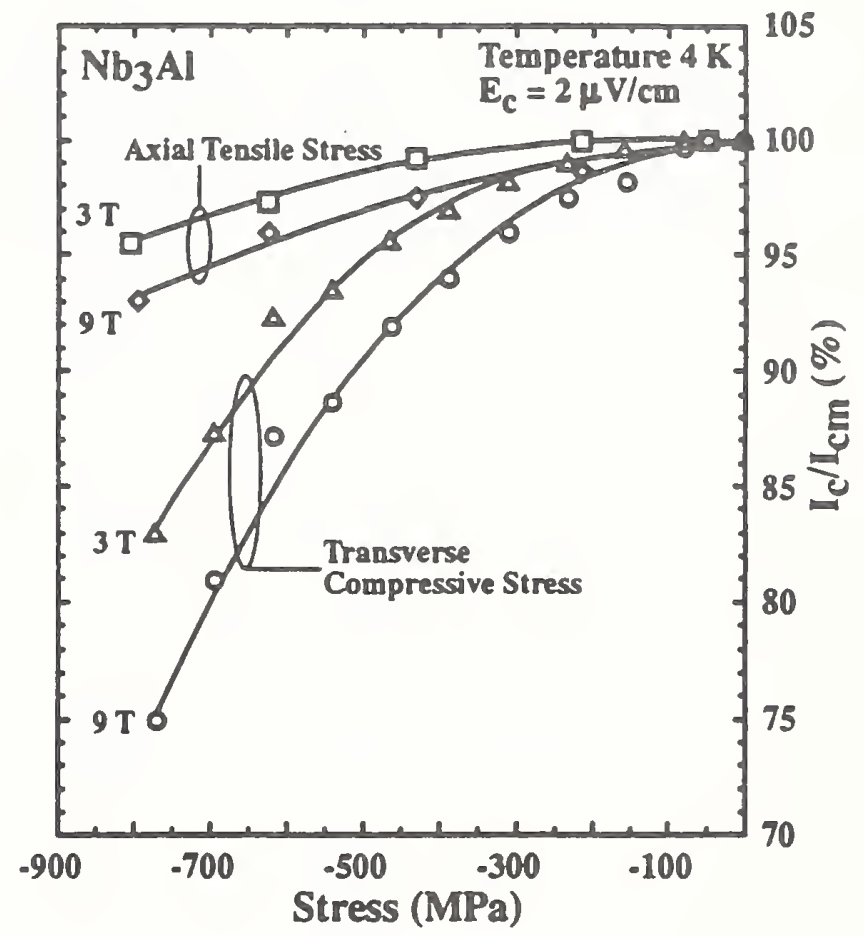

Fig. 4. Comparison between axial and transverse stress effects.

Nb3Al conductors are more sensitive to transverse stress than axial stress. This suggests that the anisotropy in stress degradation, which was first observed in $\mathrm{Nb}_{3} \mathrm{Sn}$ conductors, is not associated with a particular processing method or even a particular material. However, the difference between axial and transverse sensitivity is less for $\mathrm{Nb}_{3} \mathrm{Al}$ than $\mathrm{Nb}_{3} \mathrm{Sn}$. A given level of $\mathrm{I}_{C}$ degradation at $10 \mathrm{~T}$ in $\mathrm{Nb}_{3} \mathrm{Sn}$ requires about five times less transverse stress than axial stress; for $\mathrm{Nb}_{3} \mathrm{Al}$ at $9 \mathrm{~T}$, the ratio is only about two.

There are many factors that determine the suitability of a superconducting material for a particular application. Critical- 
current density, critical magnetic field, cost, available conductor length, and handling properties are important considerations for most applications. For the large high-field magnets needed in fusion applications, stress effects often dictate the design operating limits of the magnet. The present interest in $\mathrm{Nb}_{3} \mathrm{Al}$ superconductors is partially due to its relative insensitivity to stress. Ultimately, if $\mathrm{Nb}_{3} \mathrm{Al}$ conductors can be developed that are otherwise comparable to the existing high-field commercial superconductors, their favorable electromechanical properties may extend the operating limits for future magnet designs.

\section{ACKNOWLEDGMENTS}

The authors wish to give special thanks to C. L. H. Thieme for providing the $\mathrm{Nb}_{3} \mathrm{Al}$ elastic-modulus samples and for valuable discussions, and to S.S. Smith for modulus apparatus design and construction. This work was supported by the Department of Energy, Office of Fusion Energy, under contract No. DE-AI01-84ER52113.

\section{REFERENCES}

[1] J. W. Ekin, "Strain effects in superconducting compounds," Adv. Cryog. Eng., vol. 30, pp. 823-836, 1984.

[2] T. Takeuchi, Y. Iijima, T. Kuroda, M. Yuyama, and K. Inoue, "Effects of additive elements on continuous ultra- fine $\mathrm{Nb}_{3} \mathrm{~A}$ mf superconductor," IEEE Trans. Magn., vol. 25, pp. 2068-2075, Mar. 1989.

[3] J. W. Ekin, "Effect of transverse compressive stress on the critical current and upper critical field of $\mathrm{Nb}_{3} \mathrm{Sn}, " \mathrm{~J}$. Appl. Phys., vol. 62, pp. 4829-4834, Dec. 1987.

[4] J. W. Ekin, "Strain scaling law for flux pinning in practical superconductors. Part 1: Basic relationship and application to $\mathrm{Nb}_{3} \mathrm{Sn}$ conductors," Cryogenics, vol. 20. pp. 611-624, Nov. 1980.

[5] W. Specking, W. Goldacker, and R. Flükiger, "Effect of transverse compression on $\mathrm{I}_{C}$ of $\mathrm{Nb}_{3} \mathrm{Sn}$ multifilamentary wire," Adv. Cryog. Eng., vol. 34, pp. 569-575, 1988.

[6] L. T. Summers and J. R. Miller, "The effect of transverse stress on the critical current of $\mathrm{Nb}_{3} \mathrm{Sn}$ cable-in-conduit superconductors," IEEE Trans. Magn., vol. 25, pp. 18351838, Mar. 1989.

[7] H. Boschman and L. J. M. van de Klundert, "Effects of transverse stress on the current carrying capacity of multifilamentary wires," Adv. Cryog. Eng., vol. 36, pp. 93-100, 1990.

[8] D. S. Easton, D. M. Kroeger, W. Specking, and C. C. Koch, "A prediction of the stress state in $\mathrm{Nb}_{3} \mathrm{Sn}$ superconducting composites," J. Appl. Phys., vol. 51, pp. 2748-2757, May 1980.

[9] C. L. H. Thieme, "The production of Nb3Al superconducting wire by the powder metallurgy process," University of Twente, The Netherlands, Ph.D. dissertation, 1988. 
J. W. Ekin, "Superconductor Specification," Concise Encyclopedia of Magnetic \&

Superconducting Materials, ed by J. E. Evetts, p. 575 (1992).

\section{Superconducting Materials: Specification}

The specification of superconductors is needed both in the purchase of practical superconductors and in the characterization of superconductor materials for research. Parameters such as the critical temperature $T_{c}$ and the upper critical field $H_{c 2}$ are intrinsic to the material and are usually adequately specified just by specifying the material (i.e., by the ratio of elements in the superconducting alloy or compound). Extrinsic parameters that vary with processing technique and conductor design, on the other hand, are much more variable and need to be specified and measured on a conductor-to-conductor basis, especially for the procurement of superconductors for practical applications. (see Multifilamentary Superconducting Composites). Such parameters include the physical shape of the conductor, critical current, matrix resistivity and mechanical properties. In this article, the emphasis will be on practical superconductor materials and, primarily, specification of their extrinsic parameters.

Furthermore, the article concentrates on the specification of single-strand multifilamentary conductors and does not include additional parameters needed for cable specification. The single-strand multifilamentary parameters, however, form the basis for most cond uctor specification and are a key element for the more complex cable conductors.

The extrinsic parameters of single-strand conduc. tors are described here under three general headings:
Table 1

Example of superconductor wire specification

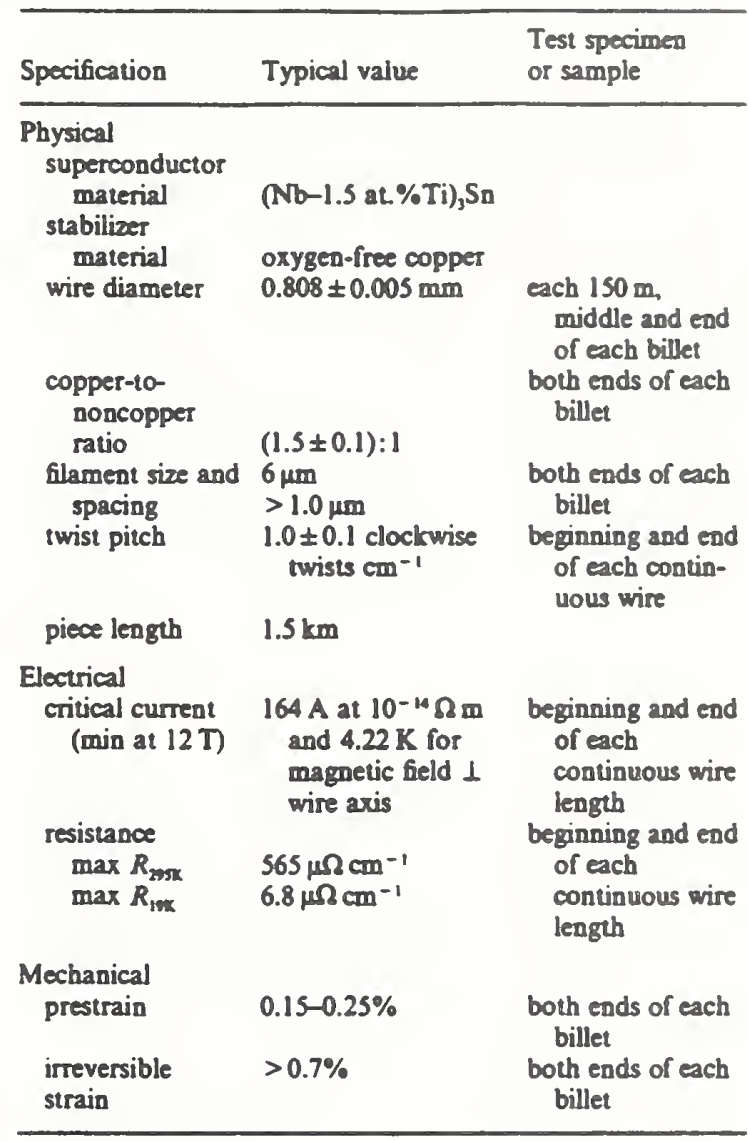

physical, electrical and mechanical specifications. An example of a set of typical superconductor specifications for a $\mathrm{Nb}_{3} \mathrm{Sn}$ superconductor is given in Table 1 .

\section{Physical Specifications}

\subsection{Superconductor Material}

Superconductor material should be specified in order to determine $T_{\mathrm{c}}$ and $H_{\mathrm{c} 2}$. Also, the mechanical properties inherent to the material will need to be considered in application of the material. For example, NbTi superconductors are easy to bandle mechanically, because they are ductile. However, they are commonly used in magnet applications up to a magnetic field of only about $8 \mathrm{~T}$. Nb,Sn superconductors, on the other hand, are commonly used at higher fields up to about $14 \mathrm{~T}$, but, being brittle, they require special handling and special mechanical design for applications.

Furthermore, the specific superconductor composi- 
tion should be prescribed because some compositions are better for obtaining high current density $J_{\mathrm{c}}$ at high magnetic field. while other compositions are better for low fields. For example, in NbTi superconductors. the nominal composition of niobium and titanium should be prescribed along with alloy homogeneity. For $\mathrm{Nb}, \mathrm{Sn}$. the superconductors either can be binary (just niobium and tin) or third (and sometimes fourth) elements. such as titanium or tantalum, can be added in order to increase $J_{c}$ at very high magnetic fields.

\subsection{Stabilizer Material}

The type of material used as a stabilization matrix (see Fig. 1) should be specified in order to ensure adequate electrical and thermal conductivity to protect the conductor against thermal runaway. For example, oxygen-free copper is a common stabilizer material. Specification of the type of stabilizer material ensures that the conductor will be adequate to meet the residual resistivity ratio requirements discussed in Sect. 2.2.

\subsection{Conductor Size}

The cross-sectional dimensions of the conductor should be specified so that they are consistent with the current capability of the power supply and the desired magnet inductance. The tolerance for variation in these dimensions can be critical for some magnet applications. The cross-sectional dimensions are also needed to calculate the critical current density from the critical current, described in Sect. 2.1.

\subsection{Copper-10-Noncopper Ratio}

The copper-to-noncopper ratio specifies the volume of stabilizer material relative to the superconductor

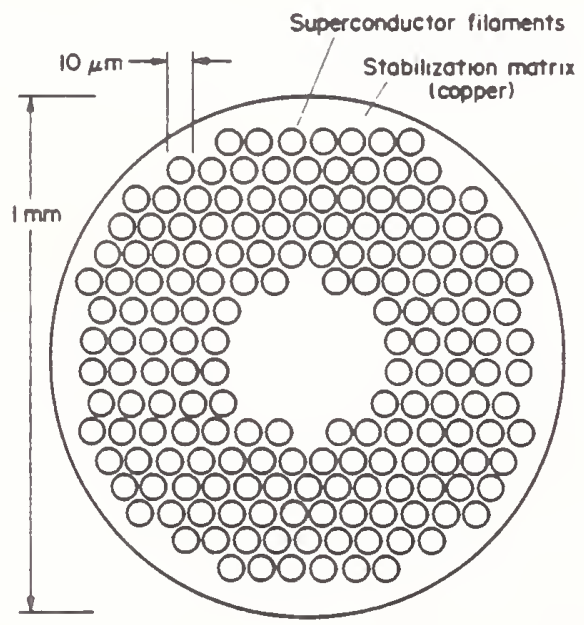

Figure I

Cross-sectional view of a typical NbTi, copper-stabilized superconducting composite (after Ekin 1983b) material. It must not be too low, or the conductor will be unstable and susceptible to thermal runaway. If the ratio is too high, on the other hand. the overall critical current density suffers. Values from 1:1 to $5: 1$ are typical, with the higher ratios needed to ensure stability in large magnets where the stored energy can be very great.

The copper-to-noncopper ratio is usually measured by weighing a sample of the conductor, chemically etching away the copper with a $50 \%$ nitric acid solution, drying the remaining superconducting filaments, and reweighing. The copper mass is obtained from the difference. The copper-to-noncopper ratio is then determined by taking the ratio of the weight of copper to the remains and dividing by the ratio of specific gravities for copper and the noncopper material.

\subsection{Filament Size and Spacing}

The diameter of the superconducting filaments should be specified in order to ensure that hysteretic ac losses in the conductor filaments are reduced to an acceptable level. The smaller the filament size, the lower the losses. Too small a diameter, however, results in filament cross-sectional inhomogeneities and a lowering of the critical current density. A filament diameter of about $5 \mu \mathrm{m}$ is a typical compromise.

The spacing between filaments must also be kept above a minimum value, typically $1 \mu \mathrm{m}$ or more, edge to edge, in order to electrically decouple neighboring filaments. If the filaments couple, low-field ac losses can reach unacceptable levels.

Filament size and spacing are usually determined from a photomicrograph of a polished cross section of the conductor. Several filament diameters and spacings are measured and the results averaged.

Instead of specifying filament diameter and spacing, the maximum acceptable level of ac loss can be stipulated, along with the method by which it should be measured. This is usually preferable because it ensures a minimum performance level. Two methods are in common use: magnetization and calorimetry. The calorimetric method (using a boil-off technique, for example) measures a total ac loss and is therefore usually favored, but it is more difficult than magnetization measurements.

\subsection{Twist Pitch}

The filaments in a practical superconductor are twisted to reduce ac loss heating that would otherwise occur when the conductor is subjected to magnetic fields that change with time (see $A C$ Applications of Superconducting Materials; $A C$ Losses in Superconducting Materials). The rates of change can be particularly large in pulsed magnet applications, but can be significant in dc magnets as well, because of the need to charge and discharge the magnet. The number of twists per unit length, or the twist pitch (the length of one twist), is specified in order to ensure that ac 
losses are reduced to an acceptable level. A twist pitch of about one centimeter is typical for a small ( $1 \mathrm{~mm}$ diameter) conductor.

\section{I.7 Piece Length}

The minimum acceptable length of continuous superconductor is usually specified in order to avoid an excessive number of joints between lengths. Sometimes the minimum length is determined by requirements on the joint location as well. For example, in superconducting electromagnets, the piece length needs to be long enough that the joints between conductors can be made in a low-magnetic-field region.

\section{Electrical Specification}

\section{I Critical Current}

The critical current $I_{\mathrm{g}}$ is perhaps the most important parameter from a practical standpoint. Because the rise in the voltage-current $(V-I)$ characteristic of a superconductor is not infinitely sharp (see Fig. 2), the critical current is arbitrary, unless a criterion is specified to determine the critical current (see Critical Current Density). This is usually done by using an electric field criterion or resistivity criterion. For example, the critical current $I_{\mathrm{c}}$ can be defined as the current at which the electric field $E$ along the conductor reaches a specific value, such as $1 \mu \mathrm{V} \mathrm{cm}^{-1}$. This is shown by the intersection of the $V-I$ curve and the horizontal dashed line in Fig. 2. Alternatively, $I_{c}$ can be defined as the current at which the resistivity of the conductor rises to a specific value, such as $10 \mathrm{p} \Omega \mathrm{cm}$, shown by the dashed line passing through the origin in Fig. 2. When using the resistivity criterion. the cross-sectional area to be used in the determination should be specified. Finally, when the rise in the $V-I$ characteristic is very gradual, much of the arbitrariness and variability is eliminated by using the offset criterion. As shown in Fig. 2, it is determined by taking the tangent to ine $V-I$ curve at a specified electric field.

The critical current density $J_{c}$ is defined as the critical current divided by the cross-sectional area $A$ of the superconductor,

$$
J_{\mathrm{c}} \equiv I_{\mathrm{c}} / \mathrm{A}
$$

Usually the area $A$ is taken as just the cross-sectional area of the conductor minus the cross-sectional area of the copper stabilizer; this is commonly referred to as the noncopper area.

Sometimes the shape of the voltage-current curve is also specified to indicate the quality of the superconductor. A sharp transition is desirable, indicating the rapid disappearance of resistivity below the nominal value of $I_{c}$. A common method for representing the sharpness of the resistive transition is through the use of the $n$ value defined by a simple power law

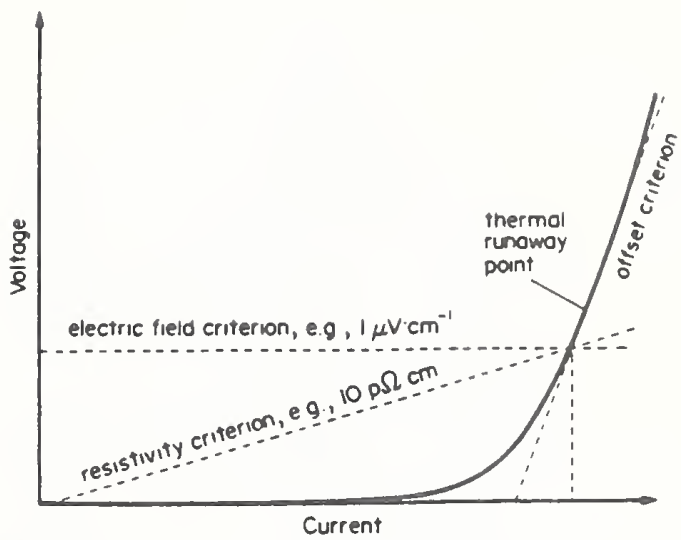

Figure 2

The voltage-current characteristic of a practical superconductor, showing electric-field and resistivity criteria for determining critical current

$$
V \propto I^{n}
$$

or equivalently

$$
E \propto J^{n}
$$

Here $E$ is the electric field along the conductor and $J$ is the current density. Values of the power $n$ are easily determined by plotting the $V-I$ or $E-J$ curves on a log-log plot and determining the slope of the curve at a designated electric field (the curve is typically linear over a considerable range of electric field). Values of $n$ generally lie between 20 and 100 for high-quality superconductors (see Resistive Transition and Flux Flow in Superconducting Malerials). Lower $n$ values usually indicate inhomogeneities in the local critical current density. Other methods of fitting the shape of the $V-I$ curve are also used, usually involving more fitting parameters. However, this empirical formula is simple, involves only a single fitting parameter (other than a proportionality constant) and, consequently, is easy to use.

The critical current is also strongly dependent on the magnetic field magnitude (see Fig. 3) and direction. Typically, $I_{\mathrm{c}}$ values are prescribed at one or more magnetic fields, usually for the magnetic field applied perpendicular to the wire axis. This perpendicular orientation for the magnetic field usually corresponds to the worst case (lowest $I_{\mathrm{c}}$ ), but is the most common orientation in superconductor magnet applications.

The critical current is also strongly dependent on temperature (see Fig. 3). Usually the temperature at which liquid helium boils at atmospheric pressure is used, that is, $4.2 \mathrm{~K}$. If the critical current measurement cannot be carried out at precisely $4.2 \mathrm{~K}$, small temperature corrections can be made to the measured $I_{\mathrm{c}}$ values using the "linear temperature" formula 


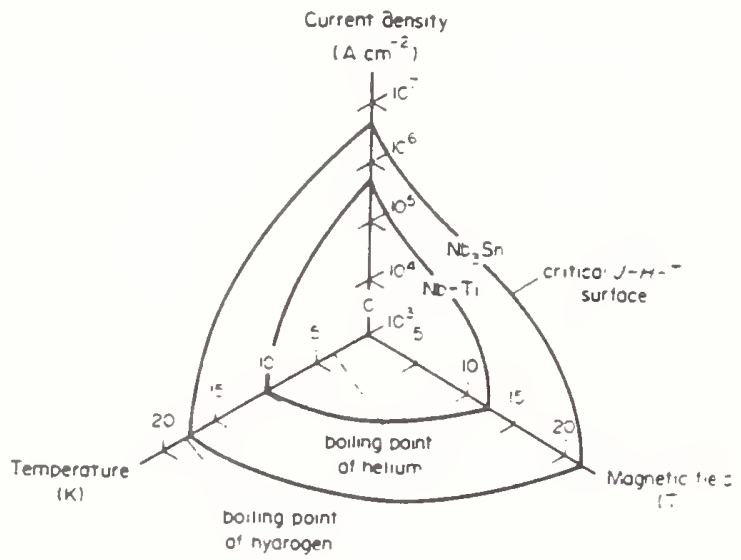

Figure 3

Interrelation of critical current density, magnetic field and temperature for $\mathrm{Nb}, \mathrm{Sn}$ and $\mathrm{NbTi}$ (courtesy of $\mathrm{W}$. A. Fie(z). In the region between the origin and the critical $J-B-T$ surface the material is superconducting; beyond this critical surface the material is in the normal state

$$
I_{\mathrm{c}} / I_{\mathrm{m}}=\left(T_{\mathrm{c}}-T\right) /\left(T_{\mathrm{c}}-T_{\mathrm{m}}\right)
$$

where $T_{\mathrm{c}}$ is the transition temperature at the specified magnetic field, $I_{\mathrm{m}}$ is the current measured at temperature $T_{m}$ and $I_{\mathrm{c}}$ is the critical current at the specified temperature $T$.

Usually, the critical current is measured on samples taken from each continuous length of conductor. For testing, these samples are wound typically onto a cylindrical sample holder, such as shown in Fig. 4, and a four-terminal transport $I_{c}$ measurement is carried out in accordance with a specific measurement procedure such as American Society for Testing and Materials (ASTM) Standard Test Method B714-82. A minimum length of sample for the critical current measurement should be prescribed, since inhomogeneities along the conductor have a greater effect on $I_{\text {c }}$ over longer conductor lengths. A $25 \mathrm{~cm}$ length of sample between the voltage taps in Fig. 4 would be a typical test length. Long test lengths also allow a more sensitive measurement of low electric fields along the conductor, which permits a sensitive critical current criterion to be used.

\subsection{Resistance at Room Temperature and $T_{c}$}

The conductor resistance at room temperature $\left(R_{295 \mathrm{X}}\right)$ is determined mainly by the amount of copper matrix. Thus, it can be used to provide an independent measure of the volume of copper to superconductor. The conductor resistance just above the superconducting transition temperature $R_{T_{c}}$ is mainly determined by the purity of the matrix material. Thus, the resistance just above $T_{\mathrm{c}}$ is important because it gives a measure of the ability of the matrix to stabilize and protect the conductor from thermal runaway, should a disturbance raise a portion of the superconductor above $T_{\mathrm{c}}$. Typically the ratio, $R_{295 \mathrm{~K}} / R_{T_{\mathrm{c}}}$, called the residual resistance ratio (RRR), is specified. The higher the RRR value, the greater the purity of the copper matrix material and the better the stabilization of the conductor. Values of RRR of about 70 or more are typically achieved using oxygen-free copper.

Room-temperature resistance is usually measured using a four-terminal resistance measurement technique, similar to the critical current measurement, except that the $V-I$ curve is linear and the measuring current is kept small to avoid sample heating. Temperature control for measuring $R_{T_{\mathrm{c}}}$ just above $T_{\mathrm{c}}$ can be achieved fairly easily by lowering the sample into a liquid helium bath and then raising it above the liquid helium a couple of centimeters and recording the resistance as the temperature rises through $T_{c}$. The superconductor is thus used as a fixed-point thermometer: as the temperature of the conductor increases, the resistance rises rapidly at $T_{c}$, then becomes constant just above $T_{c}$. This region of relatively constant resistance on warming is taken to be $R_{T_{\mathrm{c}}}$. The RRR is then just the quotient $R_{29 s \mathrm{k}} / R_{T_{\mathrm{c}}}$ of these two measured resistances.

\section{Mechanical Parameters}

For compound superconductors, such as $\mathrm{Nb}_{3} \mathrm{Sn}$, $\mathrm{V}_{3} \mathrm{Ga}$ or $\mathrm{Nb}_{3} \mathrm{Al}$, several mechanical parameters need to be specified because of the sensitivity of the critical current of these materials to strain.

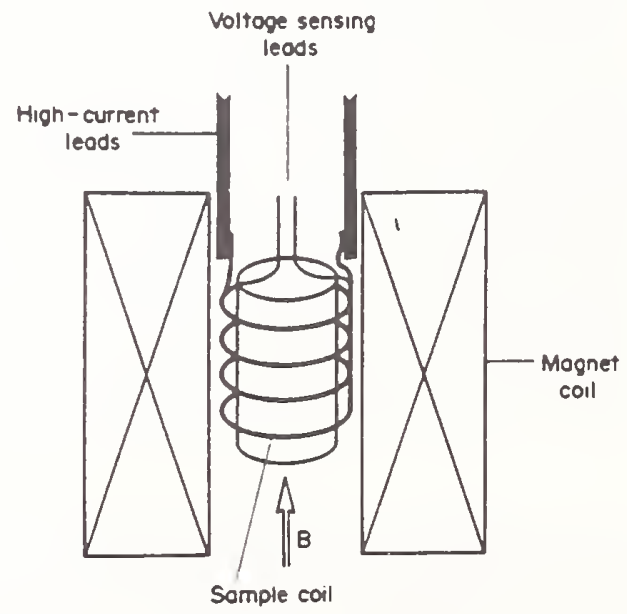

Figure 4

A typical cylindrical sample bolder for measuring the critical current of a spirally wrapped superconducting wire sample (adapted from Goodrich and Fickett 1982). The sample holder assembly is placed inside the bore of a solenoid magnet that provides a background field along the axis of the holder (perpendicular to the sample). In this way, a long superconducting sample can be tested in the confined space of a high-field background magnet 


\section{I Prestrain}

The different materials that make up a composite superconductor (stabilizer matrix, tin-bronze matrix for $\mathrm{Nb}, \mathrm{Sn}$ conductors, superconducting material and diffusion barriers) all thermally contract by different amounts as the conductor is cooled from its fabrication temperature (typically $700^{\circ} \mathrm{C}$ ). This places the superconducting material under an initial prestrain $\varepsilon_{\mathrm{m}}$, usually compressive, which arises from differential thermal contraction of the various materials making up the conductor.

The value of the prestrain $\varepsilon_{\mathrm{m}}$ is also needed to compare critical currents in different samples equally. Either compressive or tensile strain $\varepsilon$ degrades the superconductor; thus, because of the inital compressive prestrain, the critical current will start at a degraded value (see Fig. 5), then pass through a maximum at zero "intrinsic" strain where the applied tensile strain removes all the precompression and the superconducting material itself is in a relatively strainfree state, and then again decrease when the intrinsic strain within the superconducting material becomes tensile. This results in the peaked curves shown in Fig. 5. The value of the prestrain can be determined by applying tension to a conductor and measuring the strain where the critical current passes through a maximum. Critical currents should be compared at the peak, or at comparable intrinsic strain relative to the peak, for the purpose of selecting conductors.

Because of the effect of strain on the critical current, the compressive prestrain $\varepsilon_{\mathrm{m}}$ from differential thermal contraction should be specified in order to set strain limits in designing magnets and specifying reinforcing structures for magnets. Ideally, the superconductor should operate just on the compressive side of maximum (about $0.1-0.2 \%$ intrinsic compressive strain) when the conductor is under full operating load. In such a case $J_{c}$ is near maximum, but there is still a sufficient margin for additional strain.

\subsection{Irreversible Strain}

Irreversible strain specines the strain beyond which the conductor is permanently damaged and $J_{c}$ is irreversibly degraded. The importance of this parameter is that it sets a strain-handling limit in bending and spooling a conductor during magnet fabrication. It also defines the ultimate practical strain the conductor can tolerate in the mechanical design of the conductor support structure.

The irreversible strain is determined by measuring the critical current of a conductor as a function of tensile strain and periodically unloading the conductor to determine if the $J_{c}$ vs $\varepsilon$ curve retraces itself, that is. to see whether it is reversible. For example, in Fig. 6. the critical current on unloading from strain point $A$ was measured to be at the + marked $A^{\prime}$, right on the original curve. The same was true after unloading from strain point B; that is, the critical current was reversible. However, after unloading from strain

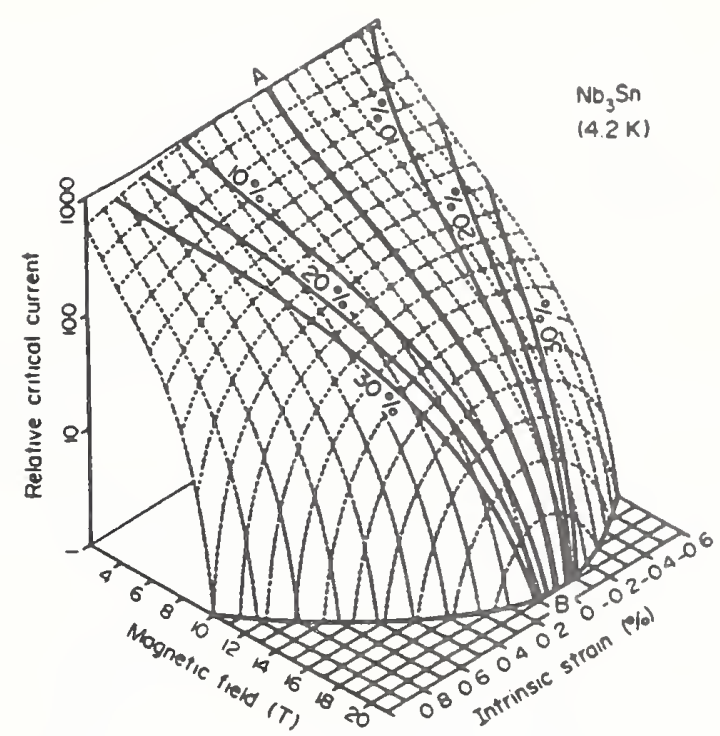

Figure 5

$J-B-\varepsilon$ critical surface for $\mathrm{Nb}, \mathrm{Sn}$ showing the reversible degradation of critical current at either tensile or compressive strain as a function of magnetic field (after Ekin 1983a). Line A-B represents the maximum (strain-free) value of the critical current as a function of magnetic field. Corresponding pairs of curves on either side of line A-B show the strain window for mechanical design which will result in a critical current within the indicated percentage of maximum

point $C$, the critical current was irreversible as shown by point $C^{\prime}$. which falls below the original $I_{c}$ vs strain curve. Thus, the reversibility of the $I_{c}$ vs $\varepsilon$ curve is lost and permanent damage occurs to the superconducting material when the conductor is strained beyond point $\mathbf{B}$, which is defined as the irreversible strain limit.

\section{Future Specification Needs}

Future needs for specification parameters will change with both applications and materials. For example, in new applications, superconductor magnets that use very rapidly changing ac currents will impose severe ac-loss requirements on the conductor. This problem is overcome by using very-small-diameter filaments and a short twist pitch (see AC Applications of Superconducting Materials). However, the very small filament diameter may well require a filament uniformity specification to avoid a lowering of the critical current from localized necking of the filament. Alternatively, the critical current may have to be specified at a very low criterion level to discriminate against the low voltages associated with such filament nonuniformity.

In the materials area, the advent of high- $T_{c}$ super- 


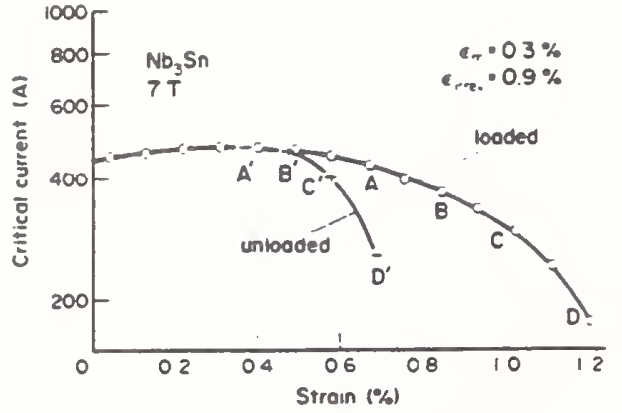

Figure 6

Illustration of the irreversible strain limit (after Ekin 1981). Corresponding loaded and unloaded data points are labelled by letters (A, B, C, etc.). The irreversible strain limit $\varepsilon_{\mathrm{um}}$ occurs just beyond point $\mathrm{B}$, after the conductor has been loaded to about $0.9 \%$

conductors brings with it a new set of specifications. Mechanical parameters will become particularly important in these brittle ceramic materials. Also, the very low critical current densities of some bulk high$T_{\text {c }}$ conductors and the gradual rise of the $V-l$ characteristic (see Fig. 2) make the specification of a critical current somewhat arbitrary with conventional criteria. More universal critical current criteria such as the offset criterion are being used to meet this need.

See also: Measurements in Superconducting Materials; Multiflamentary Superconducting Composites; Resistive Transition and Flux Flow in Superconducting Materials; Superconducting Magnets

\section{Bibliography}

Annual Book of ASTM Standards 1982a Standard definitions of terms relating to superconductors. ASTM B71382. American Society for Testing and Materials, Philadelphia, PA

Annual Book of ASTM Standards 1982b Standard test method for dc critical current of composite superconductors, ASTM B714-82. American Society for Testing and Materials, Philadelphia, PA

Clark A F, Ekin J W 1977 Defining critical current. IEEE Trans. Magn. 13: 38-40

Ekin J W 1981 Mechanical properties and strain effects in superconductors. In: Foner S, Schwartz B (eds.) 1981 Superconducting Materials Science: Metallurgy, Fabricarion and Applications. Plenum, New York, pp. 455-510

Ekin J W 1983a Four dimensional $J-B-T-\varepsilon$ critical surface for superconductors. J. Appl. Phys. 54: 303-6

Ekin J W 1983b Superconductors. In: Reed R P. Clark A F (ed.) 1983 Materials at Low Temperatures. American Society for Metals, Metals Park, OH. pp. 465-513

Ekin J W 1987 Irregularity in Nb-Ti filament area and electric field vs current characteristics. Cryogenics 27: $603-7$

Ekin J W 1989 Offset criterion for determining superconductor critical current. Appl. Phys. Lell. 55: 905-7
Goodrich L F. Bray S L 1990 High- $T_{\text {s }}$ superconductors and critical current measurement. Cryogenics 30: 667-7

Goodrich L F, Fickett F R 1982 Critical current measurements: a compendium of experimental results. Cryogenics 22: $225-41$

Larbalestier D C. West A W. Starch W'. Warnes W. Lee P. McDonald W K. Olarey P, Hemachalam K. Zeitlin B. Scanlan R 1985 High critical current densities in industrial scale composites made from high homogeneity $\mathrm{Nb}$ 46.5 Ti. IEEE Trans. Magn. 21: 269-72

Plummer C J G. Evetts J E 1987 Dependence of the resistive transition on composite inhomogeneity in multifilamentary wires. IEEE Trans. Magn. 23: 1179-82.

J. W. Ekin

[National Institute of Standards and Technology, Boulder, Colorado, USA] 


\section{THE DEVELOPMENT OF AN INTERNAL-TIN NB3SN STRAND FOR FUSION APPLICATIONS}

\section{E. GREGORY 1 , J.W EKIN² G. GRUNBLATT 3 , H.G. KY 3 , G.M. OZERYANSKY 1 AND B.A. ZEITLIN1}

IIGC / Advanced Superconductors, 1875 Thomaston Avenue, Watcrbury, CT 06704, U.S.A.

2Electromagnetic Technology Division, National Institutc of Standards and Technology, Boulder, CO 80303, U.S.A.

${ }^{3}$ Alsthom Intermagnetics (AISA), 3 avenuc des trois Chēnes, 90018 Belfon, France

A high $\mathrm{J}_{c}$ internal-tin $\mathrm{Nb}_{3} \mathrm{Sn}$ strand with relativcly low losscs has been developed for fusion applications. This paper will present the results obtained on this surand as fabricated and supplied for the European fusion program. More than $10 \mathrm{~km}$ of chrome plated strand has been supplied in a variety of configurations and with different barriers. The test results on some of these strands, after they have been given different heat treatment cycles, are reported. The manner in which fabrication problems have been overcome are explained and methods to improve reliability and reproducibility of properties along the length of these strands, are also described. It las been shown that applying hot isostatic pressure (HIP) to the wire at the intermediate homogenization temperature of $580^{\circ} \mathrm{C}$ doubles the intrinsic irteverible strain.

\section{INTRODUCTION}

There is a need, in the fusion field for a reliable, economical material which will exhibit high current densities and low losses in the $121015 \mathrm{~T}$ field region.

$\mathrm{Nb}_{3} \mathrm{Sn}$ is one of the very few matcrial options available for these applications and, while the material has been obtainable for thirty years (ref. 1), its wide application for large magnets has becn rclatively limitcd. The reasons for this arc many and varied. They involve the strand, the total conductor, the insulation, the magnet design and its fabrication.

$\mathrm{Nb}_{3} \mathrm{Sn}$ is a less forgiving material than $\mathrm{NbTi}$ and therefore the intcrrclationships of all these factors is of greatcr importance if we are to cnsure the reliable perlormance of magnets in the size and ficld range required for fusion. In this paper, however, we will concern ourselves only with the optimization of the strand in such a way as to achieve high $\mathrm{J}_{\mathrm{c}}$. low losses and good mechanical and electrical reliability of the composites. It has been known, for some time, that internal-tin matcrial can provide high $J_{c}{ }^{\text {'s }}$ (ref. 2) and in recent years, we have bcen exploring various methods of increasing piccc length, reducing losscs and improving casc of fabrication and reliability of performance (ref. 3.5).

Some strands supplied earlier for the NET program, and the properties which they exhibited, are reponted upon. Arcas in which work is being carried out to improve these products are also described.

\section{SAMPLE MATERIAL SUPPLIED TO NET}

Over a year ago some trial samples of 7 and 19 subelement internal-tin materials were supplied to NET for evaluation. Cross sections of the materials which contain filaments of Nb 7.5 w1.\% Ta, are shown in Figures $1 \& 2$. The properties were close 10 those required $10 \mathrm{meet}$ the NET spccification.

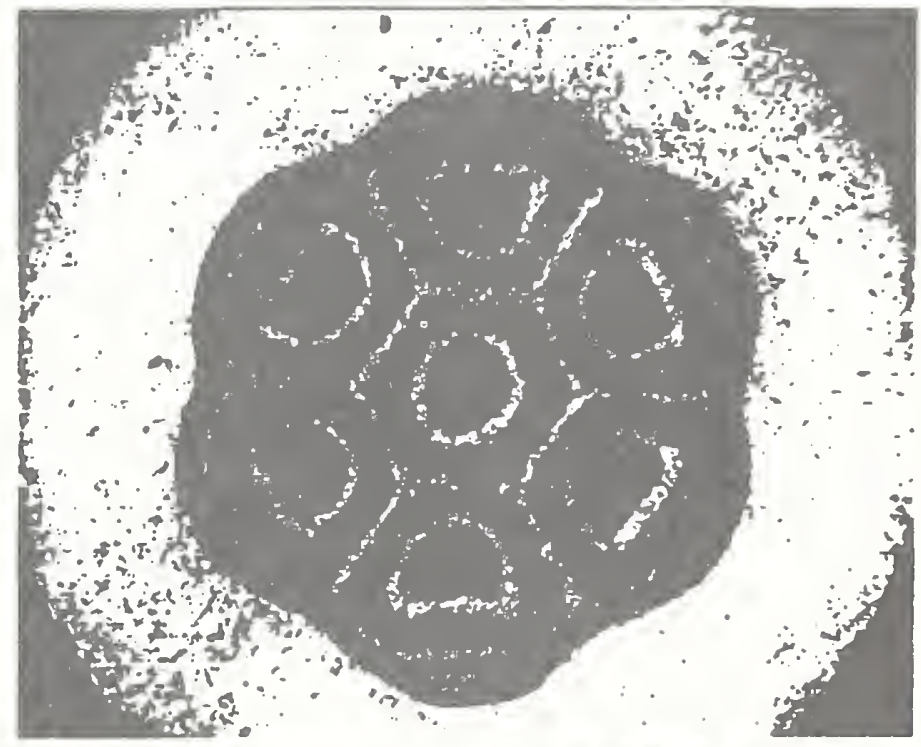

Figure 1. Seven subclement maicrial

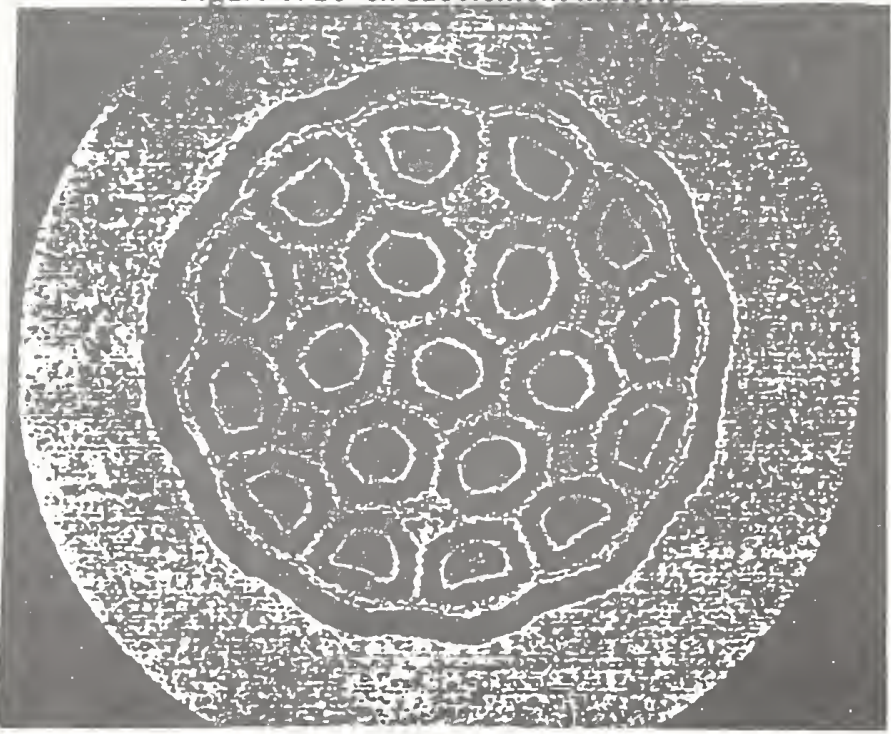

Figure 2. Nineteen subclement material 
The strand diamcier was $0.73 \mathrm{~mm}$, the $\mathrm{Cu}$ to non $\mathrm{Cu}$ ratio was $1.5: 1$ and the strand iwist pitch Iength was icss than $10 \mathrm{~mm}$. The heat treatment used on both matcrials to provide homogenization was $200^{\circ} \mathrm{C} 96 \mathrm{~h}+375^{\circ} \mathrm{C} 24 \mathrm{~h}+580^{\circ} \mathrm{C} 48 \mathrm{~h}$. This was followed by a $700^{\circ} \mathrm{C}$ reaction heat useatment which was for $180 \mathrm{~h}$ in the case of the 7 subclement matcrial and $96 \mathrm{~h}$ for the 19 subelement array.

\section{TESTS PERFORMED}

The material was tested for $I_{c}$ at the University' of Twente and four samples were measured for cach design. The hysteresis loss specimens were prepared at ECN and tested at the Rutherford Laboratory. The RRR measurements were made between room temperature and $20 \mathrm{~K}$ and measured at the Rutherford Laboratory and the University' of Tu'cnte. The reported results were obiained from 5 specimens of cach type. The results of these tests are show'n in Table !

\section{RESULTS}

Since the acceptance requirement for NET was $J_{c}>635 \pm 5$ $\mathrm{A} / \mathrm{mm}^{2}$ at $12.5 \mathrm{~T}, 4.2 \mathrm{~K}$ and $0.1 \mu \mathrm{V} / \mathrm{cm}$, ncither group of samples fully meets the $J_{c}$ specification. The 7 subelement material, while it has an average $J_{c}$ that is higher than the specification shows a wide variation from sample to sample and a low " $n$ " value. The 19 subelement material is more consistent in $\mathrm{J}_{c}$ and shows higher " $n$ " values but it needs to be optimized further to meet the $J_{c}$ specification. The hysteresis losses are lower than the spccification but the results on the 19 subclement material indicate that the smaller filaments lead to morc bridging.

Measurements on the healt treated non Cr-plated specimens show good results while those on matcrials which have been heat treated after plating, are poor, particularly in the case of the 7 subelement material that w'as heated for i longer time at $700^{\circ} \mathrm{C}$. It appears that the problem is not a result of barrier breakdown but one related to diffusion of the $\mathrm{Cr}$ (or more likely impurities in the $\mathrm{Cr}$ ) into the $\mathrm{Cu}$.

\section{RECENT WORK}

\subsection{Current density and variability of $\mathrm{J}_{\mathrm{c}}$}

Since the 7 subclement material shows low " $n$ " values and a considerable variability in propertics, it was decided to concentrate, in our present and future work, on the 19 subclement material that has performed well in the past when it conlained an extruded $\mathrm{Nb}$ barrier (ref. 6.7). Al the lime when the specimens described above were prepared, extruded barricr matcrial was not available and a wrapped barrier technique was employed. When this assembly method is used for 19 subclement arrays, it is necessary to incorporate an internal copper tube below the barrier to ensure that a uniform array can be established. This results in a ring of bronze betwcen the filament array and the barricr and this reduces the $J_{c}$ by over 20 q (rcf. 6).

Since this time we have devcloped a new facility for barricr extrusion and Figure 3 shows a 19 subclement material with material with an extruded tantalum barrier and no "under barrier" copper. This matcrial we expect to yicld a $\mathrm{J}_{c}$ well within the NET specification.

Although in Table 1. the 19 subelement material shows less variability in $\mathrm{J}_{\mathrm{c}}$ than the 7 subelement material, it still show's a dispersion of $\pm 4.5 \%$.

\subsection{HIP Experiments}

In order to improve the uniformity of properties, hot isostatic pressure (HIP) experiments have been carried out on these wires, both at the final heat treatment temperature of $700^{\circ} \mathrm{C}$ and also at $580^{\circ} \mathrm{C}$ (ref. 5). The idea of HIP'ing the

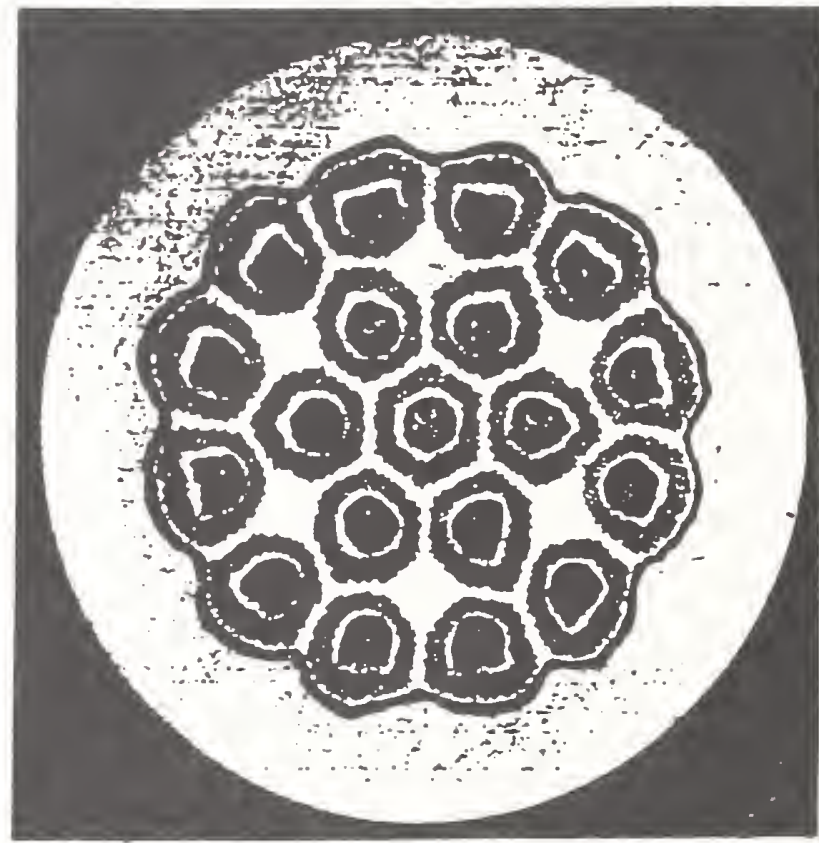

Figure 3. 19 subelement with an extruded Ta barrier

TA BLE, I

MEASURED PROPERTIES OF NET SAMPLES

\section{PROPERTIES}

Heat treatment

$\mathrm{J}_{\mathrm{c}}(0.1 \mu \mathrm{V} / \mathrm{cm}, 12.5 \mathrm{~T} 4.2 \mathrm{~K})$

635

$\mathrm{n}>20$

Hysicresis Losses $\pm 3 \mathrm{~T} \mathrm{mJ/cc}<850$

RRR (barc)

(Cr plated)

$>100$
SPECIFICATIONS

7 SUBELEMENTS

$180 \mathrm{~h}$ at $700^{\circ} \mathrm{C}$

$627,716,663,615$.

Mcan 655.5. Dispcrsion $\pm 7.7 \%$

$\mathrm{n}=17$

533

207 Rutherford, 219 Twente

33.8 Rutherford. 34.4 Twente

\section{SUBELEMENTS}

$96 \mathrm{~h} 700^{\circ} \mathrm{C}$

$561,609,609,615$.

Mcan 598.8, Dispersion $\pm 4.5 \%$

$\mathrm{n}=25$

682

309 Rutherford, 290 Twente 78.3 Rutherford, 81.5 Twente 
TABLE, 2.

COMIPARISON OF JC IN HIP'D AND UNHIP'D MATERIAL

$\begin{array}{ccc}\text { Ficld } & \begin{array}{c}\mathrm{J}_{C}\left(\mathrm{~A} / \mathrm{nm}^{2}\right) \\ \text { (Non 1HIP'd) } \\ \text { Samplc I }\end{array} & \begin{array}{c}\mathrm{J}_{C}\left(\mathrm{~A} / \mathrm{mmi}^{2}\right) \\ \text { Non HIP'd) } \\ \text { Sample 2 }\end{array} \\ 9 & 1101.8 & 1101.8 \\ 10 & 916.2 & 916.2 \\ 11 & 749.0 & 766.5 \\ 12 & 622.8 & 622.8 \\ 13 & 507.8 & 515.0 \\ 14 & 401.2 & 407.2 \\ 15 & 316.2 & 318.6 \\ 16 & 239.5 & 241.9 \\ 17 & 174.3 & 178.4 \\ 18 & 121 & 122.8 \\ 19 & 76.2 & 79.5 \\ 20 & 46.0 & 48.4\end{array}$

$\begin{array}{cc}\mathrm{J}_{\mathrm{C}}\left(\mathrm{A} / \mathrm{mm}^{2}\right) & \mathrm{J}_{\mathrm{c}}\left(\mathrm{A} / \mathrm{Inm}^{2}\right) \\ \text { (HIPd) } & (\mathrm{IIIP} d) \\ \text { Samplc } 1 & \text { Samplc 2 }\end{array}$

808.4

658.7

$419.2 \quad 438.3$

$299.4 \quad 330.5$

$215.6 \quad 227.5$

$149.7 \quad 155.7$

$101.8 \quad 103.6$

$\begin{array}{ll}64.7 & 64.7\end{array}$

$35.9-37.1$

matcrial at $580^{\circ} \mathrm{C}$ was to fully hoinogenize the bronze and then densify it complctely before significant $\mathrm{Nb}_{3} \mathrm{Sn}$ formation takes place The subsequent final heat ucatment at $700^{\circ} \mathrm{C}$ does not lead to the redevelopment of large areas of porosity. Thus the propertics can be expected to be more uniform after HIP'ing. In Table 11 and Figure 4 a comparison is made of the 19 subelement matcrial HIP'd and unHIP'd. This work which was reponed some time ago (ref. 5), was performed at the Francis Bitter National Magnet Laboratory of the Massachusetts Institutc of Technology (MIT) by Dr. M. Sucnaga of the Bronkhaven National Laboratory (BNL). Whilc the data were limited, there appeared to be an additional residual effect of HIIP'ing that, at high ficlds, overrides the inproved $\mathrm{J}_{\mathrm{c}}$ noted at ficlds bclow $15 \mathrm{~T}$.

\subsection{Je is axial strain}

In order to scek an explanation for this, we compared $J_{c}$ vs suain for HIP'd and unHIP'd NET subclement material, shown in Figures 5 \& 6 . Unforiunatcly comparisons of the $12 \mathrm{~T}$ data arc the only ones that can be made from these figures. While the zcro strain Jc's are only slightly different, the most interesting result of the NIST tests is the apparent cnhancement of the irreversible strain $\varepsilon$ inev as a rcsult of HIP'ing at the intermediate tempcrature of $580^{\circ} \mathrm{C}$. The irreversible strain limit for permanent dimage was increased from $0.9 \%$ in the unHIP'd material $101.4 \%$ in the matcrial that was HIP'd at $580^{\circ} \mathrm{C}$. This corresponds 10 an enhancement of the intrinsic irreversible strain $\left(\equiv \varepsilon_{\mathrm{irrev}}-\varepsilon_{\mathrm{m}}\right)$ increase from $0.6 \%$ to over $1.1 \%$ - essentially a cloubling. A similar effect was found by Ekin some ycars ago on Japancse malerial, HIP'd aficr the final heal treatment (ref. 8)

The " $n$ " vilues slowed that at 12 T. HIP'd mallcrial had a valuc of 22 as compared with 17 in the unHIP'd matcrial.

The aim would be to HIP the cabled material after the bronze has been homogenized and before the cable is introduced into the conduit. The chrome plating would prevent sintering and, if the amount of $\mathrm{Nb}_{3} \mathrm{Sn}$ reaction is small, the britllencis of the high tin bronze may not causc damage that cannot be licaled during final reaction heat treatnent. Experiments are underway to determine if such a treatment can be performed

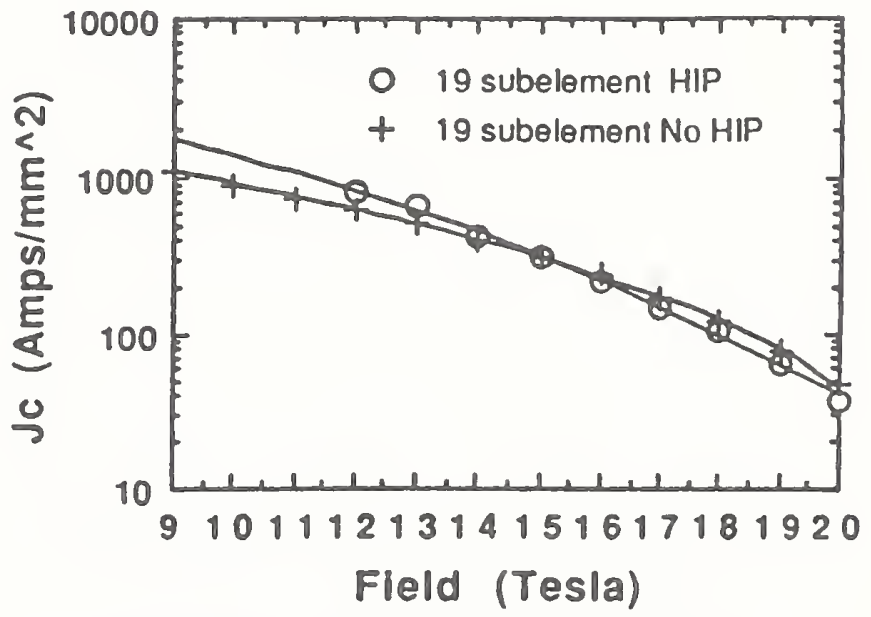

Figure 4. Comparison of $\mathrm{J}_{c}$ in HIP'd and unHIP'd 19 subelement material.

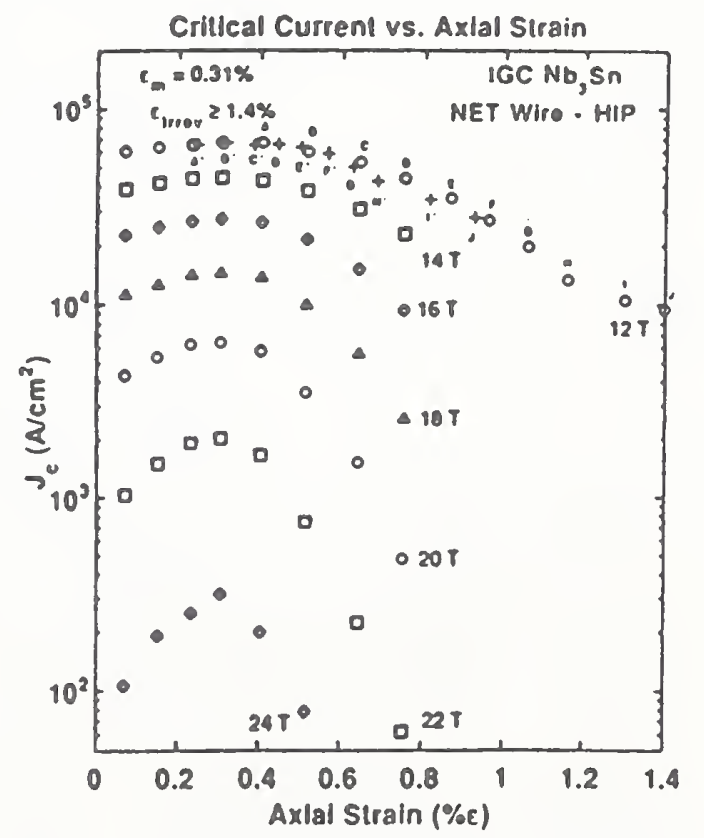

Figure 5. $J_{c}$ vs. axial strain for HIP'd 19 subclement wire. $\varepsilon_{\text {irrev }}$ is the irreversible strain and $\varepsilon_{m}$ is the strain where $\mathrm{J}_{c}$ is a maximum. 


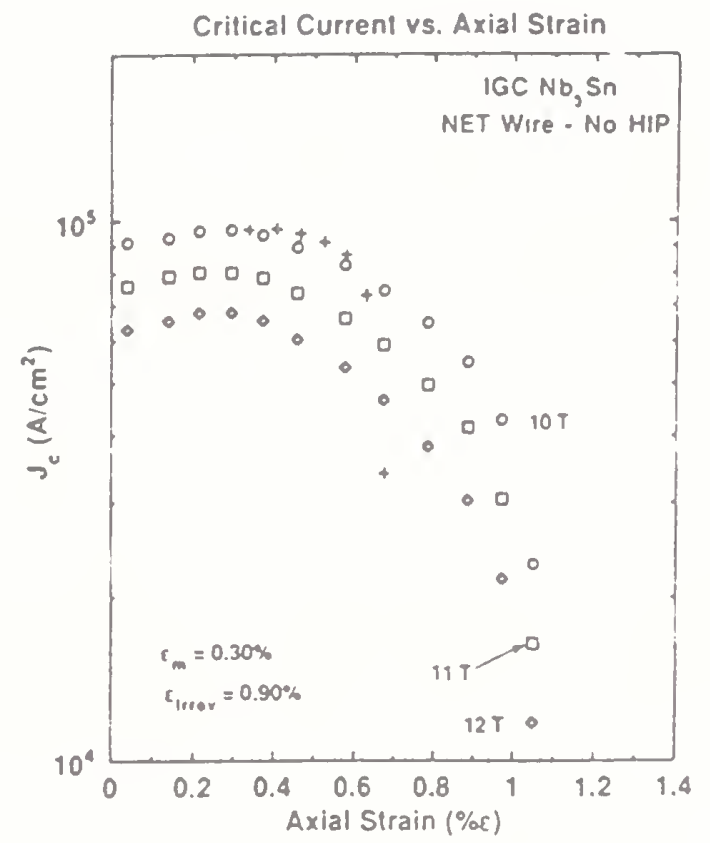

Figure 6. Jc vs. Axial Strain for unHIP'd 19 subclement wirc.

practically. When the cable is in the homogenized condition rather than the reacied onc, it should be much casicr to handle without causing permanent damage.

The extent to which HIP'ing increases the ac losses is also being investigated. Significanlly more bridging $\alpha$ curs in the HIP'd material than in the unHIP'd matcrial as can be secn in Figures $7 \& 8$. Tentative results of squid magnetometer work on HIP'd and un-HIP'd malcrial is show'n in Figure 9. The work was carried out al BNL by Dr. M. Sucnaga

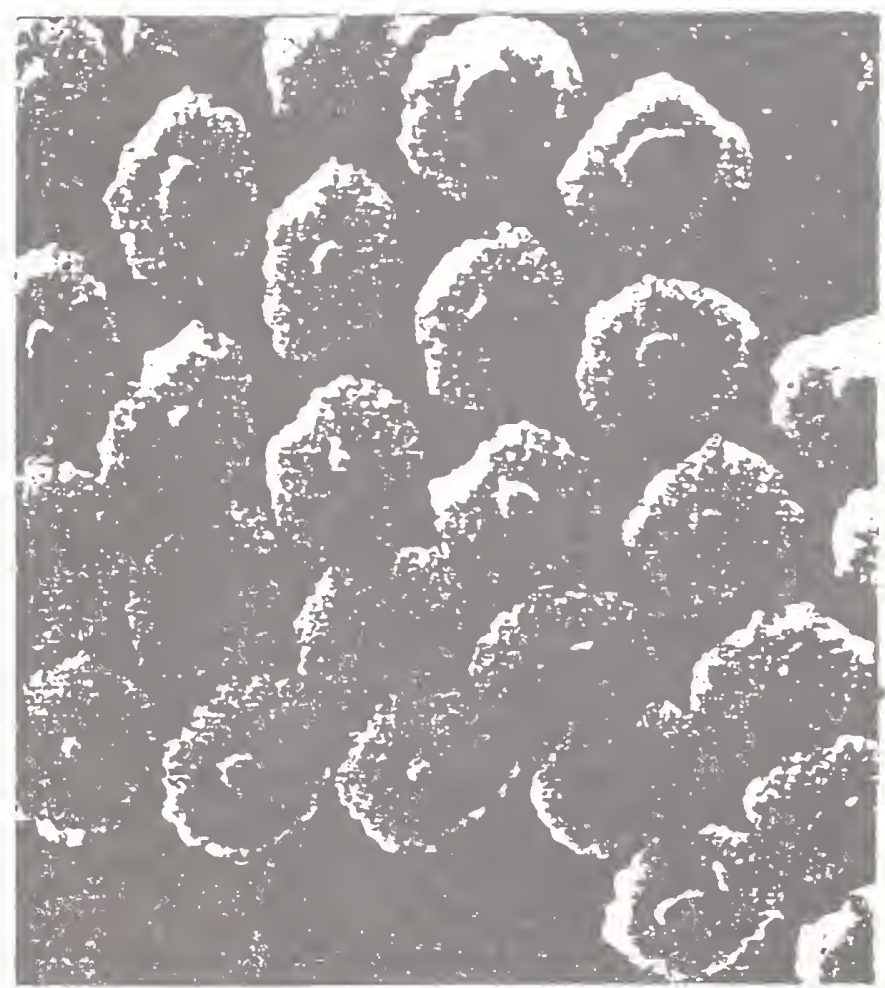

Figure 7 Cross section of filaments in. HIP'd material after reaction

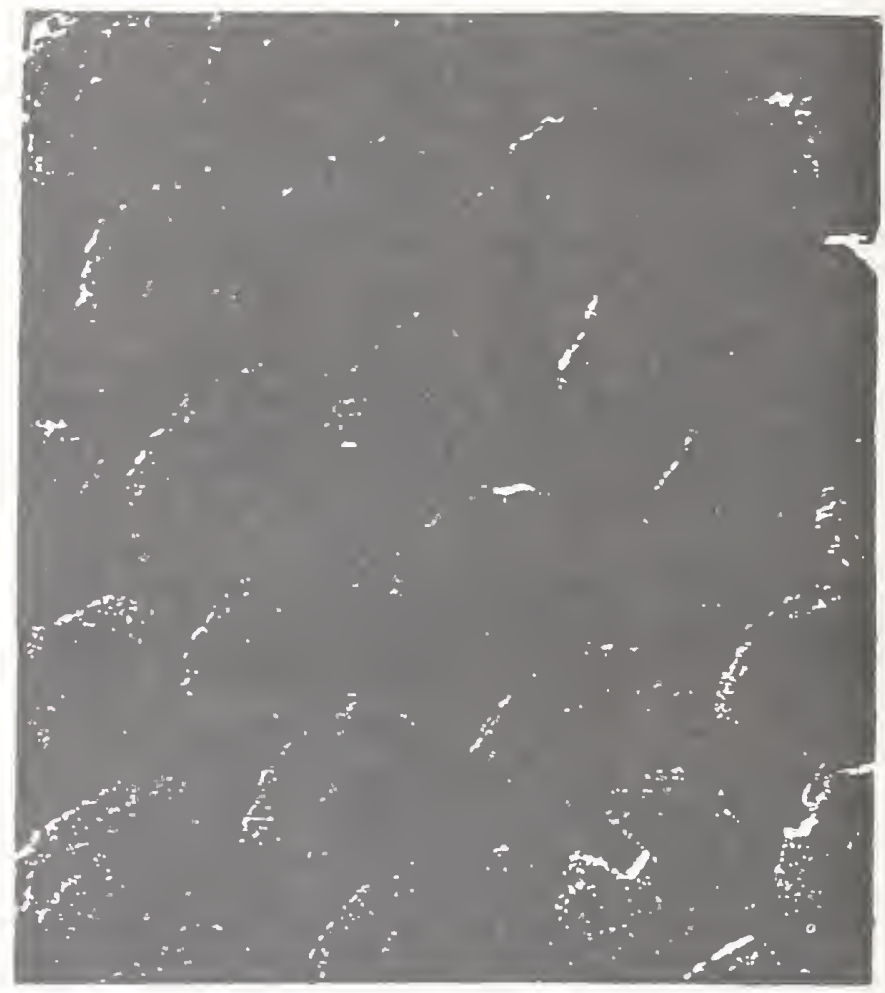

Figure 8 Cross section of filaments in unHIP'd material after rcaction

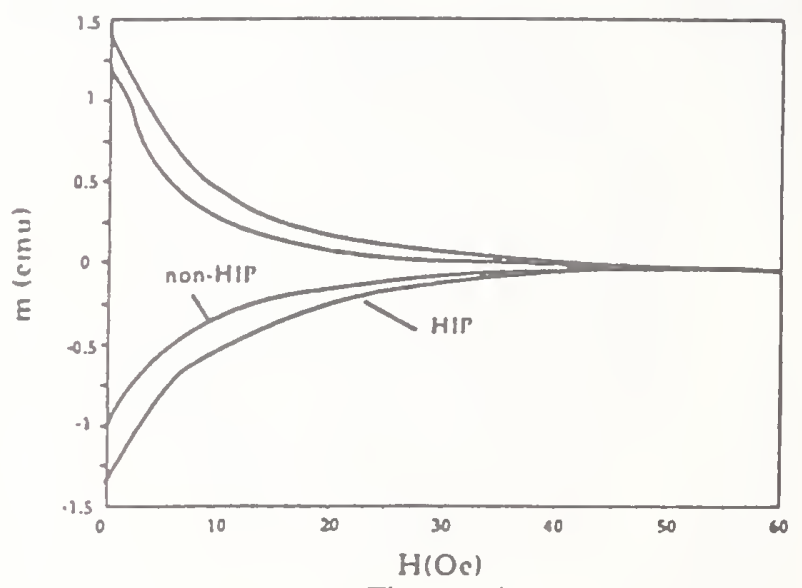

(Thousands)

Figure 9 Comparison of hystcresis measurements on HIP'd and un HIP'd matcrials

\section{CONCLUSIONS}

The poor RRR values obtained after prolonged heat treatments appear to be related to contaminants in the $\mathrm{Cr}$ plating bath and methods of improving the clcanlincss of the process and the use of altemative insulation techniques are being explored.

It has been show'n that the 19 subelement matcrial with an extruded Ta barier and no copper ring immediatcly under it, can be successfully fabricaled to the NET size and beyond without problems. It is expected that this matcrial will meet the NET $J_{c}$ specification with a comfortablc margin. The matcrial is already within the NET specification for losscs, (Table 1). 
There are indications thatl HIP'ing the Iy subelement matcrial at $580^{\circ} \mathrm{C}$ doubles the intrinsic irreversible strain as incasured in tensile tests. Investigations are being carricd out to deicrinine the extent to which HIP'ing improves $J_{c}$. " $n$ ", and reliahility of propertics along the length of the wires. Also work is heing carricd out to detcrmine the extent to which wires and cables can be handled after HIP'ing at intermediate tcmperatures without creating permanent damagc.

\section{ACKNOWLEDGMENTS}

The authors would like to acknowledge the financial assistance of the US Department of Energy through the Small Business Innovative Rescarch Program. Much of the work described here was carried out on DOE SBIR Grant No. DE. FG02-90ER 80925 The funding for the work at NIST on $J_{c}$ vs. axial strain was from DOE Office of Fusion Encrgy. Contract H 91-ER-54125.

The authors would also like to acknowledge the assistance of Dr. M. Sucnaga of BNL for the work on high field $J_{c}$. losses and bridging. Both sets of high ficld data (JVEE and MS) were ohtained using the magnet facilitics of the Francis Bitter National Magnet Laboratory, of MIT.

The help of the above individuals and our colleagues at IGC. particularly R. Colaco, D. Birdsall and R. Boyle, is greatly appreciated.

\section{RE,FF,RF,NCES}

1. J.E. Kunz.ler, E. Buehler, F.S.L. Hsu and J.H. Wernick, Phys. Rev. Lell. 1961, Vol 6 p 86.

2. R.E. Schwall, G. M. Ozcryansky, D.W. Hazelton, S.F. Cogan and R.M. Rose, "Propertics and Performance of High Current Density Sn-Core Process MF Nb3 $\mathrm{Sn}^{\prime}$. IEEE Trans, MAG-19, 3, pp. 1135-1138, (1983).

3. E. Gregory, G.M. Ozcryansky, R.M. Schaedler, H.C. Kanithi and B.A. Zcitlin, "An Internal Tin Conductor with Nb I w'. \% Ti Filaments". Adv. in Cryo. Eng. Vol. 36 pp. 147-155, eds. R.P. Recd and F.R. Fickell, Plenum Press, New York, NY, 1990.

4. E. Gregory, G.M. Ozeryansky, and B.A. Zeitlin, "Improvement of the structure and propertics of intemal tin Nb3Sn, Adv. in Cryo. Eng. Vol. $38 b$ pp. 579.586 eds. F.R. Fickelt and R.P. Reed. Plcnum Press, New York, NY, 1992.

5. E. Gregory, G.M. Ozcryansky, and M. Sucnaga, "Some cffects of porosity and HIP'ing on critical currents in internal tin-processed multifilamentary $\mathrm{Nb}_{3} \mathrm{Sn}$ wires", 7th US-Japan Workshop on High Field Superconduciors, Fukuoka, 21-23 Oct. 1991.

6. L.T. Summers, A.R. Duenas and C.E. Karlsen, G.M. Ozcryansky and E. Gregory, "A Characterization of Internal - $\mathrm{Sn} \mathrm{Nb3Sn} \mathrm{Superconductors} \mathrm{for} \mathrm{use} \mathrm{in} \mathrm{the}$ Proof of Principles (POP) Coil", IEEE Trans, 27. 2. pp. 1763-1766. (1991).

7. W.D. Markiewicz, G.M. Cianceua, A.W. Grandin, D.W. Hazclion, and H.P. Hwang. "20 T Model Coil for a Very High Ficld NMR Spectrometer Magnet", Adv. in Cryo. Eng. Vol. 37a pp. $361-368$ cd.. R.W. Fast, Plenum Press, New York, NY, 1992.

8. J.W. Ekin Sth US-Japan Workshop on High Field Supcrconduciors. Tsukubil. Janan. 1987 
VAMAS INTERCOMPARISON OF CRIIICAL CURRENT MEASUREMENI IN $\mathrm{Nb}_{3} \mathrm{Sn}$ WIRES

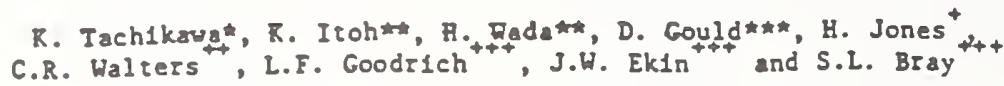

* Tokal UnIversity, Hiratsuka, Kanagawa 259-12, Japan

* National research Institure for Metals, Isukuba, Ibarak1 30s, Japan

* Comission of the European Comunities, Brussels, B-1049, Belgium + Clarendon Laboratory, Oxford, OXI 3PU, United KIngdom

++ Rutherford Applezon Laboratory, D1dcor, OXIl OQX, Unfted KIngdom ++ National Bureau of Standards, Boulder, Co 80303, USA

\section{Abstract}

The VAYAS technical working party in the area of superconducting and cryogentc struetural materials has recently carrled out the first world-wide intercomparison of critical current, I , weasurement on multifllameniary $\mathrm{Nb}_{3} \mathrm{Sn}$ wires. Three sample wires were supplied from each of EC (European Communitles), Japan and USA. The roral number of particlpant labs vere 24 (EC 11, Japan 8 and USA 5). There were feu restrictions for the I measurement at part1c1pant labs. The standard deviations of the $I_{c}$ values reported from these labs varfed among test samples, and were $6-21 \%$ of averaged I 's at 12 Iesla.

\section{Introduction}

The superconductivity rechnology may have tremendous impact on frportant areas of selence and technology and should be developed under the concept of the long term project whereby international cooperation would play an essential role. Ihis is the underlying idea in the VAYAS which stands for the Versallles Projects among sumelt parkicipant countries on Advanced Materials and Standards. The VAMAS Techn1cal Working Party (IWP) on superconducting and cryogenic structural materials consists of representatives of participant countries. The TWP has carried out an intercomparison on the critical current, I, measurement in $\mathrm{Nb}_{3} \mathrm{Sn}$ multifllamentary ures: I 'is the most fmportant superconducting parameter from the practical point of view.

The purpose of the present intercomparison (round robin) test on $I$ is to 1dentify parameters affecting

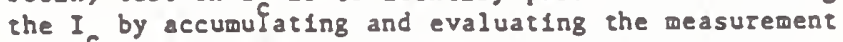
resulfs. The eventual goal of the research is to provide recomendations for the performance of short sample crit1cal-current measurements of $\mathrm{Nb}_{3} \mathrm{Sn}$ superconduetors.

\section{Particlpants, Samples and Test Procedure}

11 EC, 8 Japanese and $S$ US laboratories 11sted 10 Iable I have partielpated in the round rob1n test on the I. The distribution of test samples and accumulation of resulting I data in EC, Japan and USA were performed by the respective central labs; BCIN(BelgIU⿴), NRIM, and NBS.

Multiflamentary $\mathrm{Nb}_{3} \mathrm{Sn}$ wres with relatively small current carrying capacity ( $<500 \mathrm{~A}$ at 8 Tesla) were chosen as the test samples which could easily be tested at any partfcipant laboratory. Three sample wres were supplied, one from each of EC, Japan and USA; these samples are labeled disorderly just as sample $A, B$ and C In this paper.

Manuscript recelved August 22, 1988.
Sample A fabricated by a bronze method has a wire dlameter of 0.8 and 114 sub-bundles each containing $90 \mathrm{Nb}-\mathrm{Ta}$ fllaments in a bronze matrix. The Cu stabilizer is located at the center of the wre and separated from the fllament region by a barrier. The volume fraction of Cu stabilizer in the wre is wuch swaller compared to those in other 2 samples.

Sample $B$ has a vire dlameter of 1.0 mo and 7 subbundles each separated by a Nb barrfer from the $\mathrm{Cu}$ stab1lizer outside. Each sub-bundle contains $721 \mathrm{Nb}$ fllaments in a Cu-Sn-T1 alloy matr1x. Th1s sanple was also fabricated by a bronze process.

Sample C prepared by an Internal-Sn diffusion method has a wire dlameter of $0.68 \mathrm{gm}$ and 37 sub-bundles each containing $150 \mathrm{Nb}$ fllaments. The filament region is separated from the outer layer of $\mathrm{Cu}$ by a single $\mathrm{Ta}$ barrier.

Spectfications and the cross sectional views of these samples are given in F1g 1. Upper critical flelds, $H_{c 2}$, for sample $A$ and sample $B$ are enhanced by

Table I. Partcipant laboratories in I round robin test.

Europe (11)

Atominstitut der Desterrefehischen Un1v. (Austria)

Inst. Experfmental Physik, Oester. Univ. (Austria)

S.C.K./C.E.N (Belglum)

S.N.C.I., C.N.R.S. (France)

Kernforschungszentrum Karlsruhe (FRG)

Stemens AG (FRG)

Vacuumschmelze CombH (FRG)

E.N.E.A, Centro d1 Erascat1 (Italy)

High Field Magnet Lab., U. N1jmegen (Netherlands)

Clarendon Laboratory (UK)

Rutherford Appletos Laboratory (UK)

Japan (8)

Electrotechnical Laboratory

Furukawa Electric Co., Lid.

Hitachl Ltd.

I.M.R., Tohoku Unlversity

I.S.I.R., Osaka University

Japan Atomlc Energy Research Institute

Kobe Steel, Lid.

Natfonal Research Institute for Metals

USA (S)

Brookhaven Nat1onal Laboratory

F.B.N.M.L., Massachuserts Inst1tute of Technology

Lawrence Livermore National Laboratory

National Bureau of Standards

University of Wisconsin 
additions of $T_{2}$ and $I_{1}$, respectively.

Spec1men wres frow these amplea, each several weters long, vere distributed to participant labs through relevant central labs. Such wres were cur into parts as spectmens at each particlpant lab and one specimen, wound on a heat treatment holder of drum shape, was collected from particlpane labs and heat treated at the relevant central labs (central reaction). The reacted specimens vere then returned to the particlpant labs for measurements. In some cases, the particlpant labs also performed thelr own heat treatments on additional specimens of the samples (self reaction). The self reaction of samples was not possible at all labs.

Speciflcations of heat treatment holders were different frow lab to lab. At most of the labs stainless steel tubes with a splral groove on the outer surface were used to have a definire coll plich. The surfaces of such tubes vere usually coated with ceramics or oxidized prior to specimen mouning, in order to avold reaction of the specimen with the holder. At some labs the same holders vere used for both heat treatment and measurement, thereby reducing the possibllity to damage the specimen by handling.

Central reaction was carried out in the following manner. For samples $A$ and $B$, all specimens were heat treated in one vacuum furnace at once. The remperature of the furnaces was well controlled within $\pm 5^{\circ} \mathrm{C}$ with eine and in space. For sample $C$, specimens vere individually heat treated in a dynarle vacuua. Both ends of a specimen of internal-sn processed sample $C$ vere extended to a position there the temperature was kept below the meling point of $\mathrm{Sn}$ in order to avold the outflow of molten $S n$ from the wire. The heat treatwent condirions for semples A, B and C were $700^{\circ} \mathrm{C}$ for $96 \mathrm{hr}$, $670^{\circ} \mathrm{C}$ for $200 \mathrm{hr}$ and $700^{\circ} \mathrm{C}$ for $48 \mathrm{hr}$, respectively.

More than half of self reactions were done in vacuum. Ar other labs specimens vere encapsulared and heat treated in an argon or a hydrogen stmosphere. The

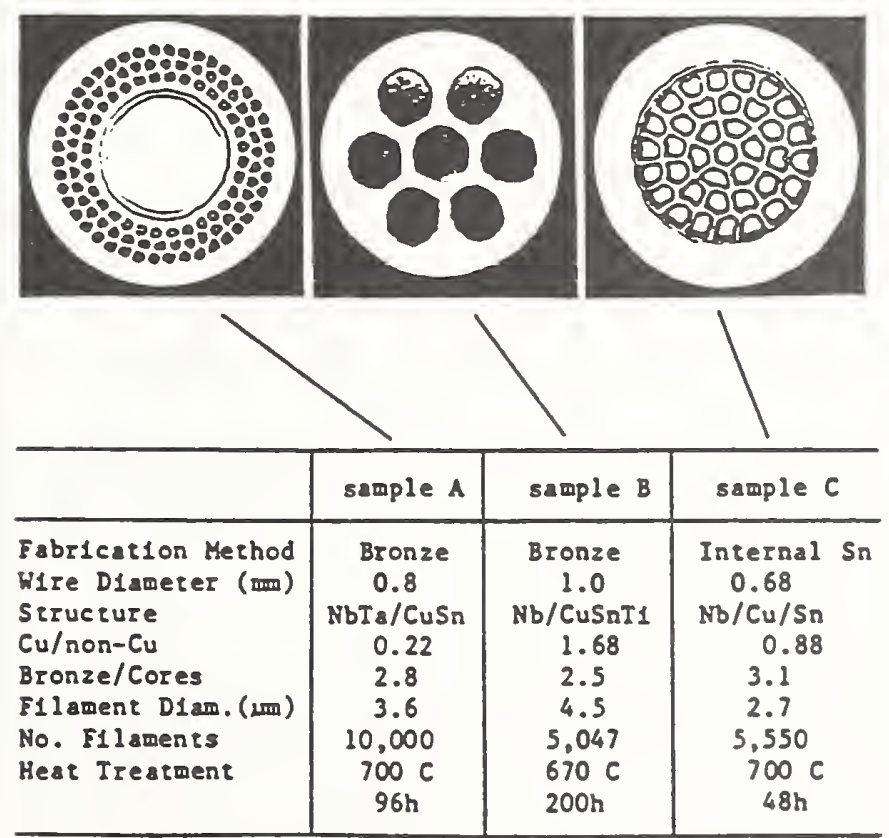

F18.1 Specifications and cross eectional vieus of round robin cest amples. hear treatment remperature was also well regulared in the self reaction.

\section{Apparatuses and Measurement Conditions}

Informations about measurement apparatuses and experimental conditions at each laboratory were described 10 formatied sheets prepared and distributed prior to the measurements.

At most of participant labs superconducing solenold magners were used to generate flelds of 8-16.5 Tesla. At some labs copper solenold magnets or hybrid rype magnets vere used which can generate flelds over 20 Tesla. In any of these magnets rus ripple flelds which may cause heat generation in the specimen, were less than $0.1 \%$ of the fleld generated. Fleld determinarion was carrled out by means of MR, Hall probe or rotating coll magnetometer, with est1mated accuractes of $0.1 \%$ to 12 .

At most of the labs transistor type poiver sources were used to supply electric currents ro the specimen. ras Ilpple nolses were less than $0.1 \%$ of the full porer. The accuracy of current determinarion was wthin $0.5 \%$ at most of the labs. In order to amplify the voltage signals generated in the speclmen, nanovoltmeters vere used at most of the labs. At some labs the signals were direcily led ro high sensirlve XY recorders. The typical level of nolses observed varied from $0.01 \mu \mathrm{V}$ to $2 \mu \mathrm{V}$, depending on the apparatuses used.

The rotal length of a specimen, the distance betueen voltage taps and the distance between current tap and lis nearest voltage tap were much varled among labs. The shorrest specimen used in a lab had a rotal length of about 215 am and 1.5 turns of vinding on the measurement holder. The longest specimen used was 2000 long and had 30 turns on the holder.

The variety of materials, e.g., fiberglass reinforced plasile (FRP), stainless steel, alumina, hastelloy and brass vere used as the measurement holder. The

Table II. Homogenelty study on sample A a SCK/CEN. Averages and standard deviarions of $I_{c}$ 's for flelds of 7-10 Tesla.

\begin{tabular}{lr|rrrr}
\hline Fleld (Tesla) & \multicolumn{1}{|c}{7} & 8 & 9 & \multicolumn{1}{c}{10} \\
\hline Average (A) & 424.5 & 354.8 & 296.6 & 246.4 \\
Std. Dev. (A) & 6.0 & 5.8 & 5.0 & 5.8 \\
Std.Dev/Ave(Z) & 1.5 & 1.7 & 1.7 & 2.4 \\
\hline
\end{tabular}

Iable III. Homogenelty study on sample B at Clarendon Lab. Averages and standard deviations of $I_{c}$ 's for flelds of $8-14$ Tesla.

\begin{tabular}{l|rrrr}
\hline Fleld (Tesl a) & \multicolumn{1}{|c}{8} & \multicolumn{1}{c}{10} & \multicolumn{1}{c}{12} & \multicolumn{1}{c}{14} \\
\hline Average (A) & 303.8 & 214.1 & 150.9 & 102.3 \\
Sid. Dev. (A) & 2.5 & 2.8 & 1.6 & 1.0 \\
Sid.Dev/Ave(Z) & 0.8 & 1.3 & 1.0 & 1.0 \\
\hline
\end{tabular}


holders had Ilng or bar shaped current terminals of copper. Most of holders bad a splral groove on them. The opeeisen was wounted in a groove on the bolder witb bo:h ends soldered to current rerminals, and flxed using a bond such as grease, varnish, epoxy, and solder. In some cases no bond was used.

The Lorentz force caused by the inceraction of the transport current with the applled fleld has an essent1al effect on the I. This force acis as a tensile or compressive stress to specimen when the splral specimen generates a central fleld parallel or antiparallel to the direction of the applied fleld. At most labs, the direction of both flelds vere antiparallel. The effect of the fleld direction on the $I_{c}$ was examined at several labs.

The I yas defined at a current where a certaln voltage gradient or a certain resistivity appeared along the superconducting specimen. Values of $I$ at 5 , 10 , and $100 \mathrm{\nu V} / \mathrm{m}$ and at integer numbers of magnelic flelds vere requested to be reported in the present round robin test; I values at $10^{-I f}$ and $10^{-13} \Omega$ a vere optional.

The relationshlp between the voltage $V$, and the transpore current, I is empirically expressed as $v \propto I$

where the exponent $n$ is rearly constant in the small voltage reglon. A larger n corresponds to a sharper transition in the specimen. n values were also requested to be reported. In the case where $n$ values vere not reported by the partelpant, they were estloated by using the following relation, $n=1 / \log I_{c}(100 \mu \mathrm{V} / \mathrm{m}) / I_{c}(10 \mu \mathrm{V} / \mathrm{m})$.

\section{Homogenelty Study}

As the purpose of this test was the intercomparison of results obtalned at different labs, it was absolutely 1mportant that all the test specimens supplied should have 1dentical superconducting propertles. It is difficult, however, to fabricate a sample with homogeneous propertles along the whole length of a wre because of the complicated structure of $\mathrm{Nb}_{3} \mathrm{Sn}$ multifllamentary composite. The homogenelty in supercondueting properties was examlned on sample $A$ at SCK/CEN and on sample $B$ at Clarendon Lab.

The homogenelty study at SCK/CEN was perforwed on 21 spec1mens of sample A. Specimens were taken from the varlous parts of a test wire, each wound on a holder and heat treated at Rutherford Lab together with those of central reaction. The I measurement was carrled out at $4.3 \mathrm{~K}$ and at 7-10 Tesla.

$115 \mathrm{I}$ data defined at voltage of $10 \mathrm{uV} / \mathrm{m}$ for 21 specimens were analyzed at SCK/CEN. For voltages larger than $10 \nu \mathrm{V} / \mathrm{m}$ specimens showed a tendency to quenching. 15 specimens quenched under a volrage of $10 u v / m$. The queach currents were usually lower conpared to the true I 's expected, and were not taken into account in the statistical treatment of the I dara. For each magnetic fleld averages and standard deviations of I 's vere calculated according to the 10 V/a voltage and listed In Iable II. Standard devlatlons are 2.47 of average of $I_{c}^{\prime}$ s at 10 Iesla and decrease to 1.57 at 7 Tesla.

The homogenelty in sample B was examined at Clarendon Lab. 7 speclmens were taken from the rest wire, each mounted onto atalnless steel holder, and heat treated at Rutherford Lab al together in a furnace. The I measurements vere carrled out at $4.2 \mathrm{~K}$ and at 7-15 Iésla. Averaged I 's at a voltage of $10 \mathrm{\mu V} / \mathrm{m}$ and standard deviarlons are sumartzed in Iable III.

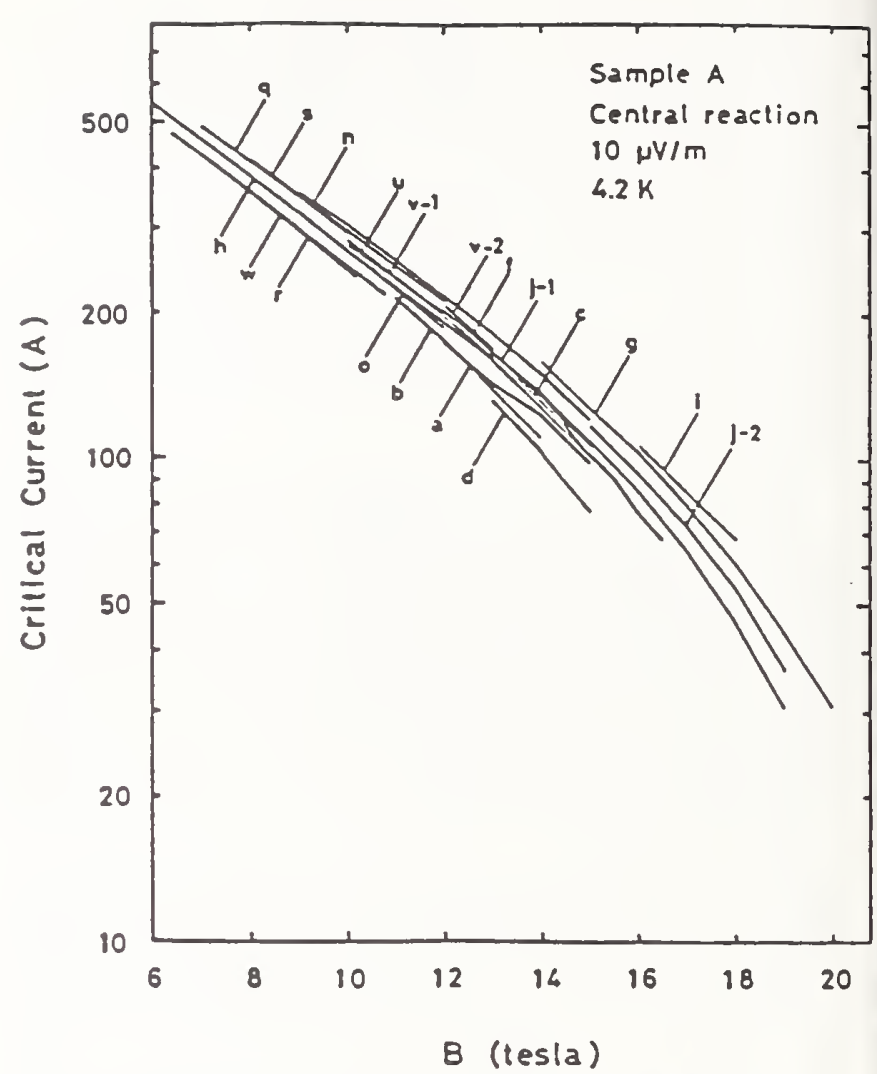

E1g.2 I 's at $10 \mu \mathrm{V} / \mathrm{w}$ as a function of fleld for sample $A$ of central reaction; resules of pariclpant labs.

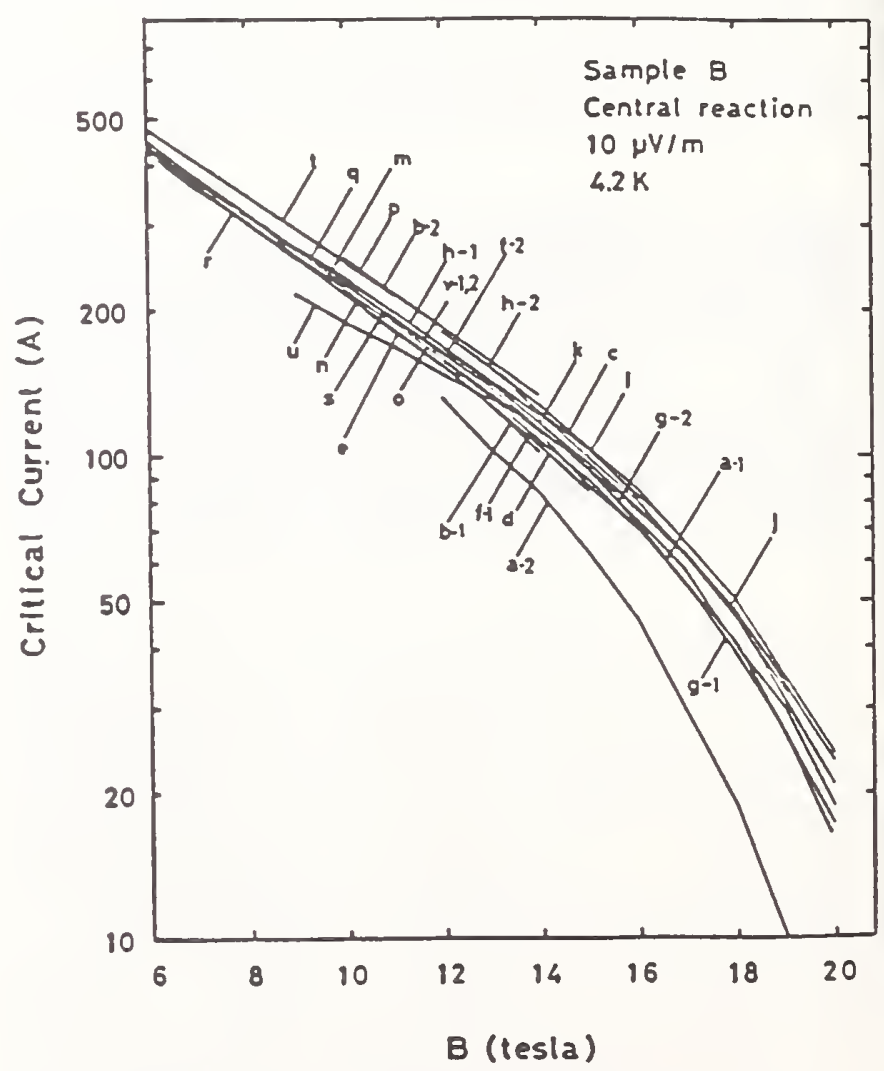

F18.3 I 's at $10 \mathrm{\mu V} / \mathrm{m}$ as a function of fleld for sample B of central reaction; resules of partelpant labs. 


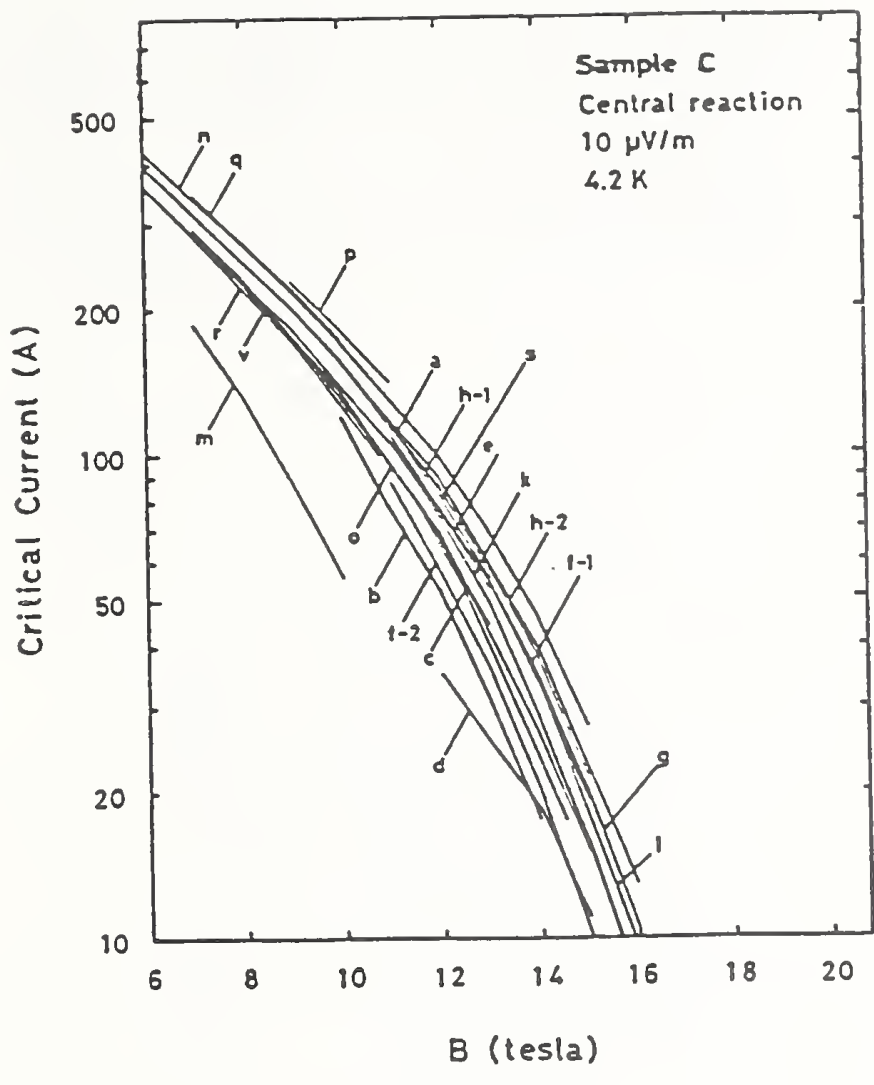

F1g.4 I 's at $10 \mathrm{LV} / \mathrm{d}$ as a function of fleld for sáaple $C$ of central reaction; resules of pariclpane labs.
Standard deviations are within $1.3 \%$ at all fields.

Based on these homogenelty studles, 1t may be concluded that the present test samples $A$ and $B$ are rather homogeneous in superconducting propertles over the whole length of wire and adequate for the round robin test. The howogenelicy siudy has not yer been carrled out on sazple $C$.

\section{Results of the Round Robin Iest}

In $51 \mathrm{gs} \mathrm{2,3}$ and $4 \mathrm{I}$ 's at $10 \mathrm{\mu V} / \mathrm{m}$ are shown as a function of applied fle fd for samples $A, B$ and $C$, respecively. The nawe of labs is coded like $a, b, c$ in no speclal order. These results were obtalned in the antiparallel self field except for those of labs $q$ and 3 .

The semilogarithmic plots show that for samples $A$ and $B$ the logs of the $I$ decreases almost linearly with Increasing fleld up to about 15 Iesla, and then drops off more rapidly above this fleld. I's in sample $C$ decrease in a similar vay but with a steeper slope, and start to drop off above about 12 Iesla. The averaged $n$ values generally decrease with increasing magnetic field and are much more scattered than the $I_{c}$ 's, especlally for sample A.

In Tables IV and $V$ are shown averages and standard deviations of $I$ data and n values obtalned at particlpant labs, Fespectively. Four extraordinartly ourlylng dara sets were excluded in the calculations because these data sets were obtained in cases where the specimens stuck to the reaction holders and vere likely damaged in removal or for other simliar reasons. There was no single magnetic field where all labs reported data on any sample. A future publication comparing all data sets at a single magnetic fleld, by means of a Kramer extrapolation method, is planned. Coefficients of vartation of I's ar $10 \mathrm{\mu V} / \mathrm{m}$ and 12 Iesla are about 7,6 and $21 \%$ of the averages for samples $A, B$ and $C$ of central reaction, respectively, and become larger at higher magnerfc flelds. These values are appreclably larger than those obtalned in the homogenelty studies which are 2.4 and $1.3 \%$ for samples $A$ and $B$, respecitvely.

Table IV. Averages and standard deviations of critical currents at $10 \mu \mathrm{H} / \mathrm{m}$ for samples $A, B$ and $C$ of central reaction.

\begin{tabular}{|c|c|c|c|c|c|c|c|c|c|c|c|c|}
\hline \multirow[b]{2}{*}{$\begin{array}{l}\text { Field } \\
\text { (Iesla) }\end{array}$} & \multicolumn{4}{|c|}{ sauple A } & \multicolumn{4}{|c|}{ sample B } & \multicolumn{4}{|c|}{ sample $C$} \\
\hline & No. & $\begin{array}{l}\text { Ave. } \\
\text { (A) }\end{array}$ & ${ }_{(A)}^{\sigma}{ }^{\sigma}$ & $\begin{array}{c}\sigma / \text { Ave } \\
(\bar{z})\end{array}$ & No. & $\begin{array}{l}\text { Ave. } \\
\text { (A) }\end{array}$ & ${ }_{(A)}^{\sigma} \sigma$ & $\begin{array}{r}\text { /Ave } \\
(z)\end{array}$ & No. & $\begin{array}{l}\text { Ave } \\
\text { (A) }\end{array}$ & ${ }_{(A)}^{\sigma}$ & $\begin{array}{l}\text { /Ave } \\
(z)\end{array}$ \\
\hline 6 & 1 & 544.1 & 0.0 & 0.0 & 4 & 447.4 & 18.7 & 4.2 & 3 & 393.8 & 25.7 & 6.5 \\
\hline 7 & 4 & 447.9 & 26.2 & 5.9 & 7 & 372.2 & 15.4 & 4.1 & 7 & 309.3 & 24.3 & 7.9 \\
\hline 8 & 5 & 388.7 & 21.8 & 5.6 & 8 & 315.2 & 13.0 & 4.1 & 6 & 248.6 & 20.8 & 8.4 \\
\hline 9 & 7 & 327.4 & 23.3 & 7.1 & 10 & 265.3 & 11.1 & 4.2 & 9 & 197.3 & 20.6 & 10.4 \\
\hline 10 & 9 & 277.1 & 18.0 & 6.5 & 15 & 229.1 & 13.1 & 5.7 & 11 & 150.0 & 18.5 & 12.3 \\
\hline 11 & 7 & 234.4 & 14.3 & 6.1 & 13 & 195.3 & 12.6 & 6.5 & 13 & 106.9 & 16.2 & 15.1 \\
\hline 12 & 11 & 195.7 & 13.6 & 6.9 & 17 & 163.6 & 10.4 & 6.3 & 16 & 72.5 & 15.2 & 20.9 \\
\hline 13 & 10 & 158.0 & 14.5 & 9.2 & 14 & 134.6 & 7.2 & 5.3 & 13 & 45.4 & 10.7 & 23.6 \\
\hline 14 & 10 & 130.5 & 15.5 & 11.9 & 16 & 114.3 & 7.8 & 6.8 & 13 & 30.0 & 8.4 & 28.0 \\
\hline 15 & 10 & 106.7 & 12.9 & 12.1 & 12 & 92.2 & 5.0 & 5.4 & 10 & 16.9 & 5.0 & 29.4 \\
\hline 16 & 6 & 91.9 & 10.8 & 11.8 & 10 & 75.8 & 4.8 & 6.4 & 7 & 8.5 & 2.6 & 30.5 \\
\hline 17 & 3 & 71.8 & 6.3 & 8.8 & 4 & 57.5 & 2.5 & 4.4 & 2 & 3.4 & 0.2 & 6.4 \\
\hline 18 & 4 & 57.4 & 9.0 & 15.7 & 7 & 43.7 & 2.6 & 8.4 & 2 & 2.1 & 0.7 & 33.7 \\
\hline 19 & 3 & 36.8 & 5.3 & 14.4 & 4 & 30.6 & 2.6 & 8.4 & 1 & 1.0 & 0.0 & 0.0 \\
\hline 20 & 2 & 26.4 & 4.4 & 16.7 & 5 & 19.4 & 2.7 & 13.9 & & & & \\
\hline
\end{tabular}


In F1g. S I 's at 10 LV/W and at 12 Tesla reported troo labs are conpared. In cases no I values were reporied at $12 \mathrm{I}$. they vere estimated by extrapolations not exceeding $2 \mathrm{I}$. In the flgure, $\Delta I / \sigma$ denotes the difference in $I$ between $l a b$ and averaze normalized to the standard Eeviation, $\sigma$. Labs are arranged in incremental order of mean laboratory value of $\Delta I_{c} / \sigma$. The arrows attached to some of the data syabols Indleate that these data actually lie elther above or below the vertical lialts of the plo:. The maxisum to minimum spread in I at each $1 \mathrm{ab}$ is almost ulthin 2 times of $\sigma$, rather šmall compared to the total maxioum to minimum spread ( 6 tiwes of $\sigma$ ). These results clearly Indicare sysrematlc differences among the labs in the measured I of each sample. These differences may be due to the

Table V. Averages and standard deviations of $n$ values for samples $A, B$ and $C$ of central reaction.

\begin{tabular}{|c|c|c|c|c|c|c|c|c|c|c|c|c|}
\hline \multirow[b]{2}{*}{$\begin{array}{l}\text { Fleld } \\
\text { (Iesla) }\end{array}$} & \multicolumn{4}{|c|}{ sample A } & \multicolumn{4}{|c|}{ sample B } & \multicolumn{4}{|c|}{ sample C } \\
\hline & No. & Ave. & $\sigma$ & $\begin{array}{c}\sigma \text { /Ave } \\
\text { (z) }\end{array}$ & No. & Ave. & $\sigma$ & $\begin{array}{r}\sigma \text { /Ave } \\
(z)\end{array}$ & No. & Ave & $\sigma$ & $\begin{array}{r}\sigma \text { /Ave } \\
(z)\end{array}$ \\
\hline 6 & & & & & 4 & 37.2 & 2.4 & 6.5 & 3 & 32.2 & 2.8 & 8.5 \\
\hline 7 & & & & & 6 & 39.3 & 5.0 & 12.8 & 7 & 32.8 & 7.6 & 23.3 \\
\hline 8 & 4 & 78.3 & 33.9 & 43.4 & 8 & 36.8 & 5.6 & 15.2 & 6 & 32.5 & 4.9 & 14.9 \\
\hline 9 & 5 & 87.8 & 38.5 & 43.8 & 10 & 34.2 & 4.5 & 13.1 & 9 & 28.6 & 3.5 & 12.1 \\
\hline 10 & 7 & 58.0 & 21.4 & 36.9 & 13 & 32.6 & 5.5 & 16.8 & 11 & 26.7 & 5.2 & 19.3 \\
\hline 11 & 6 & 50.0 & 23.3 & 46.7 & 13 & 32.3 & 8.2 & 25.3 & 13 & 26.8 & 8.8 & 32.8 \\
\hline 12 & 9 & 52.7 & 18.7 & 35.5 & 17 & 30.3 & 6.6 & 21.8 & 16 & 21.9 & 7.7 & 35.0 \\
\hline 13 & 8 & 43.9 & 16.5 & 37.7 & 15 & 28.3 & 7.5 & 26.7 & 13 & 18.7 & 7.4 & 39.7 \\
\hline 14 & 7 & 35.1 & 14.8 & 42.3 & 16 & 27.8 & 6.2 & 22.2 & 13 & 14.5 & 5.1 & 34.9 \\
\hline 15 & 6 & 37.3 & 13.1 & 35.1 & 12 & 28.1 & 5.1 & 18.0 & 10 & 12.4 & 3.5 & 28.5 \\
\hline 16 & 3 & 33.0 & 3.6 & 10.8 & 10 & 25.9 & 4.0 & 15.4 & 7 & 10.5 & 2.7 & 25.5 \\
\hline 17 & & & & & 4 & 24.2 & 5.3 & 21.9 & 2 & 8.8 & 1.6 & 17.7 \\
\hline 18 & 1 & 22 & 0.0 & 0.0 & 7 & 20.6 & 4.3 & 20.9 & 3 & 6.3 & 0.7 & 10.8 \\
\hline 19 & & & & & 4 & 19.0 & 3.5 & 18.2 & 1 & 5.2 & 0.0 & 0.0 \\
\hline 20 & & & & & 5 & 12.8 & 2.3 & 17.8 & & & & \\
\hline
\end{tabular}

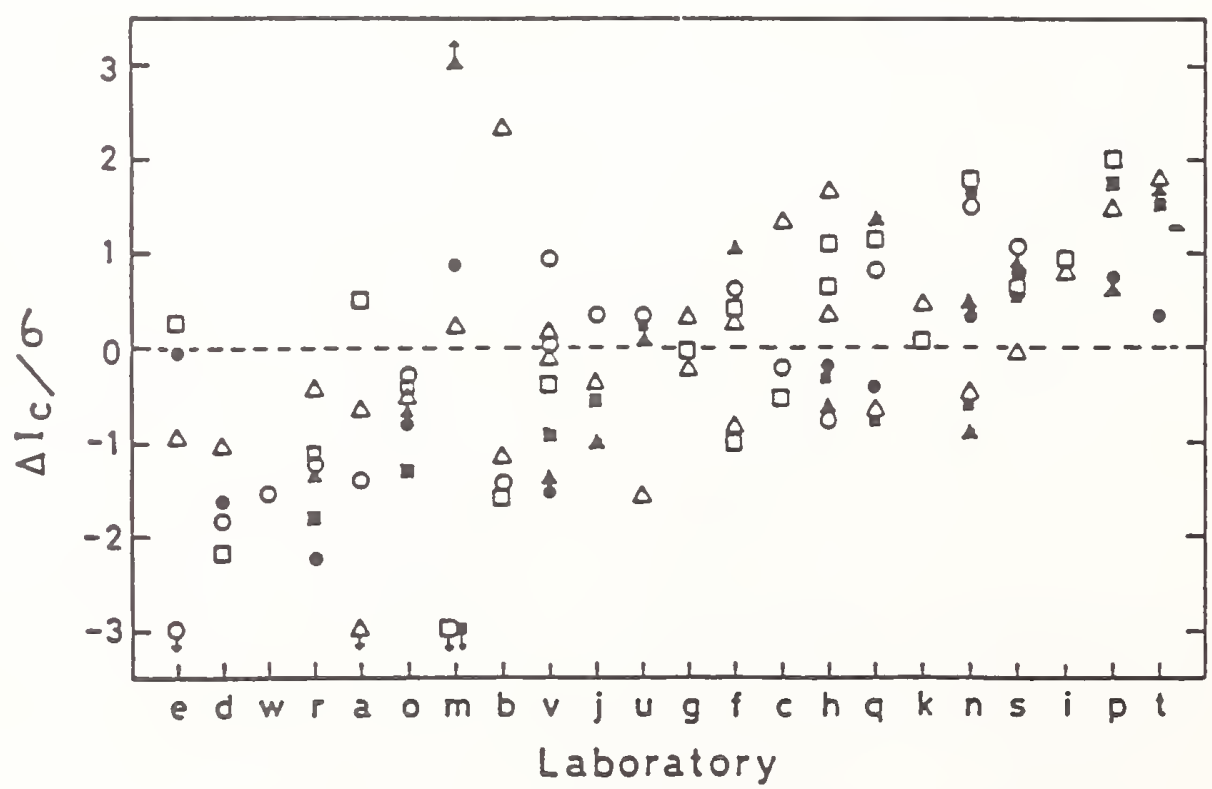

F18. 3 Comparison of I 's among particlpant labs at 12 I. Symbols $(0,0)$, $(\Delta, \Delta)$ and $(\mathcal{E}, \mathbf{n})$ refer to the sapples $A, B$ and $C$ (central reaction, self reacilon), respectively. 
differene saaple holders, sample handling, the weasuremen: method, and varlasloos 10 instrument callbration. More deralled papers addressing these possible sources of systerailc differences are planned for furure publicaicion.

The ratios of $I(\mid 1)$ to $I(\mid \beta)$ are shown in E1g. 6 for sample $B$. I $\left(\begin{array}{l}c \\ p\end{array}\right)$ and $I_{(}\left(\begin{array}{l}f \\ p\end{array}\right)$ denore the $I_{\text {'s }}$ for whteh the self and the applfed fields are in parallel and antiparallel directions, respectively. If the specimen is tightly flxed on the holder, there should be no difierence between $I_{e}(i \mid)$ and $I_{f}(i b)$, the ratio of $I_{c}(f \mid)$ to $I_{e}(\mid t)$ being unity. The tightness of the fixing depends on the bonding material and its amount. Epoxy resins such as 'stycast' seem to give betcer fixing than grease, as is apparently shown In $\mathrm{E} 1 \mathrm{~g} .6$. Some of the curves of the ratio $I_{f}(f \mid) / I_{c}(\mid b)$ drop below unity at higher flelds in Fig. 6. If a specimen is uniformly deformed by concentrle hoop siress, the rat10 u1ll approach unity as the fleld increases. Therefore, nonuniform deformation of specimen may result in the rat1o less than unity.

In order to see $1 f$ the 'self reaction' carried our at each lab was the exact copy of the 'central reaction', daca of I 's for two reactions were compared. This comparison between self and central reactions did not lnelude all of the avallable data, but rather, it only included data from labs that measured boch of cheir specimens on similar holders. Averaged I 's of self reacted sample $B$ are nearly the same as those of centrally reacied one. However, averaged I 's of celf reacted saople $A$ are always smaller than those of centrally reacted one, while those of self reacted sample $C$ are smaller at lower flelds and larger ar higher flelds than those of centrally reacted one. These resulis indicate that I 's of samples $A$ and $C$ are more sensitive to the heat treacment condition than those of sample $B$. The reaction t1me for sample $C$ is the shortest of the three sasples and, consequenty, the sensilivity of sample $C$ to both reaction time and temperature may be greater than for the other samples. Furthermore, sample C's apparent sensilivity to the reaction conditions may be due to an inadequate conflnement of the internal tin at the specimen ends during the hear treatment. The coefficient of variarion of I of self reacted samples, which way reflect the difference in reaction conditlons among labs, correspond to 4-8 2 of I almost Independent of magnerle fleld and sample. The possibllity of sample damage incurred during shipping is also a variable in the comparlson between the self and central reactions.

\section{Strain Effect}

The tensile strain effect on I's were examined at NBS, Osaka UnIV. and Rutherford lab ustng the round robin test sanples. Although the measurement detalls were different, there was good agreement among three sets of data. As examples, resulis for 14 Tesla at NBS and those for 15 Iesla at Osaka Univ. are compared in F1g. 7 where I 's have been normallzed to the maximum values. The $I_{c}^{c}$ of $\mathrm{Nb}_{3} \mathrm{Sn}$ conductor Inereases with increasing tensife strain up to $0.2-0.3 \%$ where the precompressive strati 1mposed on the $\mathrm{Nb}_{3} \mathrm{Sn}$ compound is mosily released. As can be seen in this flgure, the tenslle stain sensftivity of I is largest for sample $C$ and relartvely sall for sample $B$. This may be relared partly to the $\mathrm{H}^{2}$ of chese samples; sample $C$ has a relatively low $\mathrm{E}^{2}$ of $\sim 19$ Tesla, whlle $1 \mathrm{is} \sim 24$ Iesla for samples ${ }^{2} A$ and $B$. A more complece comparison of the straln effect data w11 be the subject of a future paper.

Effects of the thfekness of the BRP holder on the I vere examined at $\mathrm{NBS}^{2}$ using specimens of samples $B$ and

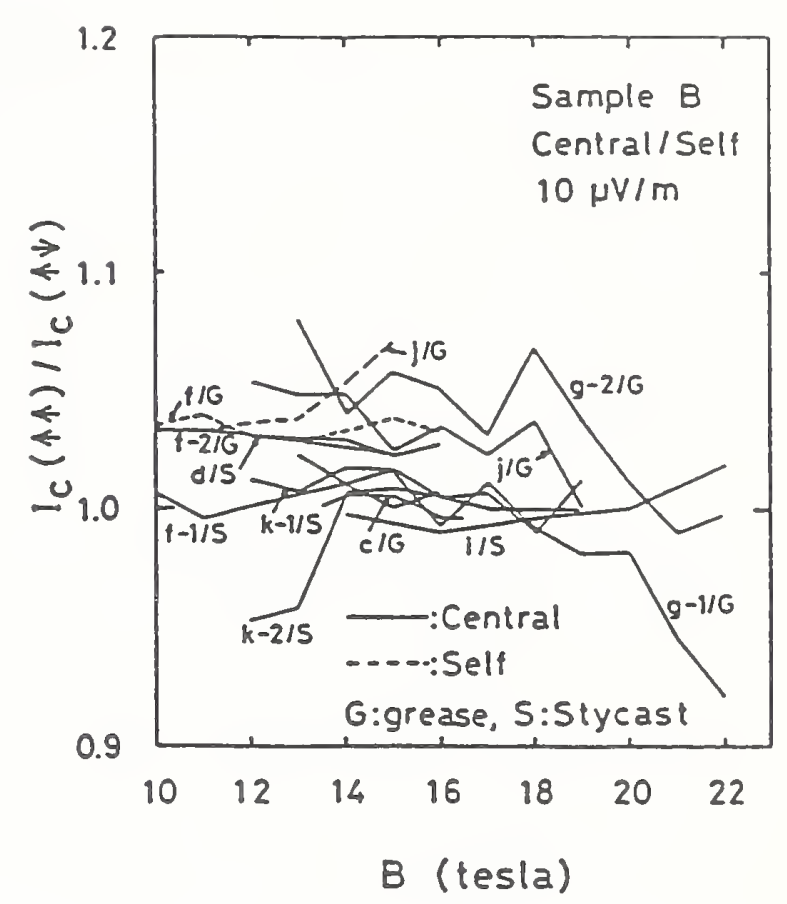
F18.6 Rat10, $I_{e}(\mid f) / I_{e}(\{\mid)$ vs. f1eld curves for sample
B.

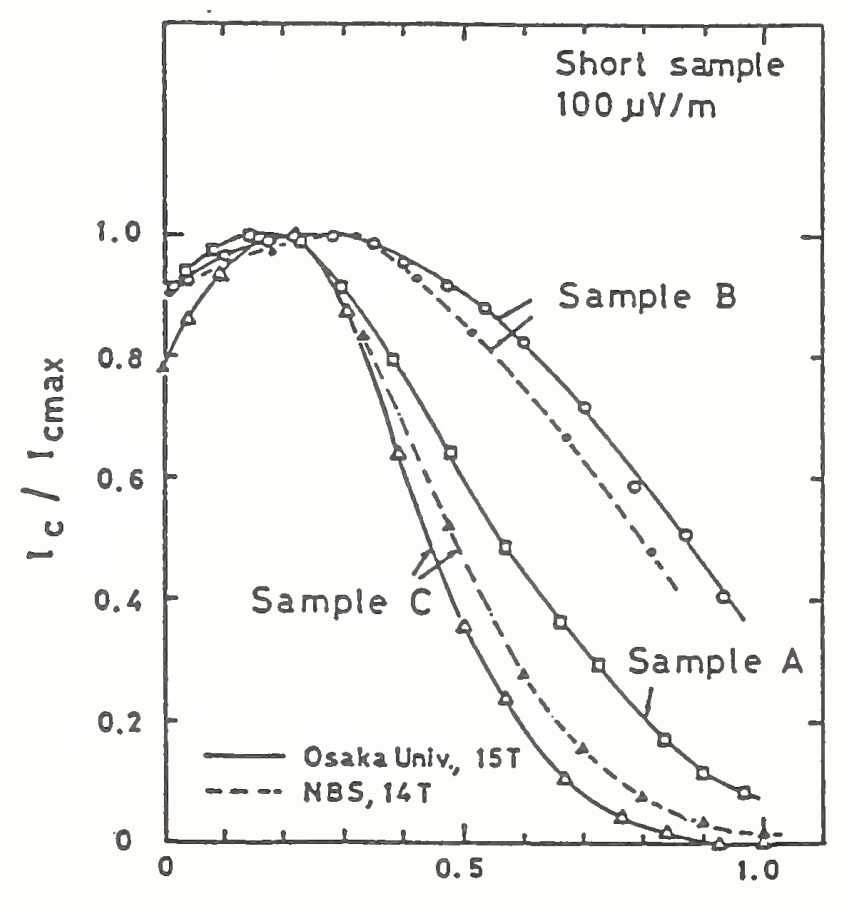

Strain $(\%)$

F1g.7 I vs. atrain curves for samples $A, B$ and $C$ obtalned at NBS and Osaka Univ. I is normal1zed to lis maximum value. 
C. Specimens were first mouated on tblck yalled FRP holders. Nter the I measureneat ibe bolders vere bored so as to have thin walls. It was found that I 's for these bored holders with thin walls were slightly enhanced. The therral coneracelons of thick and thin wall holders are different due to the textured structure of FRP, and estimated to be about $0.4 \%$ for thick wall and abour $0.25 \%$ for thin wall on coollng from room temperature to $4.2 \mathrm{~K}$. It was concluded that the compressive strain in the specimen resulting from the thermal differential contraction between the FRP holder and the speciaen was responsible for the discrepancy in I In those specimens mounted on thick and thin wall hôlders.

The sample holder materlal and geometry, in conjunction with the specimen bonding method, can have an effect on the strain state of the specimen and this w11 have a slgniflcant effect on the results of the I. measurements. Thus, this could be a major source of the observed systematic variation in the measured $I_{c}$ 's.

\section{Conclusions}

Resul ts of the present round robln test may be summarized as follows.

a) Homogenelty rest on the I showed the present samples vere enough homogeneous along the whole length of wire to be used in the round robin test.

b) Coefficlents of varlation of $I$ 's were $7 \%, 6 \%$ and $21 \%$ at 12 Iesla for samples $A,{ }^{C} B$ and $C$, respectively. They were largest for sample $C$ which was most sensitive to straln and heat ireatment cond1rlons. Coeffletent of varlation increased at higher flelds for all of samples.

c) n values showed larger coefflclent of varlation than I. n values were rather soall in case the speclaen wâs soldered on metallic holder.

d) Strain effects on the I of three wires were examined. It was pointed out that the seraln in the specimen was a major origin for the scatter in $I_{c}{ }^{\circ}$

e) Materials of the specimen holder and t1ghtness of flxing have significant effects on the $I_{c}$ through the straln effect.

Several parameters influencing the I value of $\mathrm{Nb}_{3} \mathrm{Sn}$ wres have been extracted and analyzed Ehrough the VAMAS round robin cest. Eowever, the present round robin rest was performed with few restrictions on the measurement method, and more strict determination of measurement conditions will be required to minimize the scatter in I and to furnish a really effective standard method of the $I_{c}$ measurement.

A more complete report on the present round robin test w1l be submitted to the steering complitee of VAMAS from the Technical Work1ng Party. A number of papers addressing spectflc aspects of this round robla test are planned for furure publlcation.

Trede names are used in thts document to spectfy the measurearent deta11s. In no Instance does this 1deniffeation 1mply endorsement by the authors or thels Insticutions, nor does it Imply that the particular products are necessarily the best avallable.

The authorg wish to thank all the scientists and representatives who have been involved In the present round robln test for thelt cooperation.

\section{References}

(1) H. Jones, "Firse Meeting of the VAMas Iechnical Working Party on Superconductors and Cryogenlc Seructural Materlals". Cryogenles, vol. 26, Pp. 488-489, Auguse (1986).

[2] L.F. Goodr1ch and S.L. Bray, "Cr1t1cal-Current Measurements of $\mathrm{Nb}_{3} \mathrm{Sn}$ Superconductors: NBS Con"ribution to the VAMAS Interlaboratory Comparison", subaleted for publication in Cryogenics. 
VAMAS Interlaboratory Comparisons of

Critical Current vs. Strain in $\mathrm{Nb}_{3} \mathrm{Sn}$

\author{
J. W. Ekin \\ National Inst. of Standards and Technology \\ Electromagnetic Technology Division \\ Boulder, Colorado 80303
}

\title{
Abstract
}

A comparison is made of measurements of the effect of axial tensile strain on the critical current of multifllamentary $\mathrm{Nb}_{3} \mathrm{Sn}$ superconductors by three different laboratories. Two of the laboratories used short sample testing apparatus wherein a straight section of conductor was cooled in a force-free stare. One of the laboratories used a spring apparatus wherein a long sample was reacted in a coil shape and attached to a spring sample holder. The agreement between the results for the two laboratories that used the straight sample apparatus was quite good, within $15 \%$ for all three conductors at 15 I. except at very high strain for one conductor which had an upper critical field close to the measurement field. To make a comparison with the data obtained using the spring method, it was necessary to fit the data to the compressive prestrain determined using the stralght-sample technique. With such a fit, the agreement was variable, between 15 and 258 depending on the conductor. Values of the prestrain and irreversible strain obtained from the straight sample data agreed within 0.068 and 0.058 respectively. Values of the maximum (strain-free) upper critical fields agreed within several tenths of a tesla.

During the course of the VAMAS interlaboratory testing of the critical current density $J_{c}$ of $\mathrm{Nb}_{3} \mathrm{Sn}$ multifilamentary superconductors, the effect of axial tensile strain on $J_{c}$ was measured by three laboratorles. This paper presents a brief comparison of those resules.

Three conductors designated as A, B, and $C$ were tested. Detalls of the wire characteristics sie given in Ref. 1. Three laboratories participated in the testing. Laboratories I and II used a short-sample testing apparatus wherein a straight section of conductor was cooled in a force-free state, and then axial tensile strain was applied and measured using custom low-force straln extensometers. Laboratory III used a spring apparatus wherein a long sample was reacted in a coil shape and attached to a spring sample holder. The spring was then bent, tightening the sample against the spring, which would then applied tensile strain to the sample. The advantages of the spring method are that the long sample length allows $J_{c}$ to be measured directly at more sensitive criterion levels and permits sampling $J_{c}$ over a longer sample length; the disadvantages are that the prestrain value cannot be measured because of differential thermal contaction between the spring materlal and superconductor, and variable bending strain can be introduced into the sample from the tightening of the sample onto the spring as it is initally bent.

The results from laboratory I were obtained at 15 I only, so this was chosen as the fleld for comparison of results. The results from laboratories II and III were measured as a function of magnetic fleld. However laboratory II's results were obtained at even values of the flelds only, so the $14 \mathrm{~T}$ and 16 I results were used to interpolate the results at 15 I using the strain scaling law. ${ }^{2}$
Contribution of NIST, not subject to copyright.
Proceedings of the 6th Japan-U.S. Workshop on High Field Superconducting Materials and Standard Proceedures for High Field Superconducting Materials Testing Edited by K. Tachikawa, K. Yamafuji, H. Wada, J. W. Ekin, and $M$. Suenaga

Japan, 1989 

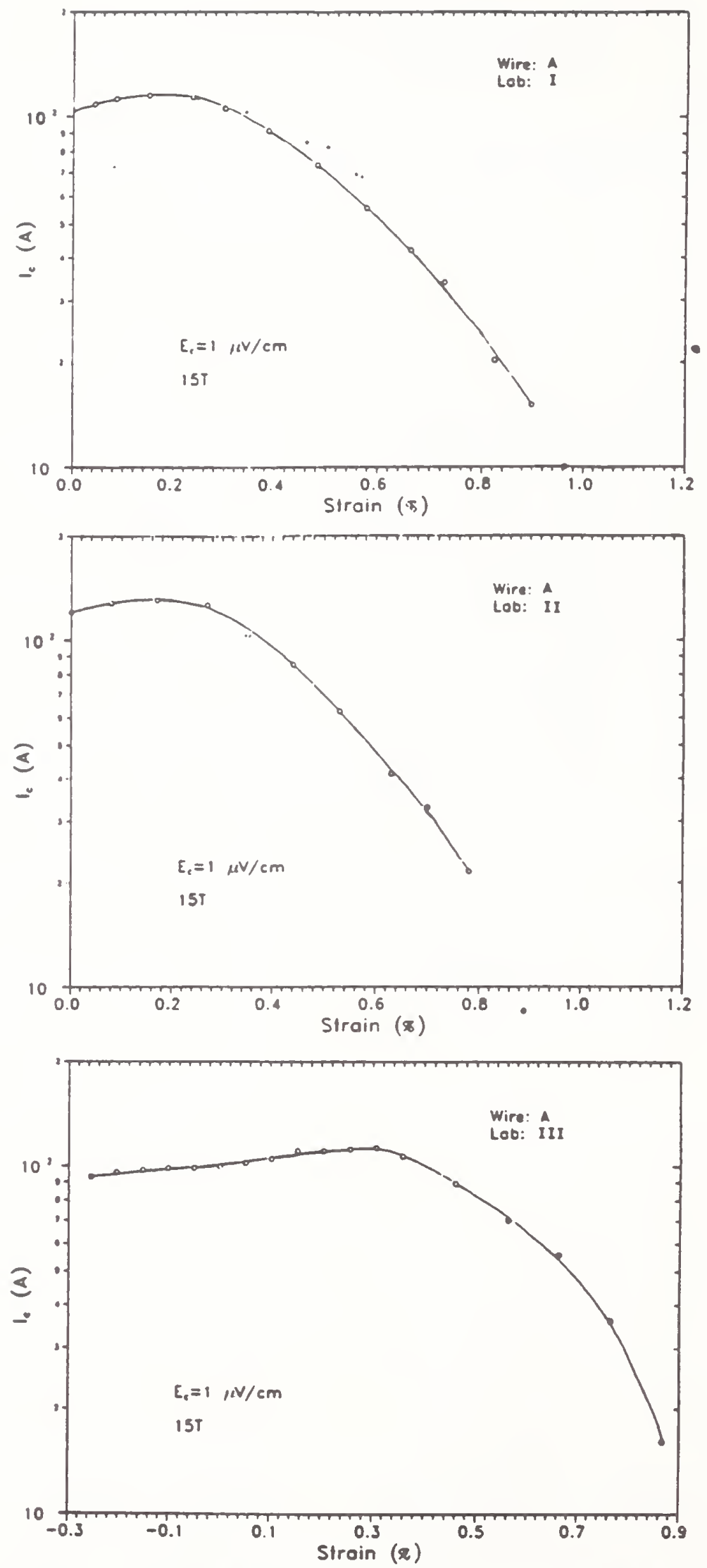

Fig. I J Vs. strain characteristic for conductor $A$, as measured using short. sample apparatus with force free cooling (laboratories I \& II) and long-sample spring method (laboratory III). Unloaded $J_{c}$ data are denoted by the symbol $x$. 

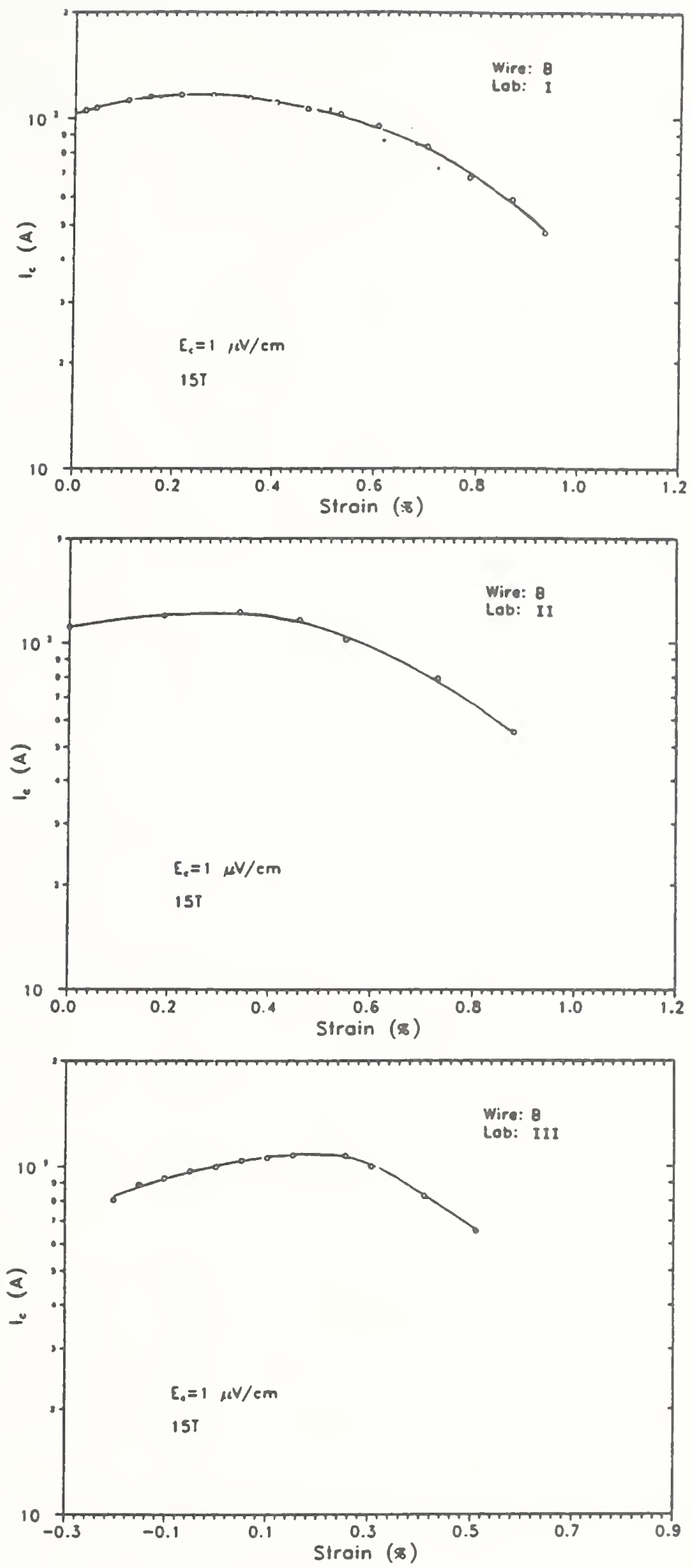

Fig. $2 \mathrm{~J}_{c}$ vs. strain characteristic for conductor $B$, as measured by laboratories I, II, \& III. 
Table I. Comparison of Electromechanical Parameters

\begin{tabular}{|c|c|c|c|c|c|}
\hline Conductor & Meas. Lab. & $\varepsilon_{\mathrm{m}}$ & Eirrev & $\epsilon_{0}$, irrev & $\underline{B}_{c}^{*} 2 m$ \\
\hline \multirow{3}{*}{ A } & $I$ & 0.188 & $\geq 0.978$ & $\geq 0.798$ & $\cdots$ \\
\hline & II & 0.188 & $\geq 0.808$ & $\geq 0.628$ & $24.6 \mathrm{~T}$ \\
\hline & III & $\cdots$ & - & $\cdots$ & $24.5 \mathrm{I}$ \\
\hline \multirow{3}{*}{ B } & I & 0.258 & 0.85 & 0.68 & $\ldots$ \\
\hline & II & 0.318 & 0.828 & 0.518 & $25.7 \mathrm{I}$ \\
\hline & III & $\cdots$ & - & $\cdots$ & $26.2 \mathrm{~T}$ \\
\hline \multirow{3}{*}{ C } & I & 0.208 & $\geq 1.088$ & $\geq 0.888$ & $\cdots$ \\
\hline & II & 0.218 & 1.108 & 0.898 & $\cdots$ \\
\hline & III & $\cdots$ & - & -. & $\cdots$ \\
\hline
\end{tabular}
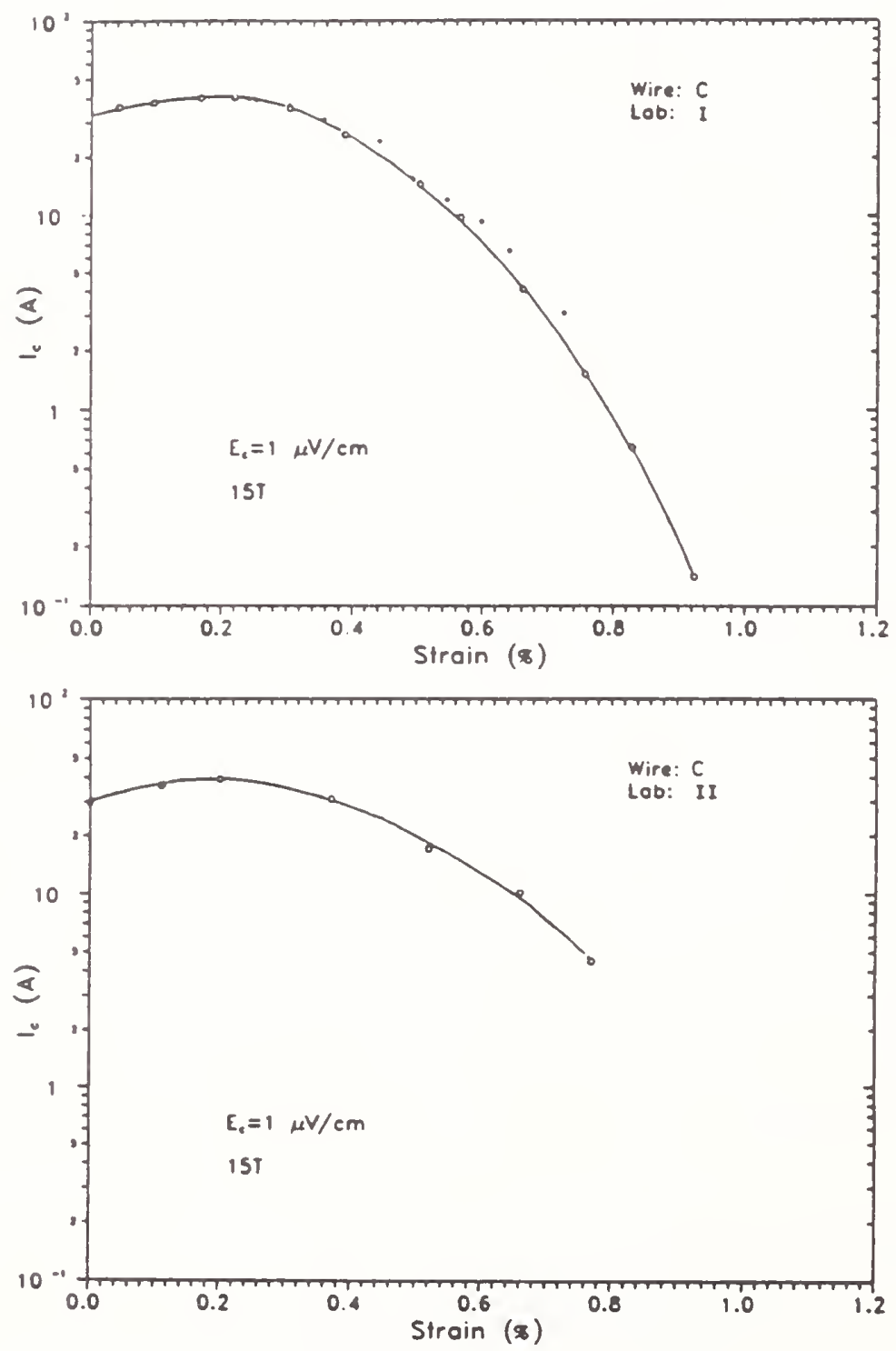

Fig. $3 \mathrm{~J}_{c}$ vs. strain characteristic for conductor $C$, as measured by laboratorles I and II. 
Figs. 1a-1c show the comparison of results for conductor A obtained by all three laboratories. Figs. $2 a-2 c$ compare the results for conductor $B$, and Figs. $3 a-3 b$ show the results for conductor $C$.

The agreement between laboratories I and II is quite good, within 158 for all three conductors at $15 \mathrm{I}$, except at very high strain for conductor $C$ where the initially low value of $B_{c 2}$ resulted in $B_{C 2}$ being degraded to the point that it approached $15 \mathrm{~T}$. In this case, the interpolation and measurement errors become extreme because of the rapid change of $J_{c}$ near $B_{c 2}$. Overall an agreement within 158 at such a high fields is considered to be fairly good considering the mechanical nature of the measurements, range of data, and types of conductor tested.

To make a comparison with the data from laboratory III, it was necessary to fit the data to the prestrain $\epsilon_{\mathrm{m}}$ values determined by laboratories $I$ and II, which used the force-free cooling technique. With such a fit, the data from laboratory III agreed within 158 for the conductor $A$ and within 258 for conductor B.

The agreement of the strain sensitivity (slope of the $J_{c}$ vs. strain curve) for laboratory III compared with I and II was variable, well matched for one conductor, Fig. 1, but not for the other, Fig. 2.

Values of the prestrain ${ }^{3} \epsilon_{m}$, irreversible strain 4 irrev, and intrinsic irreversible strain

$\epsilon_{0}$,irrev $=\epsilon_{\text {irrev }} \epsilon_{\mathrm{m}}$ were obtained from the data for laboratories I and II and are compared in Table I.

The prestrain values agreed within 0.068 . The comparison of irreversible strain values is more limited, but where directly measured (conductor $B$ ) the agreement was well within 0.058 (which is also consistent with the lower limit data available for conductors $A$ and $C$ ).
Values of the maximum (strain-free) $B_{C 2 m}^{*}$ for each sample are also shown in the last column of Table I for laboratories II and III. (A maximum $B_{c 2 m}^{*}$ value for laboratory I could not be determined since data were available at only one field.) The maximum $B_{c 2 m}^{\star}$ values determined from the data of laboratories II and III agreed within several tenths of a resla.

Acknowledgements

The help of R. Gerrans and G. Reinaker in analyzing and plotting the results is gratefully acknowledged. S. Bray assisted with the high-field data. acquisition. K. Katagiri, T. Okada, and C. Walters contributed data for this intercomparison.

\section{References}

1. K. Tachikawa, K. Itoh, H. Wada, D. Gould, H. Jones, C. R. Walters, L. F. Goodrich, J. W. Ekin, and S. L. Bray, IEEE Trans. Mag. MAG-25(2), 2368 (1989).

2. J. H. Ekin, Cryogenics 20,611 (1980).

3. G. Rupp, IEEE Trans. Mag. MAG-13, 1565 (1977).

4. J. W. Ekin, IEEE Trans. Mag. MAG-15, 197 (1979).

5. J. W. Ekin, Adv. in Cryo. Eng. 30. 823 (1984) 
K. Katagiri, K. Saito, M. Ohgami, T. Okada, A.Nagatat, K. Notot+, K. WaranabetH, K. Itoh*, H. Wada* K. Tachikawa**, J.W. Ekint, and C.R. Walterstt,

ISIR, Osaka University, Ibarak1, Osaka 567, Japan

+Fac. Mining, Akita University, Akita 010, Japan

+Fac. Eng., Iwate University, Morioka, Iwate 020, Japan

HIMR, Tohoku University, Senda1, Miyag1 980, Japan

*Nat. Res. Inst. Metals, Tsukuba, Ibaraki 305, Japan

**Fac. Eng., Tokai Universicy, Hiratsuka, Kanagawa 259-12, Japan

tNat. Inst. Stand. Tech., Boulder, CO 80303, USA

t+Rutherford Appleton Lab., Didcor, OXI1 OQX, UK

\section{ABSTRACT}

The strain characteristics of critical current, $I_{C}$, In three kinds of VAMAS round robin test wires were evaluated. The multifilamentary Nb3S samples measured are: bronze roure $T a$ added and Internally stabilized wire $A, T i$ added and externally stabllized wire $B$ and internal $t$ in diffusion processed wire $C$, respectively. The strain for $I_{c}$ peak ranged $0.20-0.30 \%$ and the reversible strain limtt $0.8-1.1 \%$. The results obtained at $15 \mathrm{~T}$ in three institutes, NIST, Rutherford Lab. and Osaka/Tohoku Univ., are compared. Fairly good agreement was obtalned. The strain sensitivity was higher in the order of $C, A$ and $B$. This can be mainly attributed to the effect of addition of the third element. The correlation between the strain sensitivity and the scatter of critical currents measured in the round robin test participant laboratories is briefly discussed.

\section{INTRODUCTION}

Interlaboratory comparison of the critical current, $I_{C}$, measurements using common multifilamentary $\mathrm{Nb} 3 \mathrm{Sn}$ sample superconducting wires (round robin test) have been successfully carrled out as an activity of VAMAS (Versallles Project on Advanced Materials and Standards). 1-3 The summary report suggested that there exists a strong correlation between the scatter of $I_{c}$ values and strain effects associated with the measurements. This paper describes interlaboratory comparisons of the strain effects of VAMAS wires measured in three laboratories and discusses how strain effects in the conductor influence $I_{c}$ measurements. 
Table 1. Specication of samples

\begin{tabular}{lccc}
\hline & Wire A & Wire B & Wire c \\
\hline Fabrication Method & Bronze & Bronze & Internal Sn \\
Wire Diameter (mm) & 0.8 & 1.0 & 0.68 \\
Structure & NbTa/CuSn & Nb/CuSnTi & Nb/Cu/Sn \\
Cu/non-Cu & 0.22 & 1.68 & 0.88 \\
Bronze/Cores & 2.8 & 2.5 & 3.1 \\
F1lanent Diam. $(\mu \mathrm{m})$ & 3.6 & 4.5 & 2.7 \\
No. F1laments & 10,000 & 5,047 & 5.550 \\
Heat Treatment & $973 \mathrm{~K}$ & $943 \mathrm{~K}$ & $973 \mathrm{~K}$ \\
& $96 \mathrm{~h}$ & $200 \mathrm{~h}$ & $48 \mathrm{~h}$ \\
\hline
\end{tabular}

\section{EXPERIMENT}

Samples

Three multifflamentary $\mathrm{Nb3Sn}$ sample wires were tested. The first and the second, $A$ and $B$, are bronze route wires with Nb3Sn filaments containing the third additional elements of $\mathrm{Ta}$ or $\mathrm{T} 1$, respectively. Wire $\mathrm{A}$ is stabilized by copper internally and B externally. The third, $C$, is an internal Sn processed wire with no third element addition. Brief sample specifications are given in Table 1. Further detalls have already been previously reported. 1

\section{Apparatus and Measurement}

Three groups of laboratories participated in the strain effects evaluation tests using apparatus of their own. They are Inst. Sci. Ind. Res., Osaka Univ./Mater. Res. Inst., Tohoku Univ., National Inst. Standard Technology and Rutherford Appleton Lab.; these institutes are labeled disorderly as Laboratory I, II and III in this paper. Laboratories I and II used a short straight sample testing apparatus.4,5 Axial tensile strain was applied in the magnet bore perpendicularly to the magnetic field; the $I_{c}$ was measured using custom low-force clip-on gauge. The sample was cooled in a force-free state. Laboratory III used a long coll shape sample soldered on the outer periphery of a spring sample holder. Twisting the spring results in tensile or compressive strains in the sample. 6

Only the data at magnetic fields of $15 \mathrm{~T}$ were provided by laboratory I, whereas mure detafled results measured as a function of the magnetic field were presented by laboratories II and III. The results are compared based on the data at this field using an $I_{c}$ crfterton of $1 \mu \mathrm{V} / \mathrm{cm}$. The data at $15 \mathrm{~T}$ of laboratory II are obtained through simple interpolation using points at 14 and $16 \mathrm{~T}$.

\section{RESULTS AND DISCUSSION}

\section{Serain Effect}

As an example of results, the strain dependence of $I_{c}$ in wire $C$ is shown in Fig. 1. The $I_{c}$ increases with strain to the peak, $I_{c m}$, at $\varepsilon_{m}$ where compressive pre-strain in $\mathrm{Nb} 3 \mathrm{Sn}$ induced by the other constituents with different thermal contraction coefficients on cooling is released. It decreases on further straining. The irreversible strain limit $\varepsilon$ irrev is determined as a strain beyond which the $I_{C}$ value on unloading does not fall 


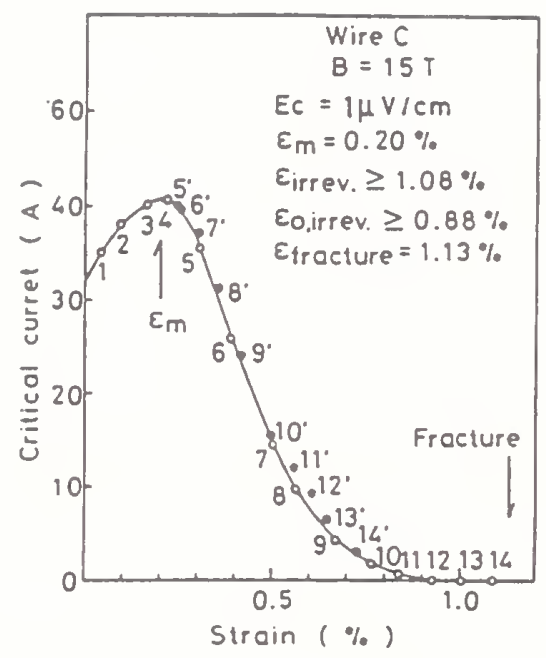

Fig. 1. Ic vs. strain characteristic for wire C (laboratory I). (Open circles are obtained on loading, solid unloading)

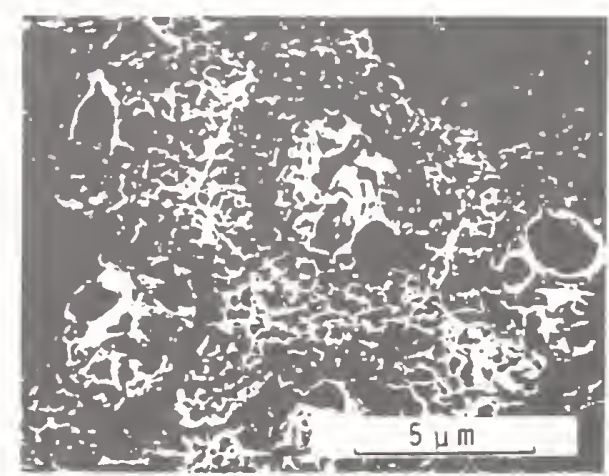

Fig. 2. Fracture surface of wire C. $(4.2 \mathrm{~K}, 15 \mathrm{~T})$.

on the curve obtained by previous loading. Figure 1 indicaces $\varepsilon_{m}=0.2 \%$ and $I_{c}$ is reversible until the wire is nearly strained to fracture, $\varepsilon f$. The highly reversible characteristics of this wire is ascribed to the wire construction: The fractograph of this wire at $4.2 \mathrm{~K}, 15 \mathrm{~T}$ indicated that the size of volds observed in the distributed $S n$ core is small, which does not induce a significant strain concentration (Fig.2). This is in contrast with the large volds observed in internal tin diffusion processed wires with larger core size, in which the Eirrev is small and the strain sensitivity of Ic is high. 7,8

\section{Comparison of Measurements Among Laboratories}

Values of $\varepsilon_{\mathrm{m}}$, Eirrev, and fracture strain $\varepsilon_{f}$ obtained in each laboratory are compared in Table 2. The prestrain value $\varepsilon_{m}$ agrees within $0.06 \%$ for laboratories I and II. The $\varepsilon_{\mathrm{m}}$ values differ somewhat from the 
Table-2. Comparison of characteristic strain values

\begin{tabular}{llccc}
\hline & & $\varepsilon_{\text {II }}(\%)$ & $\varepsilon_{\text {irrev }(\%)}$ & $\varepsilon_{\text {f }(\%)}$ \\
\hline \multirow{2}{*}{ Wire A } & lab.I & 0.18 & $>0.97$ & 1.02 \\
& lab.II & 0.18 & $>0.80$ & 0.91 \\
& lab.III & 0.25 & - & - \\
& & & & \\
Wire B & lab.I & 0.25 & 0.85 & $>3.5$ \\
& lab.II & 0.31 & 0.82 & $>1.70$ \\
& lab.III & 0.20 & - & - \\
& & & & \\
Wire C & lab.I & 0.20 & $>1.08$ & 1.13 \\
& lab.II & 0.21 & $>1.05$ & 1.34 \\
& lab.III & - & - & - \\
\hline
\end{tabular}

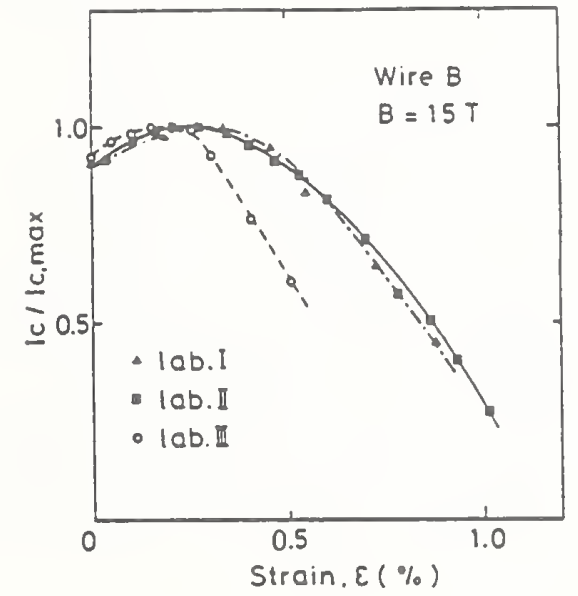

a)

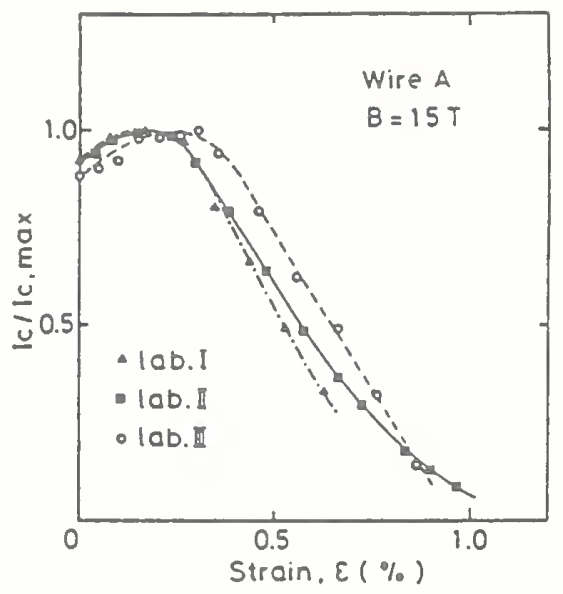

b)

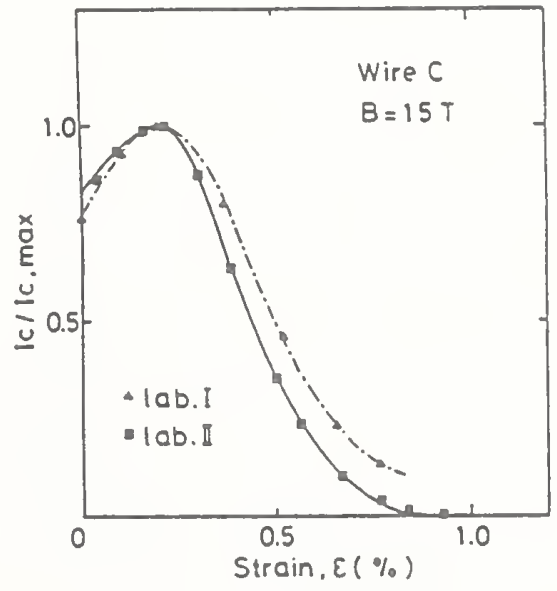

c)

Fig. 3. Strain dependence of $I_{c} / I_{c m}$. 
results obtained by others for laboratory III. The irreversible strain limit values, or its lower limit values, agreed well, within $0.05 \%$, in wire $B$ and are somewhat scattered in wires $A$ and $C$. The reason for large scatter of Eirrev is that the reversible strain limit coincides with the wire fracture strain at which $I_{c}$ can be no longer determined. The fracture is controlled by the weakest defect in wires $A$ and $C$, whereas the reversible strain limit in ductile wire $B$ is determined by micro-fracture in the filaments prior to the final fracture.

The strain dependence of $I_{c}$ for the three wires obtained by the three laboratory groups are shown in Fig. 3. The $I_{c}$ is normalized to that at peak strain, $I_{\mathrm{Cm}}$. The agreement of $\varepsilon_{\mathrm{m}}$, as mentioned above, as well as the strain sensitivity between laboratories I and II is quite good. To make a meaningful comparison with the data from laboratory III, in which the wire is soldered to a strip of copper firmly laid over the surface of the titanium spring, it appears necessary to fit the data to the prestrain values determined by laboratories I and II, which are obtained through force-free cooling.

The $\varepsilon_{\mathrm{m}}$ is largest in wire $B$ in which both the bronze-to-core ratio, $R$, and the copper-to-non-copper ratio, $S$, are high. The smallest $\varepsilon_{m}$ in wire $A$ is presumed to be the consequences of low $R$ and $S$ and the position of the stabilizer. 9

\section{Strain Sensitivities and Scatter of $I_{c}$ Measurements}

Figure 4 shows comparison of tensile strain sensitivities for three wires obtained in laboratory $I$. The sensitivity is highest in the wire $C$ and tends to decrease lower in the order of $A$ and $B$. These are mainly controlled by their upper critical field, $B_{c} 2 ; 19 \mathrm{~T}, 24.5 \mathrm{~T}$, and $26 \mathrm{~T}$, respectively. The change in $B_{C} 2$ is attributed to the species and the amount of additional elements to $\mathrm{Nb} 3 \mathrm{Sn}$; no addition, $\mathrm{Ta}$, and $\mathrm{Ti}$ respectively. The strain sensitivity of $I_{C}$ is known to be higher in the conductor with a higher $R$ ratio and higher $\varepsilon_{m} .10$ The ratio $S$ is also supposed to contribute to it in the same direction. It seems worthy to note that $I_{c}$ in the wires stabilized internally are more sensitive as compared with that in externally stabilized wires. 9 However, it appears that these effects are masked by the vast difference in $B_{c}$.

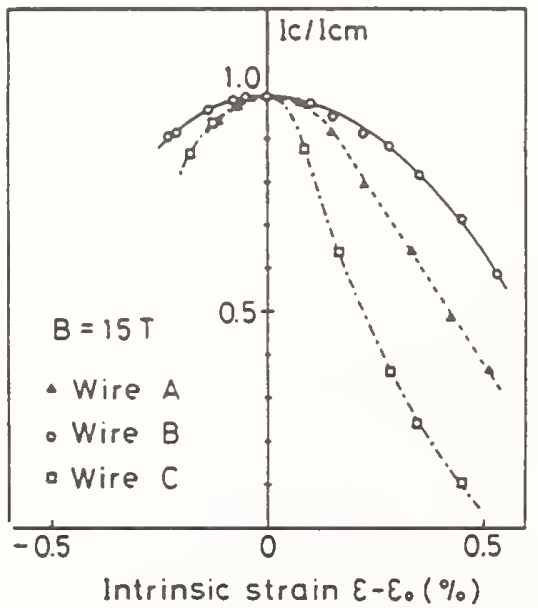

Fig. 4. Strain sensitivity of Ic (laboratory I). 

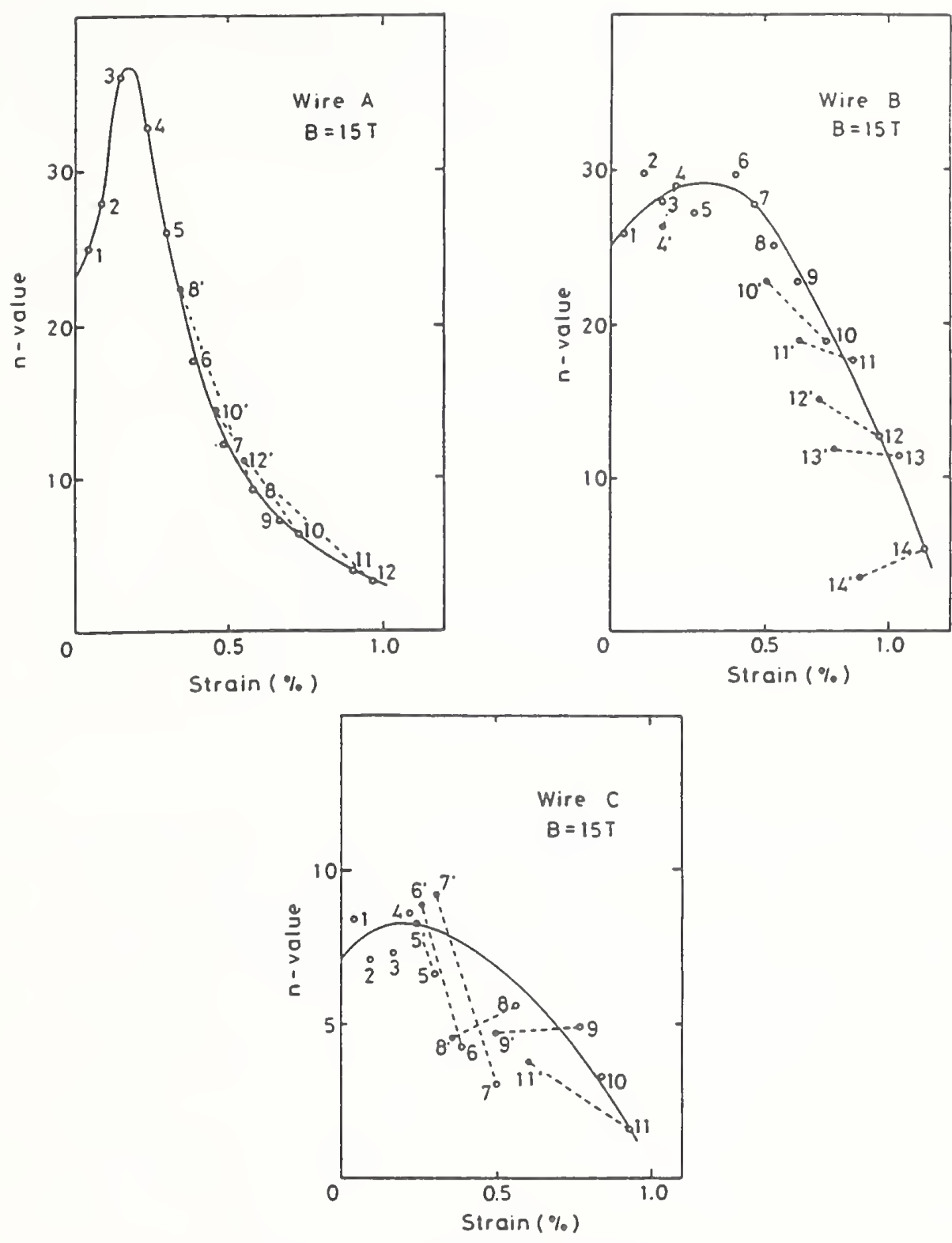

Fig. 5. Strain dependence of " $n$ " value (laboratory I). (Open circles are obtained on loading, solid unloading)

According to a summary of the round robin test of $I_{c}$ determined by the criterion of $10 \mu \mathrm{V} / \mathrm{m}$, the coefficient of variation in $I_{c}$ data, s/Ave where $s$ is standard deviation and Ave is averaged value of $I_{c}$ 's, increases as the magnetic field is increased. Further, the variance is larger in the order of samples $C, A$, and $B ; s / A v e$ are $29.4,12.1$, and $5.4 \%$ at $15 \mathrm{~T}$, respectively. The order coincides with that of the strain sensitivity of $I_{C}$ mentioned above. These facts indicate that the scatter in the $I_{C}$ measurements is closely related to the strain characteristics of the wire; the intrinsic sensitivity of the conductor associated with the prestrain during handling and/or cooling down. The systematic differences among 
Table 3. Comparison of Icm

\begin{tabular}{llc}
\hline & & Icm, A \\
\hline \multirow{2}{*}{ Wire A } & lab.I & 115 \\
& $1 \mathrm{ab} . I I$ & 132 \\
& $1 \mathrm{ab} . I I I$ & 114 \\
& lab.I & 116 \\
Wire B & $1 \mathrm{ab} . I I$ & 124 \\
& $1 \mathrm{ab} . I I I$ & 107 \\
& & \\
Wire C & $1 \mathrm{ab} . I$ & 40 \\
& $1 \mathrm{ab} . I I$ & 41 \\
\hline
\end{tabular}

laboratories in the round robin test have also been mainly attributed to the strain effect associated with the sample holder (Fig. 5 in the reference 1 ).

So long as the value of the prestrain experienced before the $I_{c}$ measurement is small, the importance of the magnitude of $\varepsilon_{m}$ is to be emphasized. Because the extent of change in $I_{c}$ is directly associated with the strain sensitivity around the zero applied strain, the value of $\varepsilon_{m}$, the deviation from the peak, has significant meaning not only for the Ic value itself but also the scatter of $I_{c}$ measurement.

It must be noted, however, that the values of $I_{c m}$, the $I_{c}$ free from strain are also different among the laboratories (Table 3). This indicates that factors other than strain still can exist in the measurements of each laboratory; variation of magnetic field, parameters specific to the apparatus (excluding strain effect), recording equipments, and variation of sample itself. The parameters excepting the last one can partly be responsible for the systematic differences among laboratories. Difference in heat treatment condition also leads to variation of $B_{c} 2, I_{c m}$ and, therefore, the strain effect. More significant variation is induced in the samples with shorter heat treatment time in the order of wire $C, A$, and $B$. The situation for wire $C$ is particularly bad because there is another problem with inadequate confinement of internal tin in short sample during heat treatment. The filament diameter (increasing in the order of wire C, A and B) may in part be responsible for a variation in the longitudinal homogeneity of the wires. The results of a homogeneity check for wires has been reported, except wire C. The scatter in wires A and B is rather low.

Strain Sensitivity of "n" Value

In the course of $I_{c}$ round robin tests, $n$ values specifying the relationship between the voltage $V$ and the transport current I in a empirical expression $V \propto I^{n}$ has been also evaluated. A larger $n$ value corresponds to a sharper transition in the specimen and is an index of good homogeneity.11 The dependence of $I_{c}$ on criterion voltage is higher for conductors of smaller $n$ values. 12 Changes in $n$ values determined within the voltage range of 0.5 to $5 \mu \mathrm{V} / \mathrm{cm}$ versus strain for three wires are shown in Fig. 5. Although the scatter of $\mathrm{n}$ is rather large, especially in wire $\mathrm{C}$, $\mathrm{n}$ changes with strain as in the case of $I_{c}$. Because $n$ reflects the homogeneity of the conductor, the irreversibility in $n$ value is presumed to be caused by damage in the filaments. The change in $\mathrm{n}$ is larger in the wires $C$ and $A$. The value of $\Omega$ near the peak $I_{C m}$ is larger in wire $A$, but at strains other than the peak region it is rather small as compared to wire $B$. 
The effect of the difference in position of stabilizer on the $n$ value is not clear at present. The $n$ values in wire $C$ are erratic and small. A dull increase in voltage, i.e. smaller $n$ value, will result in scatter of Ic if $I_{c}$ criteria is of high accuracy, $1 \mu \mathrm{V} / \mathrm{cm}$ or smaller, or when the voltage base line in measurement has some fluctuation.

\section{CONCLUSIONS}

1. Interlaboratory comparisons of strain effects in three VAMAS sample superconductors showed fairly good agreement in prestrain $\varepsilon_{m}$, irreversible strain Eirrev, and strain sensitivity of $I_{C}$.

2. Scatter of $I_{c}$ measurement in the round robin test samples is mainly ascribed to strain effects; strain sensitivity and magnitude of prestrain.

\section{ACKNOWLEDGMENTS}

The authors are grateful to the members of HFLSM, Tohoku University for giving convenience to use $16.5 \mathrm{I}-\mathrm{SM}$. This work is partly supported by Grant in Aid for Scientific Research No. 63050006, Ministry of Education, Sclence and Culture, Japan.

\section{REFERENCES}

1. K. Tachikawa, K. Itoh, H. Wada, D. Gould, H. Jones, C.R. Walters, L.F. Goodrich, J.W. EkIn and S.L. Bray, IEEE Irans. Magn., 25:2368 (1989).

2. K. Tachikawa, "Proc. 6th Japan-US Workshop for High Field Superconductors", Boulder, 1989, in press.

3. J.W. Ekin, ibid.

4. J.W. Ekin, Cryogenics, 20:611 (1980).

5. K. Katagir1, M. Fukumoto, K. Saito, M. Ohgami, T. Okada, A. Nagata, K. Noto, and K. Watanabe, Presented at the ICMC, Los ANGELES, CA, July $24-28,1989$.

6. C.R. Walters, I.M. Davidson, and G.E. Tuck, Cryogenics, 26:406 (1986).

7. M. Umeda, H. Yamazaki, M.Watanabe, Y. Kimura, Cryog. Eng., 22:110 (1987) (in Japanese).

8. K. Katagiri, K. Saito, M. Ohgami, T. Okada, A. Nagata, K. Noto, and

K. Watanabe, in: "New Developments in Applied Superconductivity", p. 401 Y. Murakami ed., World Sc1. Publ. (1989) SINGAPOLE.

9. K. Katagiri, M. Ohgami, T. Okada, T. Fukutsuka, K. Matsumoto, M. Hamada, K. Noto, K. Watanabe, and A. Nagata, Presented at the ICMC, Los ANGELES, CA, July 24-28, 1989.

10. T. Luhmann, M. Suenaga, D. O. Welch and K. kaiho, IEEE Trans. Magn. $15: 699$ (1979).

11. W.H. Warnes, D.C. Larbalestier, in: "Proc. Int. Symp. Flux Pinning Electromagn. Prop. Superconds.", T. Matsushita, K. Yamafuji and F. Irie, eds., P. 156, Matsukuma Press, Fukuoka (1985).

12. L.F. Goodrich and F.R. Ficket, Cryogenics, 225 (1982). 


\section{VAMAS $\mathrm{Nb}_{3} \mathrm{Sn}$ Test Conductor}

A bronze-process $\mathrm{Nb}_{3} \mathrm{Sn}$ conductor was measured as part of the second VAMAS (Versailles Project on Advanced Materials and Standards) international critical-current round robin. The conductor specifications are given in Table 15. The critical current was measured as a function of magnetic field and axial tensile strain. The measured data are presented in Table 16 and in Figs. 23 and 24. The $I_{C}$ and $J_{C}$ values are based on an electric field criterion $\left(E_{c}\right)$ of $1 \mu \mathrm{V} / \mathrm{cm}$. In the first VAMAS round robin tests, differences in the test specimens' axial strain, caused by variations in the thermal contraction of different test fixtures, was a major source of interlaboratory variation in the critical-current data. Consequently, electromechanical characterization of the test specimen is important for data interpretation and error analysis. In the second round robin, the test apparatus and procedure were more rigidly specified. This increased experimental control reduced the critical-current variation by a factor of 3.5. The results of our measurements will be published in the final VAMAS report.

Table 15. VAMAS $\mathrm{Nb}_{3} \mathrm{Sn}$ test conductor specifications.

$\begin{array}{ll}\text { Wire Diameter } & 1.0 \mathrm{~mm} \\ \text { Cu:Non-Cu Ratio } & 1.68: 1 \\ \text { Bronze:Core Ratio } & 2.5: 1 \\ \text { Filament Dia. } & 4.5 \mu \mathrm{m} \\ \text { Filament No. } & 5047\end{array}$


Table 16. High-field critical current of VAMAS $\mathrm{Nb}_{3} \mathrm{Sn}$ test conductor as a function of axial tensile strain applied at $4 \mathrm{~K}$.

\begin{tabular}{|c|c|c|c|c|c|c|c|}
\hline SP & $\mathrm{E}(\%)$ & E0 (\%) & FIELD (T) & Ic (A) & $\mathrm{Jc}\left(\mathrm{MA} / \mathrm{m}^{\wedge} 2\right)$ & Ic/Icmax & $\mathrm{N}$ \\
\hline \multirow[t]{9}{*}{0} & 0.045 & -0.205 & 12 & 187.95 & 641.46 & 1.00 & 25.70 \\
\hline & & & 14 & 134.76 & 459.92 & 0.94 & 34.54 \\
\hline & & & 15 & 110.99 & 378.80 & 1.00 & 29.12 \\
\hline & & & 16 & 91.18 & 311.20 & 0.92 & 30.22 \\
\hline & & & 18 & 56.12 & 191.54 & 0.88 & 23.73 \\
\hline & & & 20 & 28.81 & 98.32 & 0.81 & 16.17 \\
\hline & & & 22 & 10.15 & 34.64 & 0.68 & 8.91 \\
\hline & & & 24 & 1.36 & 4.63 & 0.48 & 3.57 \\
\hline & & & 25 & 0.24 & 0.81 & 0.44 & 1.98 \\
\hline \multirow[t]{7}{*}{1} & 0.119 & -0.131 & 14 & 140.08 & 478.10 & 0.97 & 34.39 \\
\hline & & & 16 & 95.41 & 325.64 & 0.96 & 27.37 \\
\hline & & & 18 & 59.61 & 203.45 & 0.94 & 22.22 \\
\hline & & & 20 & 32.30 & 110.25 & 0.91 & 17.34 \\
\hline & & & 22 & 12.73 & 43.45 & 0.85 & 11.62 \\
\hline & & & 24 & 2.08 & 7.11 & 0.74 & 4.55 \\
\hline & & & 25 & 0.35 & 1.18 & 0.65 & 2.08 \\
\hline
\end{tabular}

$\begin{array}{lll}2 \quad 0.219 \quad-0.031 & 14 \\ & & 16 \\ & 18 \\ & 20 \\ & 22 \\ & 24 \\ & 25\end{array}$

$\begin{array}{lll}3 \quad 0.297 & 0.047 & 14 \\ & & 16 \\ & 18 \\ & 20 \\ & 22 \\ & 24 \\ & 25\end{array}$

$\begin{array}{rrrrr}14 & 143.23 & 488.86 & 0.99 & 29.24 \\ 16 & 99.27 & 338.82 & 1.00 & 30.59 \\ 18 & 63.18 & 215.62 & 0.99 & 24.14 \\ 20 & 35.39 & 120.78 & 1.00 & 19.49 \\ 22 & 14.63 & 49.92 & 0.98 & 12.23 \\ 24 & 2.81 & 9.59 & 1.00 & 5.42 \\ 25 & 0.54 & 1.83 & 1.00 & 2.48\end{array}$

$\begin{array}{rrrrrrrr}4 & 0.374 & 0.124 & 14 & 142.34 & 485.81 & 0.99 & 32.41 \\ & & 16 & 97.83 & 333.88 & 0.99 & 32.09 \\ & & 18 & 61.74 & 210.71 & 0.97 & 24.57 \\ & & 20 & 33.42 & 114.06 & 0.94 & 15.96 \\ & & 22 & 12.51 & 42.70 & 0.84 & 9.05 \\ & & 24 & 1.91 & 6.53 & 0.68 & 3.89 \\ & & & 25 & 0.33 & 1.14 & 0.62 & 2.05 \\ & & & & & & & \\ 5 & 0.448 & 0.198 & 14 & 136.55 & 466.04 & 0.95 & 30.07\end{array}$


Table 16 cont'd

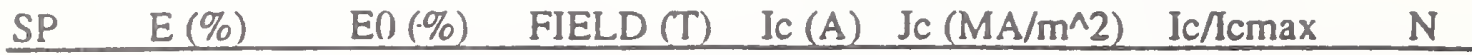

\begin{tabular}{|c|c|c|c|c|c|c|c|}
\hline & & & 16 & 91.86 & 313.50 & 0.93 & 25.92 \\
\hline & & & 18 & 56.54 & 192.98 & 0.89 & 20.93 \\
\hline & & & 20 & 27.98 & 95.50 & 0.79 & 11.10 \\
\hline & & & 22 & 17.72 & 60.47 & 1.19 & 5.62 \\
\hline & & & 24 & 1.01 & 3.45 & 0.36 & 2.53 \\
\hline & & & 25 & 0.15 & 0.51 & 0.28 & 1.49 \\
\hline 6 & 0.521 & 0.271 & 14 & 127.88 & 436.46 & 0.89 & 24.21 \\
\hline & & & 16 & 83.90 & 286.34 & 0.85 & 19.46 \\
\hline & & & 18 & 49.14 & 167.71 & 0.77 & 14.87 \\
\hline & & & 20 & 22.04 & 75.24 & 0.62 & 8.75 \\
\hline & & & 22 & 5.79 & 19.76 & 0.39 & 4.65 \\
\hline & & & 24 & 0.58 & 1.99 & 0.21 & 2.32 \\
\hline & & & 25 & 0.07 & 0.23 & 0.13 & 1.28 \\
\hline $6 u$ & 0.355 & 0.105 & 14 & 145.46 & 496.45 & 1.01 & 34.64 \\
\hline 7 & 0.61 & 0.36 & 14 & 116.40 & 397.27 & 0.81 & 21.64 \\
\hline & & & 16 & 74.10 & 252.91 & 0.75 & 16.18 \\
\hline & & & 18 & 38.95 & 132.92 & 0.61 & 9.69 \\
\hline & & & 20 & 15.99 & 54.56 & 0.45 & 7.32 \\
\hline & & & 22 & 3.20 & 10.93 & 0.21 & 3.52 \\
\hline & & & 24 & 0.20 & 0.67 & 0.07 & 1.46 \\
\hline & & & 25 & 0.04 & 0.13 & 0.07 & 1.21 \\
\hline $7 \mathrm{u}$ & 0.401 & 0.151 & 14 & 142.41 & 486.05 & 0.99 & 31.80 \\
\hline 8 & 0.688 & 0.438 & 14 & 107.25 & 366.04 & 0.74 & 23.17 \\
\hline & & & 16 & 63.97 & 218.32 & 0.64 & 15.03 \\
\hline & & & 18 & 31.35 & 106.98 & 0.49 & 8.88 \\
\hline & & & 20 & 10.20 & 34.80 & 0.29 & 5.19 \\
\hline & & & 22 & 1.63 & 5.56 & 0.11 & 2.72 \\
\hline & & & 24 & 0.11 & 0.39 & 0.04 & 1.44 \\
\hline & & & 25 & 0.03 & 0.09 & 0.05 & 1.18 \\
\hline $8 u$ & 0.463 & 0.213 & 14 & 138.38 & 472.30 & 0.96 & 28.24 \\
\hline 9 & 0.78 & 0.53 & 14 & 89.30 & 304.76 & 0.62 & 13.75 \\
\hline & & & 16 & 52.00 & 151.47 & 0.45 & 7.80 \\
\hline & & & 18 & 21.61 & 73.74 & 0.34 & 7.25 \\
\hline & & & 20 & 5.39 & 18.40 & 0.15 & 3.92 \\
\hline & & & 22 & 0.62 & 2.11 & 0.04 & 1.97 \\
\hline & & & 24 & 0.04 & 0.15 & 0.02 & 1.28 \\
\hline
\end{tabular}


Table 16 cont'd

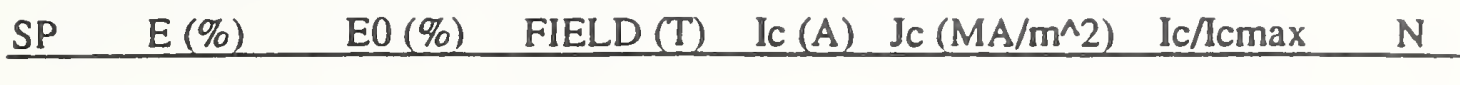

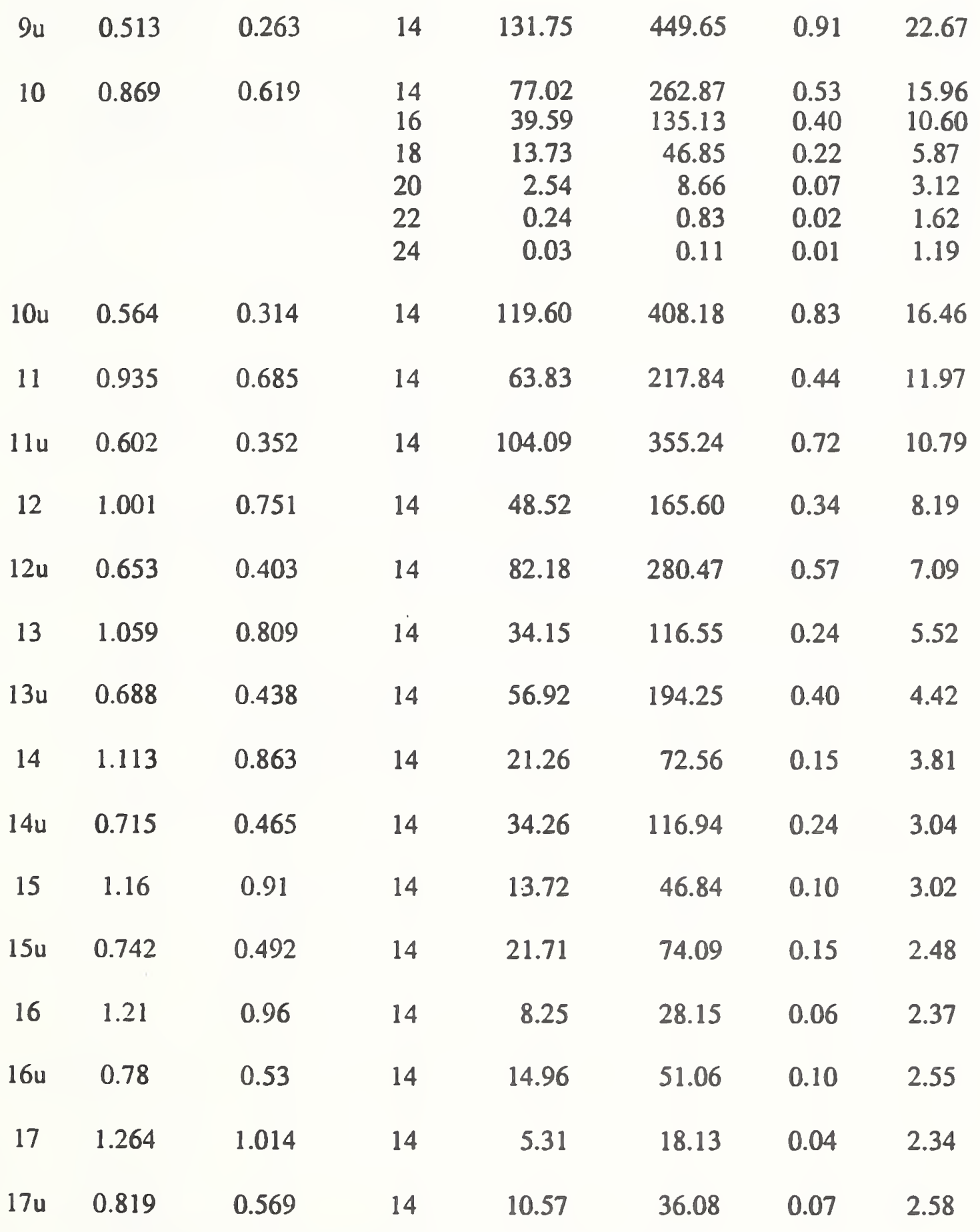




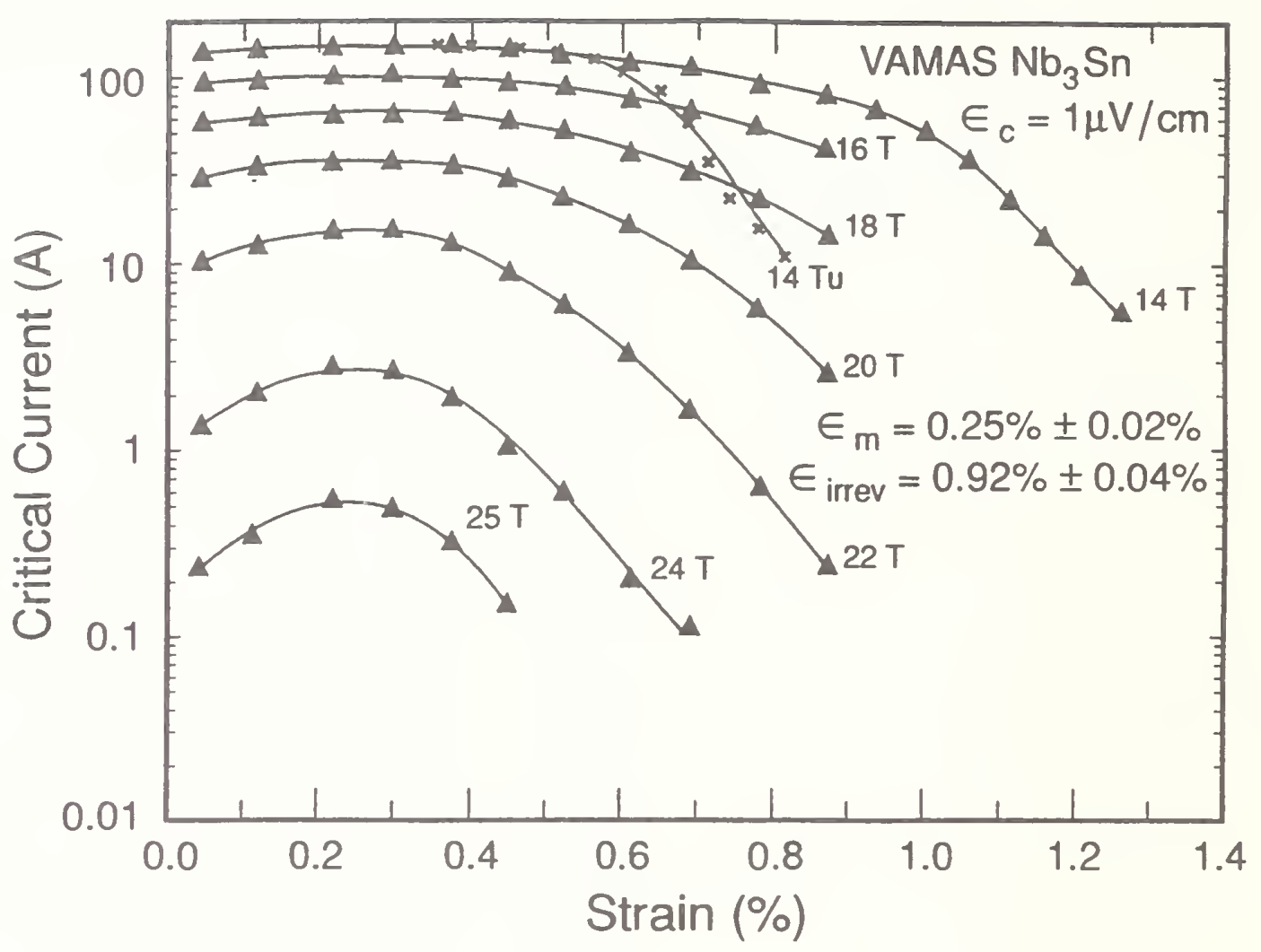

Figure 23. Effect of axial tensile strain on the critical current of the VAMAS $\mathrm{Nb}_{3} \mathrm{Sn}$ test conductor at $4 \mathrm{k}$ and several magnetic fields.

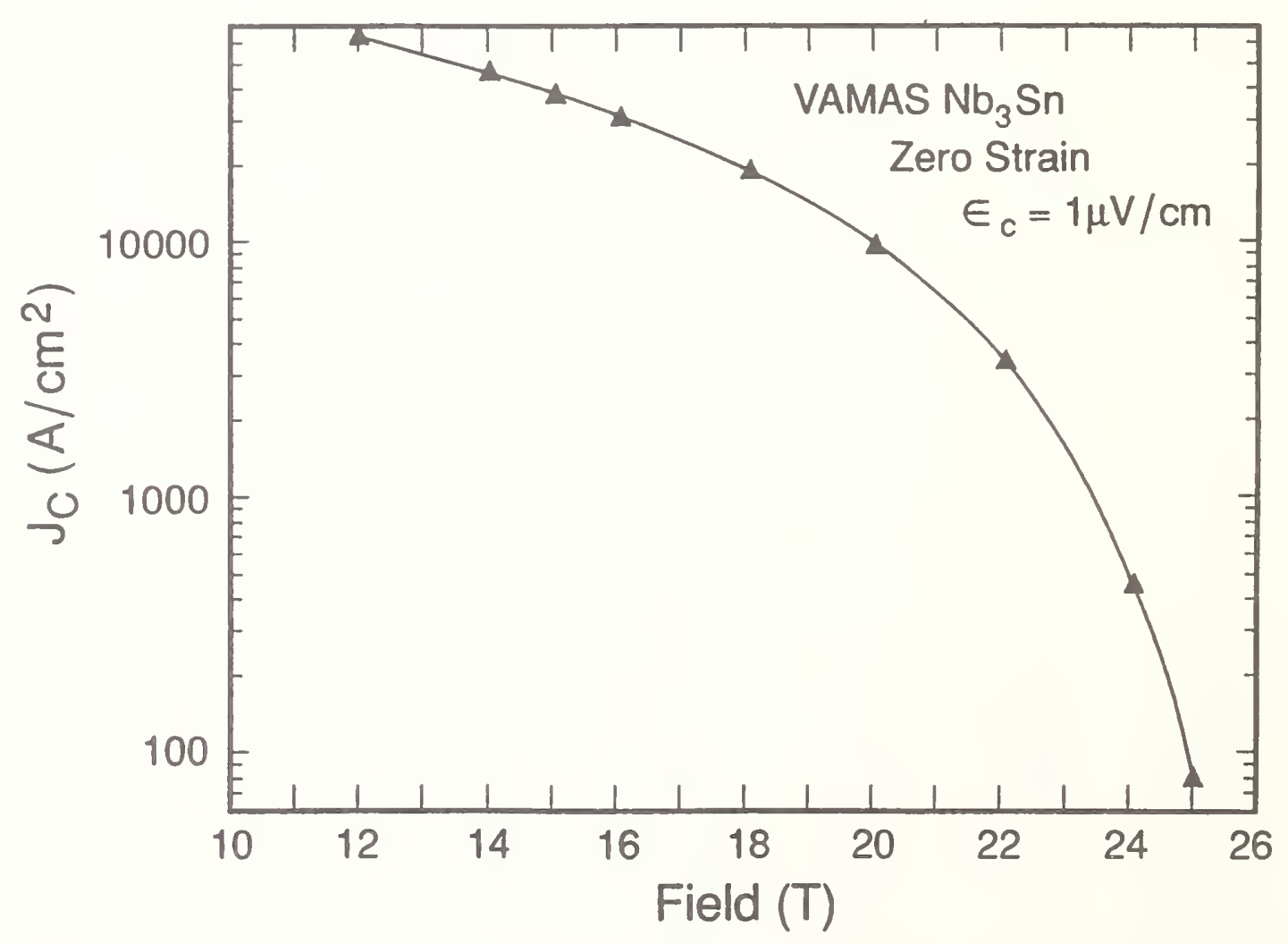

Figure 24. Effect of magnetic field on the critical current density of the VAMAS test conductor at $4 \mathrm{~K}$. *U.S. GOVERNMNENT PRINTING OFFICE:1994-573-013/89062 

